\title{
SHEAR STRENGTH EVALUATION OF REINFORCED RECYCLED AGGREGATE CONCRETE BEAMS
}

\author{
BY \\ Roya Shoghi Haghdoost \\ M.Sc., Iran University of Science and Technology, Tehran, Iran, 2009 \\ A project report \\ presented to Ryerson University \\ In partial fulfillment of the requirements for the degree of \\ Master of Engineering \\ in the Program of \\ Civil Engineering
}

Toronto, Ontario, Canada, 2016

๑) Roya Shoghi Haghdoost, 2016 


\section{AUTHOR'S DECLARATION}

I hereby declare that I am the sole author of this thesis. This is true copy of the thesis, including any required final revisions, as accepted by my examiners.

I authorize Ryerson University to lend this thesis to other institution or individuals for the purpose of scholarly research.

I further authorize Ryerson University to reproduce this thesis by photocopying or by other means, in total or in part, at the request of other institutions or individuals for the purpose of scholarly research.

I understand that my thesis may be made electronically available to the public.

Author's Signature:

Date: 


\title{
SHEAR STRENGTH EVALUATION OF REINFORCED RECYCLED AGGREGATE CONCRETE BEAMS
}

\author{
Roya Shoghi, Master of Engineering, 2016 \\ Department of Civil Engineering \\ Ryerson University, Toronto
}

\begin{abstract}
A theoretical study is conducted to investigate the shear behaviour of recycled aggregate concrete (RAC) beams with and without shear reinforcements along with the performance evaluation various Code based/other existing equations in predicting shear strength. In addition, three artificial neural network (ANN) models for shear strength prediction of RAC beams with and without shear reinforcements are developed and their performance validated by using 108 beams from available research studies. Most of the Codes and existing methods underestimate the shear capacity of RAC beams with/without shear reinforcement. However, over estimation of shear strength by Codes/existing methods for about $10 \%$ RAC beams needs to be addressed when using such Codes/existing methods for shear strength prediction. All three ANN models are found to predict shear strength of RAC beams. Developed ANN models are able to simulate the effect of shear reinforcement on the shear strength of RAC beams.
\end{abstract}




\section{ACKNOWLEDGEMENTS}

I would like to express my sincere gratitude to my research supervisor Dr. Khandaker M. Anwar Hossain without whom this study would not be accomplished. His persistent support, encouragement, and valuable suggestions have guided me throughout each stage of my graduate study. My knowledge on the specialized subject of my research study has enhanced significantly due to my supervisor's vast experience, and sophisticated understanding for which I am truly grateful.

I also acknowledge the support provided by PhD Candidate Ehsani Yeaganeh Ali, during the development of ANN models.

And finally, I am deeply and forever indebted to my family, for their love, encouragement, and support throughout my entire life. 


\section{TABLE OF CONTENT}

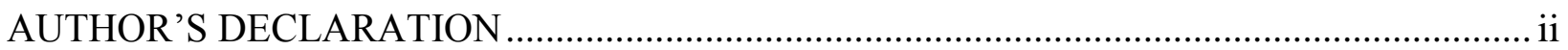

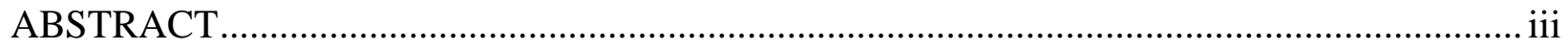

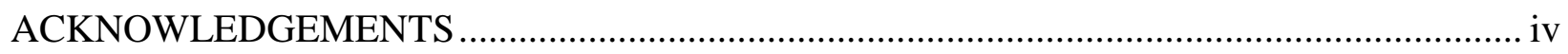

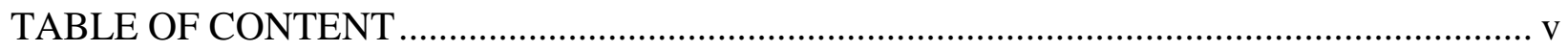

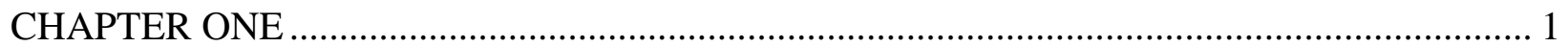

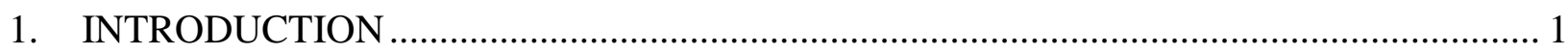

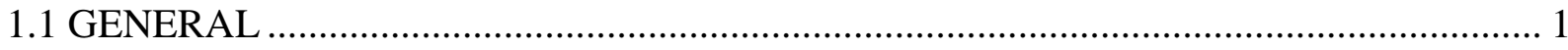

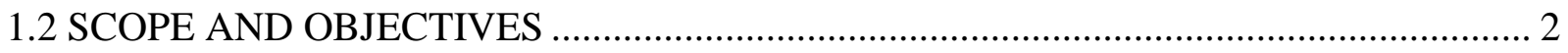

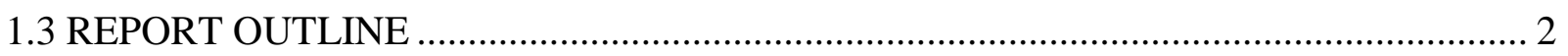

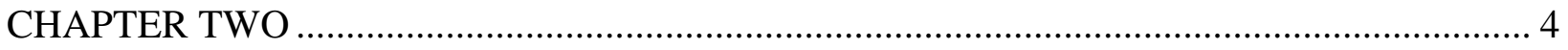

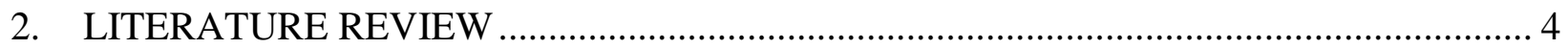

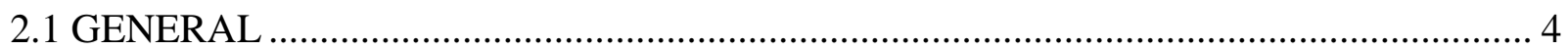

2.2 RECYCLED AGGREGATE CONCRETE ………….................................................. 4

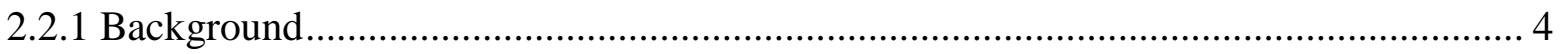

2.2.2 A review of experimental studies ........................................................................... 5

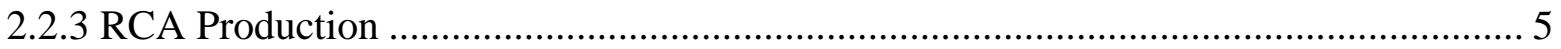

2.2.4 Recycled concrete aggregates (RCA) properties............................................................ 7

2.2.5 Use of RCA in different types of concrete …………….............................................. 9

2.2.6 Hardened RCA concrete properties ................................................................................. 9

2.3 SHEAR STRENGTH EVALUATION OF RC BEAMS .................................................. 10

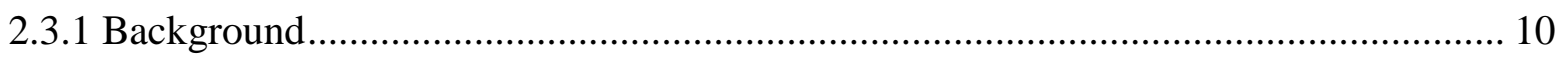

2.3.2 Shear behavior of reinforced concrete beams....................................................... 10

2.3.3 Shear strength parameters.......................................................................................... 12

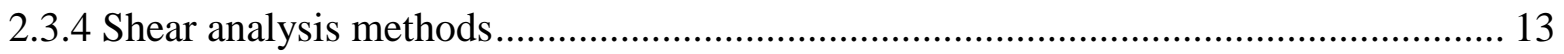

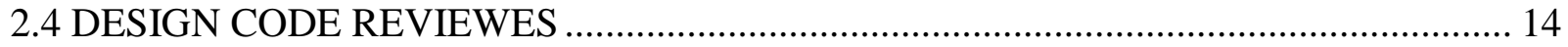

2.4.1 American Concrete Institute, ACI 318-01 (2011) …………………………............ 15

2.4.2 Canadian Standards Association, CSA A23.3-04 (2004) ........................................... 15

2.4.3 Australian Standards: AS3600 (2009) ......................................................................... 17 


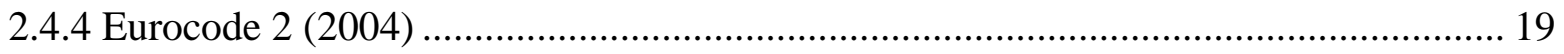

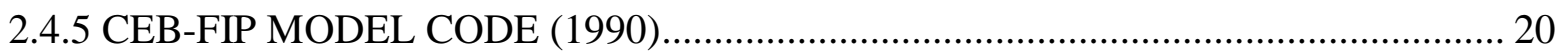

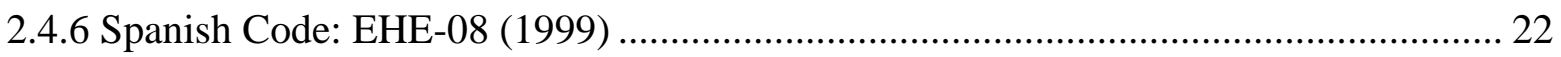

2.4.7 NZS 3101 (2006) ………………………………………………………………. 25

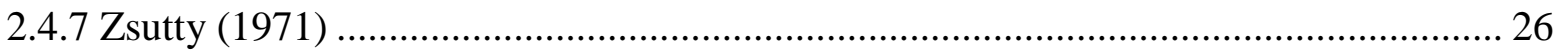

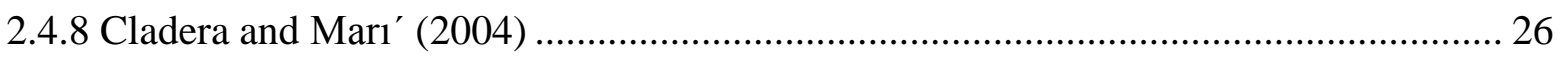

2.4.9 Gastebled and May (2001) ……………………………........................................... 27

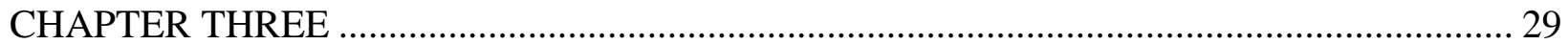

3. AN ANALYTICAL STUDY TO EVALUATE THE PERFORMANCE OF CODES/EXISTING PROVISIONS FOR SHEAR STRENGTH PREDICTION OF RCA

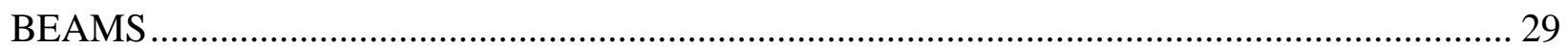

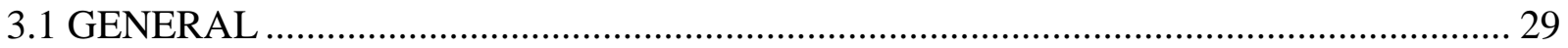

3.2 REINFORCED CONCRETE BEAMS WITHOUT WEB REINFORCEMENT ............... 29

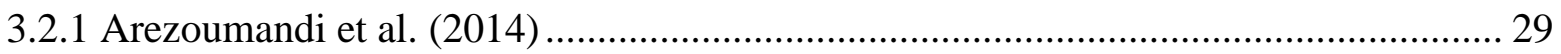

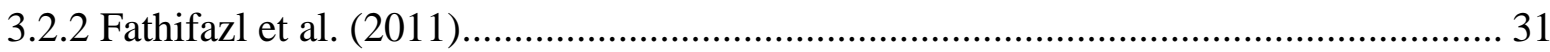

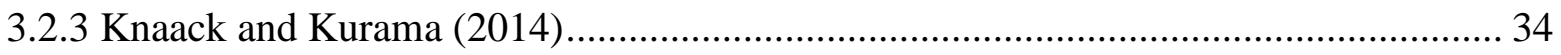

3.3 REINFORCED CONCRETE BEAMS WITH WEB REINFORCEMENT ........................ 36

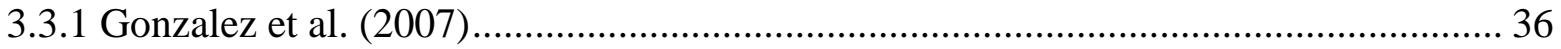

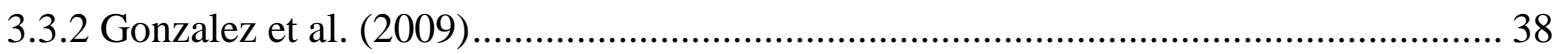

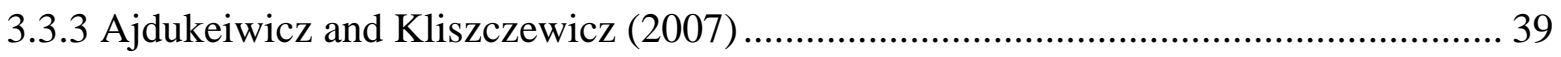

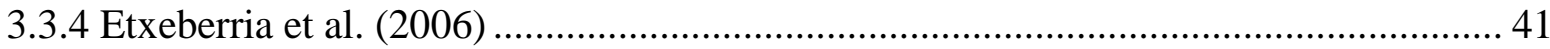

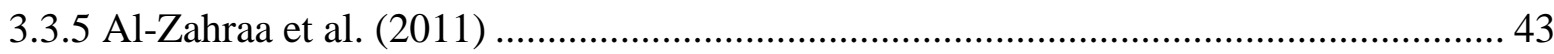

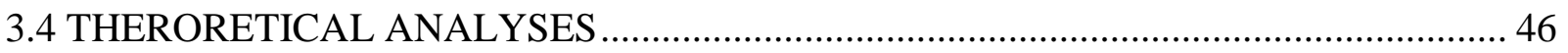

3.4.1 Performance analysis of Codes/existing equation for predicting shear strength of RAC

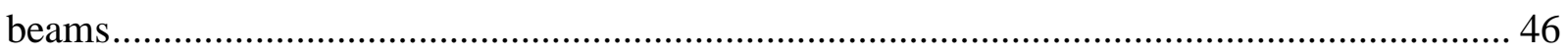

3.4.2 Comparison of the influence of shear span to depth ratio............................................... 59

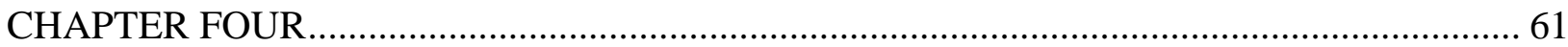

4. DEVELOPMENT OF ANN MODEL FOR PREDICTING SHEAR STRENGTH OF RAC

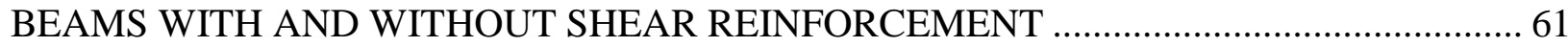

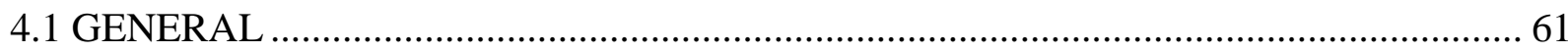

4.2 Development of Artificial Neural Network (ANN) Model................................................. 61

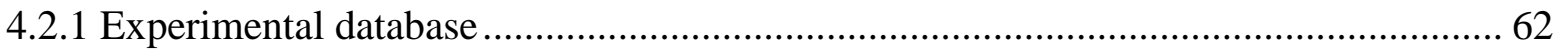




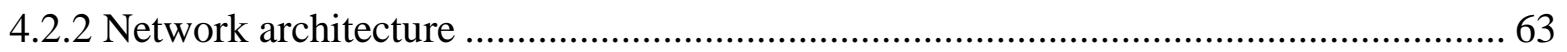

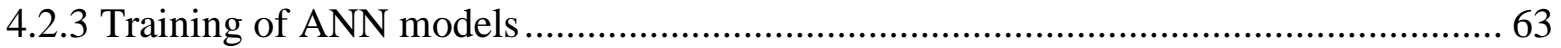

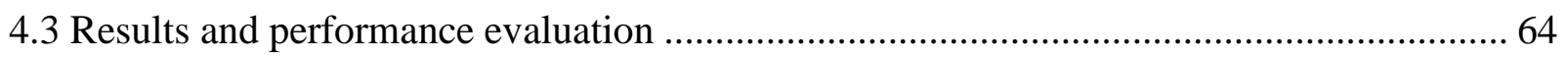

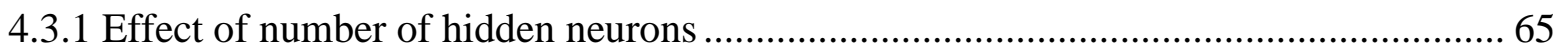

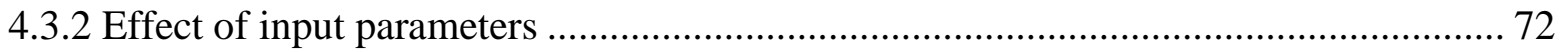

4.3.3 Validating the performance ANN models ......................................................... 78

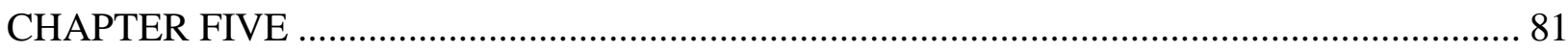

CONCLUSIONS AND RECOMMANDATIONS ............................................................ 81

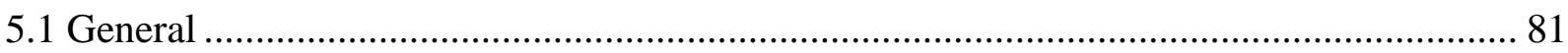

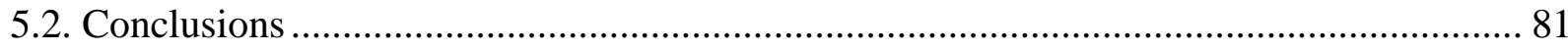

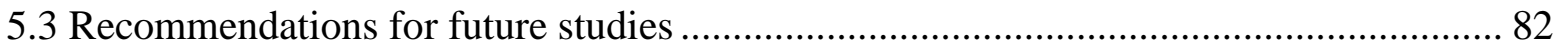

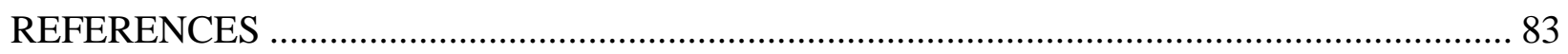

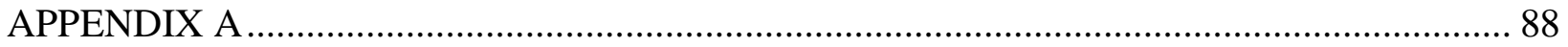

Spreadsheets of evaluation of shear capacity based on code provisions and compare them by experimental shear values for tested beams without stirrups. 88 


\section{LIST OF FIGURES}

Figure 2.1Various types of RCA comprising (a) a granite particle surrounded by adhering mortar, (b) three granite particles held together and surrounded by mortar, (c) only mortar

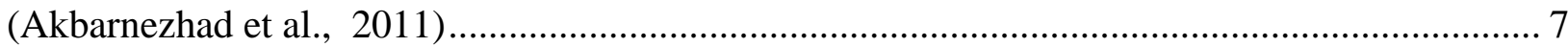

Figure 2.2 Interfacial Transition Zones (ITZs) locations on RCA concrete (Ryu, 2002) ............ 8

Figure 2.3 Shear failure of RC beams (Neilson, 2004)..................................................... 11

Figure 2.4 Forces at a diagonal crack in a beam without web reinforcement (Neilson, 2004) .... 12

Figure 2.5 Internal forces at an inclined crack (Hong and Ha, 2001) ..................................... 14

Figure 2.6 Equivalent truss of a beam (Hong and Ha, 2001) .............................................. 14

Figure 2.7 Truss model and notation for shear reinforced members .................................... 20

Figure 2.8 Web model (CEB-FIP model code, 1990) ....................................................... 21

Figure 2.9 Compression of web concrete (CEB-FIP model code, 1990) ................................. 21

Figure 2.10 Tension of web steel (CEB-FIP model code, 1990) ............................................ 21

Figure 3.1 Cross sections and reinforcement layout of the test beams (Arezoumandi et al., 2014)

Figure 3.2 Cross sections and reinforcement layout of the test beams (Fathifazl et al., 2009) .... 32

Figure 3.3 Cross sections and reinforcement layout of the test beams (Knaack and Kurama, 2014) 35

Figure 3.4 Cross sections and reinforcement layout of the test beams (Gonzalez et al., 2007) ... 37

Figure 3.5 Cross sections and reinforcement layout of the test beams (Gonzalez et al.2009) ..... 39

Figure 3.6 Cross sections, reinforcement layout and loading system of the test beams

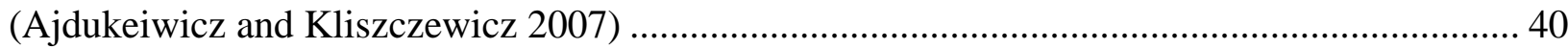

Figure 3.7 Two point loads test set-up (Etxeberria.et al. 2006) ............................................... 42

Figure 3.8 Arrangements for the three types of reinforcements (Etxeberria.et al. 2006) ............ 42

Figure 3.9 (a) Details of group (G1) of tested beam specimens (b) details of group (G2) of tested beam specimens (c) details of group (G3) of tested beam specimens (d) details of group (G4) of tested beam specimens(Al-Zahraa et al., 2011)

Figure 3.10 Ratio experiment-to-predicted values using ACI 318-11: (a) with stirrups (b) without stirrups. 47 
Figure 3.11 Ratio experiment-to-predicted values using CSA A23.3-04: (a) with stirrups (b) without stirrups 48

Figure 3.12 Ratio experiment-to-predicted values using AS 3600: (a) with stirrups (b) without stirrups.

Figure 3.13 Ratio experiment-to-predicted values using Eurocode 2: (a) with stirrups (b) without stirrups 50

Figure 3.14 Ratio experiment-to-predicted values using CEB-FIP: (a) with stirrups (b) without stirrups.

Figure 3.15 Ratio experiment-to-predicted values using EHE-08: (a) with stirrups (b) without stirrups.

Figure 3.16 Ratio experiment-to-predicted values using NZS 3101: (a) with stirrups, (b) without stirrups

Figure 3.17 Ratio experiment-to-predicted values using Cladera and Mari (2004): (a) with stirrups (b) without stirrups.

Figure 3.18 Ratio experiment-to-predicted values using Zsutty (1971): (a) with stirrups (b) without stirrups 55

Figure 3.20 Effect of a/d on the shear strength of RAC beams without stirrups 59

Figure 3.21 Effect of a/d on the shear strength of RAC beams with stirrups 60

Figure 4.1 ANN Architecture 62

Figure 4.2 Predicted versus experimental shear capacity from various numbers of hidden neurons for Model 1 67

Figure 4.3 Predicted to experimental shear capacity from various numbers of hidden neurons for Model 2

Figure 4.4 Predicted to experimental shear capacity from various numbers of hidden neurons for Model 3 71

Figure 4.5 Predicted to experimental shear strength from various input combinations for Model 1 73

Figure 4.6 Predicted versus experimental shear strength from various input combinations for Model 2

Figure 4.7 Experiment-to-predicted shear strength ratio for ANN Model 1: beams with and without stirrups 
Figure 4.8 Experiment-to-predicted shear strength ratio for ANN Model 2: beams without

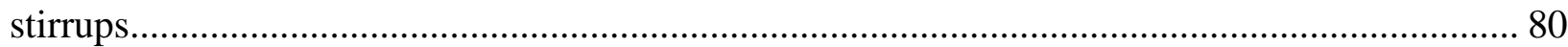

Figure 4.9 Experiment-to-predicted shear strength ratio for ANN Model 3: beams with stirrups 80 


\section{LIST OF TABLES}

Table 2.1 Partial factors for materials for ultimate limit states (Eurocode 2, 2004)................. 19

Table 2.2 Partial safety factors for the materials for the Ultimate Limit States (EHE-99, 1999). 25

Table 3.1 Details of Reinforced Concrete Beams tested by Mahdi Arezoumandi et al. (2014)... 31

Table 3.2 Details of Reinforced Concrete Beams tested by Fathifazl et al. (2011)................... 33

Table 3.3 Details of Reinforced Concrete Beams tested by Knaack and Kurama (2014)........... 36

Table 3.4 Details of Reinforced Concrete Beams tested by Gonzalez et al. (2007)................... 37

Table 3.5 Details of Reinforced Concrete Beams tested by Gonzalez et al. (2009)................... 39

Table 3.6 Details of reinforced concrete beams tested by Ajdukeiwicz and Kliszczewicz (2007) ..

Table 3.7 Details of Reinforced Concrete Beams tested by Etxeberria.et al. (2006) ................. 42

Table 3.8 Details of Reinforced Concrete Beams tested by Al-Zahraa et al. (2011) ................. 44

Table 3.9 Maximum, minimum, average and standard deviation of $\mathrm{V}_{\mathrm{e}} / \mathrm{V}_{\mathrm{p}}$ for beams without

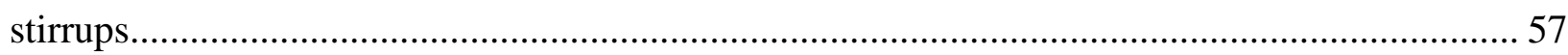

Table 3.10 Maximum, minimum, average and standard deviation of $\mathrm{V}_{\mathrm{e}} / \mathrm{V}_{\mathrm{p}}$ for beams without

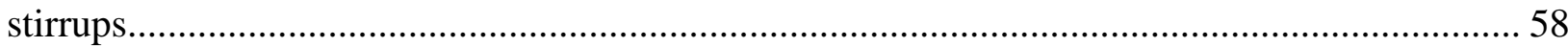

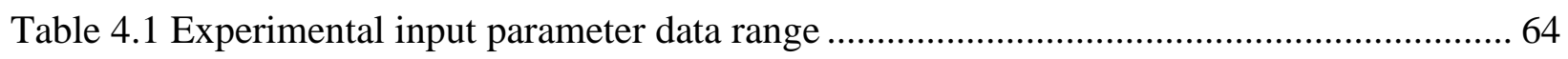

Table 4.2 Evaluation of Number of Hidden Neurons for Model 1, beams with and without

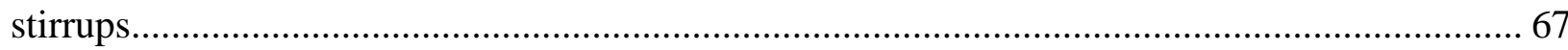

Table 4.3 Evaluation of number of hidden neurons for Model 2, beams with stirrup................ 68

Table 4.4 Evaluation of number of hidden neurons for Model 3, beams without stirrups .......... 71

Table 4.5 Evaluation of input combinations with 8 hidden neurons for Model 1 .................... 72

Table 4.6 Evaluation of input combinations with 6 hidden neurons Model 2 …...................... 75

Table 4.7 Evaluation of input combinations with 6 hidden neurons for Model 3 (Beams without

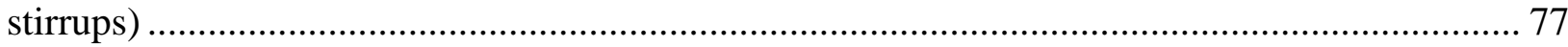

Table 4.8 Validation of Model 1 using data from Han et al. (2001) and (Pellegrino and

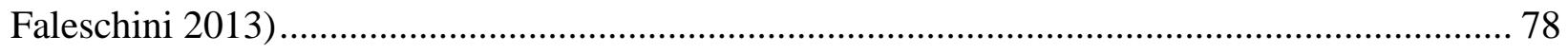

Table 4.9 Validation of Model 2 using data from Han et al. (2001) and (Pellegrino and Faleschini $2013)$

Table 4.10 Validation of Model 3 using data from Han et al. (2001) and (Pellegrino and

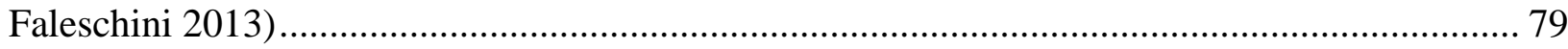


Table A.1 Shear strength comparison results for beams without stirrups based on CSA A23.3-04 88

Table A.2 Shear strength comparison results for beams without stirrups based on ACI 318-11. 90 Table A.3 Shear strength comparison results for beams without stirrups based on AS 3600 ...... 91

Table A.4 Shear strength comparison results for beams without stirrups based on CEB-FIP ..... 92 Table A.5 Shear strength comparison results for beams without stirrups based on Cladera\& Mari 93

Table A.6 Shear strength comparison results for beams without stirrups based on Eurocode-2.. 94 Table A.7 Shear strength comparison results for beams without stirrups based on EHE-08 ...... 95 Table A.8 Shear strength comparison results for beams without stirrups based on Gastebled \&

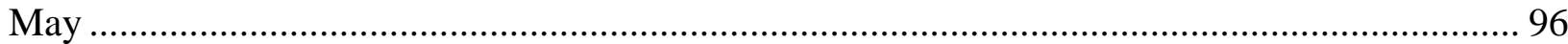

Table A.9 Shear strength comparison results for beams without stirrups based on NZS3101 .... 97

Table A.10 Shear strength comparison results for beams without stirrups based on Zsutty ........ 98

Table A.13 Shear strength comparison results for beams with stirrups based on ACI 318-11 .. 101 Table A.14 Shear strength comparison results for beams with stirrups based on Cladera \& Mari

Table A.15 Shear strength comparison results for beams with stirrups based on Eurocode-2... 103 Table A.16 Shear strength comparison results for beams without stirrups based on AS 3600 .. 104 Table A.17 Shear strength comparison results for beams without stirrups based on EHE-08 ... 105 Table A.18 Shear strength comparison results for beams without stirrups based on CEB-FIP . 106 


\section{NOTATIONS}

$\begin{array}{ll}A_{s,} A_{s w} & \text { The cross-sectional area of longitudinal reinforcement } \\ A_{v}, A_{v s} & \text { Area of vertical reinforcement } \\ a, a_{V} & \text { Shear span } \\ a / d & \text { Shear span to depth ratio } \\ a_{g} & \text { Maximum aggregate size } \\ b_{v}, b_{w} & \text { Width of the web section } \\ d, \mathrm{z} & \text { Distance from the extreme compression fiber to the center of gravity of the steel } \\ d_{v} & \text { Effective shear depth, taken as the greater of } 0.9 \mathrm{~d} \text { or } 0.72 \mathrm{~h} \\ b_{0} & \text { The net minimum width of the member } \\ b_{r e d} & \text { Reduced web breadth } \\ d_{0} & \text { Depth to the outermost layer of tensile reinforcement } \\ \varepsilon & \text { Degree of agreement } \\ f^{\prime}, f_{1 c d} & \text { Concrete compressive strength } \\ f_{y} & \text { Specified yield strength of non-prestressed reinforcement or anchor steel } \\ f_{c k} & \text { Characteristic, compressive cylinder strength of concrete at } 28 \text { days } \\ f_{c \mathrm{~d} 2} & \text { Design value of the concrete tensile strength } \\ f_{\mathrm{cv}} & \text { The effective shear strength of the concrete } \\ F_{r c w} & \text { The compression of web concrete } \\ F_{r t w} & \text { Thetension of web steel } \\ f_{s y}, f_{y t} & \text { Yield strength of the stirrups } \\ f_{y w d} & \text { Design value of the web (shear) reinforcement } \\ f_{y a d} & \text { The design strength of reinforcement } \\ h & \text { Number of hidden neurons } \\ i & \text { Number of inputs } \\ j_{d} & \text { Internal lever arm } \\ M_{\mathrm{f}} & \text { Factored moment at the section } \\ M_{u} & \text { Factored moment at the section } \\ o & \text { Number of outputs } \\ \mathrm{RAC} & \text { Recycled aggregate concrete (concrete made by recycled aggregates) }\end{array}$




\begin{tabular}{|c|c|}
\hline RCA & Recycled concrete aggregate (aggregates produced from recycling concrete) \\
\hline$s$ & Spacing of the transverse reinforcement \\
\hline$s_{\mathrm{Z}}$ & Equivalent crack spacing parameter \\
\hline$V$ & Shear force in the section \\
\hline Vavg & Difference between the averages predicted value and the average target value \\
\hline$V_{c V}$ & Difference between the coefficient of variance of the predicted and target \\
\hline$V_{c z}$ & Concrete shear force \\
\hline$V_{d}$ & Dowel force in equation \\
\hline$V_{i}$ & Interface shear force \\
\hline$V_{\max }$ & Difference between the maximum value of predicted data and target data \\
\hline$V_{\min }$ & Difference between the minimum value of the predicted data and target data \\
\hline Vrange & Difference between the range of predicted values and the range of target values \\
\hline$V_{R d, c}$ & Design value for the shear resistance \\
\hline$V_{u}$ & Factored shear force on the section \\
\hline$V_{u 1}$ & The ultimate shear force failure due to diagonal compression in the web \\
\hline$V_{\mathrm{u} 2}$ & The ultimate shear force failure due to tension in the web \\
\hline$V_{u c}$ & Shear resisted by concrete \\
\hline$V_{u s}$ & Shear resisted by stirrups \\
\hline$V_{\sigma}$ & Difference between the standard deviation of the predicted data and the target data \\
\hline$V_{e}$ & Experimentally determined total shear resistance \\
\hline$V_{f}$ & Factored shear force \\
\hline$V_{p}$ & Predicted total shear resistance \\
\hline$V_{\mathrm{r}}$ & Factored shear resistance \\
\hline$V_{c}$ & Nominal shear strength provided by concrete \\
\hline$V_{n}$ & Nominal shear strength \\
\hline$V_{s}$ & Nominal shear strength provided by shear reinforcement \\
\hline$w / c$ & Water-cement ratio \\
\hline$z$ & The mechanic lever arm \\
\hline$\alpha$ & The angle of the reinforcement with the member's axis \\
\hline$\varepsilon_{\mathrm{x}}$ & The longitudinal strain in the web \\
\hline$\Phi$ & Strength reduction factor \\
\hline
\end{tabular}




$\begin{array}{ll}\phi_{\mathrm{c}} & \text { Resistance factor for concrete } \\ \phi_{\mathrm{s}} & \text { Resistance factor for non-prestressed reinforcing bars } \\ \rho_{v} & \text { Transverse reinforcement ratio } \\ \rho_{w,} \rho_{l,} \rho_{\mathrm{s},} \rho & \text { Ratio of longitudinal reinforcement } \\ \theta_{v, \theta} & \begin{array}{l}\text { The angle between the axis of the concrete compression strut and the longitudinal } \\ \text { axis of the member }\end{array} \\ \gamma_{c} & \text { The partial safety factor for concrete }\end{array}$




\section{CHAPTER ONE}

\section{INTRODUCTION}

\subsection{GENERAL}

The worldwide high volume generation of construction and demolition waste (CDW) requires sustainable solutions to reduce the environmental impacts like landfill extensions and to support the preservation of our limited natural resources. Concrete is one of the most widely used construction material with the largest volume of consumption. According to CSI (The Cement Sustainability Initiative), concrete is the second most consumed material after water with 25 billion globally manufacturing every year. Aggregates are the major components of concrete and have a significant effect on engineering properties of the final product (Manzi et al., 2013). They make about $70-80 \%$ of concrete components while they are the recyclable part of the concrete. The demand of new aggregates in United States is estimated to be two billion tons for each year, while the annual production of construction waste is estimated to be 123 million tons according to the Federal Highway Administration (FHWA, 2004). In Europe, CDW has been identified as a major waste stream according to European Union. Eurostat estimates 970 million tons/year for Europe (Sonigo et al., 2010). Korean domestic construction waste is generated at a rate of more than 100,000 tons every day. This amount will be 90 million tons, considering the current rate by 2021(Thomas et al., 2014).

Many of countries have already started to use recycled concrete aggregate (RCA). Japan was the first country to become interested in the study of RCA concrete and Kasai (1974) first released the criteria for RCA and RCA concrete in 1974 (Thomas et al., 2014). According to Construction Materials Recycling Association (CMRA, 2010), nearly 140 million tons of concrete end up to recycling plants every year.

There are some concerns about using of recycled aggregate concrete in the structural elements. The quality of recycled aggregates affected by several parameters like quality of the parent concrete. Moreover, recycled aggregate particles naturally contain virgin aggregate with part of remaining mortar attached to the surface of aggregate called adhered mortar. According to the research, this residual mortar negatively effects the physical properties of RCA. It increases water 
absorption and porosity, while decreases density and specific gravity of RCA comparing to natural aggregates (NA). As a matter of fact, the use of recycled aggregate decreases the mechanical properties of hardened concrete. It can increases the drying shrinkage, creep, carbonation rate and water sorptivity, and decreases the compressive strength, modulus of elasticity and freezing and thawing resistance in comparison with concrete made by natural aggregate. These weaknesses are able to be improved with the use of appropriate mix design and mineral admixtures (Kou and Poon, 2015). The other drawback of using RCA lies in its characterization which requires comprehensive studies and is not an easy procedure as the properties of RCA varies by the types, quality and functionality of the sources of aggregates.

\subsection{SCOPE AND OBJECTIVES}

The potential of using of RCA in construction industry is enormous as it can lead to cost-effective sustainable structures. The objectives of this study are to:

- Conduct a literature review on recycled concrete aggregate concrete,

- Study the shear behavior of reinforced concrete (RC) beams made by recycled concrete aggregates,

- Investigate the applicability of the current Code based and other existing equations to evaluate the shear strength of recycled aggregate concrete (RAC) beams with and without shear reinforcements and

- Develop artificial neural network (ANN) models for predicting the shear strength recycled aggregate concrete beams with and without web/shear reinforcements based on the currently available experimental results.

A database of 96 beams gathered from different experimental studies of previous researches is used to accomplish these objectives.

\subsection{REPORT OUTLINE}

This project report contains five chapters. Chapter One gives an overview about the recycled aggregate concrete and scope/objectives of the study. Chapter Two includes a literature review covering the background of recycled aggregate and its application in different types of concrete. It also provides information about the physical properties and mechanical properties of the hardened 
concrete made with recycled concrete aggregate (RCA). A brief review of the evaluation of shear strength of reinforced concrete beams and truss analogy method is also presented in this chapter. Moreover, the various code provisions currently available and existing design equations from different research studies have also been discussed in this chapter.

Chapter Three includes the analysis of performance of various Code based and existing equations for predicting shear strength of RC beams made with recycled concrete aggregates. Experimental details and results of previous research studies are described to understand the shear behaviour of RCA beams. In total, 96 full-scale RC beam specimens made with RCA are introduced in two groups: beams with and without web reinforcements. Each testing program planned to investigate the effect of two or more influential parameters on shear strength of the beams. The experimental shear strengths of beams are compared with those obtained from current Codes, standards and existing design equations/methods.

In Chapter Four, three ANN models for predicting the shear strength of RCA beams with and without web reinforcements are developed. ANN models are trained and their performance is validated using experimental data collected from previous research studies described in Chapter Three.

Chapter Five presents conclusions of this study and suggests recommendations for future research. 


\section{CHAPTER TWO}

\section{LITERATURE REVIEW}

\subsection{GENERAL}

This chapter is presented in three parts. The first part comprised a literature review on recycled concrete aggregate. The second part provides a review of different mechanisms of the shear behavior of reinforced concrete beams and the corresponding design approaches. The third part introduces design codes and other exiting design equations/ methods to evaluate the shear capacity of RC beams.

\subsection{RECYCLED AGGREGATE CONCRETE}

\subsubsection{Background}

Construction and demolition waste (CDW) is recognized as a major waste stream made by human around the world. Although there is no global statistical data for CDW generation, but it is stated that approximately 900 million tonnes of construction and demolition waste is generated in USA, Europe and Japan (WBCSD, 2012). Recycling of concrete is a relatively new approach to address the two main environmental concerns, to manage the uninterrupted waste generation and to protect the raw material resources. Many of countries have already started to use recycled aggregates. According to Construction Materials Recycling Association (CMRA, 2010), nearly 140 million tons of concrete end up to recycling plants every year.

Japan was the first country to become interested in the study of RCA concrete and Kasai (1974) first released the criteria for RCA and RCA concrete in 1974. The first investigation on the recycled aggregate concrete beams is also published in Japan (Mukai and Kikuchi, 1988). Italy is one of the countries that provides for $30 \%$ coarse RCA replacement of virgin aggregate, in order to make structural concrete. This process has been taking place since 2009 (Corinaldesi, 2011). Germany has been set recycling of building and demolition waste at $40 \%$ since 1991. Holland has

allowed $20 \%$ of RCA for course aggregate to produce new concrete, while considering the same properties of fresh and hardened conventional concretes since 1994 (Oikonomou, 2005). 
The European Code EN 206 (Annex E) allows for the usage of up to 50\% replacement of coarse recycled material in specific conditions (European Committee for Standardization, 2012). In order to ensure the success of reuse of recycled aggregates, it is important to ensure that three main things are achieved (Dosho, 2007):

- assurance of safety and quality of the recycled aggregate

- decrease in environment impact by conserving the natural aggregate

- increase in cost effectiveness of construction

\subsubsection{A review of experimental studies}

Although the study of the structural behavior of recycled aggregate concrete (RAC) draws attention of researchers since 1974, there is still limited experimental results. It is stated that concrete with RCA has a lower compressive strength and higher absorption at the same watercement ratio (w/c) and slump than concrete with natural aggregates (NA), while it shows higher freezing-and-thawing durability (Buck, 1977). Etxeberria et al. ((2007) conducted an experimental study of the shear behavior and strength of beams made with RAC. They examined twelve beam specimens with the same compressive strength and different RCA percentage and different transvers reinforcement. They found that the substitute of less than $25 \%$ coarse aggregate was not able to have outstanding effects on the shear capacity of RAC beams. Fathifazl et al. (2011) suggested a new mix design method known as Equivalent Mortar Volume (EMV) method. They proved that the shear capacity of recycled aggregate concrete beams will be the same or even higher than the conventional concrete provided that the EMV method applies for the mix design. Knaack and Kurama (2014) stated that the effect of recycled concrete aggregate on shear and flexural behavior of beams is small, while this effect is considerable on the initial stiffness and ultimate flexural deflection.

\subsubsection{RCA Production}

Recycled concrete aggregates (RCAs) are obtained from demolition of concrete structures after crushing equipment breaks them into smaller particles. Three main types of aggregates produced by construction and demolition waste (CDW) are introduced: crushed concrete, crushed masonry, and mixed demolition debris (Silva et al., 2015). 
Production process of RCA is similar to natural coarse aggregates and involves the use same equipment, crushers, screens, removal impurities and transportation facilities (Sharma and Singla, 2014). The Portland Cement Concrete (PCC) recycling procedure consists of demolition, breaking, removing and crushing concrete from an approved source. The steps to produce recycled concrete aggregate based on National Highway Institute (NHI, 1998) and the Environmental Council of Concrete Organization (ECCO, 1999) are as follows:

i. Evaluation of Source Concrete and Removal of Contaminants like steel reinforcing bars, wood and soil,

ii. Breaking of Demolished Concrete and Removal of Embedded Steel and

iii. Crushing and Sizing and blending

As the presence of mortar attached to the aggregate particles is recognised to be the main factor contributing to quality issues relating to RCA, the separation processes to improve the quality of RCA is an important part of the production.

According to Akbarnexhad et al. (2011), there are two types of recycled aggregates; type I and type II, as displayed in Figure 2.1. Type I has a bigger size and may be comprised of more than one natural aggregates, they are both attached to each other, and are surrounded by cement paste. Type II is comprised of only mortar, without the presence of natural aggregate. The amount of adhered mortar depends on several factors like the strength of the original concrete, particle size, crushing procedure and the number of crushing procedures, so it is different for every particle. (Akbarnezhad et al., 2013).

According to results, the average mortar content can be in the range from 20 to $70 \%$ by mass, depending on the parameters mentioned above (Li, 2008; Akbarnezhad et al., 2013). 


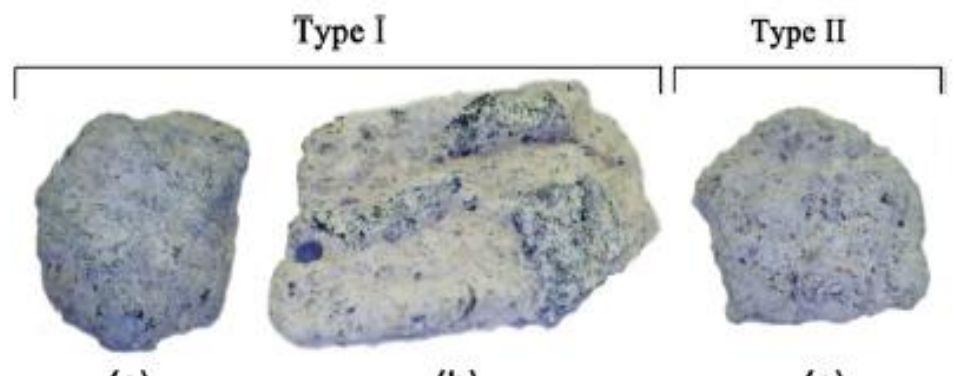

(a)

(b)

(c)

Figure 2.1Various types of RCA comprising (a) a granite particle surrounded by adhering mortar, (b) three granite particles held together and surrounded by mortar, (c) only mortar (Akbarnezhad et al., 2011)

\subsubsection{Recycled concrete aggregates (RCA) properties}

The adhered mortar and its relative content in RCA particles play a significant role in physical and mechanical properties of this type of aggregates. Concrete made by RCA contains two types of Interfacial Transition Zone (ITZ), in which one of them is between the original aggregate, and residual mortar, and the other one is between the RCA and fresh paste as shown in Figure 2.2 (Ryu, 2002). As a result, coarse RCA has relatively lower density, higher water absorption and higher abrasion loss than natural aggregate (NA), therefore the use of RCA in higher replacement ratios particularly as structural concrete is not suggested (Dhir et al., 2004; Dos Santos et al., 2004; Tam and Tam, 2008). Some of the physical and mechanical properties of RCA are discussed as follows:

Shape and texture: Previous studies done by researchers like Malhotra (1976) used microscopic scanning to identify the shape of the recycled aggregate particles. RCA demonstrated more angular particles compared to natural aggregates. The angular shape of recycled aggregate is because of adhered mortar (Topco and Mustafa, 1997). 


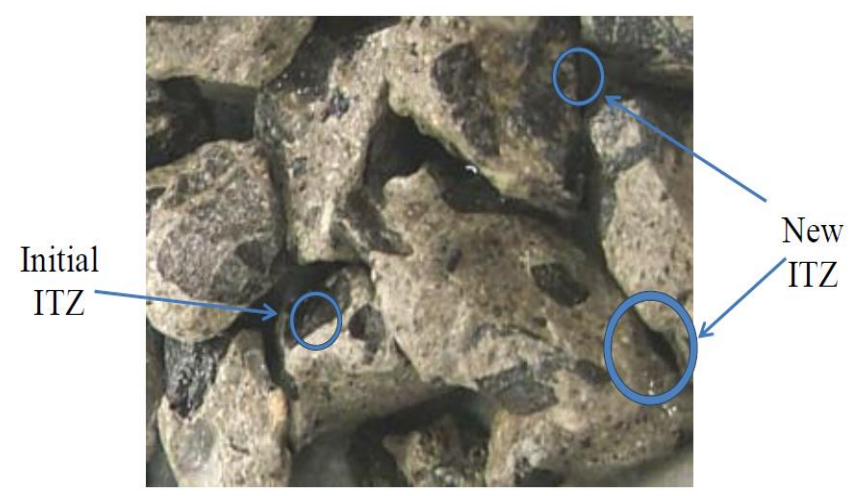

Figure 2.2 Interfacial Transition Zones (ITZs) locations on RCA concrete (Ryu, 2002)

Absorption capacity: The specific gravity and water absorption are directly affected by the presence of adhered mortar (Parekh and Modhera, 2011). The porous nature of the cement paste portion of the recycled aggregates increases its absorption capacity. Absorbing capacity can be controlled by the limited use of recycled fine aggregate.

Specific gravity: Same as absorption capacity, the specific gravity which is a measure of the density of an aggregate of RCA is adversely affected by adhered mortar. According to Hansen and Narud (2003), the specific gravity (saturated surface dry, SSD) value of the RCA is 4.6 to $6.5 \%$ less than natural aggregates. It gains lower specific gravity because of the porosity and entrained air structure of the adhered aggregate.

L.A. Abrasion mass loss: According to studies, adhered mortar in the recycled aggregate causes to form a weak zone between the parents aggregate and the cement mortar paste. As a results RCA has lower mechanical strength compare to NA and (Sharma and Singla, 2014). Based on experimental studies such as the aggregate impact value test, aggregate crushing value test and Los Angeles abrasion or micro-deval degradation tests, RCA are not as strong as the virgin aggregates (Parekh and Modhera, 2011).

Durability: Sulfate soundness test is one of the common tests implemented in USA for the prediction of freezing and thawing durability of aggregates. However, the results of different researchers show large differences about this property of RCA. This is debated by many of researchers that the sulfate soundness test is an improper test because of the fact that chemical attack occurs to the concrete materials by the exposure to environment in a long period of the time (Kou et al., 2002). 


\subsubsection{Use of RCA in different types of concrete}

RCA applies in several types of construction such as Aggregate Base Course, Pipe Bedding, Paving Blocks, Building Blocks, and Landscape Materials. It is reported by FHWA (2004), 38 states within the United Stated are recycling demolished concrete for granular base material. It is also common to use of the RCA in providing the Portland cement concrete in the structural elements. The natural aggregate is replaced by the RCA either partially or entirety considering the type of construction and the quality of the RCA.

\subsubsection{Hardened RCA concrete properties}

The effects of implementing RCA into concrete are highly dependent on the nature, composition, and gradation of the RCA (American Concrete Pavement Association, 2010). Following are a brief review of properties of the hardened concrete made by recycled aggregates:

Compressive Strength: In structural concrete with specific mix design, it is recommended that the RCA replaced with a portion of natural aggregates. In fact there is a defined limit which RCA can be replaced with NA which the compressive strength is not effected significantly, as the compressive strength of recycled aggregate concrete generally decrease with increasing recycled aggregate contents. In some research papers it is stated that concrete made with recycled aggregates has a compressive strength about 22\%-32\% less than the strength of the concrete made with natural aggregates (Jitender and Sandeep, 2014).

Tensile and Flexural Strength: The results of the experiments made by many researchers show that the tensile splitting strength of the given concrete mix decreased as the RCA content increased (Kou et al., 2007).

Modulus of Elasticity: According to the previous research the stiffness or modulus of elasticity of RCA concretes is 20 to $40 \%$ lower than that of conventional concrete with the same watercement ratio (Anderson et al. 2009). This reduction in modulus of elasticity might be due to the presence of adhered mortar which is attached to the aggregate with lower modulus of elasticity.

Drying Shrinkage and Creep: Some researchers believe that concrete mixes with RCA have higher paste content (due to adhered mortar) and higher drying shrinkage will occur to them compared with conventional concrete. According to Parekh and Modhera (2011), increase of 
shrinkage occurs due to higher water cement ratios, higher paste contents, and lower coarse aggregate contents. The amount of voids existing in fresh cement paste can control the drying shrinkage in hardened concrete.

Bond Strength between Concrete and Reinforcement: Anderson et al. (2009) observe that application of RCA in concrete can cause a remarkable reduction in bond strength between the concrete and the reinforcement used in the concrete. The reduction will be higher by fine aggregates are used.

Durability: The following characteristics can specify the durability of hardened concrete: freezethaw resistance, d-cracking susceptibility, permeability and absorption, and alkali silica reaction susceptibility. Buck (1977), stated that when comparing the two types of concretes with virgin and natural, with the same design mix, RCA shows a better frost resistance due to its higher entrained air content and porous nature of adhered mortar.

\subsection{SHEAR STRENGTH EVALUATION OF RC BEAMS}

\subsubsection{Background}

Reinforced concrete (RC) beams demonstrate a complex behavior under shear compared to their flexural behavior. The mechanism of internal load transfer is notably different before and after formation of cracks. The shear failure of RC beams has a sudden brittle nature due to lack of ductility and cracking pattern characteristics (Neilson, 2004). In this section an overview of the shear behavior of RC beams and corresponding design approaches are presented. The parameters affecting shear behavior, shear transfer mechanisms and shear design principles are also described. A brief description of the truss analogy method is presented at the end.

\subsubsection{Shear behavior of reinforced concrete beams}

The behavior of an uncracked beam subjected to flexure and shear effects is the same as homogenous elastic beam. According to the theoretical concepts, the principal stresses are acting on each of the beam small elements perpendicular to the face of the element. The direction of the principal stress varies based on the element location along the cross section of the beam from extreme compression and tension fibers to neutral axis. Stress trajectories as hypothetical curves 
could be drawn according to the values and directions of the principal stresses. When the concrete tensile stress exceeds its modulus of rupture, the diagonal tension cracks begin to occur along the theoretical stress trajectories. The most common shear failure is diagonal tension failure or shear tension failure which is characteristic of beams subjected to point loads with shear span to depth ratio (a/d) value ranging from 2.5 to 5.5. The flexural cracks begins in the mid-span, by a few fine vertical cracks and eventually grow till the bond between the reinforcing steel and the concrete decreases significantly. At this stage, one of the inclined cracks widens and the crack propagates to the top of the beam and a sudden failure occurs, as in shown in Figure 2.3.

According to ASCE-ACI 426 (1973): “ immediately after the inclined cracks develop, the concrete shear force $\left(V_{c z}\right)$ accounts for up to $40 \%$ of the total shear force, whereas the remaining portion is resisted by the dowel force $\left(V_{d}\right)$ and the interface shear force $\left(V_{i}\right)$ " as shown in Figure 2.4.

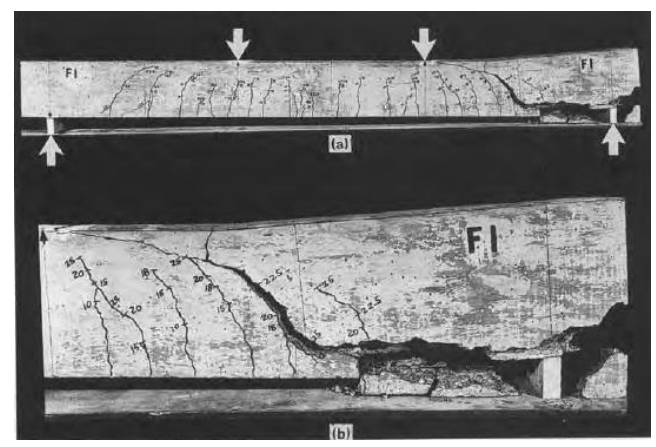

Figure 2.3 Shear failure of RC beams (Neilson, 2004)

The interface transfer shear mechanism becomes less effective by widening the crack and the $\left(V_{i}\right)$ decreases. Finally, the dowel force $\left(V_{d}\right)$ is removed and inclined cracks develop toward the upper face of the beam with an angle of almost 45 degrees. 


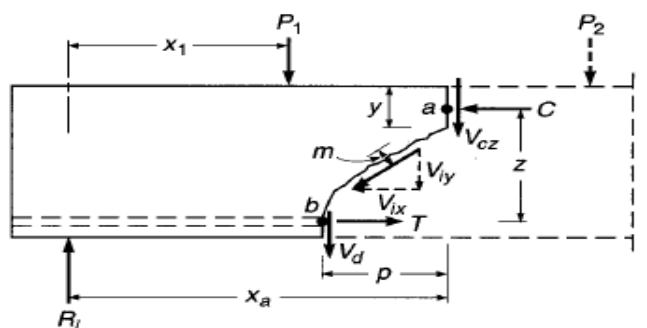

(a)

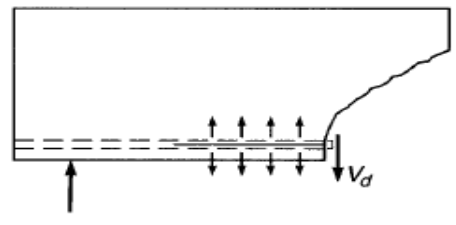

(b)

Figure 2.4 Forces at a diagonal crack in a beam without web reinforcement (Neilson, 2004)

\subsubsection{Shear strength parameters}

The factors and parameters govern the shear strength of a beam are the presence of web reinforcement, longitudinal reinforcement, coarse aggregate size, presence of axial loads, depth of the member, tensile strength of the concrete, and shear span to depth ratio $(a / d)$. Shear design equations contain some but not all the parameters mentioned above.

The effect of web reinforcement: Shear strength of concrete beams increases by using web reinforcement. The brittle nature of the concrete makes it necessary to use web reinforcement to provide more ductility in concrete beams and prevent shear failure. Vertical stirrups are normally used as web reinforcement and depending on shear requirements are spaced along the beam. Shear reinforcement has a small effect before diagonal cracks form. After cracking, major part of shear force is carried by the shear reinforcement. Moreover, it assist preventing crack growth and propagation.

The effect of longitudinal reinforcement: The longitudinal reinforcement ratio $\left(\rho_{\mathrm{s}}\right)$ increases the shear capacity of the beam section. It reduces the width and severity of flexural cracks.

The effect of aggregate size: The coarse aggregate type and size affect the shear capacity significantly, especially for beams without stirrups. As an example, the tensile strength of lightweight aggregate is lower than the normal aggregate. Moreover, large diameter aggregate increases the roughness of the crack surfaces, allowing higher shear stresses to be transferred. 
The effect of axial forces: The results of research works indicated that axial compression forces increase the shear capacity and axial tension forces decrease considerably the shear strength.

The effect of beam size: The size of the beam influence the shear capacity of beams at failure. By increasing the overall depth of a beam shear the force at failure becomes smaller.

The effect of shear span to depth ratio: The shear strength increases by the decrease of shear span to depth ratio decreases. The effect is clearly observed in deep beams $(a / d \leq 2.5)$. In deep beams, the initial diagonal cracking suddenly grows to the entire length of the test region (Wight and MacGregor, 2009).

The effect of concrete strength: The shear strength is also greatly affected by tensile strength but as the compressive strength is pretty easier to be tested than tensile strength, it is common to use compressive strength $\left(f^{\prime} c\right)$.

\subsubsection{Shear analysis methods}

According to the ASCE-ACI Committee 426 (1973), shear is transferred by the following four mechanisms: shear stress in the uncracked concrete, interface shear transfer or aggregate interlock, dowel action, and arch action. Residual tensile stresses is the new shear transfer mechanism introduced by ASCE-ACI Committee 445 in 1998. It states that after first cracks occur as long as the crack width do not exceed 0.00197-0.0059 inches, the tensile forces will still be transferred by the concrete section.

Different shear design methods and guidelines use different approaches in shear modeling such as truss model, Strut and Tie Model (STM), Modified Compression Field Theory (MCFT), and fracture mechanics approach. As it is not the purpose of this study to provide a detailed description of the design principals, a brief explanation of the truss model is given as a typical modeling.

\subsubsection{The Truss analogy method}

A conservative design requires $45^{\circ}$ angle of inclination based on the traditional truss model. The truss model theory provides an accurate modeling for shear resistance of concrete beams after cracking and various load conditions could be included reliably by applying the model (ASCEACI Committee 445, 1998; ASCE-ACI Committee 426, 1973). The model consists of the several 
vertical tension members and diagonal compression members parallel to the inclined shear crack. The stirrups crossing a crack are collected into a vertical tension member. A conservative design requires $45^{\circ}$ angle of inclination based on the traditional truss model. From the free body diagram of Figure 2-5 and 2.6, the shear force (V) can be obtained by:

$V=A_{v} f_{s y} j_{d} / s$

where, $A_{\mathrm{v}}$ is the area of vertical reinforcement, $f_{s y}$ is the yield strength of the stirrups, $j_{d}$ is an internal lever arm and $\mathrm{s}$ is the spacing of stirrup legs. The traditional truss model provides a simple design approach as shown in Figures 2.5 and 2.6. However, it has some drawbacks due to not considering the shear transfer by the aggregate interlock along the crack surface, the dowel action of longitudinal reinforcement and the uncracked compression zone (Hong and Ha, 2001).

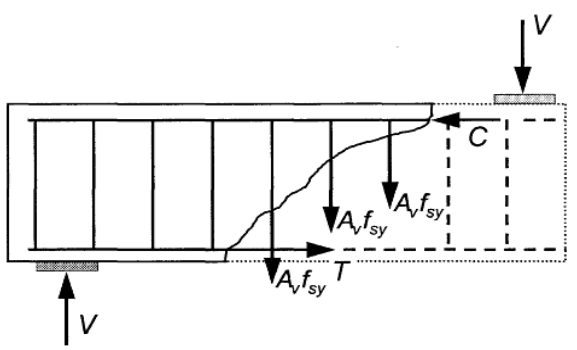

Figure 2.5 Internal forces at an inclined crack (Hong and Ha, 2001)

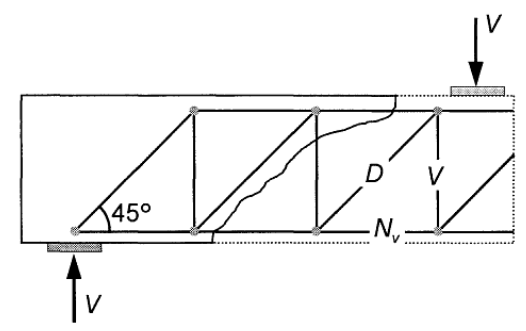

Figure 2.6 Equivalent truss of a beam (Hong and Ha, 2001)

\subsection{DESIGN CODE REVIEWES}

Various design Code/Standard provisions for shear strength evaluation are applied around the world. The main component of some of these Codes/Standards for shear strength evaluation is based on empirical formulas such as the ACI 318-11 (2011), while others such as the AASHTO LRFD(2010) rely more on concrete models like Modified Compression Field Theory (MCFT) (Bentz et al., 2006). 


\subsubsection{American Concrete Institute, ACI 318-01 (2011)}

An average shear stress distribution across the entire cross section is considered to calculate the shear strength of the beam section. As explained previously, 45 degree truss model is the basis of the formulation. ACI code presents the following basic equations for normal-weight, nonprestressed reinforced concrete, all formulas written based on imperial units:

$$
\begin{aligned}
& V_{u} \leq \phi V_{n}=\phi\left(V_{c}+V_{S}\right) \\
& V_{c}=\left(1.9 \sqrt{f_{c}^{\prime}}+2500 \rho_{w} \frac{V_{u}}{M_{u}} d\right) b_{w} d \leq 3.5 \sqrt{f_{c}^{\prime}} b_{w} d
\end{aligned}
$$

Simplified version:

$V c=2 \sqrt{f_{c}^{\prime}} b_{w} d$

$$
A_{v, \min }=\left(0.75 \sqrt{f_{c}^{\prime}} \frac{b_{w}}{f_{y t}} s\right) \geq 50 \frac{b_{w} s}{f_{y t}}
$$

$V_{s}=\frac{A_{v} f_{y t} d}{s}$

where, $V_{u}$ is the factored shear force on the section, $\phi$ is the shear strength reduction factor equal to $0.75, V_{n}$ is the nominal shear strength, $V_{c}$ is the nominal shear strength provided by concrete $V_{S}$ is nominal shear strength provided by shear reinforcement, $\rho_{w}$ is the ratio of longitudinal reinforcement equals $A_{s}$ to $b_{w} . d, A_{s}$ is the area of longitudinal reinforcement, $b_{w}$ is the width of the web, $d$ is the distance from the extreme compression fiber to the center of gravity of the steel, $M_{u}$ is the factored moment at the section, $f^{\prime} c$ is the concrete compressive strength (psi), $f_{y t}$ is the yield strength of the transverse reinforcement (psi), $s$ is the spacing of the transverse reinforcement, and $A_{v}$ is the area of stirrups and $A_{v}$ is the area of shear reinforcement.

\subsubsection{Canadian Standards Association, CSA A23.3-04 (2004)}

The Canadian Standards Association method is based on Modified Compression Field Theory, MCFT and the shear strength of beams is presented in two simplified and general methods:

$V_{r} \geq V_{f}$ 
$V_{r}=V_{c}+V_{S}$

$V_{r, \max }=0.25 \phi_{c} f_{c}^{\prime} b_{W} d_{V}$

$V_{c}=\beta \sqrt{f^{\prime}{ }_{c}} b_{w} d_{v}$

$A_{v_{\min }}=0.06 \sqrt{f^{\prime}{ }_{c}} \frac{b_{w} s}{f_{y}}$

\subsubsection{Simplified method}

a) If the section contains at least the minimum transverse reinforcement, $A_{v}<0.06 \sqrt{f^{\prime}{ }_{c}} \frac{b_{w} s}{f_{y}} \quad, \beta$ shall be taken as 0.18

b) If the section contains no transverse reinforcement and the specified nominal maximum size of coarse aggregate is not less than $20 \mathrm{~mm}, \beta$ shall be taken as:

$$
\begin{aligned}
& A_{v} \geq 0.06 \sqrt{f^{\prime}{ }_{c}} \frac{b_{w} s}{f_{y}} \text { and, } a g \geq 20 \mathrm{~mm}, \\
& \beta=\frac{230}{1000+d_{v}}
\end{aligned}
$$

c) If sections containing no transverse reinforcement for all aggregate sizes, replacing the parameter $d_{v}$ in equation (2-12) by the equivalent crack spacing parameter, $s_{z e}$, where

$$
S_{z e}=\frac{35 s_{z}}{15+a_{g}}
$$

\subsubsection{General method}

The value of $\beta$ shall be determined from the following equation:

$$
\begin{aligned}
& \beta=\frac{0.4}{1+1500 \varepsilon_{x}} * \frac{1300}{1000+s_{z e}} \\
& \varepsilon_{x}=\frac{M_{f / d_{v}}+V_{f}}{2 E_{S} A_{s}} \\
& V_{s}=\phi s \frac{A_{v} f_{y} d_{v} \cot \theta}{s} \\
& \theta=29+7000 \varepsilon_{x}
\end{aligned}
$$


where, $V_{f}$ is factored shear stress, $V_{r}$ is the factored shear resistance, $\phi_{c}$ is the resistance factor for concrete equals $0.65, \phi_{s}$ is resistance factor for non-prestressed reinforcing bars, $V_{c}$ is the nominal shear strength provided by concrete, $V_{S}$ is nominal shear strength provided by shear reinforcement, $A_{s}$ is the area of longitudinal reinforcement, $b_{v}$ is the width of the web, $\mathrm{d}$ is the distance from the extreme compression fiber to the center of gravity of the steel, $d_{v}$ is the effective shear depth, taken as the greater of $0.9 \mathrm{~d}$ or $0.72 \mathrm{~h}, M_{\mathrm{f}}$ is the factored moment at the section, $f^{\prime}{ }_{c}$ is the specified compressive strength of concrete, $f_{y}$ is the specified yield strength of non-prestressed reinforcement or anchor steel, $s$ is the spacing of the transverse reinforcement, $A_{v}$ is the area of shear reinforcement, $\beta$ is the factor accounting for shear resistance of cracked concrete, $\theta$ is the angle of inclination of diagonal compressive stresses to the longitudinal axis of the member, $s_{\mathrm{z}}$ is the equivalent crack spacing parameter, $a_{g}$ is the maximum aggregate size.

The term $a_{g}$ should be taken as zero if $f^{\prime} c$ exceeds $70 \mathrm{MPa}$. The crack spacing parameter $s_{Z}$ can be taken as $d_{v}$ or as the maximum distance between layers of distributed longitudinal reinforcement, whichever is less.

\subsubsection{Australian Standards: AS3600 (2009)}

There are two alternative methods for the shear design of beams in AS3600. The first one is based on truss analogy and the second one is based on the equations provided in the standard and utilizes the Sample Average Approximate (SAA) method. The truss analogy method takes no account of the shear resisted by the concrete compressive zone, and therefore is over-conservative in this respect (Warner et al, 1998). The ultimate shear strength $V_{\mathrm{u}}$ is given as:

$$
\begin{aligned}
& V_{u}=V_{u c}+V_{u s} \\
& V_{u c}=\beta_{1} \beta_{t} \beta_{3} b_{v} d_{o}\left[\frac{A_{s t} f_{c}^{\prime}}{b_{v} d_{o}}\right]^{1 / 3}
\end{aligned}
$$




$$
\begin{aligned}
& \beta_{1}=1.1\left[1.6-\frac{d_{o}}{1000}\right] \geq 1.1 \\
& \beta_{2}=1 \\
& \beta_{3}=1
\end{aligned}
$$

The shear force is limited to a maximum of:

$$
V_{u \text { max }}=0.2 f^{\prime}{ }_{c} b d_{\mathrm{o}}
$$

The ultimate shear strength of a beam provided with minimum shear reinforcement shall be taken as:

$$
V_{u \text { min }}=V_{u c}+0.6 b d_{\mathrm{o}}
$$

The minimum area of shear reinforcement $\left(A_{\mathrm{sv} \text {.min }}\right)$ provided in a beam shall be given by

$$
A_{s v \text { min }}=0.35 b_{s} / f_{s y}
$$

The required shear reinforcement per unit spacing, $A_{V} / s$, is calculated as follows:

If $\quad V^{*} \leq \varphi V_{u c} / 2, \quad A_{V} / s=0, \quad$ except for $d \geq 750 \mathrm{~mm}, A_{s v \cdot m i n}$ shall be provided:

If $\quad V_{u \text { min }}<V^{*} \leq V_{u}$ :

$$
\frac{A_{s v}}{s}=\frac{V^{*}-\varphi V_{u c}}{f_{s y} d_{0} \cot \theta_{v}}
$$

$A_{s v \text { min }} \geq \max \left(0.35 \mathrm{~b} / \mathrm{f}_{S Y}\right)$

$\theta_{V}=$ the angle between the axis of the concrete compression strut and the longitudinal axis of the member, which varies linearly from 30 degrees when $V^{*}=\varphi V_{u \text { min }}$ to 45 degrees when $V^{*}=$ $\varphi V_{u, \max }=35.52$ degrees. If $V^{*}>\varphi V_{\max }$, a failure condition is declared.

where $V^{*}$ is the factored shear force at a section, $V_{u c}$ is the shear force resisted by concrete, $V u s$ is the shear force resisted by steel, $d_{0}$ is the depth of the outermost layer of tensile reinforcement, $A_{s t}$ is the cross-sectional area of longitudinal reinforcement provided in the tension zone and fully anchored at the cross-section under consideration, $\varphi$ is the strength reduction factor equals 0.8 . 


\subsubsection{Eurocode 2 (2004)}

\section{- Members not requiring design shear reinforcement}

The design value for the shear resistance $V_{R d, c}$ is given by:

$V_{R d, c}=\left[C_{R d, c} k\left(100 \rho_{l} f_{c k}\right)^{\frac{1}{3}}\right] b_{w} \mathrm{~d}$

$k=1+\frac{\sqrt{200}}{\mathrm{~d}}$

$\rho_{l}=A_{s l} / b_{w} d \leq 0.02$

The values of $\mathrm{C}_{\mathrm{Rd}, \mathrm{c}}, v_{\min }$ for use in a Country may be found in its National Annex.

The recommended values for

$C_{R d, c}=0.18 / \gamma_{c}$

$V_{\min }=0.035 \mathrm{k}^{2 / 3} f_{c k}{ }^{1 / 2}$

where, $A_{\mathrm{sl}}$ is the area of the tensile reinforcement, $b_{\mathrm{w}}$ is the smallest width of the cross-section in the tensile area, $f_{c k}$ is the Characteristic compressive cylinder strength of concrete at 28 days.

The strength classes (C) in this code are denoted by the characteristic cylinder strength $f_{\text {ck }}$ determined at 28 days with a minimum value of and a maximum value of $\mathrm{C}_{\min }$ and the maximum value of $\mathrm{C}_{\max }$. The values of $\mathrm{C}_{\min }$ and $\mathrm{C}_{\max }$ for use in a Country may be found in its National Annex. The recommended values are C30/37 and C70/85, respectively.

$f_{\mathrm{ck}}=f^{\prime}{ }_{\mathrm{c}}-1.6(\mathrm{MPa}) \approx 0.95 f^{\prime}{ }_{\mathrm{c}}, \gamma_{c}$ is the Partial factor for concrete. The recommended values for "persistent \& transient" and "accidental" design situation are given in Table 2.1.

Table 2.1 Partial factors for materials for ultimate limit states (Eurocode 2, 2004)

\begin{tabular}{|l|c|c|c|}
\hline Design situations & $\gamma_{\mathrm{C}}$ for concrete & $\gamma_{\mathrm{S}}$ for reinforcing steel & $\gamma_{\mathrm{s}}$ for prestressing steel \\
\hline Persistent \& Transient & 1,5 & 1,15 & 1,15 \\
\hline Accidental & 1,2 & 1,0 & 1,0 \\
\hline
\end{tabular}

\section{- Members requiring design shear reinforcement}

For members with vertical shear reinforcement (Figure 2.7), the shear resistance, $V_{\mathrm{Rd}}$ is the smaller value of: 


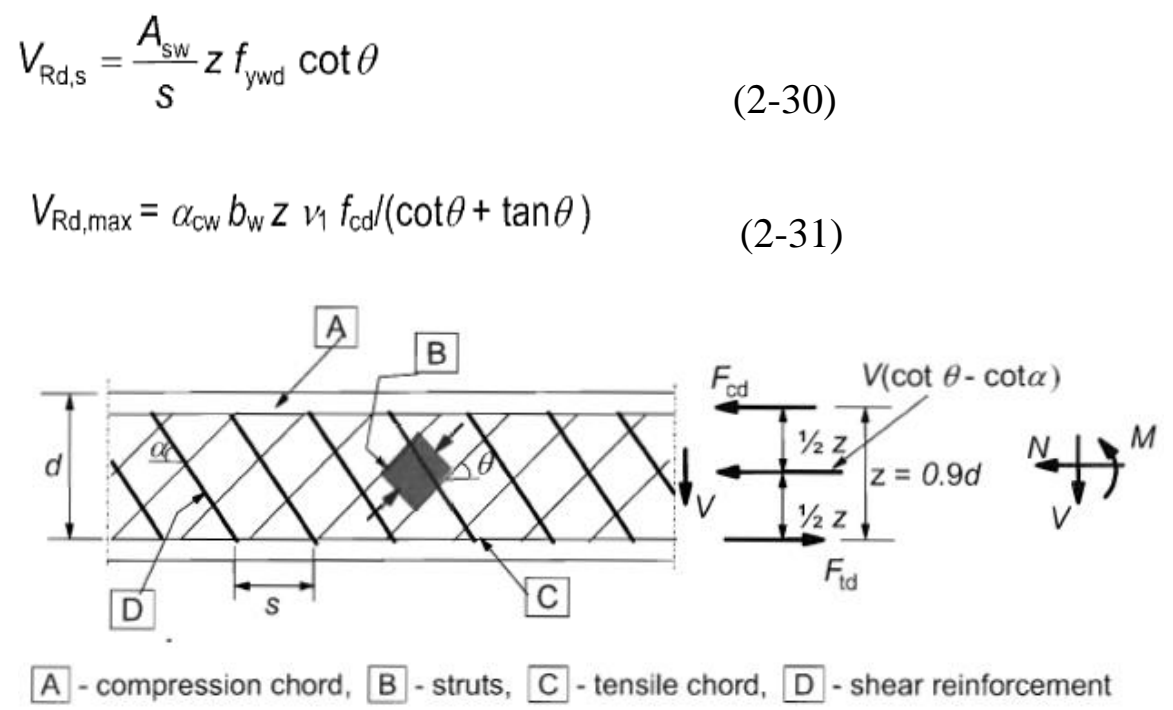

Figure 2.7 Truss model and notation for shear reinforced members

where, $\mathrm{z}$ is the inner lever arm, equals $0.9 \mathrm{~d}, A_{S W}$ is the cross-sectional area of the shear reinforcement, $s$ is the spacing of the stirrups, $f_{y w d}$ is the design yield strength of the shear reinforcement, $V_{1}$ is a strength reduction factor for concrete cracked in shear, $V_{1}=0,6$ in case of $f_{c k} \leq 60 \mathrm{MPa}, V_{1}=0.9-f_{c k} 1200>0.5$ for $f_{c k} \geq 60 \mathrm{MPa}, \mathrm{a}_{c w}$ is a coefficient taking account of the state of the stress in the compression chord, $\theta$ is the angle between the concrete compression strut and the beam axis. The limiting values of $\cot \theta$ for use in a Country may be found in its National Annex. The recommended limits are given as: $1 \leq \cot \theta \leq 2.5$.

\subsubsection{CEB-FIP MODEL CODE (1990)}

The fundamental "unit-length" of a typical part of the web model of a beam resisting shaer and axial action effects is shown in Figure 2.8. The angle $\theta$ between the web compression and the chords may be chosen freely in the range from 45 degree $(\operatorname{arc} \cot 1)$ to 18.4 degree $(\operatorname{arc} \cot 3)$. 


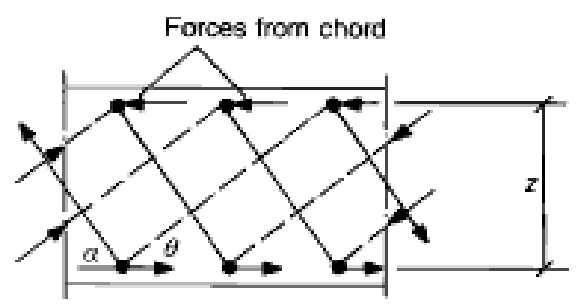

Figure 2.8 Web model (CEB-FIP model code, 1990)

The compression of web concrete, is shown in Figure 2.9 and the tension of web steel is shown in Figure 2.10.

$$
F_{R c w^{-}}=f_{c d 2} b_{w^{*}} z \cos \theta
$$

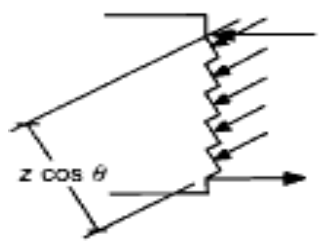

Figure 2.9 Compression of web concrete (CEB-FIP model code, 1990)

The tension of web steel is:

$$
F_{R t w}=\left[\frac{A_{s w} f_{y d}}{s}\right] z(\cot \theta+\cot \alpha)
$$

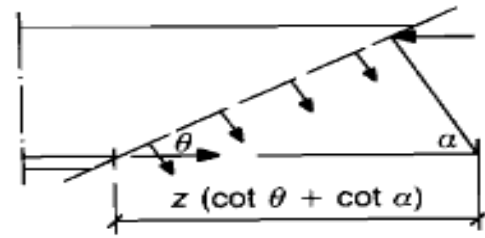

Figure 2.10 Tension of web steel (CEB-FIP model code, 1990)

For the vertical stirrups alone, the minimum amount of $\theta$ is obtained by:

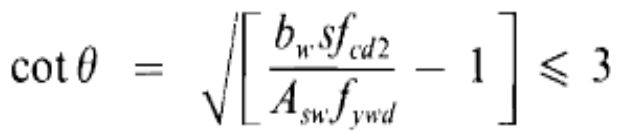

For which 


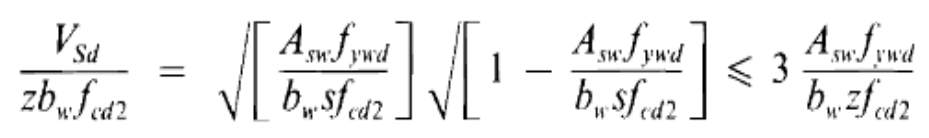

In the absence of a more precise calculation the shear force causing shear cracking, may be estimated as:

$V_{C}=0.15\left(\frac{3 d}{a_{v}}\right)^{1 / 3} \xi\left(100 \rho f_{c k}\right)^{1 / 3} b_{r e d} d$

$\xi=1+\frac{\sqrt{200}}{\mathrm{~d}}$

where, $\rho$ is the ratio of flexural tensile reinforcement $A_{s w} / b_{w} Z, a_{V}$ is the distance from major load to support, $b_{r e d}$ is the reduced web breadth, $f_{\mathrm{cd} 2}$ is the design value of the concrete tensile strength, $f_{\mathrm{ywd}}$ is the design value of the web (shear) reinforcement, $f_{c k}$ is the Characteristic, compressive cylinder strength of concrete at 28 days, $A_{s} w$ is the area of longitudinal reinforcement, $s$ is the space of shear reinforcement and $z$ is the effective depth of the beam.

\subsubsection{Spanish Code: EHE-08 (2011)}

The general design strut-and-tie method shall be used on all structural members to analyzing bearing capacity of concrete structures with regards to shear strength.

Verification at the limit state of failure due to shear may be carried out based on the effective shear stress $V_{\text {rd }}$ form the following expression:

$V_{\mathrm{rd}}=V_{\mathrm{d}}+V_{\mathrm{cd}}$

where, $V_{\mathrm{d}}$ is the design value of the shear force produced by external actions, $V_{\mathrm{cd}}$ is the design value of the component parallel to the section of the resultant normal.

The limit state of failure due to shear will be reached when either the compressive strength of the web or its tensile strength is exhausted. It is necessary to verify that the both the following conditions are simultaneously satisfied:

$V_{\mathrm{rd}} \leq V_{\mathrm{u} 1}$

$V_{\mathrm{rd}} \leq V_{\mathrm{u} 2}$ 
Where, $V_{\text {rd }}$ is the design value of the effective shear force in Equation (2-38), $V_{u 1}$ is the ultimate shear force failure due to diagonal compression in the web and $V_{\mathrm{u} 2}$ is the ultimate shear force failure due to tension in the web.

\subsubsection{Obtaining $V_{\mathbf{u} 1}$}

$$
V_{u I}=K f_{I c d} b_{0} d \frac{\operatorname{cotg} \theta+\operatorname{cotg} \alpha}{1+\operatorname{cotg}^{2} \theta}
$$

where, $f_{c d}$ is the concrete's compression strength, for $f_{c k} \leq 60 \mathrm{~N} / \mathrm{mm}^{2}$ we have $f_{i c d}=0.60 f_{c d}, b_{o}$ is the net minimum width of the member, $k$ is the coefficient which depends on the axial force and equals lin case of non-pre- stressed structures or structures without any axial compression force.

\subsubsection{Obtaining $V_{\mathrm{u} 2}$}

\subsection{Members without shear reinforcement in regions cracked in flexure}

Ultimate shear force failure due to tensile force in the web in conventional and high strength concrete members shall be:

$\mathrm{V}_{\mathrm{u} 2}=\left[\frac{0,18}{\gamma_{\mathrm{c}}} \xi\left(100 \rho_{1} f_{\mathrm{cv}}\right)^{1 / 3}+0,15 \sigma_{\mathrm{cd}}^{\prime}\right] \mathrm{b}_{0} \mathrm{~d}$

With the minimum value of:

$\mathrm{V}_{\mathrm{u} 2}=\left[\frac{0,075}{\gamma_{\mathrm{c}}} \xi^{3 / 2} \mathrm{f}_{\mathrm{cv}}^{1 / 2}+0,15 \sigma_{\mathrm{cd}}^{\prime}\right] \mathrm{b}_{0} \mathrm{~d}$

where, $\xi=1+\frac{\sqrt{200}}{\mathrm{~d}} \leq 2.0, \rho_{1}=A_{s} / b_{0} d \leq 0.02, f_{\mathrm{cv}}$ is the effective shear strength of the concrete in $\mathrm{N} / \mathrm{mm}^{2}$ with the value of $f_{c v}=f_{c k}$, with $f_{c v}$ not more than $15 \mathrm{~N} / \mathrm{mm}^{2}$ in the case of reduced concrete control, with $f_{c k}$ being the concrete's compression strength, which, for the purpose of this paragraph, shall be considered not to exceed $60 \mathrm{~N} / \mathrm{mm}^{2}$ and $d$ is the effective depth of the crosssection. 


\subsection{Members with shear reinforcement}

Ultimate shear force failure due to tensile in the web shall be as the following equation:

$V_{u 2}=V_{c u}+V_{s u}$

$V_{s u}=z \operatorname{sen} \alpha(\operatorname{cotg} \alpha+\operatorname{cotg} \theta) \Sigma A_{a} f_{y \alpha d}$

where, $A_{a}$ is area per unit length of each set of reinforcements forming an angle $\alpha$ with the main axis of the member, $f_{y \alpha d}$ is the design strength of reinforcement $A_{a}, \theta$ is the angle between the concrete's compression struts and the axis of the member and shall be satisfy following: $0.5 \leq \cot \theta \leq 2.0, \alpha$ is the angle of the reinforcement with the member's axis, $\mathrm{z}$ is the mechanic lever arm. In pure bending and in the absence of more accurate calculation, the approximate value of $\mathrm{z}=0.9 \mathrm{~d}$ may be adopted.

$$
\begin{aligned}
& V_{c u}=\left[\frac{0,15}{\gamma_{C}} \xi\left(100 \rho_{l} f_{c v}\right)^{l / 3}+0,15 \alpha_{l} \sigma_{c d}^{\prime}\right] \beta b_{0} d \\
& \beta=\frac{2 \operatorname{cotg} \theta-1}{2 \operatorname{cotg} \theta_{e}-1} \quad \text { si } 0,5 \leq \operatorname{cotg} \theta<\operatorname{cotg} \theta_{\theta} \\
& \beta=\frac{\operatorname{cotg} \theta-2}{\operatorname{cotg} \theta_{e}-2} \quad \text { si } \operatorname{cotg} \eta_{\theta} \leq \operatorname{cotg} \theta \leq 2,0 \\
& \Theta_{e}=29+7 \varepsilon_{\mathrm{x}} \\
& \varepsilon_{x}=\frac{\frac{M_{d}}{z} V_{d}}{2 E_{s} A_{s}} \cdot 1000>0
\end{aligned}
$$

where, $f_{C V}$ is the effective shear strength of the concrete in $\mathrm{N} / \mathrm{mm}^{2}, F_{c k}$ is the compression strength of the concrete in $\mathrm{N} / \mathrm{mm}^{2}, \Theta_{e}$ is the reference angle of inclination of cracks, and is calculated by the general method with Equation 2-47 and $\gamma_{c}$ is the partial safety factor for concrete obtained by the Table 2.2. 
Table 2.2 Partial safety factors for the materials for the Ultimate Limit States (EHE-99, 1999).

\begin{tabular}{|c|c|c|}
\hline Design situation & Concrete & $\begin{array}{c}\text { Steel for passive and active } \\
\text { reinforcements } \\
\gamma_{s}\end{array}$ \\
\hline Persistent or temporary & 1.5 & 1.15 \\
\hline Accidental & 1.3 & 1.0 \\
\hline
\end{tabular}

\subsubsection{NZS 3101 (2006)}

As per New Zealand Standard, the nominal shear strength for resisted by concrete for normal density concrete, $V_{c}$, shall be taken as:

$$
\begin{aligned}
& V_{\mathrm{c}}=V_{C} A_{C V} \\
& V_{\mathrm{c}}=k_{d} k_{a} V_{\mathrm{b}}
\end{aligned}
$$

where, $A_{c V}$ is the effective shear area, area used to calculate shear stress, $V_{c}$ is the shear resisted by concrete, $V_{\mathrm{b}}$ is the smaller of $\left(0.07+10 \rho_{w}\right) \sqrt{f_{c}^{\prime}}$ or $0.2 \sqrt{f_{c}^{\prime}}$ but need not be taken as less than $0.08 \sqrt{f_{c}^{\prime}}, f_{c}^{\prime}$ is the specified compressive strength of concrete and shall not greater than $60 \mathrm{Mpa}$, $k_{a}$ is the factor allows for the influence of maximum aggregate size on the shear strength, $k_{a}=1.0$, if the maximum aggregate size $=20 \mathrm{~mm}, k_{a}=0.85$, if the maximum aggregate size equals $10 \mathrm{~mm}$ or less, $k_{d}$ is the influence member depth on shear strength, $k_{d}=1$, for members with shear reinforcement equal to or greater than the nominal shear, reinforcement as given in Equation 2-51, $k_{d}=1$, for members with an effective depth equal to or smaller than $400 \mathrm{~mm}$.

For members with an effective depth of $200 \mathrm{~mm}$ or less, the value of $v_{\mathrm{c}}$ shall be taken as the larger of: $0.17 k_{a} \sqrt{f_{c}^{\prime}}$ or the value given by Equation (2-50) of the Code. For members with an effective depth between $200 \mathrm{~mm}$ and $400 \mathrm{~mm}$, the value of $v_{\mathrm{c}}$ shall be found by linear interpolation.

Nominal shear strength provided by shear reinforcement:

$V_{S}=\frac{V^{*}}{\varphi}-V_{C}$ 
Where, $V^{*}$ is the design shear force at section at the ultimate limit state. Shear force due to transverse reinforcement perpendicular to longitudinal axis of the beams can be derived as:

$V_{S}=A_{v} f_{y t} \frac{d}{s}$

where, $A_{v}$ is the area of shear reinforcement within distance s.

The minimum area of shear reinforcement for non-prestressed members shall be computed by:

$A_{v}=\frac{1}{16} \sqrt{f_{c}^{\prime}} \frac{b_{w} s}{f_{y t}}$

where, $f_{y t}$ is the lower characteristic yield strength of transverse reinforcement.

\subsubsection{Zsutty (1971)}

The shear strength of concrete beam section without web reinforcement (Vc) can be calculated by Zsutty (1971). If the shear span to depth ratio, a/d, is greater than 2.5:

$$
V_{c}=2.21\left(f_{c}^{\prime} \rho_{s} d / a\right)^{1 / 3} b_{w} d
$$

If the shear span to depth ratio, a/d, is smaller than 2.5 :

$$
V_{c}=\left[2.21\left(f_{c}^{\prime} \rho_{s} d / a\right)^{1 / 3}\right]\left(2.5 \frac{d}{a}\right) b_{w} d
$$

Where, $V_{c}$ is the shear strength provided by concrete, $\rho_{\mathrm{s}}$ is ratio of longitudinal reinforcement equals $A_{s}$ to $b_{W} . d, A_{s}$ is the area of longitudinal reinforcement, is the width of the web, $d \quad$ is the distance from the extreme compression fiber to the center of gravity of the steel, $f^{\prime} c$ is the concrete compressive strength, $a$ is the shear span and $\frac{d}{a}$ is shear span to depth ratio.

\subsubsection{Cladera and Marı' (2004)}

- Beams without web reinforcement:

$V_{c}=\left[0.225 \xi\left(100 \rho_{l}\right)^{1 / 2} f_{c}^{0.2}\right] b_{w} d$

$\xi=1+\sqrt{\frac{200}{s_{x}}} \rho_{l}=\frac{A_{l}}{b_{w} d} \leq 0.02\left(1+\frac{f_{c}}{100}\right)$

- Beams with web reinforcement:

$V_{f}=V_{c}+V_{S}$ 
$V_{c}=\left[0.17 \xi\left(100 \rho_{s}\right)^{1 / 2} f_{c}^{0.2} \tau^{1 / 3}\right] . b_{w} d$

$\xi=1+\sqrt{\frac{200}{s_{x}}} \leq 2.75 \rho_{s}=\frac{A_{l}}{b_{w} d} \leq 0.04$

$\tau=\frac{V_{d}}{b_{w} d_{v}} \leq 3 \mathrm{MPa}$

$V_{s}=d_{v} \frac{A_{w}}{s} f_{y w d} \cot \theta$

$\theta=20+15 \varepsilon_{x}+45 \frac{\tau}{f_{c}} \leq 45$

$\varepsilon_{x}=0.5 \frac{M_{d} / d_{v}+V_{d}}{E_{s} A_{l}} .1000 \leq 1$

Where, $V_{c}$ is the shear strength provided by concrete, $V_{s}$ is the shear strength provided by shear reinforcement, $V_{f}$ is the failure tension shear strength for members with web reinforcemen, $\mathrm{s}_{\mathrm{x}}$ is whichever is smaller: $d_{v}$ or the vertical distance between longitudinal distributed reinforcement, $d_{v}$ is the mechanical depth which can be taken as $0.9 . \mathrm{d}, \mathrm{d}$ is the effective depth in $\mathrm{mm}, V_{d}$ is the designing (factored) shear strength, bw is the smallest width of the crosssection area in mm, $A_{w}$ is the cross-sectional area of the shear reinforcement, $A_{l}$ is the cross-sectional area of the shear longitudinal reinforcement, $s$ is the spacing of the stirrups, $M_{d}$ is the design moment of the section, $E_{s}$ is the modulus of elasticity of the steel, $f_{c}$ is the concrete compressive strength, $f_{y w d}$ is the design yielding strength of the shear reinforcement, and $\theta$ is the angle of the compression struts, derived as above formula, $\varepsilon_{\mathrm{X}}$ is the longitudinal strain in the web expressed in $1 / 1000$, calculated by the above formula.

\subsubsection{Gastebled and May (2001)}

The shear strength of concrete beam section without web reinforcement $\left(V_{C}\right)$ is calculated by Gastebled and May (2001) :

$V_{C}=0.15 \frac{37.41}{\sqrt{d}}\left(\frac{3 d}{a}\right)^{\frac{1}{3}}\left(100 \rho_{s}\right)^{\frac{1}{6}}\left(1-\sqrt{\rho_{s}}\right)^{2 / 3}\left(f_{c}^{\prime}\right)^{0.35} b_{w} d$

Where, $V_{c}$ is the shear strength provided by concrete, $\rho_{\mathrm{s}}$ is ratio of longitudinal reinforcement equals $A_{s}$ to $b_{w} . d, A_{s}$ is the area of longitudinal reinforcement, $b_{w}$ is the width of the web, $d$ is the 
distance from the extreme compression fiber to the center of gravity of the steel, $f^{\prime} c$ is the concrete compressive strength, $a$ is the shear span and $\frac{d}{a}$ is shear span to depth ratio. 


\section{CHAPTER THREE}

\section{AN ANALYTICAL STUDY TO EVALUATE THE PERFORMANCE OF CODES/EXISTING PROVISIONS FOR SHEAR STRENGTH PREDICTION OF RCA BEAMS}

\subsection{GENERAL}

Experimental results reveal that mechanical properties and structural behavior of recycled aggregate concrete are varied from conventional concrete, and the variation depends on factors such as the percentage of recycled aggregate replaced with natural aggregate, beam size or shear span to depth ratio $(\mathrm{a} / \mathrm{d})$. As a consequence, the performance of existing guidelines and code provisions for evaluation of shear strength of recycled aggregate concrete (RAC) beams is questionable. It becomes difficult for engineers to entirely rely on existing methods and code provisions. For safety and serviceability purposes, specific code provisions needs to be re-examined or modified. This chapter presents a number of experimental studies done by previous researchers. The test results for shear strength of tested RAC beams are used to study the performance of various Codes/existing equations presented in Chapter Two. Then a comparison of test and predicted shear strengths of RAC beams is carried out to study the accuracy/performance of available Codes/existing design guidelines. The test beams were categorized in two groups: beams with and without transverse/shear reinforcements. The experimental studies are described by presenting the effect of following principal parameters on the shear strength of the tested beams: concrete type made with RAC with different proportions of replacement or conventional concrete (CC), the amount of longitudinal reinforcement, the amount of transvers reinforcement if existed, compressive strength of the concrete, beam size and shear span to depth ratio.

\subsection{REINFORCED CONCRETE BEAMS WITHOUT WEB REINFORCEMENT}

\subsubsection{Arezoumandi et al. (2014)}

An experimental investigation on the shear strength of reinforced concrete beams composed of recycled concrete aggregate was conducted. Twelve full-scale beams were constructed for tests, in which six of them were composed of $100 \%$ recycled aggregate and others with normal 
aggregate. The test parameters for this study were longitudinal reinforcement ratio and concrete type. The research objectives were:

- To compare the experimental shear strengths of the beams with the shear provisions of both U.S. and international design codes (U.S., Australia, Canada, Europe, and Japan) as well as a shear database of CC specimens.

- To evaluate the shear strengths of RAC beams based on different fracture mechanics approaches and the modified compression field theory (MCFT) method.

- To perform statistical data analyses (both parametric and non-parametric) to evaluate whether or not there was any statistically significant difference between the shear strength of the recycled aggregate concrete (RAC) and CC beams.

For each concrete type six beams without stirrups were built with three different longitudinal reinforcement ratios $(1.27 \%, 2.03 \%$, and $2.71 \%)$. The beams were designed to prevent flexural failure and satisfy the minimum and maximum longitudinal reinforcement requirements of ACI 318-11. The beams cross section are rectangular with a width of $300 \mathrm{~mm}$, a height of $460 \mathrm{~mm}$, a length of $4300 \mathrm{~mm}$, and shear span-to-depth ratios of 3.0 or greater. The details of the beams are given in Figure 3.1 and Table 3.1.

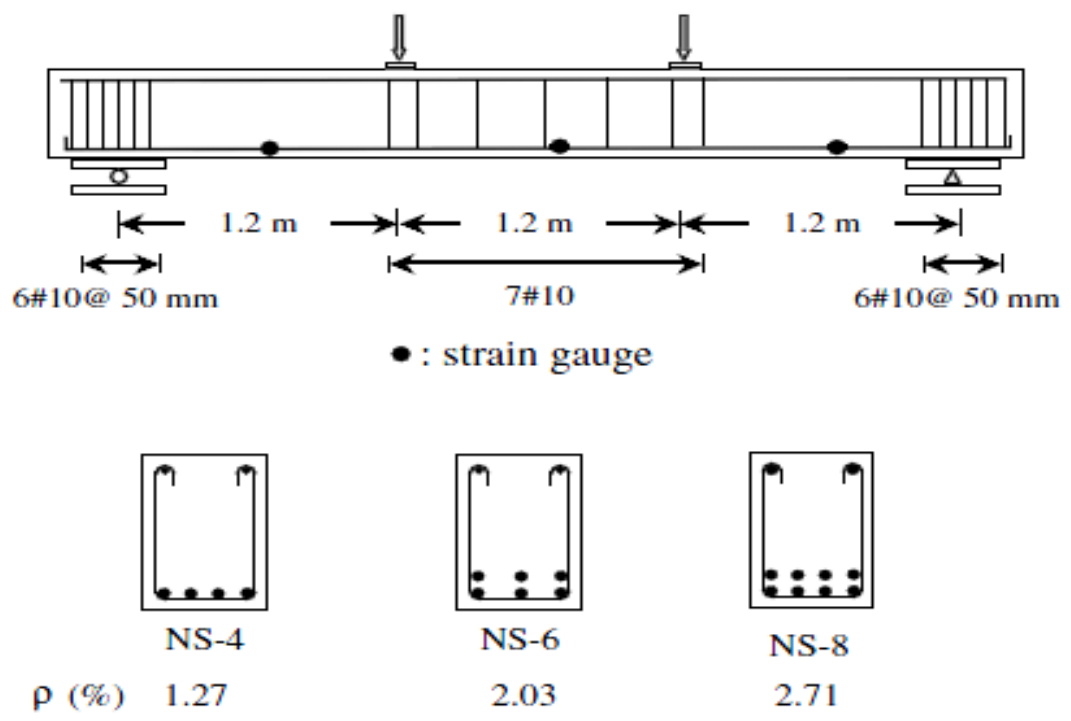

Figure 3.1 Cross sections and reinforcement layout of the test beams (Arezoumandi et al., 2014) 
Table 3.1 Details of Reinforced Concrete Beams tested by Mahdi Arezoumandi et al. (2014)

\begin{tabular}{|c|c|c|c|c|c|c|c|c|c|c|c|}
\hline \multirow{2}{*}{$\begin{array}{c}\text { Beam } \\
\text { Id }\end{array}$} & \multirow{2}{*}{ Section } & $\mathbf{f}_{\mathbf{c}}$ & $\mathbf{f}_{\mathbf{y}}$ & $\mathbf{E}_{\mathbf{s}}$ & $\mathbf{b}_{\mathbf{w}}$ & $\mathbf{a} / \mathbf{d}$ & $\mathbf{d}$ & $\mathbf{a}_{\mathbf{g}}$ & $\boldsymbol{\rho}_{\mathbf{s}}$ & $\mathbf{A}_{\mathbf{s}}$ & $\mathbf{V}_{\mathbf{c}}$ \\
\cline { 3 - 11 } & $\mathrm{MPa}$ & $\mathrm{MPa}$ & $\mathrm{Mpa}$ & $\mathrm{mm}$ & & $\mathrm{mm}$ & $\mathrm{mm}$ & & $\mathrm{mm}^{2}$ & $\mathrm{kN}$ \\
\hline NS-4 & $\mathrm{CC} 1$ & 37.3 & 449 & 193140 & 300 & 3 & 400 & 25 & $1.27 \%$ & 1520 & 121.2 \\
NS-4 & $\mathrm{CC} 2$ & 34.2 & 449 & 193140 & 300 & 3 & 400 & 25 & $1.27 \%$ & 1520 & 129.9 \\
NS-6 & $\mathrm{CC} 1$ & 37.3 & 449 & 193140 & 300 & 3 & 400 & 25 & $2.03 \%$ & 2280 & 143.2 \\
NS-6 & $\mathrm{CC} 2$ & 34.2 & 449 & 193140 & 300 & 3 & 400 & 25 & $2.03 \%$ & 2280 & 167 \\
NS-8 & $\mathrm{CC} 1$ & 37.3 & 449 & 193140 & 300 & 3 & 400 & 25 & $2.71 \%$ & 3040 & 173.5 \\
NS-8 & CC2 & 34.2 & 449 & 193140 & 300 & 3 & 400 & 25 & $2.71 \%$ & 3040 & 170.8 \\
NS-4 & RAC1 & 30 & 449 & 193140 & 300 & 3 & 400 & 25 & $1.27 \%$ & 1520 & 114.8 \\
NS-4 & RAC2 & 34.1 & 449 & 193140 & 300 & 3 & 400 & 25 & $1.27 \%$ & 1520 & 113 \\
NS-6 & RAC1 & 30 & 449 & 193140 & 300 & 3 & 400 & 25 & $2.03 \%$ & 2280 & 143.2 \\
NS-6 & RAC2 & 34.1 & 449 & 193140 & 300 & 3 & 400 & 25 & $2.03 \%$ & 2280 & 124.1 \\
NS-8 & RAC1 & 30 & 449 & 193140 & 300 & 3 & 400 & 25 & $2.71 \%$ & 3040 & 131.4 \\
NS-8 & RAC2 & 34.1 & 449 & 193140 & 300 & 3 & 400 & 25 & $2.71 \%$ & 3040 & 140.3 \\
\hline
\end{tabular}

The experimental shear strengths of the beams are compared with the shear provisions of a number of codes and standards. According to the research it is concluded that:

- The behavior of the RAC and $\mathrm{CC}$ beams was almost identical regarding to crack progression and load-deflection response.

- Results of the statistical tests show that the beams with 100\% RCA have about $12 \%$ lower shear strength compared with the $\mathrm{CC}$ beams. This result implies that the existing design standards may not be applicable to RAC without modifications to reflect the lower shear capacity.

- The fracture mechanic approaches underestimate the shear strength for both the CC and RAC beams, but appear to be equally applicable to both materials.

- The MCFT method conservatively predicts shear strength for the CC and RAC beams, although in general offers very good agreement with experimental results.

- Statistical data analysis (both parametric and nonparametric) showed that the CC beams had higher shear strength compared with the RAC beams.

\subsubsection{Fathifazl et al. (2011)}

The shear performance of reinforced concrete (RC) beams made with coarse recycled concrete aggregate (RCA) are examined based on a new method of mixture proportioning named Equivalent Mortar Volume (EMV) method. In this method, the relative amount and properties of adhered 
mortar of recycled concrete aggregates and the coarse aggregate as two different phases are considered separately. Several beams were designed based on this new mix design method and tested to study the effect of a various parameters to shear behavior of RCA concrete beams without stirrups. The test parameters for this study are the shear span-to depth ratio, beam size and the concrete type. The research objectives were:

- To determine the effect of parameters like shear span to depth ratio and beam size on shear behavior of reinforced concrete beams made by RCA by new mix design method, (EMV).

- To determine the characteristics like load-deflection curve, shear deformations, diagonal cracking load, crack pattern, ultimate shear strength and failure mode for each specimen.

To investigate the effect of shear span-to-depth ratio, a/d values of 1.5, 2, 2.7, and 4 were selected to cover short, intermediate, and long beams. Four beams were tested for each RCA source, i.e. one beam for each a/d ratio. All the beams were rectangular, $200 \mathrm{~mm}$ wide and 350-375 $\mathrm{mm}$ deep, with effective depth of $305 \pm 4 \mathrm{~mm}$. To investigate the size effect, $200 \mathrm{~mm}$ wide beams with height of $250,375,450$, or $550 \mathrm{~mm}$ with a constant shear span to depth ratio of 2.7 , were tested. Four beams were tested for each RCA source, i.e. one beam for each depth size. In addition, for each RCA source, one companion control beam was made of concrete with $100 \%$ coarse natural aggregates of the same type as the original natural aggregate in the corresponding RCA. The latter beams had a nominal a/d ratio of 2.70 and medium height of 375 and medium height of $375 \mathrm{~mm}$. The details of the beams are given in Fig. 3.2 and Table 3.2.

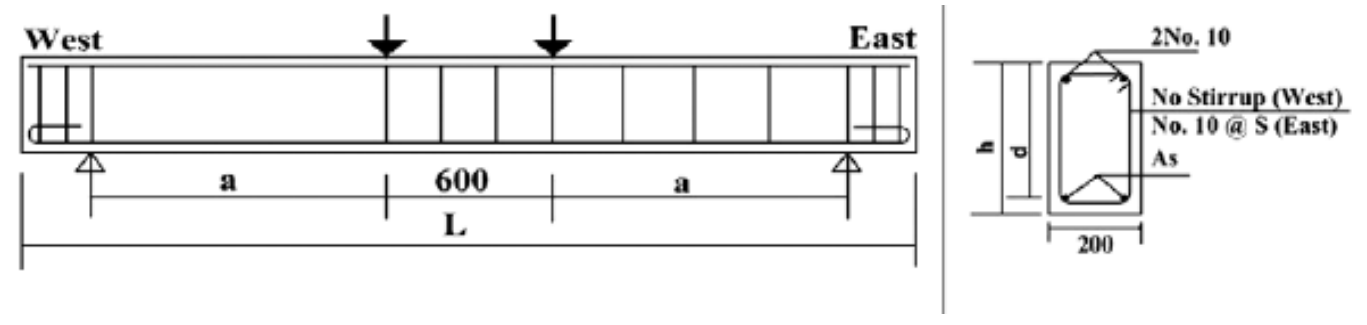

Figure 3.2 Cross sections and reinforcement layout of the test beams (Fathifazl et al., 2009)

The beams were made using concrete mixes involving RCA from two different sources. The RCA from the two sources are termed RCA-M and RCA-V, obtained from aggregate recycling plants 
in Montreal and Vancouver, Canada, respectively. The experimental shear strengths of the beams are compared with the shear provisions of a number of codes and standards.

Table 3.2 Details of Reinforced Concrete Beams tested by Fathifazl et al. (2011)

\begin{tabular}{|l|c|c|c|c|c|c|c|c|c|c|}
\hline \multirow{2}{*}{ Beam } & $\mathbf{f}_{\mathbf{c}}^{\prime}$ & $\mathbf{f}_{\mathbf{y}}$ & $\mathbf{E}_{\mathbf{s}}$ & $\mathbf{b}_{\mathbf{w}}$ & $\mathbf{a} / \mathbf{d}$ & $\mathbf{d}$ & $\mathbf{a g}_{\mathbf{g}}$ & $\boldsymbol{\rho}_{\mathbf{s}}$ & $\mathbf{A}_{\mathbf{s}}$ & $\mathbf{V}_{\mathbf{c}}$ \\
\cline { 2 - 10 } & $\mathbf{M p a}$ & $\mathbf{M p a}$ & $\mathbf{M p a}$ & $\mathbf{m m}$ & & $\mathbf{m m}$ & $\mathbf{m m}$ & & $\mathbf{m m} \mathbf{2}$ & $\mathbf{k N}$ \\
\hline EM-1.5 & 41.6 & 400 & 200000 & 200 & 1.5 & 300 & 19 & $1 \%$ & 600 & 186.7 \\
EM-2 & 41.4 & 400 & 200000 & 200 & 2 & 300 & 19 & $1.50 \%$ & 900 & 169.5 \\
EM-2.7 & 41.6 & 400 & 200000 & 200 & 2.59 & 309 & 19 & $1.62 \%$ & 1001.16 & 103.9 \\
CL-2.7 & 37.95 & 400 & 200000 & 200 & 2.59 & 309 & 19 & $1.62 \%$ & 1001.16 & 92.8 \\
EM-4 & 41.6 & 400 & 200000 & 200 & 3.93 & 305 & 19 & $2.46 \%$ & 1500.6 & 83.2 \\
EV-1.5 & 49.1 & 400 & 200000 & 200 & 1.5 & 300 & 19 & $1 \%$ & 600 & 195.3 \\
EV-2 & 49.1 & 400 & 200000 & 200 & 2 & 300 & 19 & $1.50 \%$ & 900 & 179 \\
CG-2.7 & 34.1 & 400 & 200000 & 200 & 2.59 & 309 & 19 & $1.62 \%$ & 1001.16 & 150 \\
EV-4 & 49.1 & 400 & 200000 & 200 & 3.93 & 305 & 19 & $2.46 \%$ & 1500.6 & 105.6 \\
EM-L & 41.6 & 400 & 200000 & 200 & 2.69 & 201 & 19 & $1.99 \%$ & 799.98 & 89.3 \\
EM-M & 41.6 & 400 & 200000 & 200 & 2.59 & 309 & 19 & $1.62 \%$ & 1001.16 & 103.9 \\
CL-M & 37.95 & 400 & 200000 & 200 & 2.59 & 309 & 19 & $1.62 \%$ & 1001.16 & 92.8 \\
EM-H & 41.6 & 400 & 200000 & 200 & 2.73 & 381 & 19 & $1.83 \%$ & 1394.46 & 99.5 \\
EM-VH & 41.6 & 400 & 200000 & 200 & 2.73 & 476 & 19 & $1.68 \%$ & 1599.36 & 104.6 \\
EV-L & 49.1 & 400 & 200000 & 200 & 2.69 & 201 & 19 & $1.99 \%$ & 799.98 & 122.6 \\
CG-M & 34.1 & 400 & 200000 & 200 & 2.59 & 309 & 19 & $1.62 \%$ & 1001.16 & 150 \\
EV-H & 41.6 & 400 & 200000 & 200 & 2.73 & 381 & 19 & $1.83 \%$ & 1394.46 & 111.7 \\
EV-VH & 49.1 & 400 & 200000 & 200 & 2.73 & 476 & 19 & $1.68 \%$ & 1599.36 & 88.83 \\
& & & & & & & & & & \\
\hline
\end{tabular}

The following conclusions were drawn from the research:

- Applying the EMV method of mix proportioning for RCA-concrete yields concrete mixes with comparable strength as conventional concrete mixes with equivalent amount of mortar and other ingredients.

- For RCA-concrete beams with shear span/depth ratio ranging between 1.5 and 4, regardless of the RCA source, all of the above codes gave conservative estimates of the actual strength of these beams.

- Some other theoretical/empirical expressions proposed by some investigators for determining the concrete's contribution to the shear resistance of beams without stirrups overestimated the strength of some of the current beams.

- For beams up to a total depth of $550 \mathrm{~mm}$, the forgoing codes expressions conservatively estimated the beams' shear strength. Thus within the range of depths tested in the current investigation, despite the size effect, the codes predictions are on the conservative side. 
- The shear strength of reinforced RCA-concrete beams had a tendency to increase with decreasing a/d mainly due to the contribution of an arch action mechanism at lower $\mathrm{a} / \mathrm{d}$, which conforms to the known behavior of conventional reinforced concrete beams.

\subsubsection{Knaack and Kurama (2014)}

Knaack and Kurama (2014) investigated the flexural and shear behavior of reinforced concrete beams made by recycled concrete aggregates (RCA) as replacement for coarse natural aggregates (e.g., crushed stone, gravel). The experimental results from 12 twin pairs of normal strength concrete beam specimens are presented and compared with predictions from existing code methods and analytical models for conventional concrete. The test parameters for this study is the concrete type. The research objectives were:

- To provide an experimental and analytical investigation on the behavior of reinforced concrete beams that use recycled concrete aggregates (RCA) as replacement for coarse natural aggregates (e.g., crushed stone, gravel).

- To investigate the inherent variability in the results, specifically focusing on locally available recycled materials with minimal processing and construction methods that are consistent with current U.S. practice.

To investigate the effect of shear span-to-depth ratio, a/d values of 1.5, 2, 2.7, and 4 were selected to cover short, intermediate, and long beams. Four beams were tested for each RCA source, i.e. one beam for each a/d ratio. All the beams were rectangular, $200 \mathrm{~mm}$ wide and 350-375 $\mathrm{mm}$ deep, with effective depth of $305 \pm 4 \mathrm{~mm}$. To investigate the size effect, $200 \mathrm{~mm}$ wide beams with height of $250,375,450$, or $550 \mathrm{~mm}$ with a constant shear span to depth ratio of 2.7, were tested. Four beams were tested for each RCA source, i.e. one beam for each depth size. In addition, for each RCA source, one companion control beam was made of concrete with $100 \%$ coarse natural aggregates of the same type as the original natural aggregate in the corresponding RCA. The latter beams had a nominal a/d ratio of 2.70 and medium height of 375 and medium height of $375 \mathrm{~mm}$. The details of the beams are given in Figure 3.3 and Table 3.3. The experimental shear strengths of the beams are compared with the shear provisions of ACI-318. 

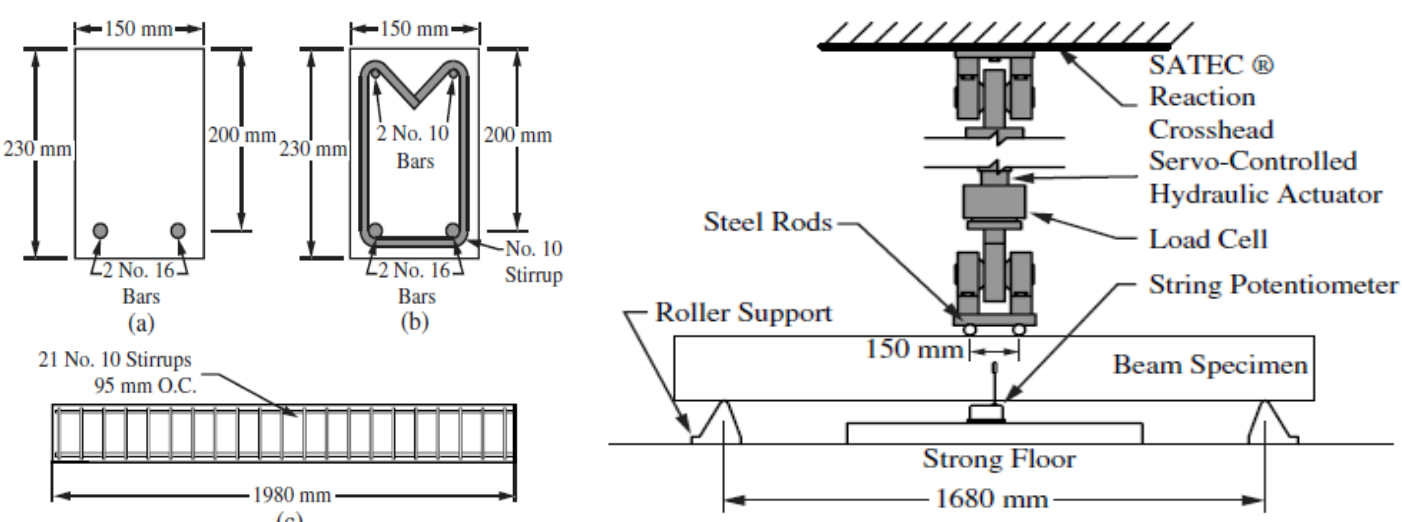

(c)

Figure 3.3 Cross sections and reinforcement layout of the test beams (Knaack and Kurama, 2014)

It is concluded that:

- RCA does not cause an observable change in the progression of nonlinear behavior and failure in flexure-critical and shear critical reinforced concrete beams.

- The predicted results are reasonably close to the measured trends, indicating that existing analytical models and code based procedures for conventional reinforced concrete beams can also be applied to RCA concrete beams.

While further research is certainly needed, a preliminary expectation from this paper is that locally available RCA with prequalified absorption and deleterious material content may be suitable for use in reinforced concrete beams constructed in a manner that is consistent with current U.S. practice for conventional concrete applications. 
Table 3.3 Details of Reinforced Concrete Beams tested by Knaack and Kurama (2014)

\begin{tabular}{|c|c|c|c|c|c|c|c|c|c|c|}
\hline Beam & $\mathbf{f}_{\mathbf{c}}^{\prime}$ & $\mathbf{f}_{\mathbf{y}}$ & $\mathbf{E}_{\mathbf{s}}$ & $\mathbf{b}_{\mathbf{w}}$ & $\mathbf{a} / \mathbf{d}$ & $\mathbf{d}$ & $\mathbf{a}_{\mathbf{g}}$ & $\boldsymbol{\rho}_{\mathbf{s}}$ & $\mathbf{A}_{\mathbf{s}}$ & $\mathbf{V}_{\mathbf{c}}$ \\
\cline { 2 - 11 } ID & $\mathbf{M P a}$ & $\mathbf{M P a}$ & $\mathbf{M P a}$ & $\mathbf{m m}$ & & $\mathbf{m m}$ & $\mathbf{m m}$ & $\mathbf{\%}$ & $\mathbf{m m}^{2}$ & $\mathbf{k N}$ \\
& & & & & & & & & & \\
\hline S0-1a & 32.6 & 572 & 198000 & 150 & 3.825 & 200 & 19 & 1.34 & 402.1 & 31.1 \\
S0-1b & 32.6 & 572 & 198000 & 150 & 3.825 & 200 & 19 & 1.34 & 402.1 & 36.9 \\
S0-2a & 50.3 & 572 & 198000 & 150 & 3.825 & 200 & 19 & 1.34 & 402.1 & 40.4 \\
S0-2b & 50.3 & 572 & 198000 & 150 & 3.825 & 200 & 19 & 1.34 & 402.1 & 42.3 \\
S50-1a & 43.6 & 572 & 198000 & 150 & 3.825 & 200 & 19 & 1.34 & 402.1 & 44 \\
S50-1b & 43.6 & 572 & 198000 & 150 & 3.825 & 200 & 19 & 1.34 & 402.1 & 39.1 \\
S50-2a & 40.2 & 572 & 198000 & 150 & 3.825 & 200 & 19 & 1.34 & 402.1 & 43.7 \\
S50-2b & 40.2 & 572 & 198000 & 150 & 3.825 & 200 & 19 & 1.34 & 402.1 & 41.2 \\
S100-1a & 41.4 & 572 & 198000 & 150 & 3.825 & 200 & 19 & 1.34 & 402.1 & 36.4 \\
S100-1b & 41.4 & 572 & 198000 & 150 & 3.825 & 200 & 19 & 1.34 & 402.1 & 38 \\
S100-2a & 35.7 & 572 & 198000 & 150 & 3.825 & 200 & 19 & 1.34 & 402.1 & 39.9 \\
S100-2b & 35.7 & 572 & 198000 & 150 & 3.825 & 200 & 19 & 1.34 & 402.1 & 36.1 \\
& & & & & & & & & & \\
\hline
\end{tabular}

\subsection{REINFORCED CONCRETE BEAMS WITH WEB REINFORCEMENT}

\subsubsection{Gonzalez et al. (2007)}

The shear behavior of concrete made with recycled concrete aggregates was examined in this study. For the purpose two sets of four test beams constructed with both conventional concrete and concrete comprising $50 \%$ recycled coarse aggregates. The test parameters are amount of transverse reinforcement and concrete type. The research objective was to examine the behavior of the recycled aggregate concrete versus conventional concrete beams in shear failure comprising the maximum deflections, the ultimate loads and crack progression.

All specimens had a rectangular cross section with $350 \mathrm{~mm}$ (depth), $200 \mathrm{~mm}$ (width) and were tested with a shear span-to-depth of 3.3 as shown in Figure 3.4 and Table 3.4. The beams were tested maintaining two symmetrical spans with different amounts of transverse reinforcement. Failure occurred only in one of the spans, the one with the smallest amount of transverse reinforcement, denominated span S6 (diameter of the vertical stirrups $=6 \mathrm{~mm}$ ). In the other span, S8 (diameter of the vertical stirrups $=8 \mathrm{~mm}$ ), it was possible to study the behavior prior to failure. 
Based on the test results each specimen without shear reinforcement exhibited an initial flexural crack at the center of the specimen and subsequent flexural cracks away from that section. As the applied load was increased, one of the flexural cracks extended into a diagonal crack near one of the supports, or a diagonal crack formed abruptly at the mid-height of the beam within the shear span. After the formation of the diagonal crack, brittle failure occurred. The specimens with shear reinforcement showed the same crack pattern as the specimens without shear reinforcement until the formation of diagonal cracking, but showed higher load-carrying capacity following it.
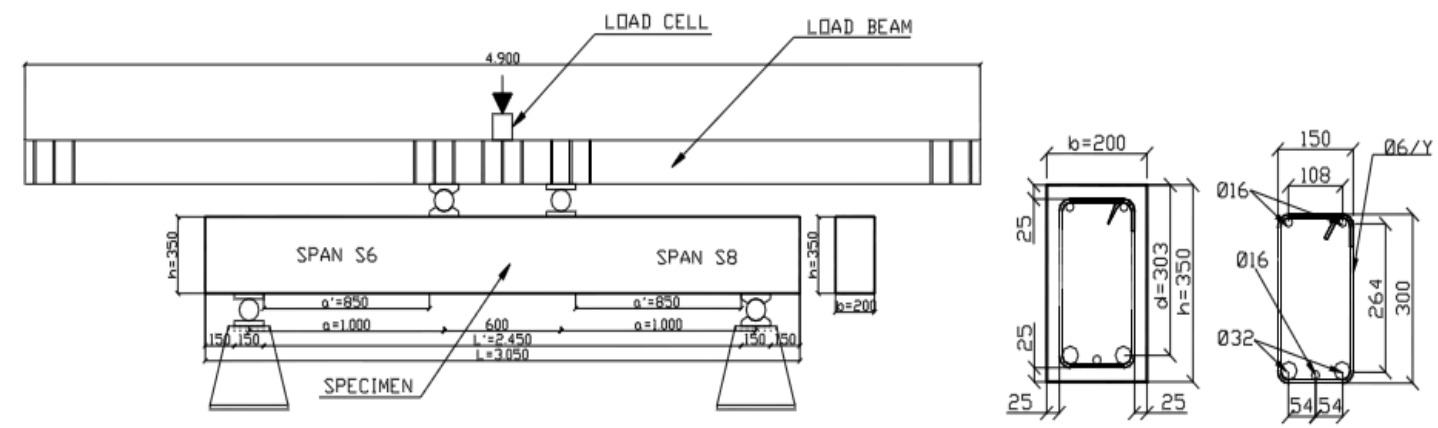

Figure 3.4 Cross sections and reinforcement layout of the test beams (Gonzalez et al., 2007)

Table 3.4 Details of Reinforced Concrete Beams tested by Gonzalez et al. (2007)

\begin{tabular}{|c|c|c|c|c|c|c|c|c|c|c|c|c|c|}
\hline $\begin{array}{c}\text { Beam } \\
\text { ID }\end{array}$ & $\mathbf{f}_{\mathbf{c}}$ & $\mathbf{f}_{\mathbf{y}}$ & $\mathbf{E}_{\mathbf{s}}$ & $\mathbf{b}_{\mathbf{w}}$ & $\mathbf{a} / \mathbf{d}$ & $\mathbf{d}$ & $\mathbf{a}_{\mathbf{g}}$ & $\boldsymbol{\rho}_{\mathbf{s}}$ & $\mathbf{A}_{\mathbf{s}}$ & $\boldsymbol{\rho}_{\mathbf{v}}$ & $\mathbf{A}_{\mathbf{v}}$ & $\mathbf{S}$ & $\mathbf{V}_{\mathbf{c}}$ \\
\cline { 2 - 14 } & $\mathbf{M P a}$ & $\mathbf{M P a}$ & $\mathbf{M P a}$ & $\mathbf{m m}$ & & $\mathbf{m m}$ & $\mathbf{m m}$ & $\boldsymbol{\%}$ & $\mathbf{m m}^{\mathbf{2}}$ & $\boldsymbol{\%}$ & $\mathbf{m m}$ & $\mathbf{m m}$ & $\mathbf{k N}$ \\
\hline V0CC & 40.2 & 500 & 200000 & 200 & 3.3 & 303 & 25 & 2.98 & 1805.88 & 0 & 0 & - & 88.86 \\
V0RC & 39.65 & 500 & 200000 & 200 & 3.3 & 303 & 25 & 2.98 & 1805.88 & 0 & 0 & - & 90.64 \\
V24CC & 39.16 & 500 & 200000 & 200 & 3.3 & 303 & 25 & 2.98 & 1805.88 & 0.12 & 57 & 240 & 127.98 \\
V24RC & 39.23 & 500 & 200000 & 200 & 3.3 & 303 & 25 & 2.98 & 1805.88 & .012 & 57 & 240 & 164.29 \\
V17CC & 39.08 & 500 & 200000 & 200 & 350 & 303 & 25 & 2.98 & 1805.88 & 0.17 & 57 & 170 & 150.83 \\
V17RC & 41.49 & 500 & 200000 & 200 & 3.3 & 303 & 25 & 2.98 & 1805.88 & 0.17 & 57 & 170 & 176.99 \\
V13CC & 37.66 & 500 & 200000 & 200 & 3.3 & 303 & 25 & 2.98 & 1805.88 & .022 & 57 & 130 & 190.29 \\
V13RC & 40.46 & 500 & 200000 & 200 & 3.3 & 303 & 25 & 2.98 & 1805.88 & .022 & 57 & 130 & 233.59 \\
& & & & & & & & & & & & & \\
\hline
\end{tabular}

The predicted capacities of the beams specimens calculated based on modified compression field theory (MCFT) and using the expressions of different codes: Little differences were observed in the structural behavior of the concrete beams in terms of both deflections and ultimate load. Differences were only evident during the analysis of cracking. 
- Premature cracking and notable splitting cracks along the tension reinforcement were observed in recycled concrete beams. Both may be controlled by introducing stricter limits on the minimum stirrups spacing.

- Not all the beams reached shear force at stirrups yield in the spans S8. This shear force was detected in the recycled concrete beams. All the beams, even those with shear reinforcement lower than the minimum demonstrate a notable strength after cracking.

\subsubsection{Gonzalez et al. (2009)}

The second stage of studies on the behavior of recycled concrete aggregate was conducted by Gonzalez et al. (2009). The results of the first stage (replacement of 50\% recycled coarse aggregate with natural aggregate) revealed minor differences between recycled concrete and conventional concrete in ultimate loads and these differences were found to increase when cracking was taken into account (Gonzalez et al., 2007). In this study, the effect of the addition of $8 \%$ silica fume to recycle concrete (recycled concrete with silica fume) is examined. The results indicate that the shear behavior of the beams made by new mix improves. Moreover, the use of this material in recycled concrete produced changes in its structural behavior similar to those induced in conventional concrete (conventional concrete with silica fume). The test parameters are amount of transverse reinforcement and concrete type. The research objectives were:

- To determine whether or not the addition of this percentage of silica fume to the recycled concrete would succeed in controlling the premature cracking detected in previous studies, thus avoiding the need to impose stricter limits on minimum stirrup spacing, which would result in reduced costs.

- To determine the possibility of improving the behavior of recycled concrete by the inclusion of a pozzolanic addition, silica fume.

All specimens had a rectangular cross section with $350 \mathrm{~mm}$ (depth) $200 \mathrm{~mm}$ (width) and were tested with a shear span-to-depth of 3.3 as shown in Figure 3.5 and Table 3.5. The beams were tested maintaining two symmetrical spans with different amounts of transverse reinforcement. Failure occurred only in one of the spans, the one with the smallest amount of transverse reinforcement, denominated span S6 (diameter of the vertical stirrups $=6 \mathrm{~mm}$ ). In the other span, S8 (diameter of the vertical stirrups $=8 \mathrm{~mm}$ ), it was possible to study the behavior prior to failure. 

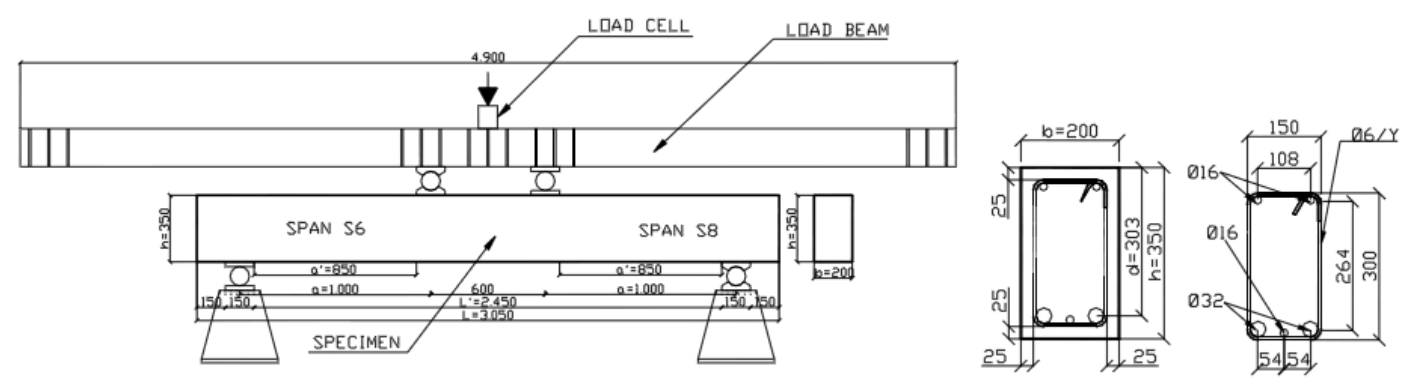

Figure 3.5 Cross sections and reinforcement layout of the test beams (Gonzalez et al.2009)

Table 3.5 Details of Reinforced Concrete Beams tested by Gonzalez et al. (2009)

\begin{tabular}{|c|c|c|c|c|c|c|c|c|c|c|c|c|c|}
\hline \multirow{2}{*}{$\begin{array}{c}\text { Beam } \\
\text { ID }\end{array}$} & $\mathbf{f}_{\mathbf{c}}^{\prime}$ & $\mathbf{f}_{\mathbf{y}}$ & $\mathbf{E}_{\mathbf{s}}$ & $\mathbf{b}_{\mathbf{w}}$ & $\mathbf{a} / \mathbf{d}$ & $\mathbf{d}$ & $\mathbf{a g}$ & $\boldsymbol{\rho}_{\mathbf{s}}$ & $\mathbf{A}_{\mathbf{s}}$ & $\mathbf{A}_{\mathbf{v}}$ & $\mathbf{s}$ & $\boldsymbol{\rho}_{\mathbf{v}}$ & $\mathbf{V}_{\mathbf{c}}$ \\
\cline { 2 - 13 } & $\mathbf{M P a}$ & $\mathbf{M P a}$ & $\mathbf{M P a}$ & $\mathbf{m m}$ & & $\mathbf{m m}$ & $\mathbf{m m}$ & $\mathbf{\%}$ & $\mathbf{m m}^{\mathbf{2}}$ & $\mathbf{m m}$ & $\mathbf{m m}$ & $\mathbf{\%}$ & $\mathbf{k N}$ \\
\hline V0CC & 46.77 & 500 & 200000 & 200 & 3.3 & 303 & 25 & 2.98 & 1805.88 & 0 & - & 0 & 100.53 \\
V0RC & 41.45 & 500 & 200000 & 200 & 3.3 & 303 & 25 & 2.98 & 1805.88 & 0 & - & 0 & 83.88 \\
V13CC & 43.66 & 500 & 200000 & 200 & 3.3 & 303 & 25 & 2.98 & 1805.88 & 57 & 130 & 0.12 & 220.08 \\
V13RC & 43.25 & 500 & 200000 & 200 & 3.3 & 303 & 25 & 2.98 & 1805.88 & 57 & 130 & .012 & 202.36 \\
V17CC & 45.16 & 500 & 200000 & 200 & 3.3 & 303 & 25 & 2.98 & 1805.88 & 57 & 170 & 0.17 & 199.79 \\
V17RC & 44.49 & 500 & 200000 & 200 & 3.3 & 303 & 25 & 2.98 & 1805.88 & 57 & 170 & 0.17 & 192.92 \\
V24CC & 42.75 & 500 & 200000 & 200 & 3.3 & 303 & 25 & 2.98 & 1805.88 & 57 & 240 & .022 & 150.07 \\
V24RC & 41.45 & 500 & 200000 & 200 & 3.3 & 303 & 25 & 2.98 & 1805.88 & 57 & 240 & .022 & 147.33 \\
& & & & & & & & & & & & & \\
\hline
\end{tabular}

The predicted capacities of the beams specimens, computed using the modified compression field theory and using the expressions of different codes are compared. The following conclusions were drawn:

- The notable splitting cracks along the tension reinforcement observed in recycled concrete beams of the first phase were mitigated by the addition of silica fume.

- It was found that the addition of silica fume to recycled concrete causes changes in its behavior similar to the changes that occur when it is added to conventional concrete.

- All the codes studied were conservative and subsequently can be used for the shear design of recycled concrete beams with silica fume.

\subsubsection{Ajdukeiwicz and Kliszczewicz (2007)}

This was an experimental study to examine the differences in particular properties on the general behavior of reinforced concrete members made of various mixtures of recycled aggregate concrete. Sixteen series of beams and 5 series of columns were tested. Different mixes made by recycled 
coarse and fine aggregates and by recycled coarse aggregates only were applied for the test beams and columns.

The test specimens constructed with different strength classes of concrete and different types of aggregates. Both cases of replacement with fine and coarse aggregates and coarse aggregates only were applied. The research objective is to determine the differences in behavior of simple structural reinforced concrete members, simply supported beams and axially loaded columns, with different contribution of recycled aggregate (RAC) in concrete mixes in comparison with concretes made by natural coarse aggregates (NAC). Sixteen series of beams were tested. There were three beams in each series prepared with the same reinforcement and from concrete of almost the same composition but mixed with different contribution of natural and recycled aggregate manufactured. The dimension of the beams and the reinforcement layout of beams is illustrated in Figure 3.6 and detailed in Table 3.6.

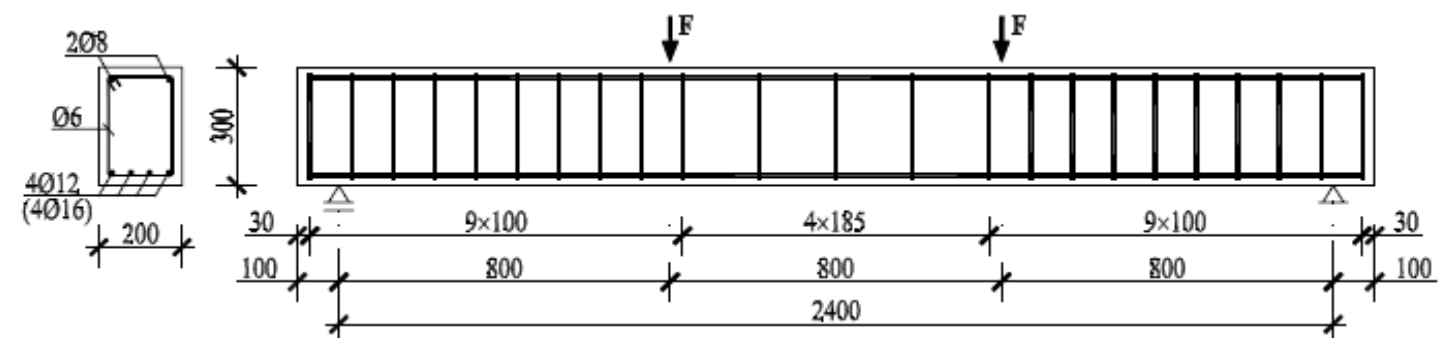

Figure 3.6 Cross sections, reinforcement layout and loading system of the test beams (Ajdukeiwicz and Kliszczewicz 2007)

A general conclusion from tests confirms the full possibility of use of good quality recycled aggregates in structural made of medium or high strength concrete. Differences in behavior of reinforced concrete members made of new, partially recycled and fully recycled aggregate were relatively small within the test series, but quite significant when strains have been analyze. 
Table 3.6 Details of reinforced concrete beams tested by Ajdukeiwicz and Kliszczewicz (2007)

\begin{tabular}{|c|c|c|c|c|c|c|c|c|c|c|c|c|}
\hline \multirow{2}{*}{$\begin{array}{c}\text { Beam } \\
\text { Id }\end{array}$} & $\mathbf{f}_{\mathbf{c}}^{\mathbf{c}^{\prime}}$ & $\mathbf{f}_{\mathbf{y}}$ & $\mathbf{f}_{\mathbf{y w}}$ & $\mathbf{E}_{\mathbf{s}}$ & $\mathbf{b}_{\mathbf{w}}$ & $\mathbf{a} / \mathbf{d}$ & $\mathbf{d}$ & $\mathbf{a}_{\mathbf{g}}$ & $\boldsymbol{\rho}_{\mathbf{s}}$ & $\mathbf{A}_{\mathbf{s}}$ & $\mathbf{A}_{\mathbf{s w}}$ & $\mathbf{V}_{\mathbf{c}}$ \\
\cline { 2 - 11 } & $\mathrm{MPa}$ & $\mathrm{MPa}$ & $\mathrm{MPa}$ & $\mathrm{MPa}$ & $\mathrm{mm}$ & & $\mathrm{mm}$ & $\mathrm{mm}$ & & & $\mathrm{mm}^{2}$ & $\mathrm{kN}$ \\
\hline ORNm-b2 & 58.3 & 410 & 210 & 193140 & 200 & 3.2 & 250 & 16 & 1.61 & 804.3 & 56.6 & 118.5 \\
GNN1-b2 & 38.7 & 410 & 210 & 193140 & 200 & 3.2 & 250 & 16 & 1.61 & 804.3 & 56.6 & 108.5 \\
GRN1-b2 & 39.3 & 410 & 210 & 193140 & 200 & 3.2 & 250 & 16 & 1.61 & 804.3 & 56.6 & 116.5 \\
GRR1-b2 & 35.8 & 410 & 210 & 193140 & 200 & 3.2 & 250 & 16 & 1.61 & 804.3 & 56.6 & 113 \\
GRNm-b2 & 59.6 & 410 & 210 & 193140 & 200 & 3.2 & 250 & 16 & 1.61 & 804.3 & 56.6 & 118.5 \\
GNNh-b2 & 93.4 & 410 & 210 & 193140 & 200 & 3.2 & 250 & 16 & 1.61 & 804.3 & 56.6 & 125 \\
GRNh-b2 & 89.1 & 410 & 210 & 193140 & 200 & 3.2 & 250 & 16 & 1.61 & 804.3 & 56.6 & 121 \\
GRRh-b2 & 82.2 & 410 & 210 & 193140 & 200 & 3.2 & 250 & 16 & 1.61 & 804.3 & 56.6 & 127.5 \\
BNN1-b2 & 39.6 & 410 & 210 & 193140 & 200 & 3.2 & 250 & 16 & 1.61 & 804.3 & 56.6 & 115.5 \\
BRN1-b2 & 38.8 & 410 & 210 & 193140 & 200 & 3.2 & 250 & 16 & 1.61 & 804.3 & 56.6 & 120.5 \\
BRR1-b2 & 31.4 & 410 & 210 & 193140 & 200 & 3.2 & 250 & 16 & 1.61 & 804.3 & 56.6 & 110 \\
BNNh-b2 & 100.9 & 410 & 210 & 193140 & 200 & 3.2 & 250 & 16 & 1.61 & 804.3 & 56.6 & 131 \\
BRNh-b2 & 107.8 & 410 & 210 & 193140 & 200 & 3.2 & 250 & 16 & 1.61 & 804.3 & 56.6 & 130.5 \\
BRRh-b2 & 100.5 & 410 & 210 & 193140 & 200 & 3.2 & 250 & 16 & 1.61 & 804.3 & 56.6 & 128 \\
& & & & & & & & & & & & \\
\hline
\end{tabular}

\subsubsection{Etxeberria et al. (2006)}

This study investigated the possibility of the use of recycled aggregate concrete as a structural material rather than s being used only as base filler for road construction. Twelve beam specimens were tested with the same compression strength and different percentages of recycled coarse aggregates and transverse reinforcement. The test parameters are amount of transverse reinforcement and percentages of recycled coarse aggregates. The research objective is to study the influence of the percentage of recycled aggregate used on their structural behaviour at service load levels and up to failure. The 12 beams had rectangular cross section of $200 \mathrm{~mm}$ width and $350 \mathrm{~mm}$ depth, a total length of $3.05 \mathrm{~m}$ and were simply-supported with a span length of $2.60 \mathrm{~m}$. The beams were subjected to a symmetric two point load system, with a shear span/depth ratio a/d equal to 3.3, as indicated in Fig. 10. The beam sections with longitudinal and three transverse reinforcement arrangements were considered, as illustrated in Figures 3.7 and 3.8 as well as in Table 3.7. 


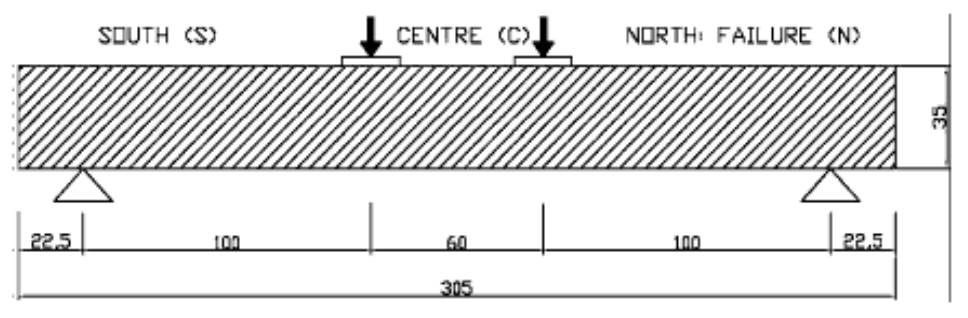

Figure 3.7 Two point loads test set-up (Etxeberria.et al. 2006)

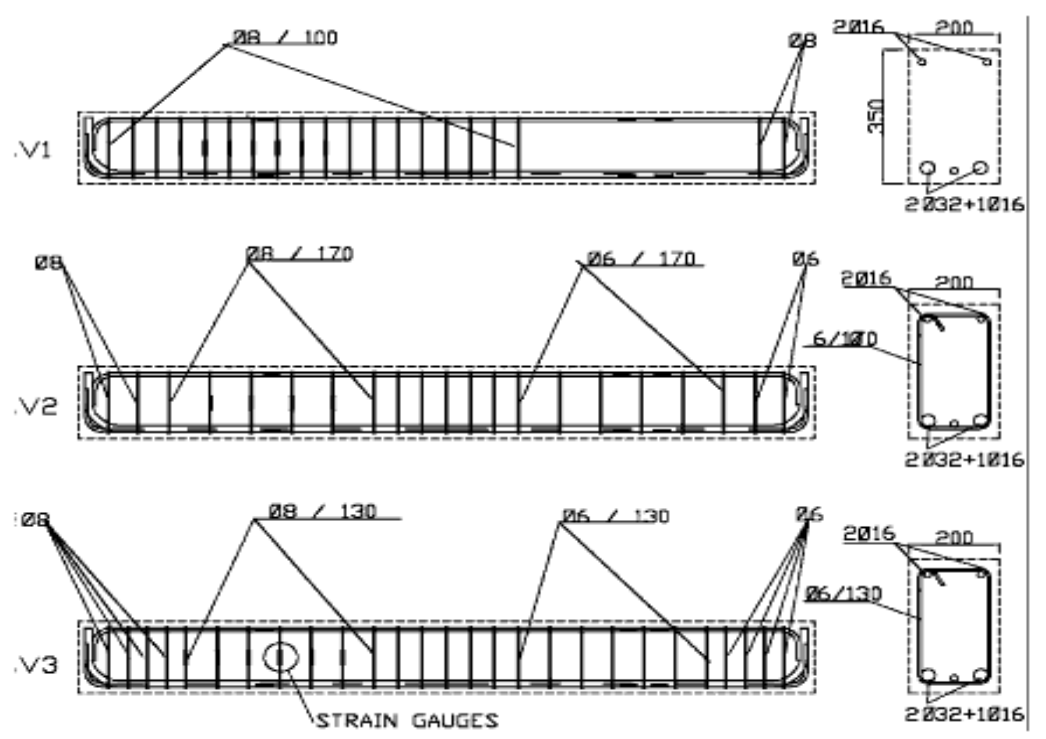

Figure 3.8 Arrangements for the three types of reinforcements (Etxeberria.et al. 2006)

The cracking load for beam specimens with recycled aggregates was lower than that of reference beams (HC), however, the failure load was very similar for all beams of that group. The failure loads are included in Table 3.7.

Table 3.7 Details of Reinforced Concrete Beams tested by Etxeberria.et al. (2006)

\begin{tabular}{|c|c|c|c|c|c|c|c|c|c|c|c|c|c|}
\hline \multirow{2}{*}{$\begin{array}{c}\text { Beam } \\
\text { ID }\end{array}$} & $\mathbf{f}_{\mathbf{c}}^{\prime}$ & $\mathbf{f}_{\mathbf{y}}$ & $\mathbf{E}_{\mathbf{s}}$ & $\mathbf{b}_{\mathbf{w}}$ & $\mathbf{a} / \mathbf{d}$ & $\mathbf{d}$ & $\mathbf{a g}$ & $\boldsymbol{\rho}_{\mathbf{s}}$ & $\mathbf{A}_{\mathbf{s}}$ & $\mathbf{A}_{\mathbf{v}}$ & $\mathbf{s}$ & $\boldsymbol{\rho}_{\mathbf{v}}$ & $\mathbf{V}_{\mathbf{c}}$ \\
\cline { 2 - 12 } & $\mathrm{MPa}$ & $\mathrm{MPa}$ & $\mathrm{MPa}$ & $\mathrm{mm}$ & & $\mathrm{mm}$ & $\mathrm{mm}$ & $\%$ & $\mathrm{~mm}^{2}$ & $\mathrm{~mm}^{2}$ & $\mathrm{~mm}$ & $\%$ & $\mathrm{kN}$ \\
\hline HC-1 & 41.91 & 500 & 200000 & 200 & 3.3 & 309 & 25 & 2.92 & 1804.56 & 0 & 0 & 0 & 100.5 \\
HC-2 & 41.91 & 500 & 200000 & 200 & 3.3 & 309 & 25 & 2.92 & 1804.56 & 57 & 130 & 0.22 & 213 \\
HC-3 & 41.91 & 500 & 200000 & 200 & 3.3 & 309 & 25 & 2.92 & 1804.56 & 57 & 170 & 0.17 & 177 \\
HR25-1 & 42.38 & 500 & 200000 & 200 & 3.3 & 309 & 25 & 2.92 & 1804.56 & 0 & 0 & 0 & 104 \\
HR25-2 & 42.38 & 500 & 200000 & 200 & 3.3 & 309 & 25 & 2.92 & 1804.56 & 57 & 130 & 0.22 & 186.5 \\
HR25-3 & 42.38 & 500 & 200000 & 200 & 3.3 & 309 & 25 & 2.92 & 1804.56 & 57 & 170 & 0.17 & 169 \\
HR50-1 & 41.34 & 500 & 200000 & 200 & 3.3 & 309 & 25 & 2.92 & 1804.56 & 0 & 0 & 0 & 89 \\
HR50-2 & 41.34 & 500 & 200000 & 200 & 3.3 & 309 & 25 & 2.92 & 1804.56 & 57 & 130 & 0.22 & 220 \\
HR50-3 & 41.34 & 500 & 200000 & 200 & 3.3 & 309 & 25 & 2.92 & 1804.56 & 57 & 170 & 0.17 & 176 \\
HR100-1 & 39.75 & 500 & 200000 & 200 & 3.3 & 309 & 25 & 2.92 & 1804.56 & 0 & 0 & 0 & 84 \\
HR100-2 & 39.75 & 500 & 200000 & 200 & 3.3 & 309 & 25 & 2.92 & 1804.56 & 57 & 130 & 0.22 & 189.5 \\
HR100-3 & 39.75 & 500 & 200000 & 200 & 3.3 & 309 & 25 & 2.92 & 1804.56 & 57 & 170 & 0.17 & 163 \\
& & & & & & & & & & & & & \\
\hline
\end{tabular}


The effect of the use of recycled aggregate on the beams' shear strength depends on the percentage of coarse aggregate substituted, especially for beams without transverse reinforcement. For low percentages of substitution (less than 25\%) it can be said that this influence is practically negligible. For beam specimens with web reinforcement, the influence of the amount of RCA in the ultimate shear is very small. Beam specimens with web reinforcement and concrete with $50 \%$ and $100 \%$ of coarse recycled aggregate achieved approximately the ultimate shear load of conventional concrete.

- In general, Code provisions for shear design overestimate the shear strength of beams made with high amounts (more than 50\%) of RCA. However, they offer good correlation for beams made with small amounts ( $25 \%$ or less) of RCA.

- Aggregate interlock and bond between concrete and the reinforcement are mechanisms that look to work correctly in reinforced concrete beams made with RCA, even for high percentages of substitution of coarse aggregate.

- As a general conclusion, it can be said that concrete made with up to $25 \%$ of RCA is suitable for structural use, provided that all measures related to dosage, compressive strength and durability aspects have been adopted. In that case, the current code provisions for shear design result adequate for their use to design RC structures with RCA.

\subsubsection{Al-Zahraa et al. (2011)}

In this research the experimental shear tests on concrete beams with recycled concrete coarse aggregates were conducted. Twelve beams with different percentage of recycled concrete aggregates, shear reinforcement and shear spans were tested under two concentrated loads up to failure. Percentage of recycled concrete aggregates, shear reinforcement and shear spans. The research objectives were:

- To determine modes of failure, deflections, strains and ultimate strength, for the tested beams,

- To compare the experimental results of the present study and other studies. All beams had a rectangular cross section of $100 \mathrm{~mm}$ width and $200 \mathrm{~mm}$ thickness, a total length of 1,700 
$\mathrm{mm}$ and were simply supported with an effective span length of 1,500 $\mathrm{mm}$. Table 3.8 gives the reinforcement details of the tested specimens.
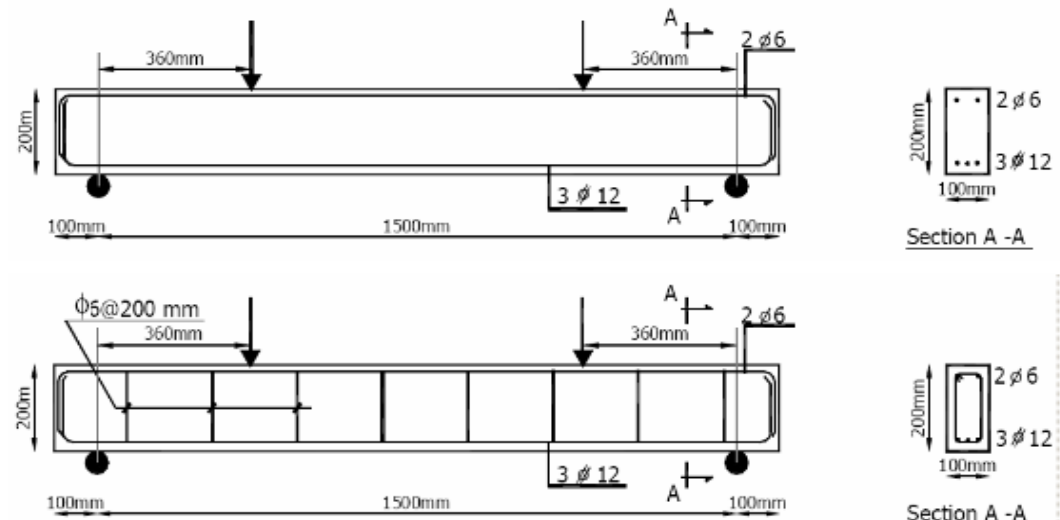

Section A - A
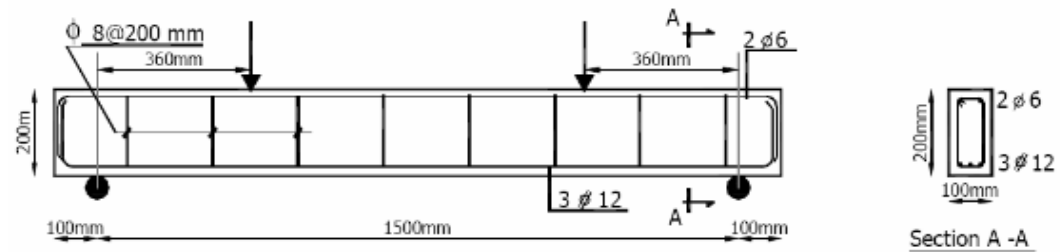

Section A -A
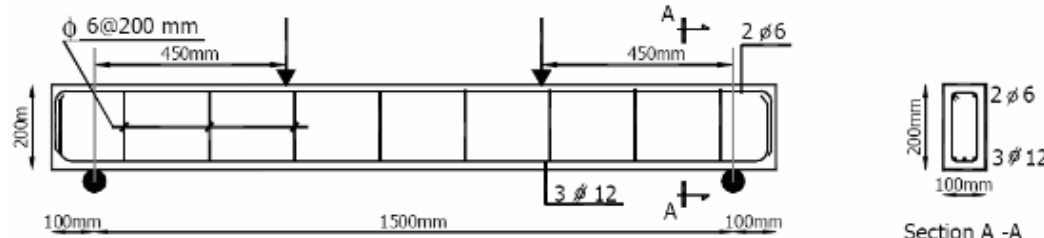

Figure 3.9 (a) Details of group (G1) of tested beam specimens (b) details of group (G2) of tested beam specimens (c) details of group (G3) of tested beam specimens (d) details of group (G4) of tested beam specimens(Al-Zahraa et al., 2011)

Table 3.8 Details of Reinforced Concrete Beams tested by Al-Zahraa et al. (2011)

\begin{tabular}{|c|c|c|c|c|c|c|c|c|c|c|c|c|c|}
\hline $\begin{array}{c}\text { Beam } \\
\text { ID }\end{array}$ & $\mathbf{f}_{\mathbf{c}}^{\prime}$ & $\mathbf{f}_{\mathbf{y}}$ & $\mathbf{E}_{\mathbf{s}}$ & $\mathbf{b}_{\mathbf{w}}$ & $\mathbf{a} / \mathbf{d}$ & $\mathbf{d}$ & $\mathbf{a g}$ & $\boldsymbol{\rho}_{\mathbf{s}}$ & $\mathbf{A}_{\mathbf{s}}$ & $\mathbf{A}_{\mathbf{v}}$ & $\mathbf{s}$ & $\boldsymbol{\rho}_{\mathbf{v}}$ & $\mathbf{V}_{\mathbf{c}}$ \\
\cline { 2 - 13 } & $\mathbf{M P a}$ & $\mathbf{M P}$ & $\mathbf{M P a}$ & $\mathbf{m m}$ & & $\mathbf{m}$ & $\mathbf{m m}$ & $\mathbf{\%}$ & $\mathbf{m m}^{\mathbf{2}}$ & $\mathbf{M m}^{\mathbf{2}}$ & $\mathbf{m m}$ & $\boldsymbol{\%}$ & $\mathbf{k N}$ \\
& & $\mathbf{a}$ & & & & $\mathbf{m}$ & & & & & & & \\
\hline B1 & 31.67 & 560 & 200000 & 100 & 2 & 180 & 20 & 1.90 & 342 & 0 & 0 & 0 & 31.50 \\
B2 & 30.42 & 560 & 200000 & 100 & 2 & 180 & 20 & 1.90 & 342 & 0 & 0 & 0 & 43.25 \\
B3 & 29.58 & 560 & 200000 & 100 & 2 & 180 & 20 & 1.90 & 342 & 0 & 0 & 0 & 35.50 \\
B4 & 31.67 & 560 & 200000 & 100 & 2 & 180 & 20 & 1.90 & 342 & 60 & 200 & 0.3 & 44.50 \\
B5 & 36.25 & 560 & 200000 & 100 & 2 & 180 & 20 & 1.90 & 342 & 60 & 200 & 0.3 & 49.75 \\
B6 & 29.58 & 560 & 200000 & 100 & 2 & 180 & 20 & 1.90 & 342 & 60 & 200 & 0.3 & 4200 \\
B7 & 37.92 & 560 & 200000 & 100 & 2 & 180 & 20 & 1.90 & 342 & 100 & 200 & 0.5 & 75.00 \\
B8 & 36.25 & 560 & 200000 & 100 & 2 & 180 & 20 & 1.90 & 342 & 100 & 200 & 0.5 & 6.100 \\
B9 & 29.58 & 560 & 200000 & 100 & 2 & 180 & 20 & 1.90 & 342 & 100 & 200 & 0.5 & 58.00 \\
B10 & 37.92 & 560 & 200000 & 100 & 2.5 & 180 & 20 & 1.90 & 342 & 60 & 200 & 0.3 & 37.00 \\
B11 & 30.42 & 560 & 200000 & 100 & 2.5 & 180 & 20 & 1.90 & 342 & 60 & 200 & 0.3 & 47.25 \\
B12 & 29.58 & 560 & 200000 & 100 & 2.5 & 180 & 20 & 1.90 & 342 & 60 & 200 & 0.3 & 34.25 \\
\hline
\end{tabular}


The beams were divided into four groups. Each group consists of three beams with three different percentages of RCA $(0 \%, 25 \%$, and $50 \%)$. The first group (G1) consisted of three beams B1, B2 and B3. The beams were tested without shear reinforcement and with shear span/depth ratio (a/d =2), as shown in Figure 3.9(a). The second group (G2) consisted of three beams B4, B5 and B6 reinforced with shear reinforcement of $6 \mathrm{~mm}$-diameter stirrups spaced at $200 \mathrm{~mm}$ along the beam length $\left(\rho_{v}=0.3 \%\right)$. The shear span/depth ratio of the tested beams was $(\mathrm{a} / \mathrm{d}=2)$, as illustrated in Figure 3.9(b). The third group (G3) consisted of beams B7, B8 and B9 reinforced with stirrups of $8 \mathrm{~mm}$-diameter bars spaced at $200 \mathrm{~mm}\left(\rho_{v}=0.5 \%\right)$ as shown in Figure 3.9(c). The shear span/depth ratio of the tested beams was also $(\mathrm{a} / \mathrm{d}=2)$. The fourth group $(\mathrm{G} 4)$ consisted of beams B10, B11 and B12. The shear reinforcement of this group is the same as group (G2) but with shear span/depth ratio equal 2.5, as shown in Figure 3.9(d).

The results showed that for beams that did not have shear reinforcement, using recycled coarse aggregate would increase the cracking load and the ultimate load. This took place despite the compressive concrete strength being identical for all the beams in this group. It might be because of better interlocking of the recycled concrete aggregate developed along the crack. It was concluded that:

- When less than $25 \%$ of recycled coarse aggregate was used, the shear strength is almost similar to using conventional concrete. Particularly for low shear reinforcement ratios (less than $0.3 \%$ ). In addition, when $50 \%$ substitution is used, the shear strength decreased by an average of $12 \%$. However, increasing the shear reinforcement ratio could improve the effect of RCA.

- The ACI procedure for shear is validated by comparisons of the predicted failure loads with results of experimental data available in the literature. The results of 38 beams tested in the current study and by other researchers revealed that the ACI Code predictions for shear strength are about $30 \%$ more than the experimental values, indicating the possibility of using the same shear design procedure for beams with RCA. 


\subsection{THERORETICAL ANALYSES}

\subsubsection{Performance analysis of Codes/existing equation for predicting shear strength of RAC beams}

The shear strength of all beam specimens (total 91 beams out of which 48 beams without web reinforcement and 43 with web reinforcement) from experimental research conducted by previous researchers (Fathifzl et al. 2011, Etxeberria et al. 2007, Ajdkiewicz et al. 2007, Knaack et al. 2014, Al-Zahraaet al. 2011, González et al. 2009, González et al. 2007 and Arezoumandi et al. 2014 described in previous section) are calculated based on Codes and existing equations. The performance of Codes/existing equations is studied in terms of the ratio of experimental $\left(V_{e}\right)$ to predicted $\left(V_{p}\right)$ value $\left(V_{e} / V_{p}\right)$ of shear strength of beams. Various Codes (ACI 318-11, 2011; CSA A23.3-04, 2004; AS3600, 2009, Eurocode 2, 2004; CEB-FIP MODEL CODE, 1990,; Spanish Code: EHE-08, 2011 and NZS 3101, 2006) and other existing equations (proposed by Zsutty 1971, Cladera and Marı 2004 and Gastebled and May 2001) as described in Chapter 2 are used for performance evaluation.

The predicted shear strength values for beams without stirrups and beams with stirrups based on Codes/formulas are presented Tables A-1 to A- 10 and Table A-11 to A-18, respectively in Appendix A.

Figures 3.10 to 3.19 present the $V_{e} / V_{p}$ values for beams with and without web reinforcement for performance evaluation of various Code based/other existing equations. The points that fall below the reference line at $V_{e} / V_{p}$ equal to .0 indicate that the predicted shear strength by Codes/existing Equations is less than that obtained from test. $V_{e} / V_{p}>1$ means Codes/existing equations are conservative and under-predicting the shear strength of RAC beams. 
AC I 318-11

Beams with Stirrups

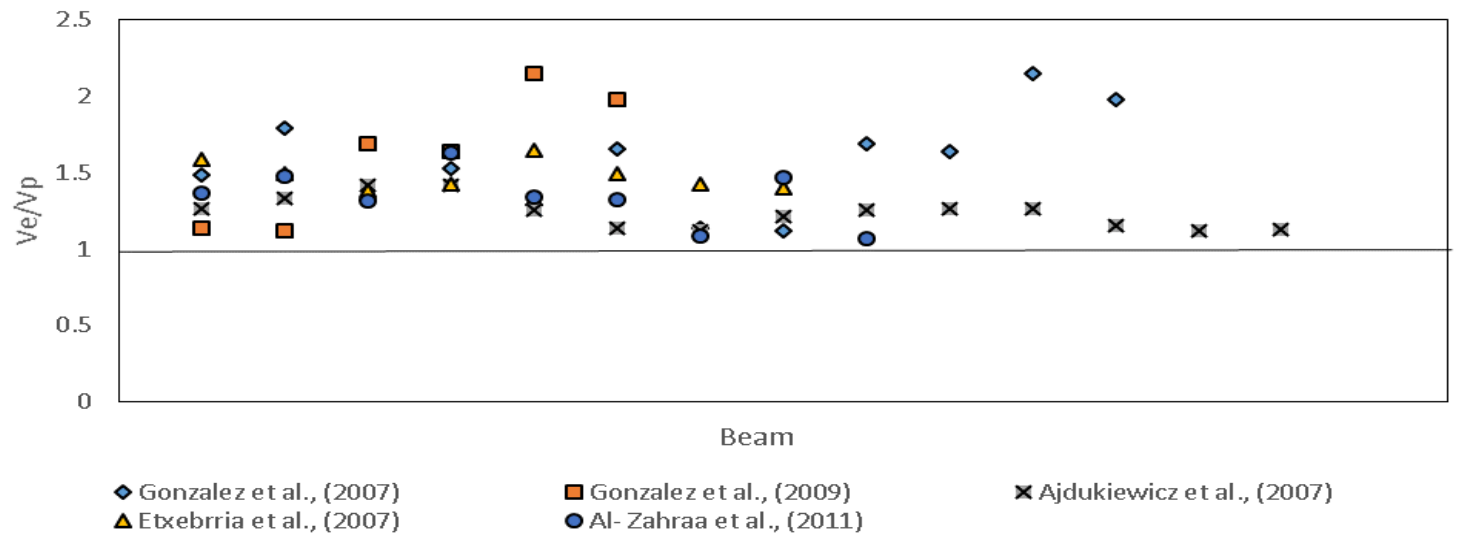

(a)

ACl 318-11

Beams without Stirrups

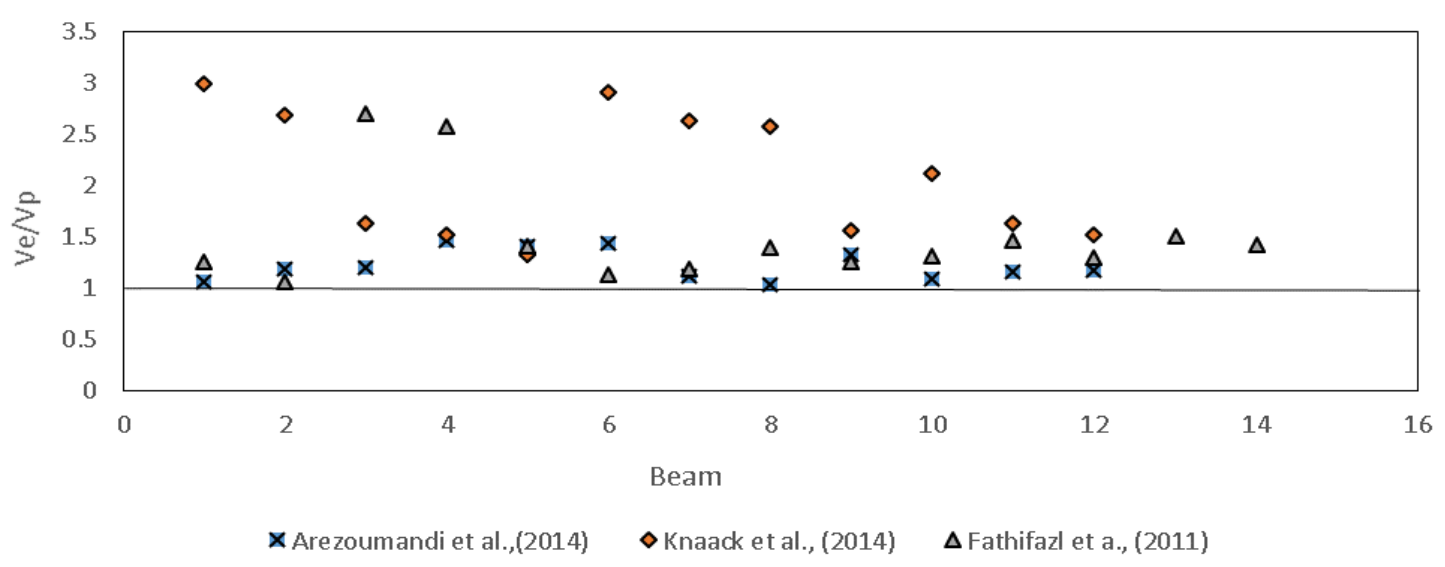

(b)

Figure 3.10 Ratio experiment-to-predicted values using ACI 318-11: (a) with stirrups (b) without stirrups 


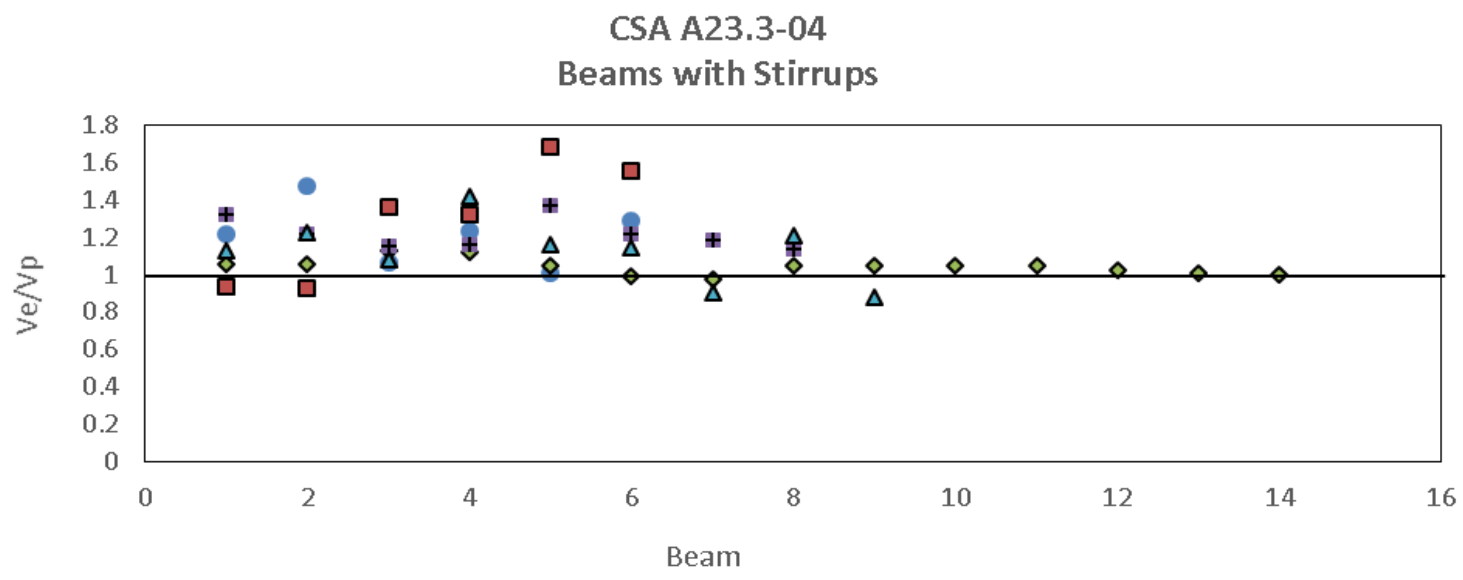

- Gonzalez et al.,(2007)

$\square$ Gonzalez et al.,(2009)

$\diamond$ Ajdukiewicz et al., (2007)

* Etxeberria et al., (2007)

$\Delta$ Al-Zahraa et al., (2011)

(a)

CSA A23.3-04

Beams without Stirrups

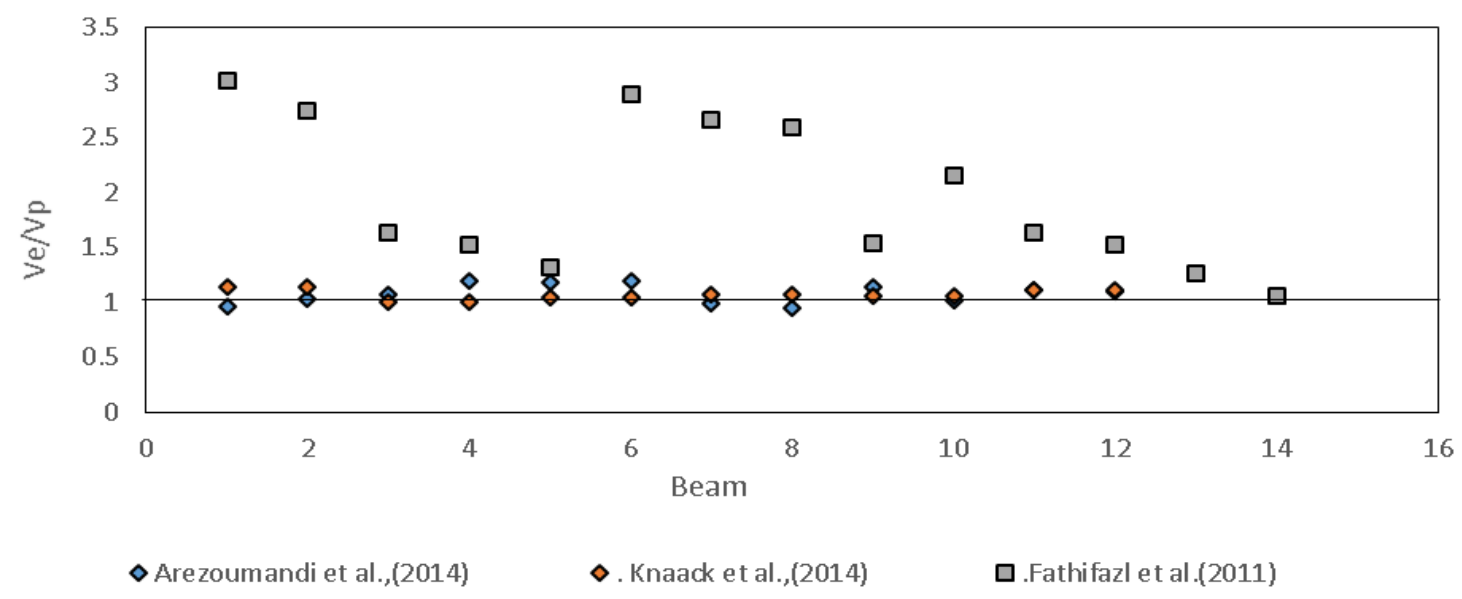

(b)

Figure 3.11 Ratio experiment-to-predicted values using CSA A23.3-04: (a) with stirrups (b) without stirrups 
AS 3600

Beams with Stirrups

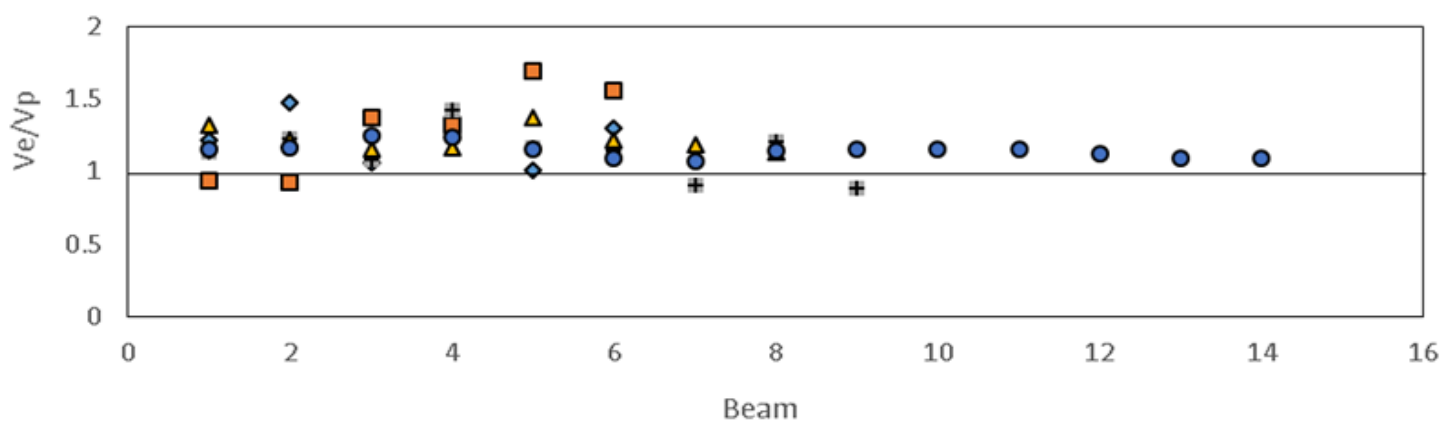

$\diamond$ Gonzalez et al.,(2007) $\quad$ 口Gonzalez et al.,(2009) \# Al-Zahraa et al., (2011)

$\Delta$ Etxeberria et al., (2007) O Ajdukiewicz et al., (2007)

(a)

AS 3600

Beams without Stirrups

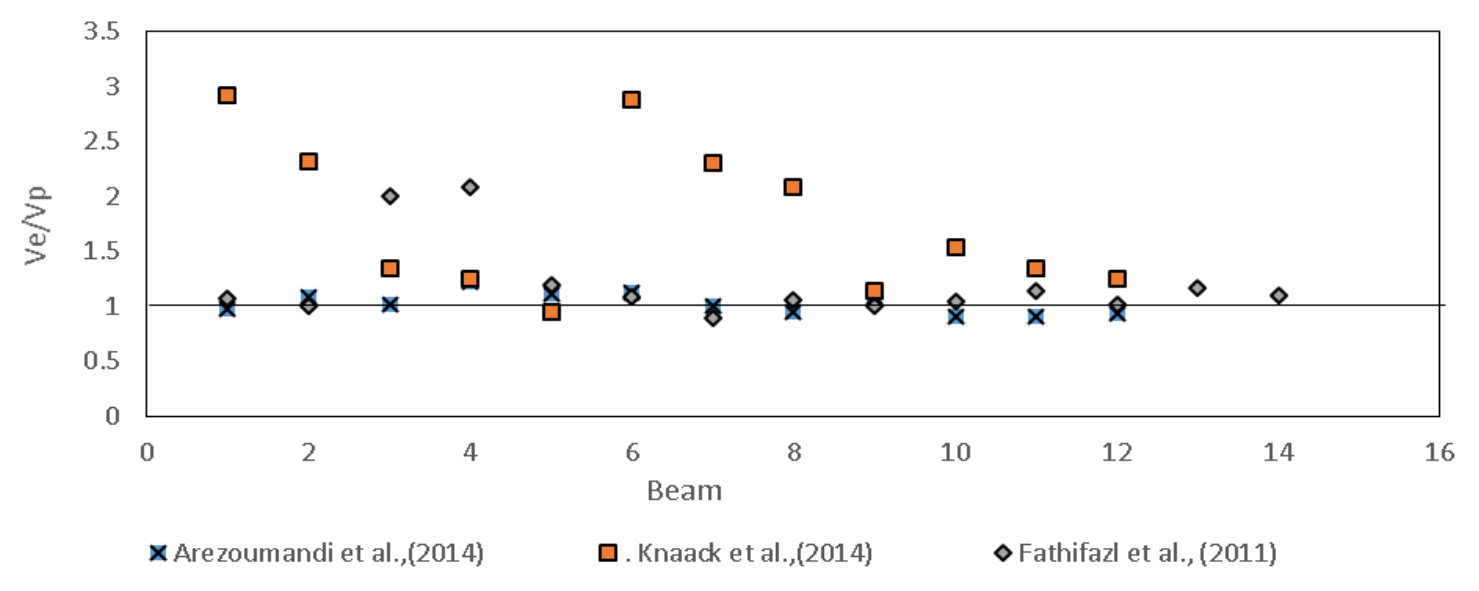

(b)

Figure 3.12 Ratio experiment-to-predicted values using AS 3600: (a) with stirrups (b) without stirrups 
Eurocode 2

Beams with Stirrups

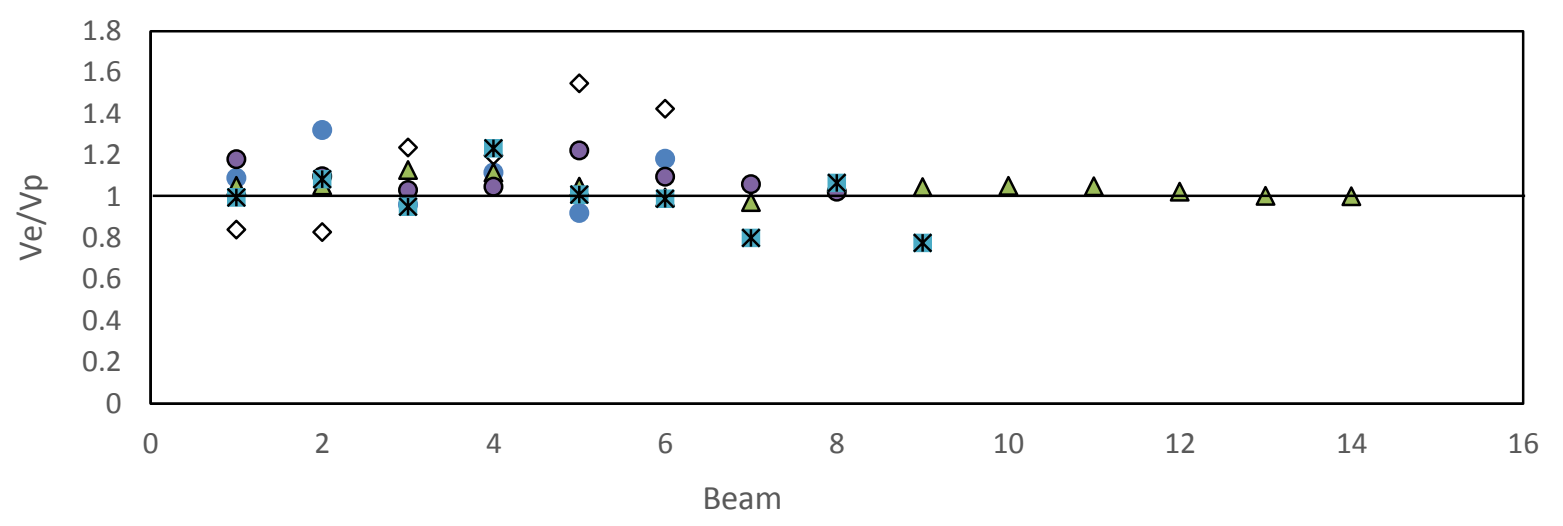

Gonzalez et al.,(2007) $\quad \diamond$ Gonzalez et al.,(2009) $\quad \Delta$ Ajdukiewicz,(2007)

O Etxeberria et al, (2007) * Al-Zahraa et al., (2011)

(a)

Eurocode-2

Beams without Stirrups

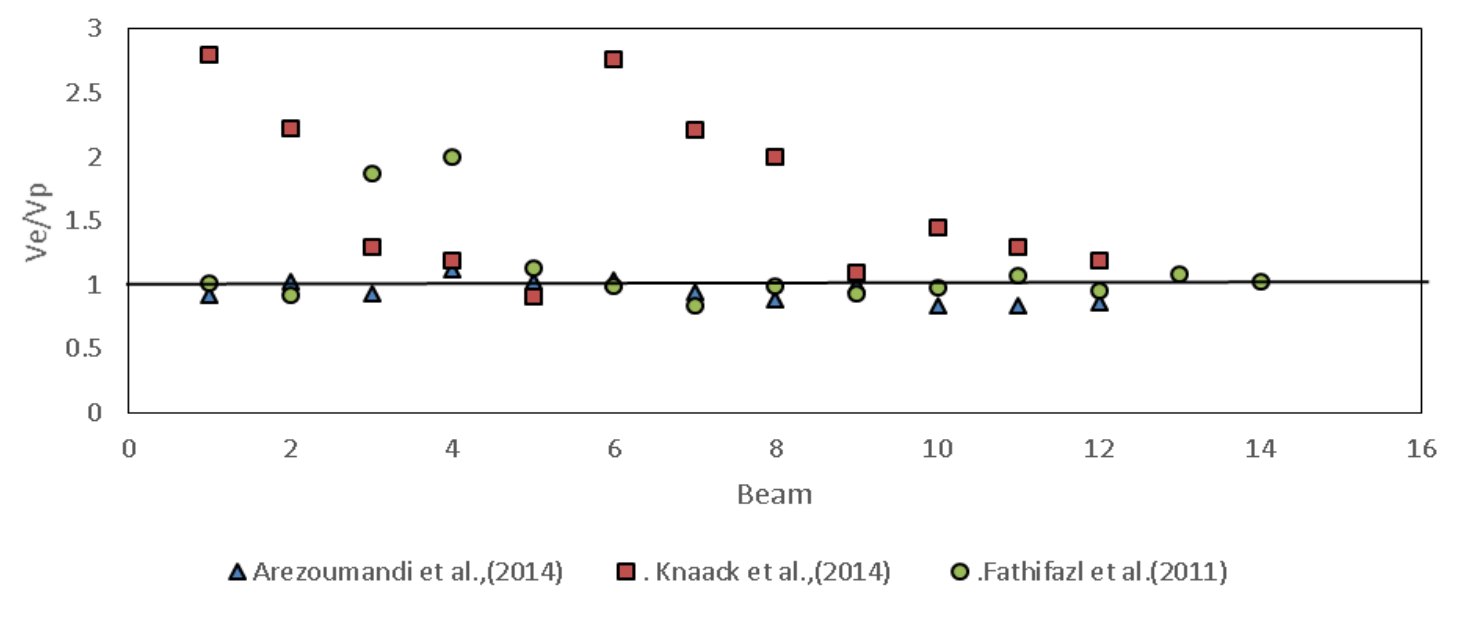

(b)

Figure 3.13 Ratio experiment-to-predicted values using Eurocode 2: (a) with stirrups (b) without stirrups 
CEB-FIP

Beams with Stirrups

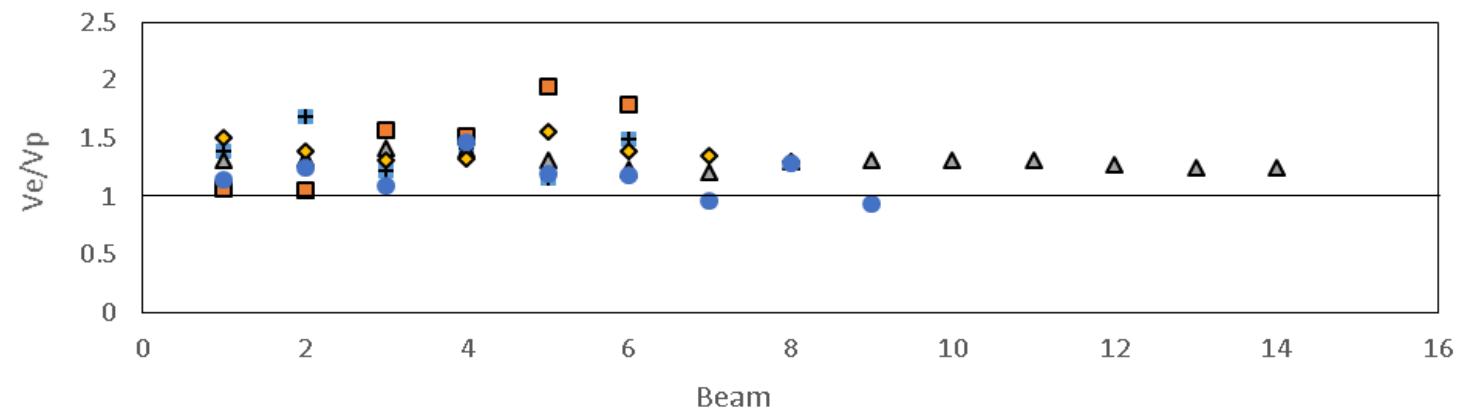

\# Gonzalez et al.,(2007)

$\square$ Gonzalez et al.,(2009)

$\Delta$ Ajdukiewicz et al., (2007)

$\diamond$ Etxeberria et al., (2007)

- Al-Zahraa et al., (2011)

(a)

CEB-FIP

Beams without Stirrups

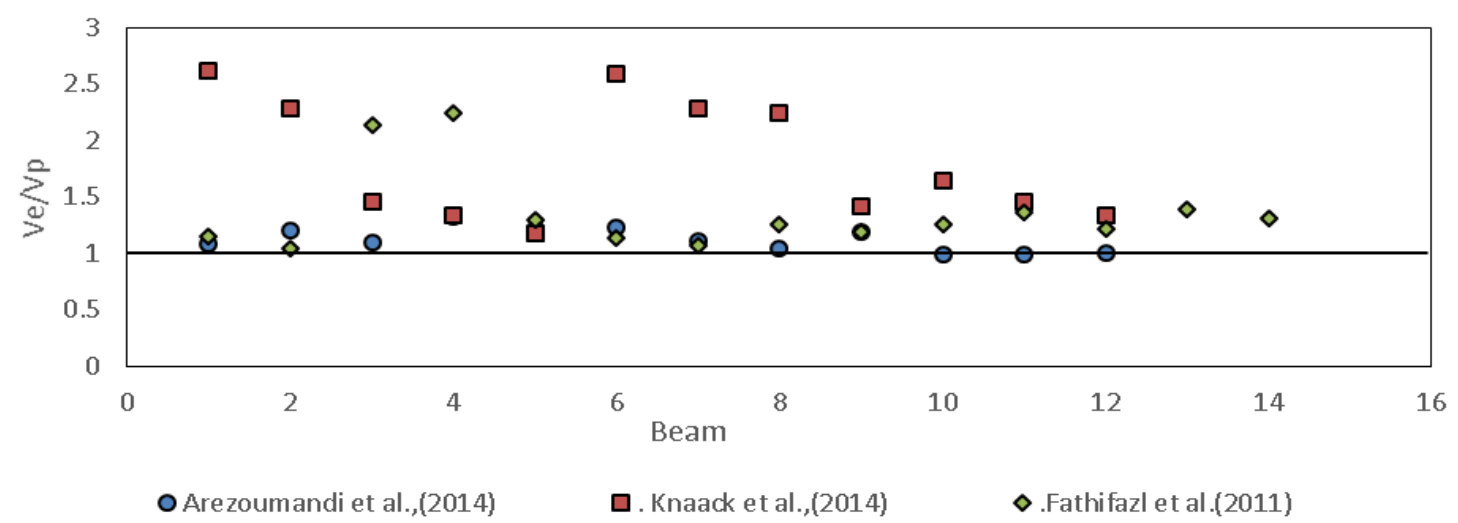

(b)

Figure 3.14 Ratio experiment-to-predicted values using CEB-FIP: (a) with stirrups (b) without stirrups 
EHE-08

Beams with Stirrups

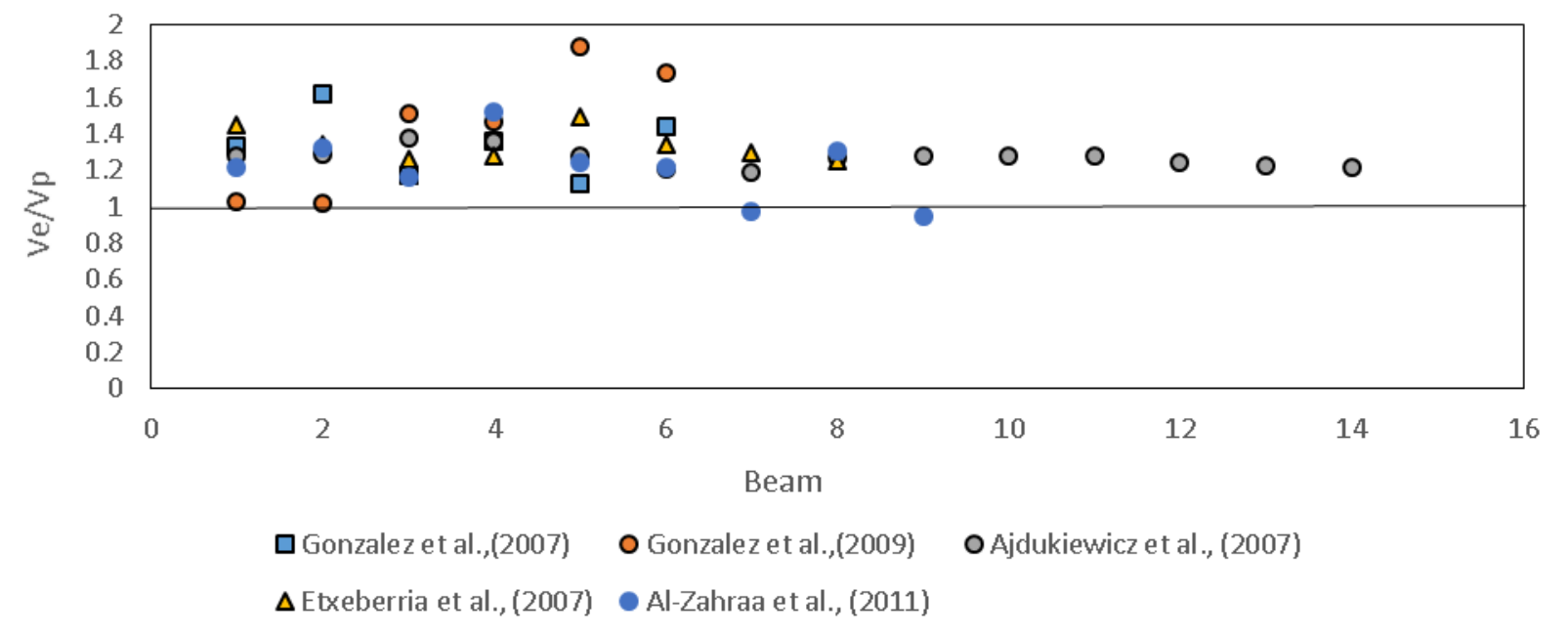

(a)

EHE-08

Beams without Stirrups

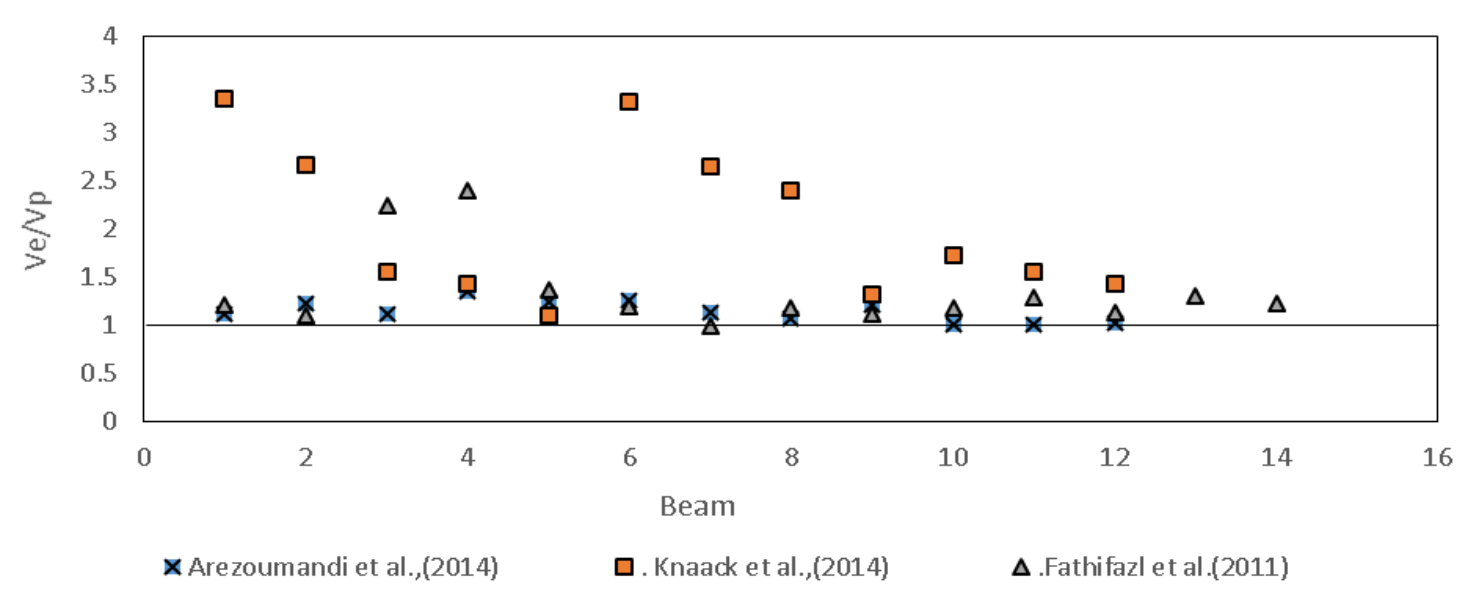

(b)

Figure 3.15 Ratio experiment-to-predicted values using EHE-08: (a) with stirrups (b) without stirrups 


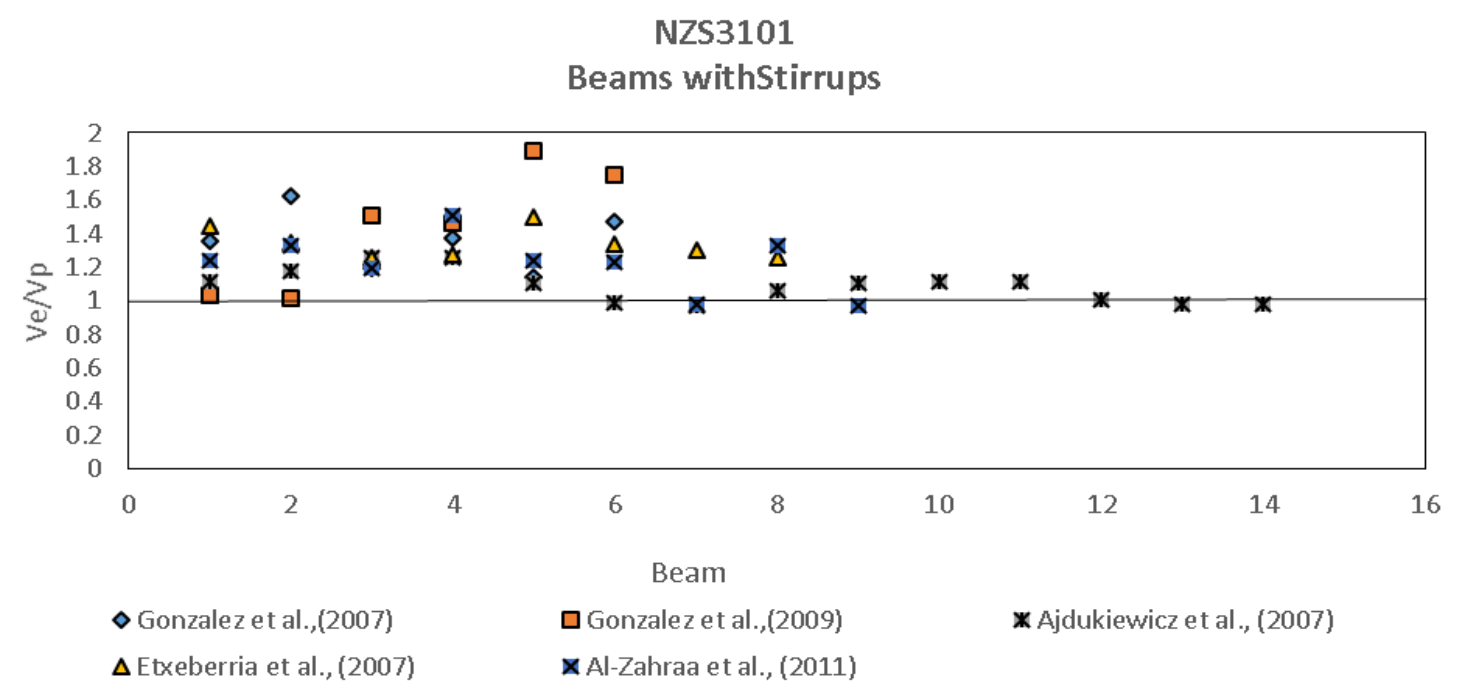

(a)

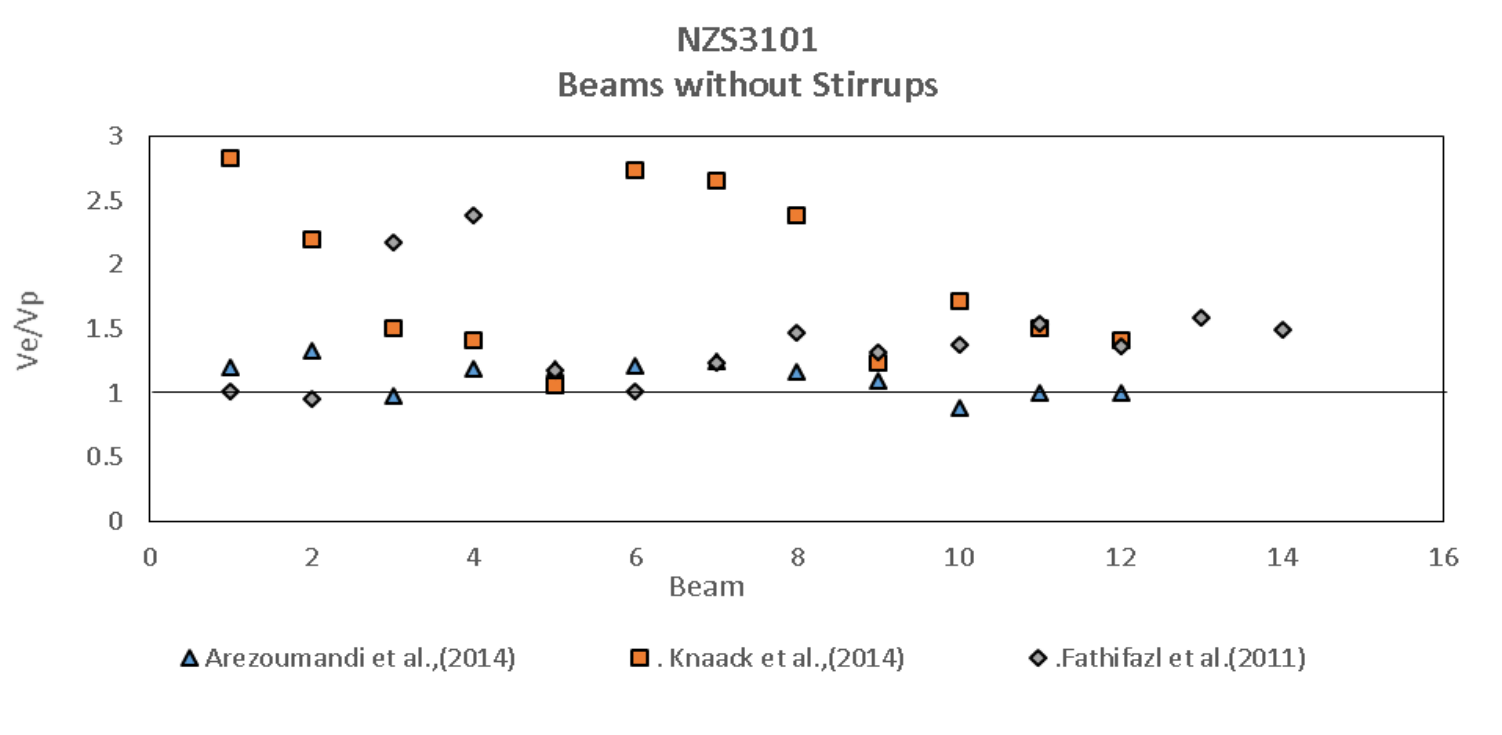

(b)

Figure 3.16 Ratio experiment-to-predicted values using NZS 3101: (a) with stirrups, (b) without stirrups 


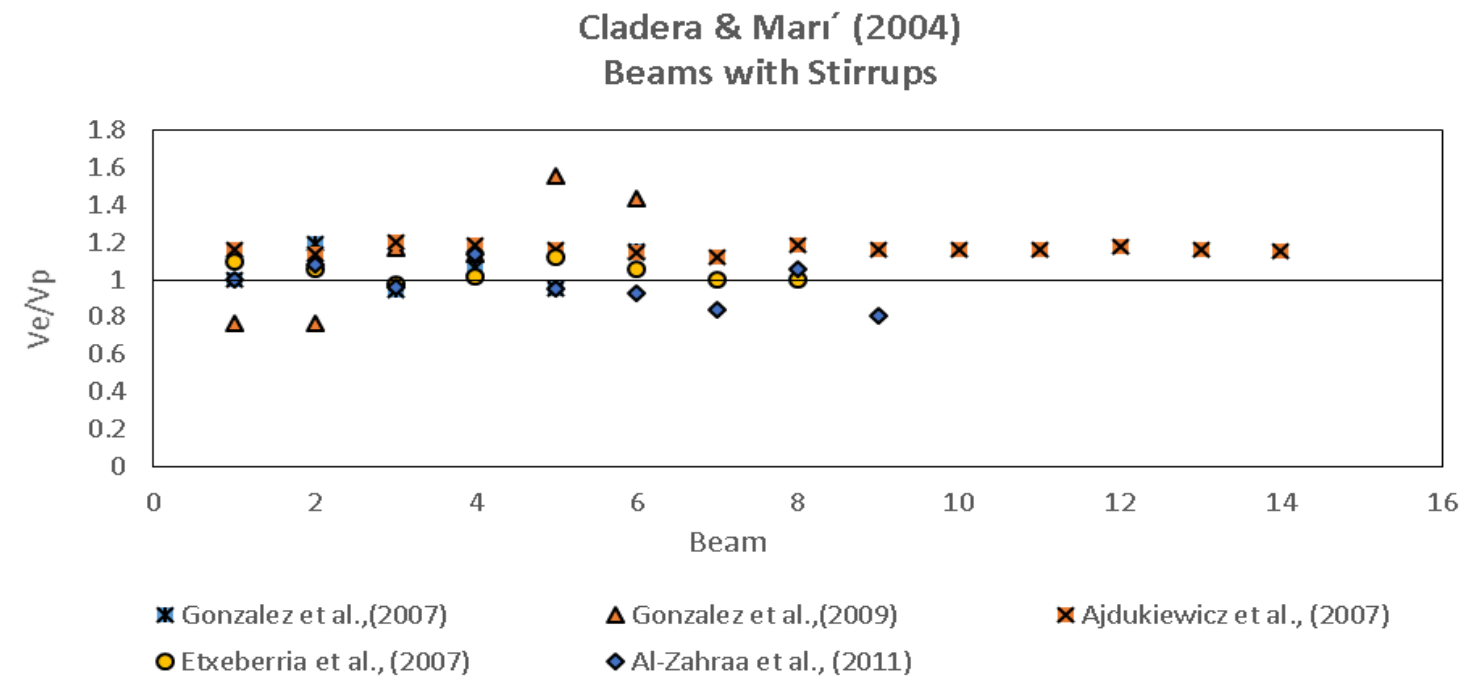

(a)

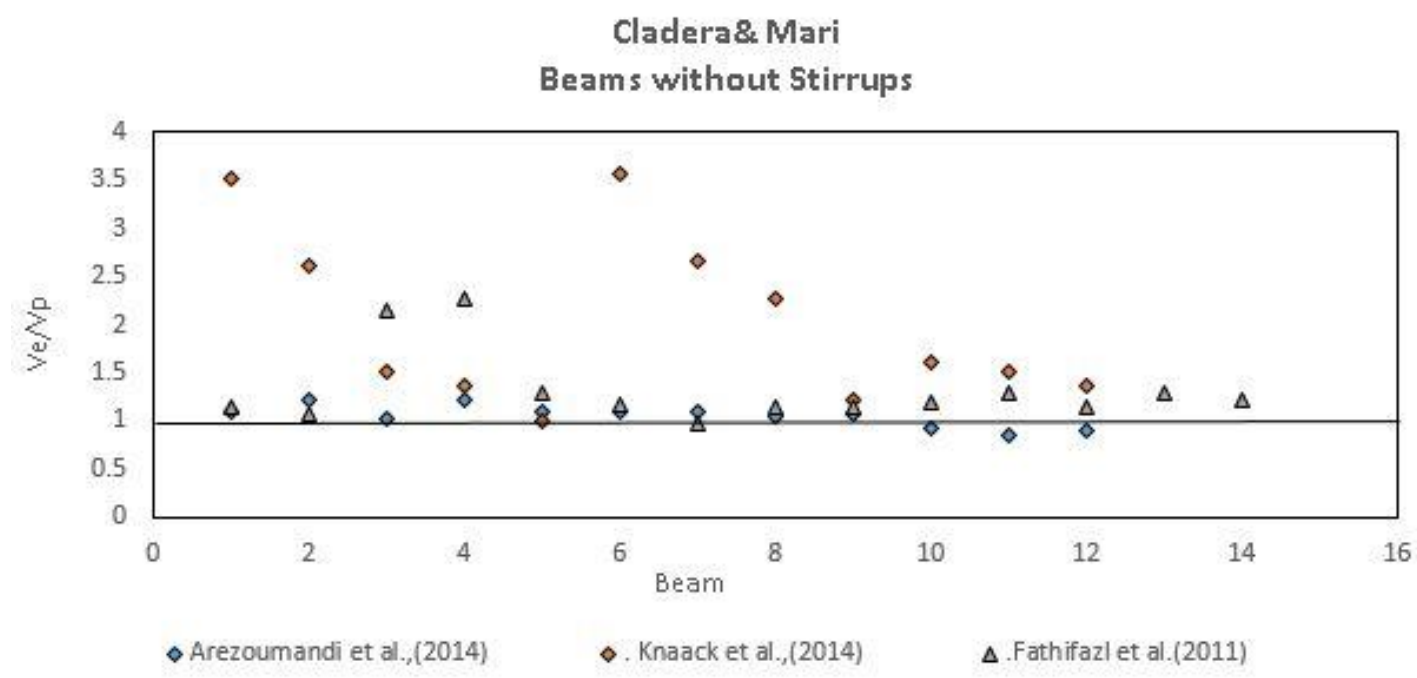

(b)

Figure 3.17 Ratio experiment-to-predicted values using Cladera and Mari (2004): (a) with stirrups (b) without stirrups 
Zsutty, 1971

Beams without Stirrups

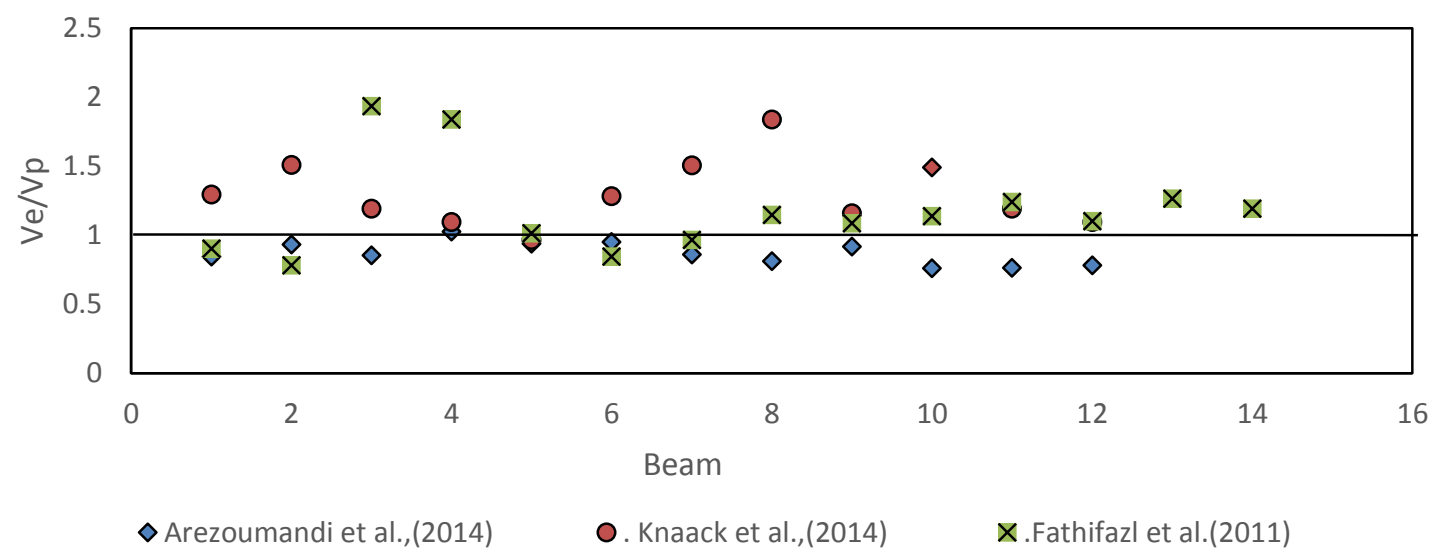

Figure 3.18 Ratio experiment-to-predicted values using Zsutty (1971) without stirrups

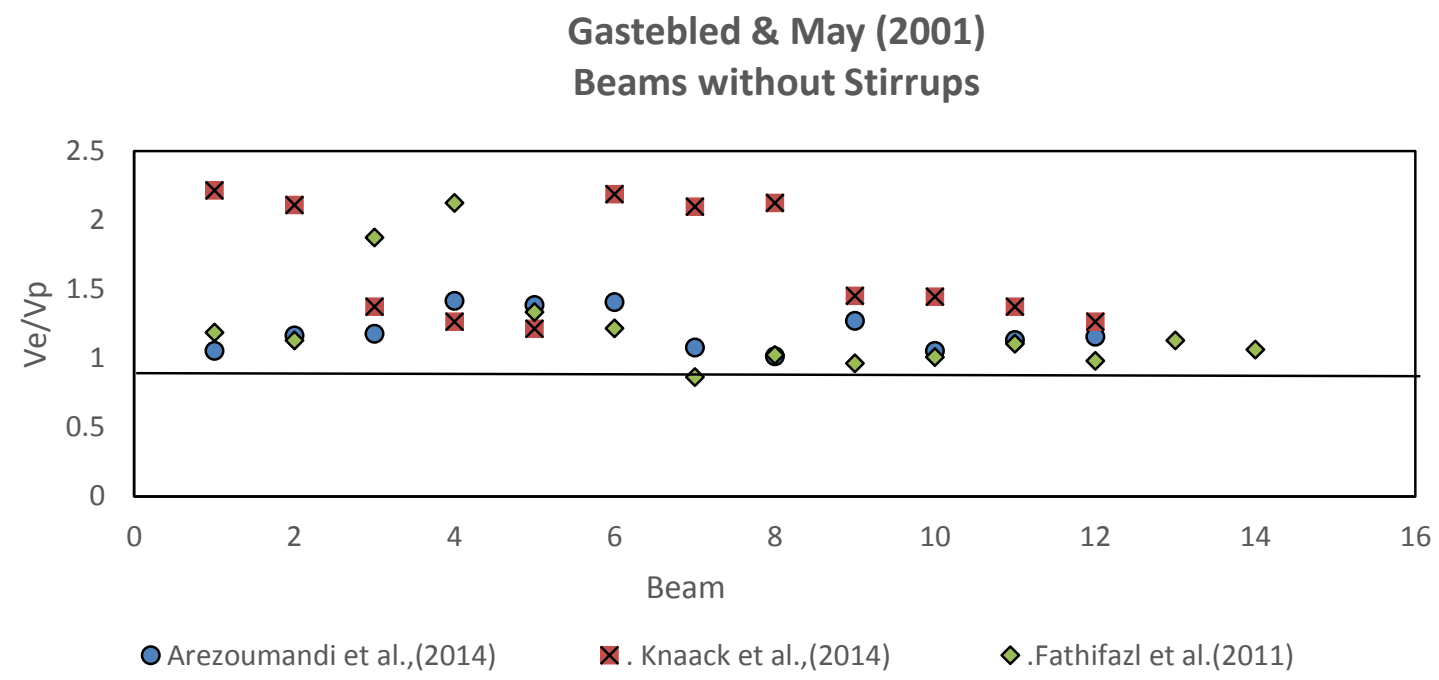

Figure 3.19 Ratio experiment-to-predicted values for Gastebled and May (2001): (a) with stirrups (b) without stirrups

Tables 3.9 and 3.10 present maximum, minimum, average and standard deviation of $V_{e} / V_{p}$ values for the analyses of predictive ability of Code based and other existing equations. Based on Figures 3.10 to 3.19 and Tables 3.9 and 3.10, the following information on the predictive ability of Code based and other existing equations are derived: 
Beams without web reinforcement: The ratio of experimented to predicted shear strength $\left(V_{e} / V_{p}\right)$ based on ACI 318-11 provisions ranges from 0.98 to 2.89 for normal and from 1.04 to 3.00 for simplified version. The shear strength of two beams out of 42 are overestimated by the Code (both general and simplified). For CSA A23.3-04, Ve/Vp ranges from 1.04 to 2.96 for simplified method and from 0.95 to 3.01 for general method. The general method overestimates the shear capacity of 3 beams out of 42 and the simplified method has no overestimation. For AS 3600, the $V_{e} / V_{p}$ ranges from 0.83 to 2.79. This Code overestimates the shear capacity of 10 beams out of 48 . For Eurocode-2, the $V_{e} / V_{p}$ ranges from 0.88 to 3.35 and overestimates the shear capacity of 16 beams over the 48 beams. For CEB-FIP, the $V_{e} / V_{p}$ ratio ranges from 0.98 to 2.61 and Code overestimates the shear capacity of 2 beams over the 48 beams. For EHE-08, the ratio ranges from 0.1 .00 to 3.35 and the shear capacity of one beam is overestimated by the Code. The NZS 3110 Code has the ratio varying from 0.86 to 2.84 and the shear capacity 4 beams are overestimated. The method offered by Cladera and Mari has the ratio varying from 0.86 to 3.56. The method overestimates the shear capacity of 5 beams out of 43 . The method of Zsutty has the ratio varying from 0.76 to 1.93 with the average of 1.09 . The shear capacity of 18 beams are overestimated. The method of Gastebled \& Mari has the ratio varying from 0.86 to 2.22 with an average value of 1.3 - the shear capacity of 7 beams are overestimated by the method.

Beams with web reinforcement: The $V_{e} / V_{p}$ based on ACI 318-11 provisions ranges from 1.07 to 2.14 (general) and from 1.07 to 2.15 (simplified) which are very close to each other. The simplified equation gives a conservative estimation for shear capacity with a mean value of 1.41. There is no overestimation of shear capacity with both of the equations. For CSA A23.3-04, the $V_{e} / V_{p}$ ranges from 0.91 to 1.97 for simplified method and from 0.95 to 1.98 for general method. Both the simplified and general methods overestimate the shear capacity of 2 beams out of 43 . For AS 3600, the ratio ranges from 0.88 to 1.69 and the Code overestimates the shear capacity of 4 beams out of 43. For Eurocode-2, the ratio ranges from 0.78 to 1.55 with a mean value of 1.07 and the Code overestimates the shear capacity of 11 beams out of 43. For CEB-FIP, the ratio ranges from 0.93 to 1.94 and the code overestimates the shear capacity of two beams out of 43. For EHE-08, the ratio ranges from 0.95 to 1.88 with an average of 1.30 and the shear capacity of 2 beams with overestimated. The NZS 3110 has the ratio varying from 0.97 to 1.65 with an average value of 1.90 and the shear capacity of 6 beams are overestimated. The method offered by Cladera and 
Mari has the ratio of 0.77 to 1.08 with an average of 1.82 . This method overestimated the shear capacity of 14 beams.

Table 3.9 Maximum, minimum, average and standard deviation of $V_{e} / V_{p}$ for beams without stirrups

\begin{tabular}{|c|c|c|c|c|c|}
\hline \multirow{2}{*}{\multicolumn{2}{|c|}{ Codes and methods }} & \multicolumn{4}{|c|}{ Beams without stirrups } \\
\hline & & \multirow{2}{*}{$\begin{array}{c}\left(\mathrm{V}_{\mathrm{e}} / \mathrm{V}_{\mathrm{p}}\right)_{\max } \\
2.89\end{array}$} & \multirow{2}{*}{$\begin{array}{c}\left(\mathrm{V}_{\mathrm{e}} / \mathrm{V}_{\mathrm{p}}\right)_{\min } \\
0.97 \\
\end{array}$} & \multirow{2}{*}{$\begin{array}{c}\begin{array}{c}\text { Average } \\
\text { of } \mathrm{V}_{\mathrm{e}} / \mathrm{V}_{\mathrm{p}}\end{array} \\
1.51\end{array}$} & \multirow{2}{*}{$\begin{array}{c}\begin{array}{l}\text { Standard } \\
\text { deviation } \\
\text { of Ve/Vp }\end{array} \\
0.55\end{array}$} \\
\hline \multirow{2}{*}{ ACI-318 } & Eq.(11-3) & & & & \\
\hline & Eq.(11-5) & 3 & 1.04 & 1.58 & 0.56 \\
\hline \multirow{2}{*}{$\begin{array}{l}\text { CSA 23.3- } \\
04 \mathrm{~A}\end{array}$} & Simplified & 2.96 & 1.04 & 1.54 & 0.55 \\
\hline & General & 3.01 & 0.95 & 1.46 & 0.63 \\
\hline \multicolumn{2}{|c|}{ AS3600 } & 2.91 & 0.89 & 1.3 & 0.5 \\
\hline \multicolumn{2}{|c|}{ Eurocode-2 } & 2.79 & 0.83 & 1.22 & 0.52 \\
\hline \multicolumn{2}{|c|}{ CEB-FIP } & 2.62 & 0.98 & 1.41 & 0.45 \\
\hline \multicolumn{2}{|l|}{ EHE-08 } & 3.35 & 1 & 1.5 & 0.61 \\
\hline \multicolumn{2}{|l|}{ NZs3101 } & 2.84 & 0.86 & 1.47 & 0.51 \\
\hline \multicolumn{2}{|l|}{ Zsutty } & 1.93 & 0.76 & 1.08 & 0.28 \\
\hline \multicolumn{2}{|c|}{ Cladera and Mari } & 3.57 & 0.86 & 1.42 & 0.65 \\
\hline \multicolumn{2}{|c|}{ Gastebled and May } & 2.22 & 0.87 & 1.32 & 0.39 \\
\hline \multicolumn{2}{|c|}{$\begin{array}{l}\text { Maximum Average and } \\
\text { Standard deviation }\end{array}$} & - & - & $1.58(\mathrm{ACI})$ & $\begin{array}{c}0.65 \\
\text { (Cladera) }\end{array}$ \\
\hline \multicolumn{2}{|c|}{$\begin{array}{l}\text { Minimum Average and } \\
\text { Standard deviation }\end{array}$} & & & $\begin{array}{c}1.08 \\
\text { (Zsutty) }\end{array}$ & $\begin{array}{c}0.28 \\
\text { (Zsutty) }\end{array}$ \\
\hline
\end{tabular}

Ve: Experimental shear strength; Vp: Predicted shear strength by Codes/existing methods 
Table 3.10 Maximum, minimum, average and standard deviation of $V_{e} / V_{p}$ for beams without stirrups

\begin{tabular}{|c|c|c|c|c|c|}
\hline \multirow{2}{*}{\multicolumn{2}{|c|}{ Codes and methods }} & \multicolumn{4}{|c|}{ Beams with stirrups } \\
\hline & & $\left(\mathrm{V}_{\mathrm{e}} / \mathrm{V}_{\mathrm{p}}\right)_{\max }$ & $\left(\mathrm{V}_{\mathrm{e}} / \mathrm{V}_{\mathrm{p}}\right)_{\min }$ & $\begin{array}{l}\text { Average } \\
\text { of } V_{e} / V_{p}\end{array}$ & $\begin{array}{l}\text { Standard } \\
\text { deviation }\end{array}$ \\
\hline \multirow{2}{*}{ ACI-318 } & Eq.(11-3) & 2.14 & 1.07 & 1.4 & 0.24 \\
\hline & Eq.(11-5) & 2.15 & 1.07 & 1.42 & 0.22 \\
\hline \multirow{2}{*}{$\begin{array}{l}\text { CSA 23.3- } \\
04 A\end{array}$} & Simplified & 1.97 & 0.91 & 1.24 & 0.22 \\
\hline & General & 1.98 & 0.95 & 1.26 & 0.21 \\
\hline \multicolumn{2}{|l|}{ AS3600 } & 1.69 & 0.88 & 1.19 & 0.16 \\
\hline \multicolumn{2}{|c|}{ Eurocode-2 } & 1.55 & 0.78 & 1.07 & 0.15 \\
\hline \multicolumn{2}{|c|}{ CEB-FIP } & 1.94 & 0.93 & 1.33 & 0.2 \\
\hline \multicolumn{2}{|l|}{ EHE-08 } & 1.88 & 0.97 & 1.25 & 0.22 \\
\hline \multicolumn{2}{|l|}{ NZS3101 } & 1.9 & 0.97 & 1.25 & 0.22 \\
\hline \multicolumn{2}{|l|}{ Zsutty } & - & - & - & - \\
\hline \multicolumn{2}{|c|}{ Cladera and Mari } & 1.56 & 0.77 & 1.08 & 0.15 \\
\hline \multicolumn{2}{|c|}{ Gastebled and May } & - & - & - & - \\
\hline \multicolumn{2}{|c|}{$\begin{array}{l}\text { Maximum Average and } \\
\text { Standard deviation }\end{array}$} & - & - & $1.42(\mathrm{ACI})$ & $0.24(\mathrm{ACI})$ \\
\hline \multicolumn{2}{|c|}{$\begin{array}{l}\text { Minimum Average and } \\
\text { Standard deviation }\end{array}$} & - & - & $\begin{array}{c}1.07 \text { (Euro } \\
\text { code-2) }\end{array}$ & $\begin{array}{c}0.15 \text { (Euro } \\
\text { code- } 2 \text { ) }\end{array}$ \\
\hline
\end{tabular}

Ve: Experimental shear strength; Vp: Predicted shear strength by Codes/existing methods

In general, most of the Codes and existing methods underestimated the shear capacity of RAC beams without stirrups with ACI 318-11 showing the highest underestimation - hence, they can be used safely for the prediction of shear capacity. However, the method of Zsutty (1971) with an average value of 1.08 for $V_{e} / V_{p}$ is found to be more accurate than Codes and other existing methods (Table 3.9).

Most of the Codes and existing methods underestimated the shear capacity of RAC beams with stirrups with ACI 318 showing the highest underestimation - hence, all the Codes/existing methods can be used for the prediction of shear capacity. However, Eurocode -2 and the method of Cladera and Mari with an average value of 1.07 and 1.08, respectively for $V_{e} V_{p}$ are found to be more accurate than other Codes and existing methods (Table 3.10).

However, over estimation by these Codes/existing methods for small percent of RAC beams in this study needs to be carefully addressed when using such Codes or methods. 


\subsubsection{Comparison of the influence of shear span to depth ratio}

The current standards/code provisions or existing methods to evaluate the shear strength of beams are the results of experimental studies conducted using conventional concrete. The shear strength of beams is affected by different parameters like the amount of web reinforcement, the amount of longitudinal reinforcement, coarse aggregate size, beam size, tensile strength of the concrete, and shear span to depth ratio $(a / d)$. The experimental results are used to study of the influencing parameters for shear strength. The shear span to depth ratio is one of the most influential parameters on the shear capacity of concrete beams. In Figure 3.20, the shear strength values of test beams without stirrups are plotted with respect to the shear span to depth ratio. The experimental results are compared with different codes/methods. The trend line is plotted based on the experimental results. To eliminate the effect of the beam size shear value (V) is divided by $b_{w} . d$. Figure 3.21 shows the $V / b_{w} . d$ values of beams without stirrups with respect to shear span to depth ratio. As the points in the Figure 3.21 overlaps each other, just three Codes are selected to show the relations. From both experimental and Code predicted values, shear strength is found to decrease with the increase of a/d ratio, as commonly observed for beams with normal aggregate concrete.

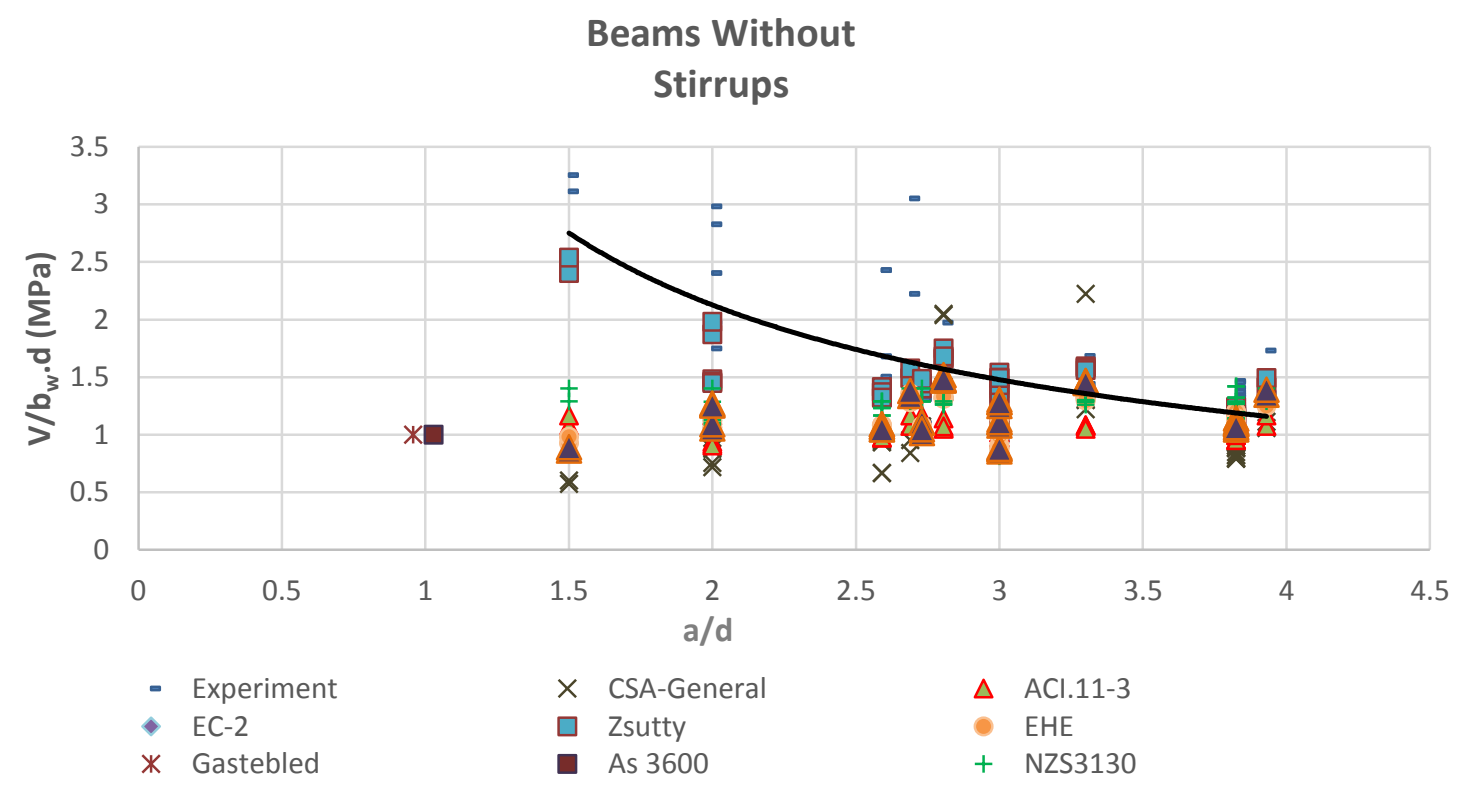

Figure 3.19 Effect of a/d on the shear strength of RAC beams without stirrups 


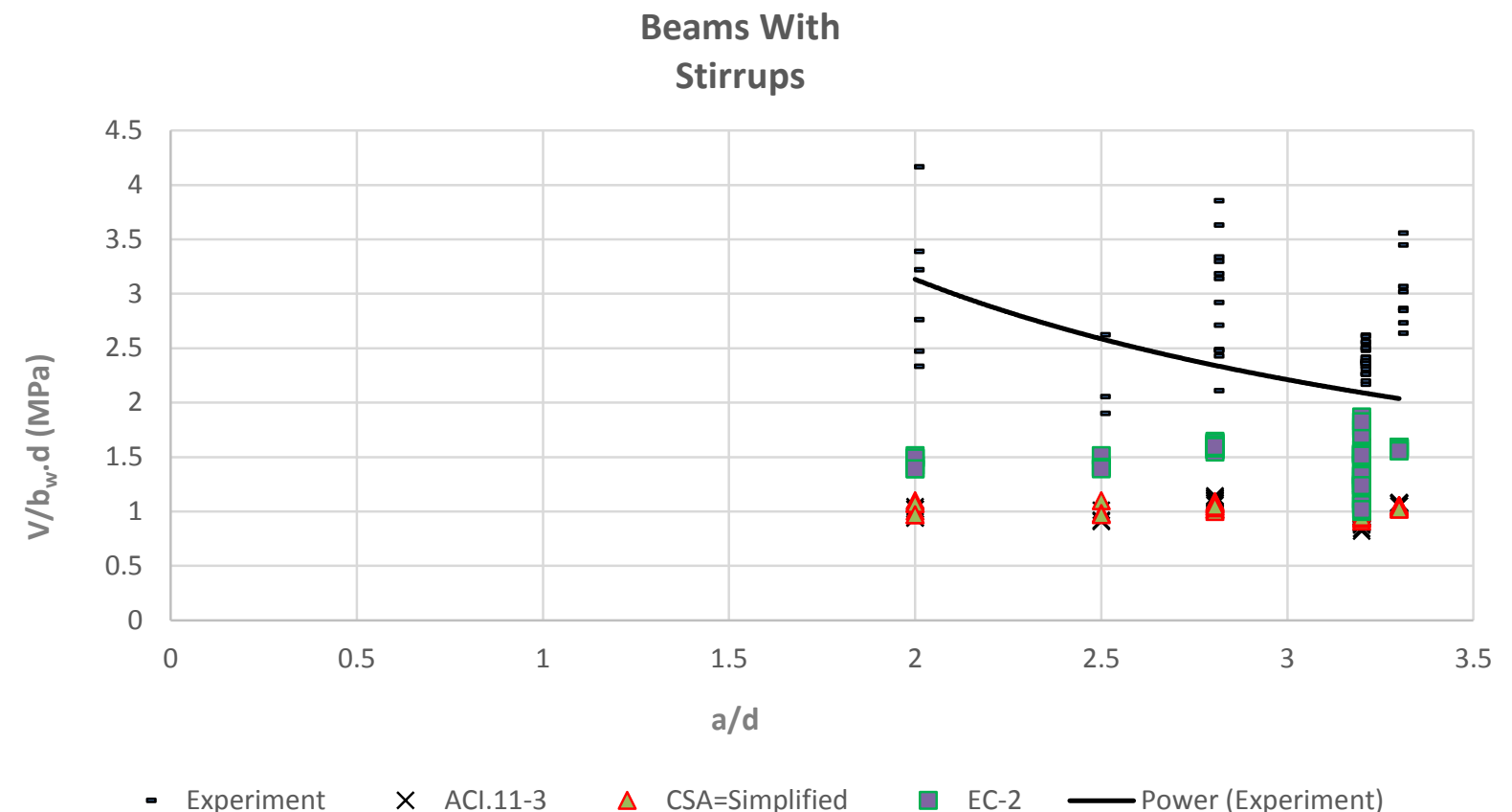

Figure 3.20 Effect of a/d on the shear strength of RAC beams with stirrups 


\section{CHAPTER FOUR}

\section{DEVELOPMENT OF ANN MODEL FOR PREDICTING SHEAR STRENGTH OF RAC BEAMS WITH AND WITHOUT SHEAR REINFORCEMENT}

\subsection{GENERAL}

Artificial neural network (ANN) modelling is a relatively new approach for analysing the behavior of recycled aggregate concrete (RAC) beams in shear. Based on the definition, an artificial neural network is a computational tool that makes a pattern of architecture similar to internal features of human brain and nervous system (Sanad and Saka, 2001). It can be applied for a wide range of system modeling. There are outstanding advantages of ANN model applications such as using various variables without needing to functional relationship amongst them.

According to previous and this research studies, existing code provisions and other existing methods to evaluate the shear strength of conventional concrete beams may need modifications for RAC beams. ANN models can be an alternative solution to predict shear strength of RAC beams. This chapter presents the development of ANN models for predicting the shear strength of $\mathrm{RAC}$ beams with/without web/shear reinforcement. The data collected from previous experimental research studies presented in chapter 3 is used to develop and train three ANN models. Model 1 is for beams with and without stirrups, Model 2 is for beams with stirrups and Model 3 for beams without stirrups. The performance three models is then validated by using twelve RAC beams from other research studies.

\subsection{Development of Artificial Neural Network (ANN) Model}

The neural network modeling in the present study is conducted by using commonly used backpropagation technique (Rumelhart et al., 1986). A typical network structure consists of couple of layers comprising an input layer, an output layer and one or more hidden layers. The influential factors are inserted in the input layer with no computational activities between them while the output layer contains one or more processing units that produce the network outputs. Hidden layers are placed between the input and output layers and various hidden processing units are expected. 
The calculation procedure uses input layer and compares the network outputs with known targets, and propagates the error back to the network. Figure 4.1 shows a simple model of a backpropagation network showing input layer, a hidden layer, an output layer, and connections are plotted.

\section{Input Layer Hidden Layer Output Layer}

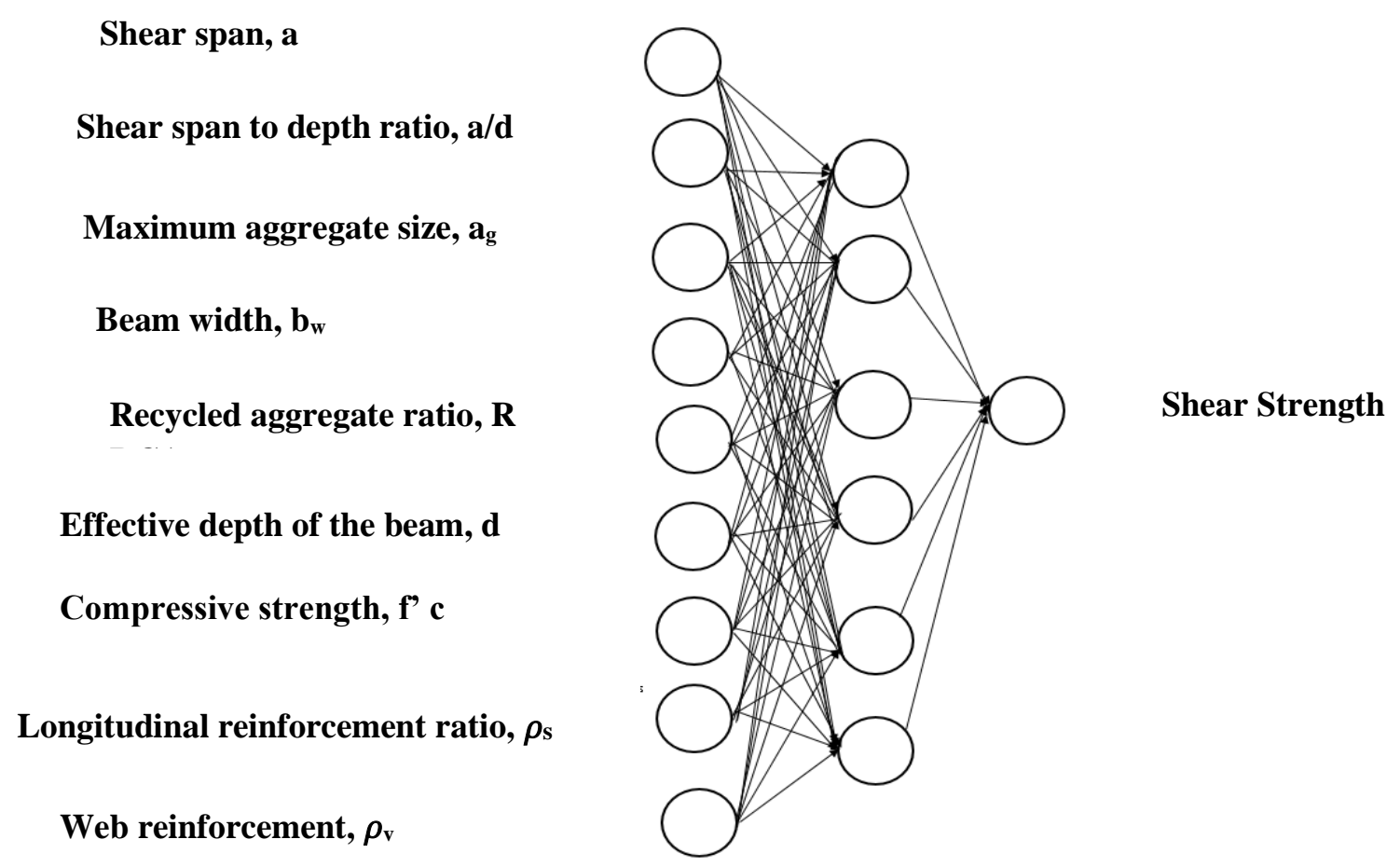

Figure 4.1 ANN Architecture

\subsubsection{Experimental database}

Data collection is an important part of the ANN model development. In this study, data is collected from previous experimental studies (described in Chapter 3) conducted by Fathifzl et al. 2011, Etxeberria et al. 2007, Ajdkiewicz et al. 2007, Knaack et al. 2014, Al-Zahraaet al. 2011, González et al. 2009, González et al. 2007 and Arezoumandi et al. 2014. A total of 96 RAC beams with and without shear reinforcements are selected to construct the database for training and development of three ANN models. Combined Model 1 developed for RAC beams with and without web 
reinforcement used all 96 beams, Model 2 developed for beams with web reinforcement used 43 beams and Model 3 developed for beams without web reinforcement used 53 beams. The performance of these three beams are validated by using additional 12 beams tested by Han et al. (2001) and Pellegrino and Faleschini (2013).

\subsubsection{Network architecture}

Determination of an optimal network architecture is another important step in the development of ANN models. To obtain the optimal network architecture the number of input variables denoted by "i" and the number of hidden neurons denoted by " $h$ " could be selected by series of trials to get output with reasonable accuracy as well as to identify the influential input parameters and to select number of hidden neurons for better model performance. The architecture is of ANN model is denoted by numbers of input, hidden and output neurons such as like "i: h: o". ANN model architecture shown in Figure 4.1 can be denoted by 9:6:1.

Nine influential input parameters that affect the shear strength are selected based on previous experimental studies and Code based/other existing. The input parameters are: concrete compressive strength $\left(f^{\prime}{ }_{c}\right)$, longitudinal reinforcement ratio $\left(\rho_{\mathrm{s}}\right)$, shear reinforcement $\left(\rho_{\mathrm{V}}\right)$, shear span(a), shear span to depth ratio a/d, beam width (b), beam effective depth (d), the recycled aggregate percentage $(\mathrm{R} \%)$ and maximum aggregate size $\left(\mathrm{ag}_{\mathrm{g}}\right)$ (Figure 4.1). The effect of these parameters on the shear strength of beams is explained in Chapter two as well as in Chapter Three. Comprehensive parametric ANN modeling is conducted to obtain the best network architecture for three ANN models and details are provided in the following sections.

\subsubsection{Training of ANN models}

The process of developing ANN model for predicting shear strength to determine the most appropriate neural network model consists of validation process which gives evidence for the effectiveness of the network architecture. The ranges of input parameters obtained from 96 experimental RAC beams are provided in Table 4.1.

To find the appropriate number of hidden neurons (h) for predicting shear capacity of RAC beams, the input variables are keep constant and further operations continued until reaching the suitable number of hidden neurons producing output of better accuracy. The next step after finding the 
most suitable number of hidden neurons, is finding the influence of each of the input parameters by excluding them one by one or two from the input layer and getting the output (shear strength of beams ' $\mathrm{V}$ ' in this study) with reasonable accuracy.

Nine input neurons are fed into the network with their specific weights and influence the generated weights of output layer. This process is repeated till the output layer has the least error based on regulated weights in each turn until to reach a constant value with respect to the experimental targets (shear Strength) (Yao, 1999). Finally, the training releases the optimized output.

Table 4.1 Experimental input parameter data range

\begin{tabular}{|l|l|l|l|l|l|l|l|l|l|l|}
\hline Input & $\begin{array}{l}\mathrm{A} \\
(\mathrm{mm})\end{array}$ & $\begin{array}{l}p_{\mathrm{s}} \\
(\%)\end{array}$ & $\begin{array}{l}p_{\mathrm{v}} \\
(\%)\end{array}$ & $\begin{array}{l}\mathrm{B} \\
(\mathrm{mm})\end{array}$ & $\begin{array}{l}\mathrm{D} \\
(\mathrm{mm})\end{array}$ & $\begin{array}{l}f^{\circ} \mathrm{c} \\
(\mathrm{MPa})\end{array}$ & $\mathrm{a} / \mathrm{d}$ & $\begin{array}{l}\mathrm{a}_{\mathrm{g}} \\
(\mathrm{mm})\end{array}$ & $\begin{array}{l}\mathrm{R} \\
(\%)\end{array}$ & $\begin{array}{l}\mathrm{V} \\
(\mathrm{kN})\end{array}$ \\
\hline Min & 360.0 & 1.00 & 0.00 & 100 & 180 & 29.58 & 1.50 & 16 & 0 & 0.942 \\
\hline Max & 1299.5 & 2.98 & 0.50 & 300 & 476 & 107.8 & 3.93 & 25 & 100 & 4.167 \\
\hline
\end{tabular}

Concrete compressive strength: f'c, longitudinal reinforcement ratio: $\rho_{\mathrm{s}}$, shear reinforcement ratio: $\rho_{\mathrm{v}}$, shear span: a, shear span to depth ratio: $a / d$, beam width: $b$, beam effective depth: $d$, the recycled aggregate percentage: $R$, maximum aggregate size: $\mathrm{a}_{\mathrm{g}}$ and shear strength of beam: $\mathrm{V}$

\subsection{Results and performance evaluation}

The results of ANN modeling are presented as statistical inferences. The value of degree of agreement denoted by $\xi$ is calculated by the equation 4.1. Perfect agreement between predicted and experimental values will yield a Degree of Agreement of 1, and no agreement between the values will yield a degree of 0 .

$\xi=1-\frac{\sum_{m=1}^{n}\left(V_{p m}-V_{e m}\right)^{2}}{\sum_{m=1}^{n}\left\{\left(V_{p m}-V_{e, a v g}\right)+\left(V_{e m}-V_{e, a v g}\right)\right\}^{2}}$

Where, $V_{p m}$ is the predicted value for the $\mathrm{m}^{\text {th }}$ entry, $V_{e m}$ is the experimental value of the $\mathrm{m}^{\text {th }}$ entry, and $V_{a v g}$ is the average experimental shear strength.

The Mean Squared Error (MSE) and the Root Mean Squared Error (RMSE) measure the amount of difference between experimental and predicted values and calculating with the equations 4-2) and 4-3):

$M S E=\frac{1}{N} \sum_{i=1}^{N}\left(V_{p m}-V_{e m}\right)^{2}$ 
$R M S E=\sqrt{\frac{\sum_{i=1}^{N}\left(V_{p m}-V_{e m}\right)^{2}}{N}}$

Where, $\mathrm{N}$ is the total number of events considered.

\subsubsection{Effect of number of hidden neurons}

In order to find the optimal number of hidden neurons, different network architecture (i:h:o) was examined by keeping the number of input variables constant and trying for two to nine hidden neurons to obtain the most appropriate shear strength with the higher degree of agreement. Tables 4.2, 4.3 and 4.4 listed the results of applied Artificial Neural Network model for modeling number one, number two and number 3, respectively. The tables contain the Network Architecture, i:h:o, where " $i$ " represents number of inputs, " $h$ " is number of hidden neurons and "o" is number of outputs; $V_{p} / V_{e}$ : ratio of shear strength from ANN model to experimental shear strength of RAC beam; $\varepsilon_{;}$degree of agreement; $V_{\text {avg: }}$ difference between the average predicted value and the average target value; $V_{\sigma}$ : difference between the standard deviation of the predicted data set and the standard deviation of the target data set; $V_{c v}$ : difference between the coefficient of variance of the predicted data set and the coefficient of variance of the target data set; $\mathrm{V}_{\text {max }}$ : difference between the maximum value in the predicted data set and the maximum value in the target data set; $V_{\min }$ : difference between the minimum value of the predicted data set and the minimum value of the target data set; $V_{\text {range: }}$ difference between the range of predicted values and the range of target values.

For Model 1 (which contains all beams with and without stirrups), the ANN model with 8 hidden neurons and network architecture of 9:8:1 is found to be in a good agreement (Table 4.2). The agreement factor, $\varepsilon_{6}$ is 0.9746 which is closer to $1, \mathrm{MSE}$ is 0.04237 which shows that the selected ANN model is having less error, $V_{p} / V_{e}$ is 0.9763 which is closer to 1 . The $V_{\text {avg }}$ of 0.0498 which shows the difference in average of ANN model output shear strength to input shear strength is in a minimum value to keep the developed ANN model in good agreement. $V_{\sigma}$ of 0.0328 is the difference in the standard deviation of output shear strength to input shear strength, standard deviation shows the variation from average and the lower the standard deviation the closer data points to expected value. $V_{c v}$ of -0.0068 is the difference in the covariance of the output shear strength and indicates a lesser variant in the ANN output average to experimental average. $V_{\min }$ is 
$0.0429, V_{\max }$ is -0.5347 and $V_{\text {range }}$ is 0.5776 . Figure 4.2 also shows that the equation of $\mathrm{y}=0.9938 \mathrm{x}$ +0.0626 for 8 hidden neurons indicates the coefficient of $x$ value of 0.9938 - which is closer to 1 indicating that the predicted shear strength is closer to experimental shear stress.
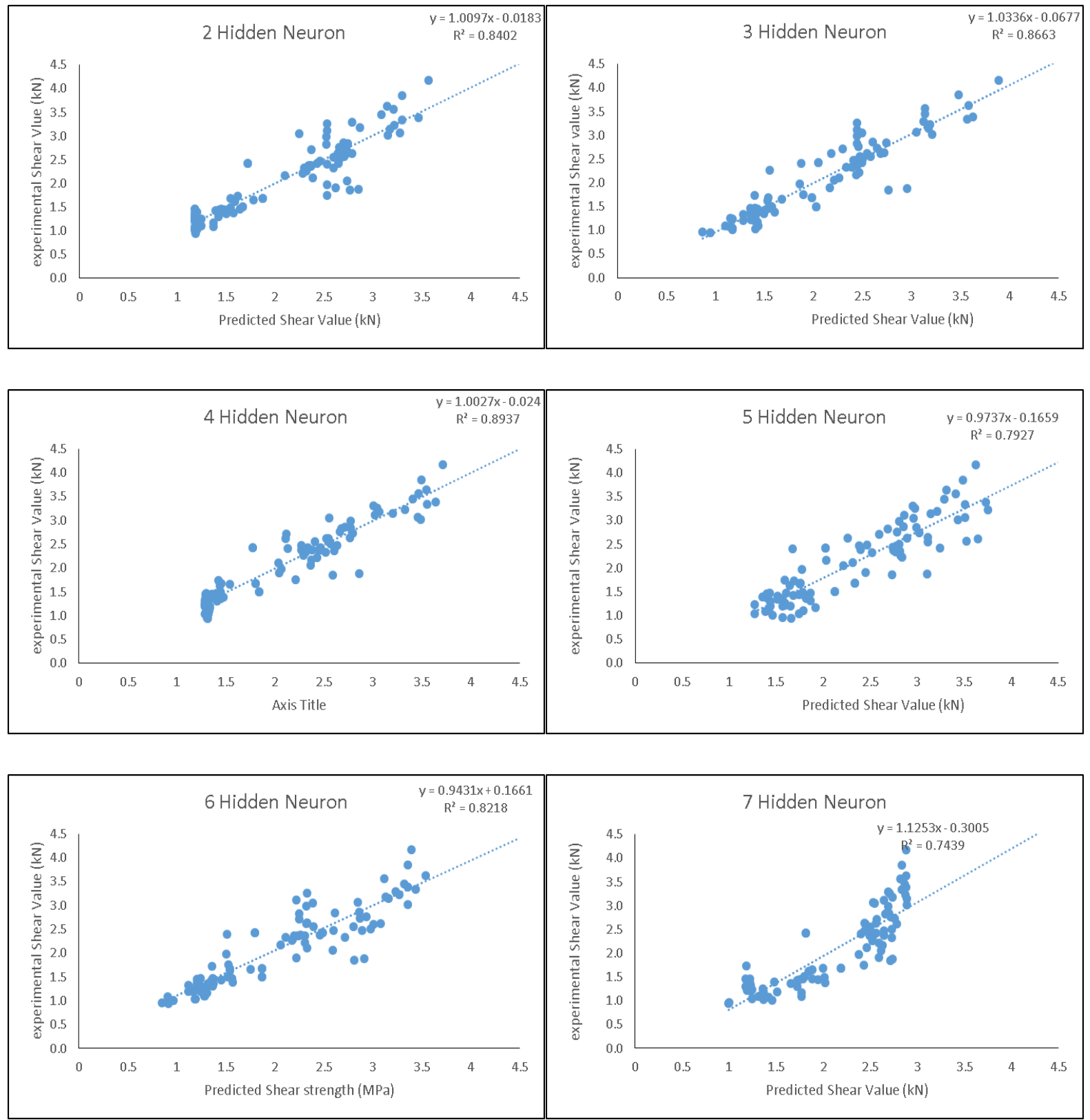

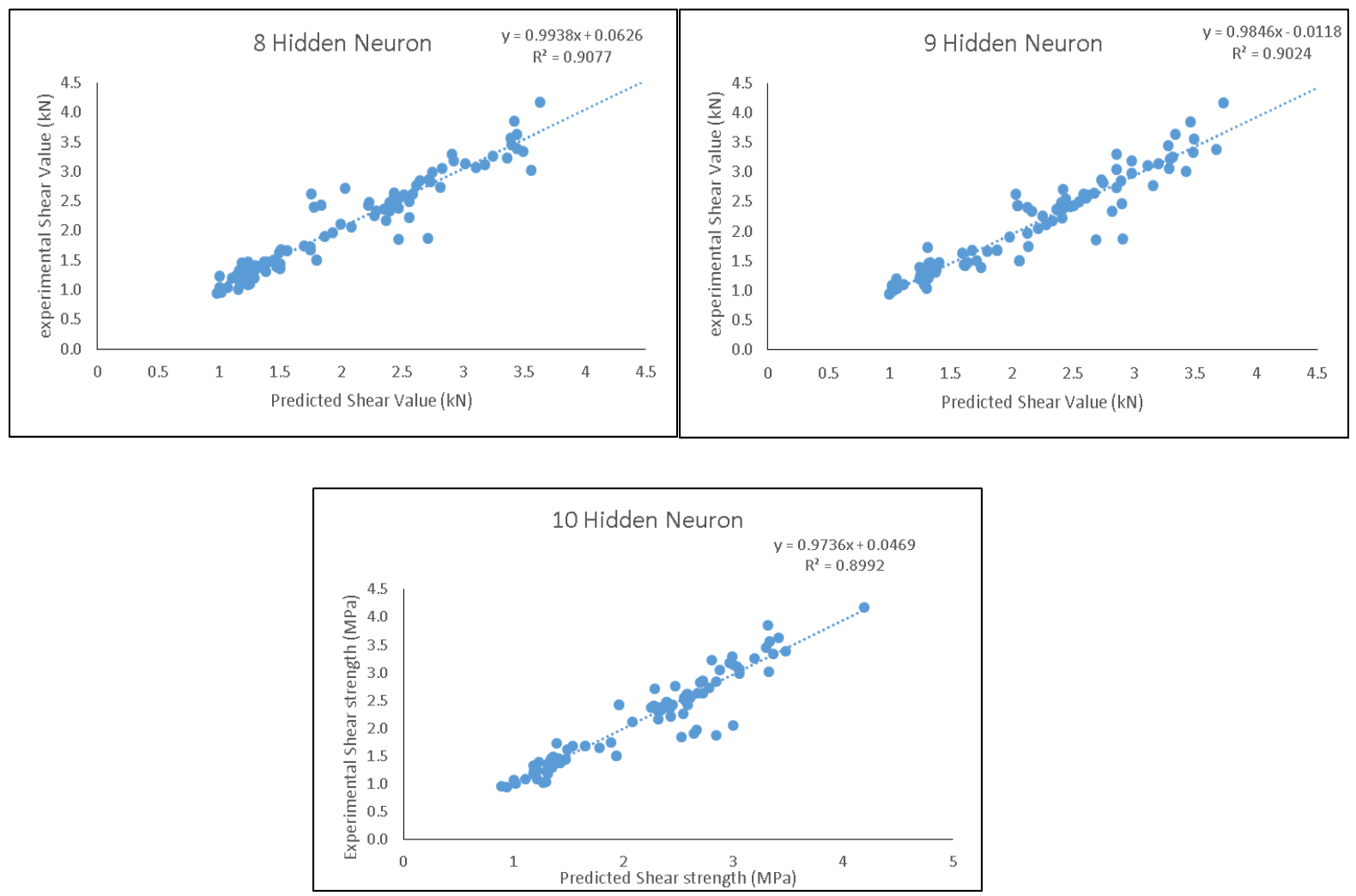

Figure 4.2 Predicted versus experimental shear capacity from various numbers of hidden neurons for Model 1

Table 4.2 Evaluation of Number of Hidden Neurons for Model 1, beams with and without stirrups

\begin{tabular}{|c|c|c|c|c|c|c|c|c|c|c|c|}
\hline $\begin{array}{l}\text { Hidden } \\
\text { Neurons }\end{array}$ & i:h:o & $\xi$ & $\mathbf{v}_{\mathbf{p}} / \mathbf{v}_{\mathbf{e}}$ & MSE & RMSE & $\mathbf{v}_{\text {avg }}$ & $\mathbf{v}_{\mathbf{\sigma}}$ & $\mathbf{v}_{\text {range }}$ & $\mathbf{v}_{\min }$ & $\mathbf{v}_{\max }$ & $\mathbf{v}_{\text {cv }}$ \\
\hline $\mathrm{n}=2$ & $9: 2: 1$ & 0.9556 & 0.9990 & 0.0703 & 0.2652 & 0.0020 & 0.0732 & 0.8375 & 0.2424 & -0.5951 & -0.0345 \\
\hline $\mathrm{n}=3$ & $9: 3: 1$ & 0.9624 & 0.9987 & 0.0592 & 0.2433 & 0.0028 & 0.0789 & 0.2021 & -0.0730 & -0.2751 & -0.0371 \\
\hline $\mathrm{n}=4$ & $9: 4: 1$ & 0.9717 & 1.0087 & 0.0470 & 0.2168 & 0.0183 & 0.0454 & 0.7929 & 0.3415 & -0.4514 & -0.0661 \\
\hline $\mathrm{n}=5$ & $9: 5: 1$ & 0.9235 & 1.1081 & 0.1278 & 0.3575 & 0.2271 & 0.0679 & 0.7389 & 0.3295 & -0.4093 & -0.0661 \\
\hline $\mathrm{n}=6$ & $9: 6: 1$ & 0.9507 & 0.9765 & 0.0814 & 0.2853 & 0.0493 & 0.0307 & 0.5323 & -0.0957 & -0.6280 & -0.0059 \\
\hline $\mathrm{n}=7$ & $9: 7: 11$ & 0.9109 & 1.0159 & 0.1175 & 0.3427 & 0.0333 & 0.1853 & 1.3279 & 0.0525 & -1.2754 & -0.0928 \\
\hline $\mathrm{n}=8$ & $9: 8: 1$ & 0.9746 & 0.9763 & 0.0424 & 0.2058 & 0.0498 & 0.0328 & 0.5776 & 0.0429 & -0.5347 & -0.0068 \\
\hline $\mathrm{n}=9$ & $9: 9: 1$ & 0.9738 & 1.0213 & 0.0444 & 0.2108 & 0.0448 & 0.0279 & 0.4861 & 0.0553 & -0.4308 & -0.0209 \\
\hline $\mathrm{n}=10$ & $9: 10: 1$ & 0.9738 & 1.0042 & 0.0447 & 0.2114 & 0.0089 & 0.0206 & 0.0755 & -0.0462 & 0.0293 & -0.0114 \\
\hline
\end{tabular}

*Network Architecture

For Model 2 (beams with stirrups), the ANN model with 6 hidden neurons and network architecture of 9:6:1 is found to be in a good agreement. The agreement factor, $\varepsilon_{0}$ is 0.9605 which is closer to $1, \mathrm{MSE}$ is 0.0239 which shows that the selected ANN model is having less error, $V_{p} / V_{e}$ is the ratio of predicted shear strength to experimental shear strength of RAC beam is 1.0288 which 
is closer to 1 . The $V_{\text {avg of }} 0.0783$ which shows the difference in average of ANN model output shear strength to input shear strength is in a minimum value to keep the developed ANN model in a good agreement. $V_{\sigma}$ of 0.1080 is the difference in the standard deviation of output shear strength to input shear strength, standard deviation shows the variation from average and the lower the standard deviation the closer data points to expected value. $V_{c v}$ of 0.0089 is the difference in the covariance of the output shear strength and indicates a lesser variant in the ANN output average to experimental average. $V_{\min }$ is $0.3837 V_{\max }$ is -0.1568 and $V_{\text {range }}$ is 0.5405 . Figure 4.3 shows that the equation $\mathrm{y}=0.9615 \mathrm{x}+0.0295$ for 6 hidden neurons indicating the coefficient of $\mathrm{x}$ of 0.9615 which is closer to 1 indicating the predicted shear strength is closer to experimental shear strength.

Table 4.3 Evaluation of number of hidden neurons for Model 2, beams with stirrup

\begin{tabular}{|c|c|c|c|c|c|c|c|c|c|c|c|}
\hline $\begin{array}{l}\text { Hidden } \\
\text { Neurons } \\
\end{array}$ & i:h:o * & $\xi$ & $V_{p} / V_{e}$ & MSE & RMSE & $\mathbf{V}_{\text {avg }}$ & $\mathbf{v}_{\sigma}$ & $V_{\text {range }}$ & $\mathbf{V}_{\min }$ & $\mathbf{V}_{\max }$ & $\mathrm{V}_{\mathrm{cv}}$ \\
\hline $\mathrm{n}=2$ & 9:2:1 & 0.910553 & 0.921315 & 0.021426 & 0.146376 & 0.213898 & 0.19852 & 0.957451 & -0.1705 & -1.12795 & -0.06226 \\
\hline$n=3$ & 9:3:1 & 0.953616 & 1.006406 & 0.023405 & 0.152986 & 0.017413 & 0.207751 & 1.014976 & 0.237397 & -0.77758 & -0.0772 \\
\hline $\mathrm{n}=4$ & 9:4:1 & 0.95373 & 1.016062 & 0.023629 & 0.153718 & 0.043664 & 0.263649 & 1.367636 & 0.57827 & -0.78937 & -0.0986 \\
\hline$n=5$ & $9: 5: 1$ & 0.964729 & 1.013442 & 0.023568 & 0.15352 & 0.03654 & 0.06306 & 0.878637 & 0.186339 & -0.6923 & -0.02553 \\
\hline$n=6$ & 9:6:1 & 0.960483 & 1.028787 & 0.023925 & 0.154678 & 0.078253 & 0.107984 & 0.540482 & 0.383687 & -0.15679 & 0.008888 \\
\hline$n=7$ & 9:7:11 & 0.893864 & 1.005876 & 0.023392 & 0.152946 & 0.015974 & 0.141932 & 0.908868 & -0.09535 & -1.00422 & -0.05307 \\
\hline$n=8$ & 9:8:1 & 0.925696 & 1.031157 & 0.02398 & 0.154856 & 0.084698 & 0.231299 & 1.04705 & 0.237772 & -0.80928 & -0.08853 \\
\hline$n=9$ & 9:9:1 & 0.965134 & 0.998175 & 0.023213 & 0.152359 & 0.00496 & 0.138155 & 0.17911 & -0.15081 & -0.32992 & -0.05055 \\
\hline $\mathrm{n}=10$ & $9: 10: 1$ & 0.975033 & 0.997218 & 0.023191 & 0.152286 & 0.007562 & 0.03462 & 0.335901 & 0.16531 & -0.17059 & -0.01222 \\
\hline
\end{tabular}

*Network Architecture

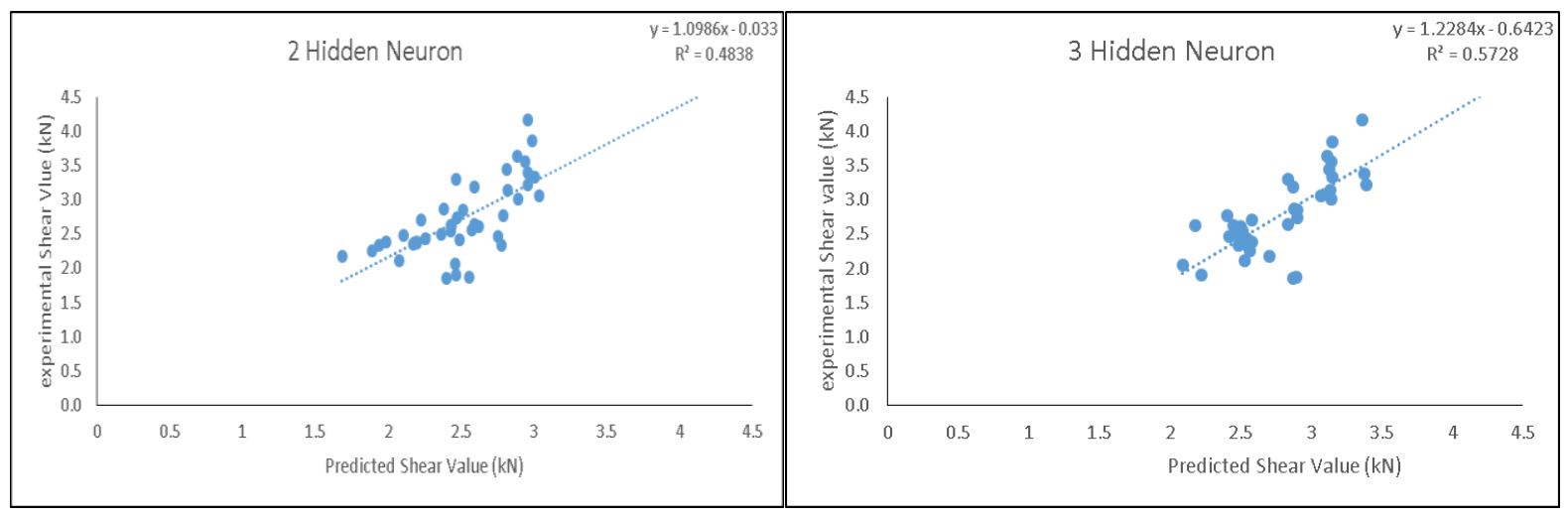



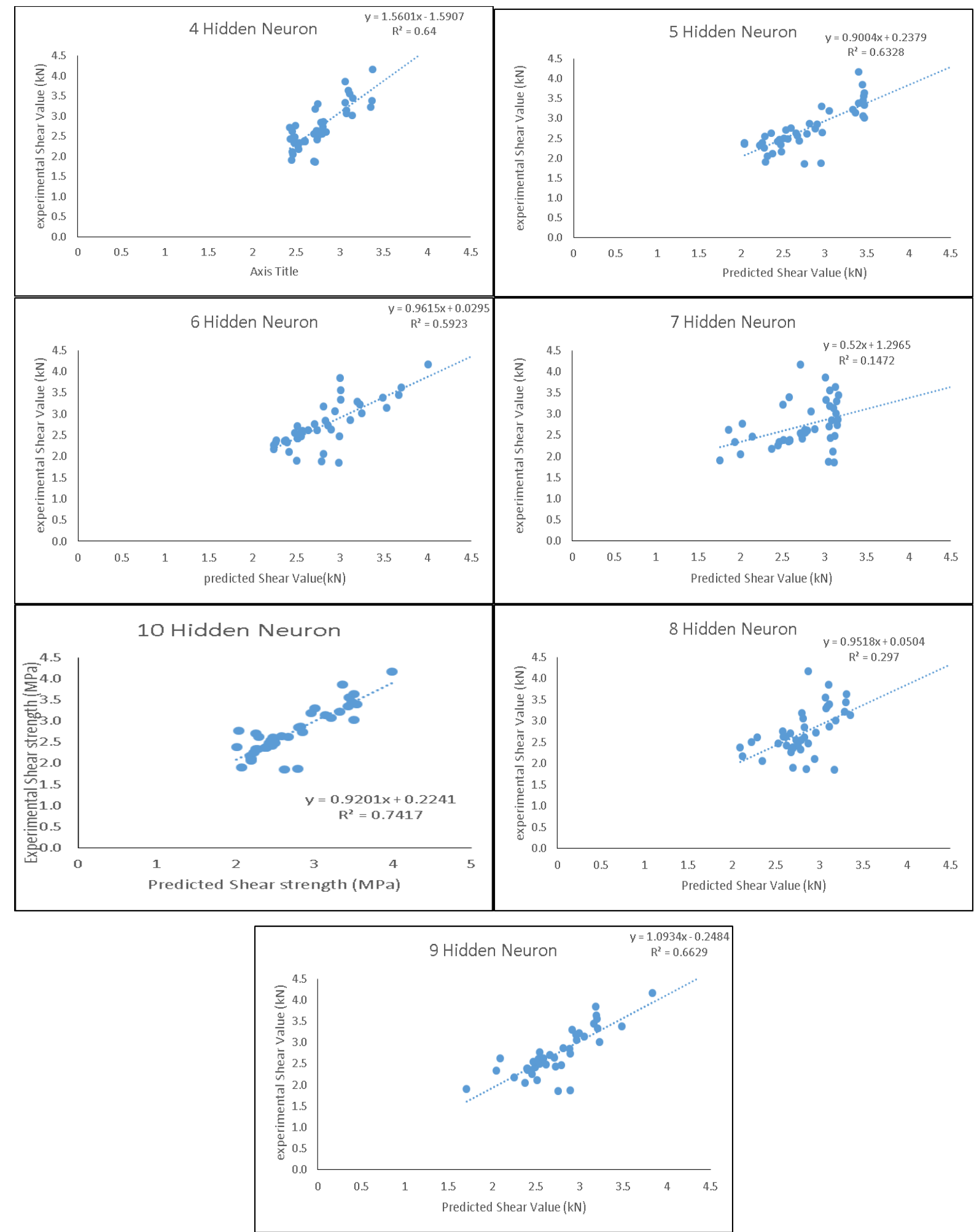

Figure 4.3 Predicted to experimental shear capacity from various numbers of hidden neurons for Model 2 
For Model 3 (beams without stirrups), the ANN model with 6 hidden neurons and network architecture of 9:6:1 is found to be in a good agreement. The agreement factor, $\varepsilon_{0}$ is 0.9901 which is closer to $1, \mathrm{MSE}$ is 0.0191 which shows that the selected ANN model is having less error, $V_{p} / V_{e}$ is the ratio of predicted shear strength to experimental shear strength of RAC beam and it is 1.0157 which is closer to 1 . The $V_{\text {avg }}$ of 0.0010 which shows the difference in average of ANN model output shear strength to input shear strength is in a minimum value to keep the developed ANN model in a good agreement. $V_{\sigma}$ of 0.0104 is the difference in the standard deviation of output shear strength to input shear strength, standard deviation shows the variation from average and the lower the standard deviation the closer data points to expected value. $V_{c v}$ of 0.0008 is the difference in the covariance of the output shear strength and indicates a lesser variant in the ANN output average to experimental average. $V_{\min }$ is $0.0009 V_{\max }$ is -0.0001 and $V_{\text {range }}$ is 0.0010 . Figure 4.4 shows that the equation $y=0.956 x+0.0463$ for 6 hidden neurons has the value of the coefficient of $\mathrm{x}$ as 0.9560 closer to 1 indicating the predicted shear strength is closer to experimental.
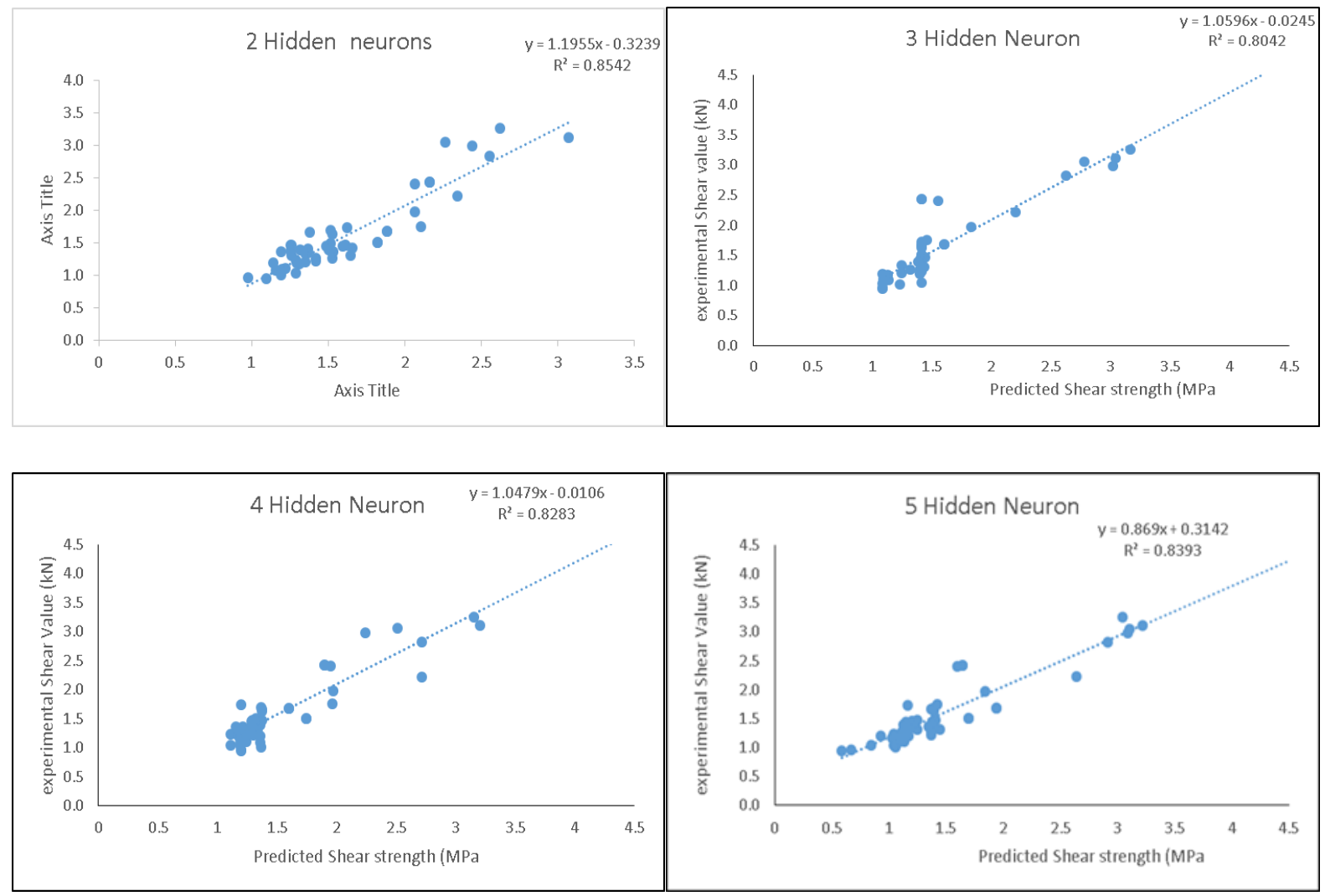

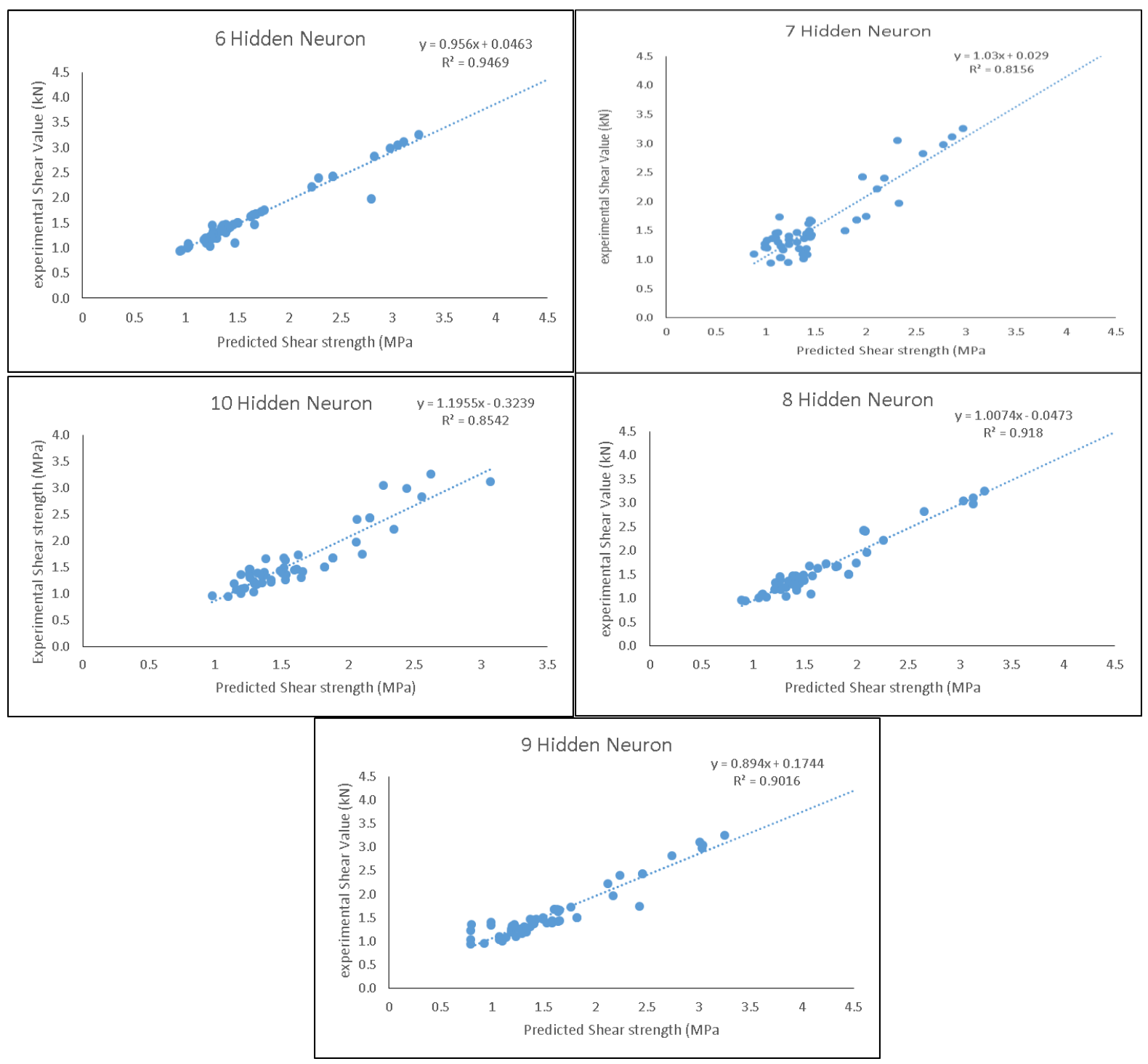

Figure 4.4 Predicted to experimental shear capacity from various numbers of hidden neurons for Model 3

Table 4.4 Evaluation of number of hidden neurons for Model 3, beams without stirrups

\begin{tabular}{|c|c|c|c|c|c|c|c|c|c|c|c|}
\hline $\begin{array}{l}\text { Hidden } \\
\text { Neurons }\end{array}$ & $\mathrm{i}: \mathrm{h:0} *$ & $\xi$ & $\mathrm{v}_{\mathrm{p}} / \mathrm{v}_{\mathbf{e}}$ & MSE & RMSE & $\mathrm{v}_{\text {avg }}$ & $\mathbf{v}_{\mathbf{\sigma}}$ & $\mathrm{v}_{\text {range }}$ & $\mathrm{v}_{\min }$ & $\mathrm{v}_{\max }$ & $\mathrm{v}_{\mathrm{cv}}$ \\
\hline $\mathrm{n}=2$ & $9: 2: 1$ & 0.9652 & 1.0060 & 0.0565 & 0.2377 & 0.2153 & 0.1325 & 0.2153 & 0.0327 & -0.1826 & -0.0846 \\
\hline $\mathrm{n}=3$ & $9: 3: 1$ & 0.9622 & 0.9582 & 0.0708 & 0.2661 & 0.2320 & 0.0897 & 0.2320 & 0.1452 & -0.0868 & -0.0427 \\
\hline $\mathrm{n}=4$ & $9: 4: 1$ & 0.9668 & 0.9606 & 0.0620 & 0.2489 & 0.2191 & 0.0768 & 0.2191 & 0.1677 & -0.0514 & -0.0350 \\
\hline $\mathrm{n}=5$ & $9: 5: 1$ & 0.9664 & 0.9245 & 0.0747 & 0.2733 & 0.3200 & 0.0317 & 0.3200 & -0.3549 & -0.0349 & 0.0513 \\
\hline $\mathrm{n}=6$ & $9: 6: 1$ & 0.9901 & 1.0157 & 0.0191 & 0.1380 & 0.0010 & 0.0104 & 0.0010 & 0.0009 & -0.0001 & 0.0008 \\
\hline $\mathrm{n}=7$ & $9: 7: 11$ & 0.9641 & 0.9533 & 0.0675 & 0.2598 & 0.2239 & 0.0719 & 0.2239 & -0.0597 & -0.2836 & -0.0293 \\
\hline $\mathrm{n}=8$ & $9: 8: 1$ & 0.9842 & 1.0220 & 0.0287 & 0.1693 & 0.0327 & 0.0286 & 0.0327 & -0.0524 & -0.0197 & -0.0253 \\
\hline $\mathrm{n}=9$ & $9: 9: 1$ & 0.9816 & 0.9965 & 0.0372 & 0.1928 & 0.1414 & 0.0362 & 0.1414 & -0.1489 & -0.0075 & 0.0241 \\
\hline $\mathrm{n}=10$ & $9: 10: 1$ & 0.9652 & 1.0060 & 0.0565 & 0.2377 & 0.2153 & 0.1325 & 0.2153 & 0.0327 & -0.1826 & -0.0846 \\
\hline
\end{tabular}

*Network Architecture 


\subsubsection{Effect of input parameters}

In Model 1, the network architecture of (9:8:1) is selected based on the optimum number of hidden neurons. Parametric studies are conducted excluding one or two input variables to verify the influence of input variables to the model. Table 4.5 shows the results of excluding input variables or their combinations with the constant hidden neurons of eight. The ANN model with all the nine input variables with an architecture network 9:8:1 is in a good agreement. The agreement factor, $\varepsilon_{\text {, }}$ is 0.9746 which is closer to 1 , MSE is 0.0424 which is less having less error, $V_{p} / V_{e}$ is $\mathrm{t}$ is 0.9763 which is closer to 1 . Figure 4.5 showing the predicted against experimental shear strength from various input combinations also confirmed that the ANN model with all the nine input variables with an architecture network 9:8:1 is good (showing value of slope of the trend line close to 1).

Table 4.5 Evaluation of input combinations with 8 hidden neurons for Model 1

\begin{tabular}{|c|c|c|c|c|c|c|c|c|c|c|c|}
\hline \begin{tabular}{|l|} 
Excluded \\
variables
\end{tabular} & i:h:o* & $\xi$ & $v_{p} / v_{e}$ & MSE & RMSE & $V_{\text {avg }}$ & $v_{\sigma}$ & $V_{\text {range }}$ & $\mathrm{V}_{\min }$ & $\mathrm{V}_{\max }$ & $\mathrm{V}_{\mathrm{cv}}$ \\
\hline None & 9:8:1 & 0.9746 & 0.9763 & 0.0424 & 0.2058 & 0.0498 & 0.0328 & 0.5776 & 0.0429 & -0.5347 & -0.0068 \\
\hline $\mathrm{a}$ & $8: 8: 1$ & 0.9756 & 0.992 & 0.0073 & 0.0854 & 0.0168 & 0.0324 & 0.2394 & -0.0965 & -0.3359 & -0.0125 \\
\hline $\mathrm{a} / \mathrm{d}$ & $8: 8: 1$ & 0.9662 & 0.9851 & 0.0072 & 0.0851 & 0.0314 & 0.0504 & 0.9056 & 0.0639 & -0.8418 & -0.0186 \\
\hline$a_{g}$ & $8: 8: 1$ & 0.9739 & 0.9987 & 0.0073 & 0.0857 & 0.0028 & 0.0044 & 0.2579 & 0.0068 & -0.2512 & -0.0016 \\
\hline$b_{w}$ & $8: 8: 1$ & 0.962 & 1.0011 & 0.0074 & 0.0858 & 0.0023 & 0.0837 & 0.5607 & 0.08 & -0.4807 & -0.0402 \\
\hline RCA & $8: 8: 1$ & 0.9721 & 0.9956 & 0.0073 & 0.0856 & 0.0093 & 0.0468 & 0.5602 & 0.01 & -0.5501 & -0.0207 \\
\hline $\mathrm{d}$ & $8: 8: 1$ & 0.908 & 1.0932 & 0.008 & 0.0897 & 0.1957 & 0.0231 & 0.2295 & 0.095 & -0.1346 & -0.0423 \\
\hline$f^{\prime}{ }_{\mathrm{c}}$ & $8: 8: 1$ & 0.9613 & 0.9802 & 0.0072 & 0.0849 & 0.0417 & 0.0841 & 0.7743 & -0.1196 & -0.8939 & -0.0332 \\
\hline$p_{\mathrm{s}}$ & $8: 8: 1$ & 0.9769 & 0.9839 & 0.0072 & 0.0851 & 0.0339 & 0.0392 & 0.2003 & 0.0416 & -0.1587 & -0.0128 \\
\hline$p_{\mathrm{v}}$ & $8: 8: 1$ & 0.8336 & 0.9864 & 0.0073 & 0.0852 & 0.0286 & 0.2392 & 1.372 & 0.1191 & -1.2529 & -0.1103 \\
\hline
\end{tabular}

*Network Architecture

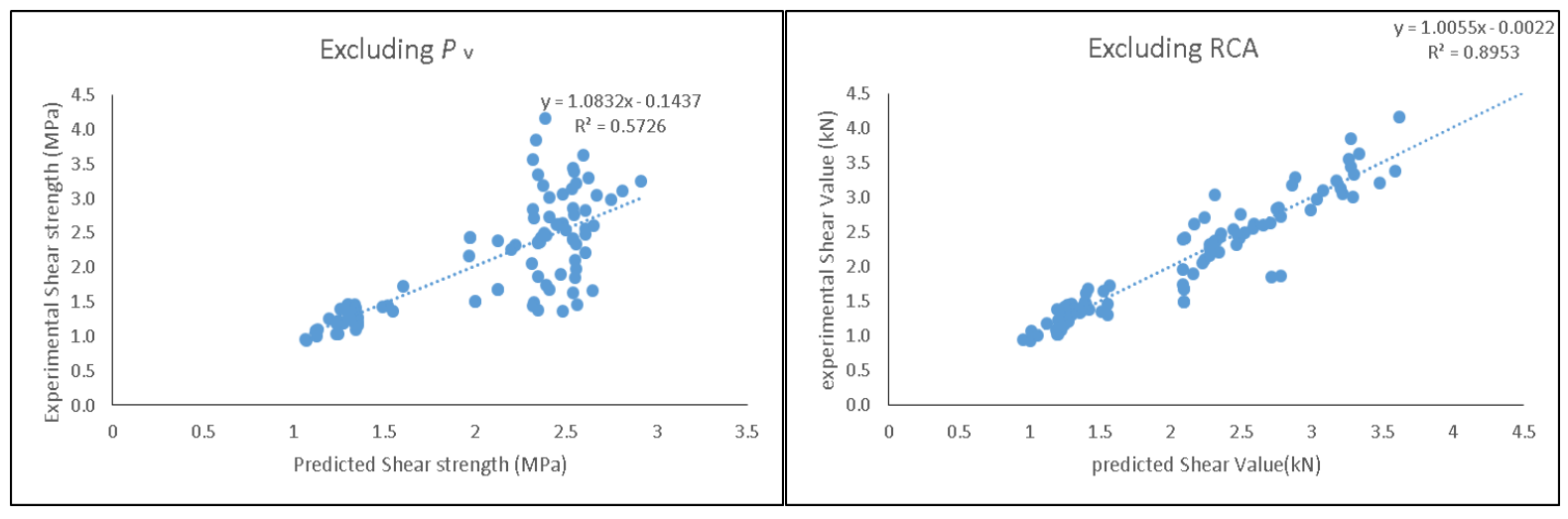



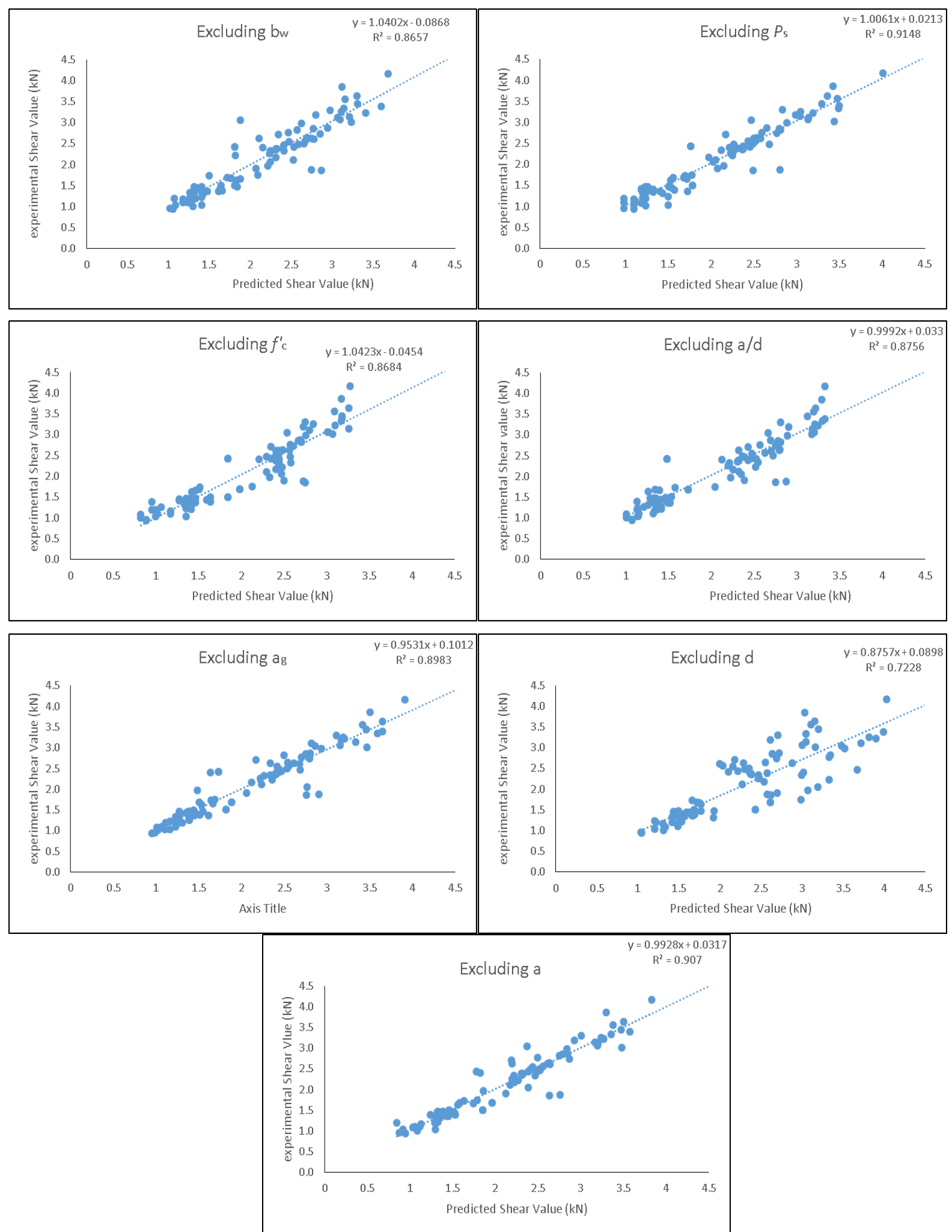

Figure 4.5 Predicted to experimental shear strength from various input combinations for Model 1 
For Model 2, the network architecture of 9:6:1 is selected based on the optimum number of hidden neurons. Table 4.6 shows the results of excluding input variables or their combinations with the constant hidden neurons of six. The ANN model with all the nine input variables with an architecture network 9:6:1 shows good agreement. The agreement factor, $\varepsilon_{\mathrm{c}}$ is 0.9605 which is closer to 1, MSE is 0.0239 which is less having less error, $V_{p} / V_{e}$ is $\mathrm{t}$ is 1.0288 which is closer to 1 . Figure 4.6 showing the predicted against experimental shear strength from various input combinations also confirmed that the ANN model with all the nine input variables with an architecture network 9:6:1 is good (showing value of slope of the trend line close to 1).
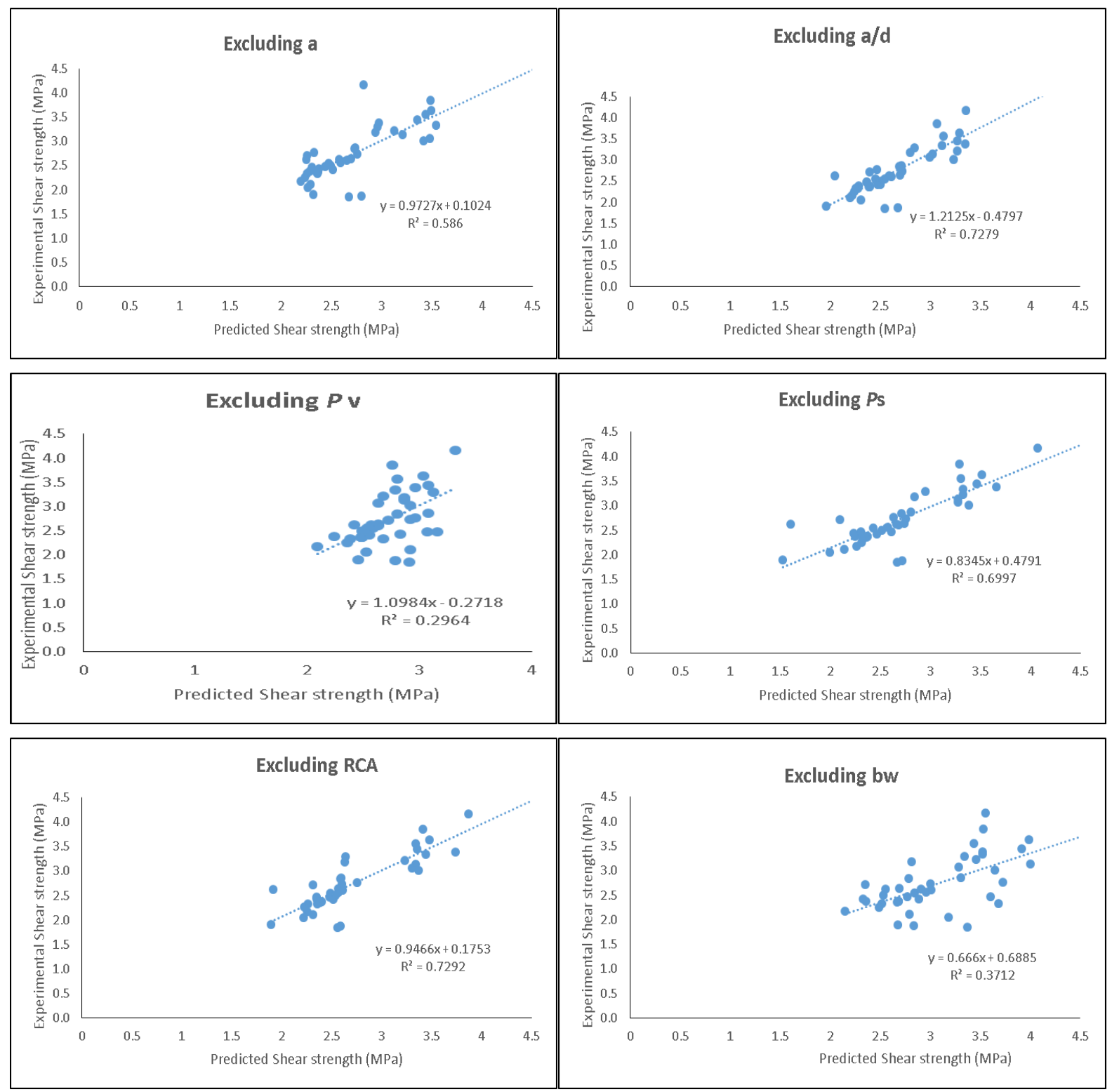

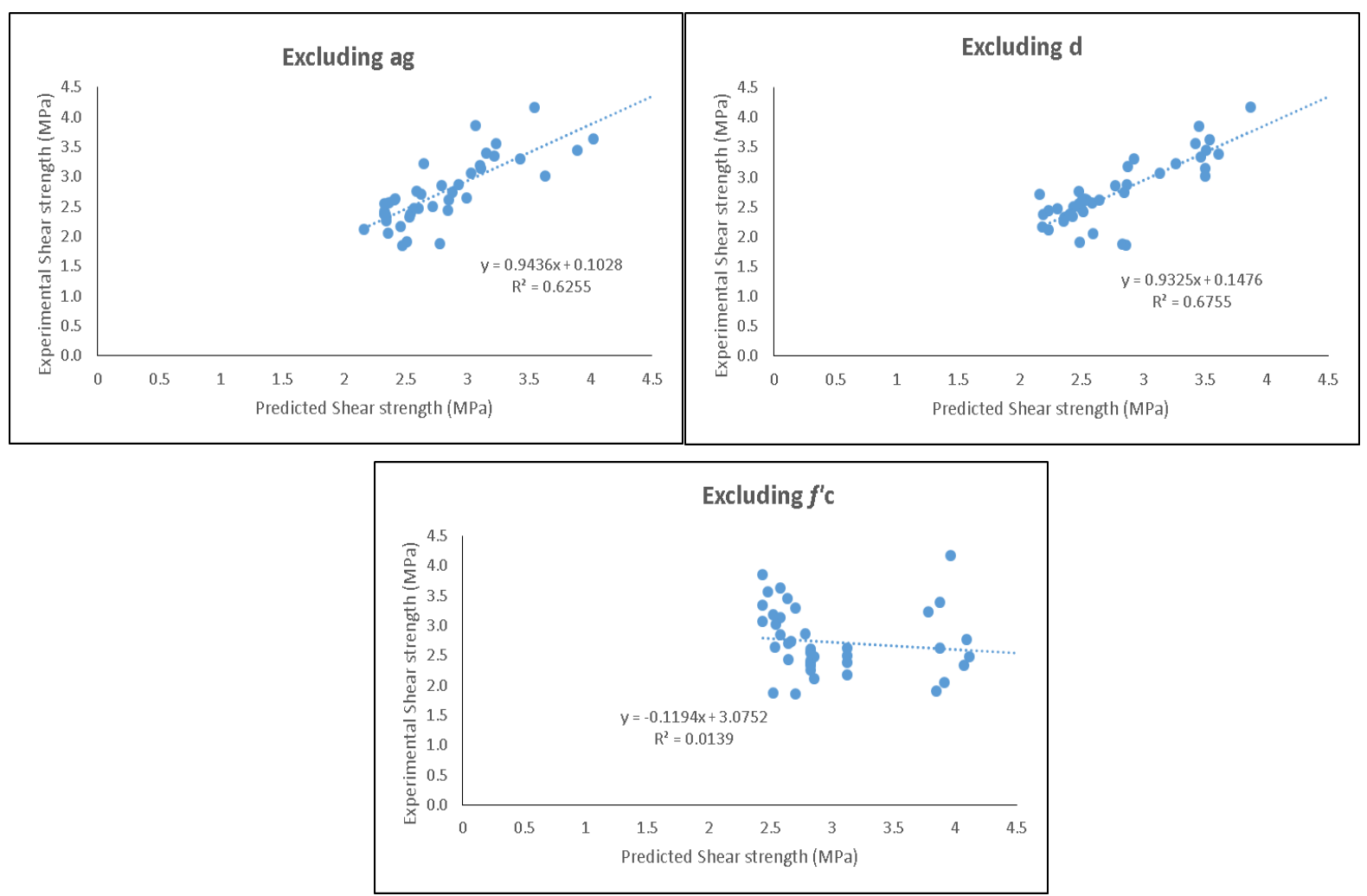

Figure 4.6 Predicted versus experimental shear strength from various input combinations for Model 2

Table 4.6 Evaluation of input combinations with 6 hidden neurons Model 2

\begin{tabular}{|c|c|c|c|c|c|c|c|c|c|c|c|}
\hline $\begin{array}{c}\text { Excluded } \\
\text { variables }\end{array}$ & i:h:o & $\boldsymbol{\xi}$ & $\mathbf{V}_{\mathrm{p}} / \mathbf{v}_{\mathbf{e}}$ & MSE & RMSE & $\mathbf{V}_{\text {avg }}$ & $\mathbf{V}_{\mathbf{\sigma}}$ & $\mathbf{V}_{\text {range }}$ & $\mathbf{V}_{\text {min }}$ & $\mathbf{V}_{\text {max }}$ & $\mathbf{V}_{\mathbf{c v}}$ \\
\hline None & $9: 6: 1$ & 0.9605 & 1.0288 & 0.0239 & 0.1547 & 0.0783 & 0.1080 & 0.5405 & 0.3837 & -0.1568 & 0.0089 \\
\hline $\mathrm{a}$ & $8: 6: 1$ & 0.9572 & 0.9893 & 0.1194 & 0.3455 & 0.0290 & 0.1153 & 0.9717 & 0.3456 & -0.6261 & -0.0407 \\
\hline $\mathrm{a} / \mathrm{d}$ & $8: 6: 1$ & 0.9653 & 0.9703 & 0.0908 & 0.3013 & 0.0808 & 0.1604 & 0.9135 & 0.1071 & -0.8064 & -0.0547 \\
\hline $\mathrm{a}_{\mathrm{g}}$ & $8: 6: 1$ & 0.9642 & 1.0197 & 0.1106 & 0.3326 & 0.0536 & 0.0876 & 0.4573 & 0.3125 & -0.1448 & -0.0354 \\
\hline $\mathrm{b}_{\mathrm{w}}$ & $8: 6: 1$ & 0.9200 & 1.1212 & 0.3152 & 0.5614 & 0.3296 & 0.0461 & 0.4583 & 0.2958 & -0.1626 & -0.0367 \\
\hline $\mathrm{RCA}$ & $8: 6: 1$ & 0.9730 & 0.9883 & 0.0791 & 0.2813 & 0.0318 & 0.0530 & 0.3330 & 0.0349 & -0.2982 & -0.0174 \\
\hline $\mathrm{d}$ & $8: 6: 1$ & 0.9691 & 1.0142 & 0.0953 & 0.3088 & 0.0386 & 0.0642 & 0.6055 & 0.3076 & -0.2979 & -0.0261 \\
\hline$f_{\mathrm{c}}$ & $8: 6: 1$ & 0.7895 & 1.0990 & 0.7031 & 0.8385 & 0.2690 & 0.0074 & 0.6335 & 0.5829 & -0.0507 & -0.0204 \\
\hline$p_{\mathrm{s}}$ & $8: 6: 1$ & 0.9684 & 0.9871 & 0.0950 & 0.3082 & 0.0350 & 0.0013 & 0.2309 & -0.3296 & -0.0987 & -0.0204 \\
\hline$p_{\mathrm{v}}$ & $8: 6: 1$ & 0.9200 & 1.0014 & 0.2019 & 0.4494 & 0.0038 & 0.2729 & 1.0796 & 0.2359 & -0.8436 & -0.1005 \\
\hline
\end{tabular}

*Network Architecture

For Model 3, the network architecture of 9:6:1 is selected based on the optimum number of hidden neurons. Table 4.7 shows the results of excluding input variables or their combinations with the constant hidden neurons of six. The ANN model with all the nine input variables with an architecture network 9:6:1 shows good agreement. The agreement factor, $\varepsilon_{0}$ is 0.9901 which is closer to $1, \mathrm{MSE}$ is 0.0191 which is less having less error, $V_{p} / V_{e}$ is t is 1.0157 which is closer to 1. 
Figure 4.7 (showing the predicted against experimental shear strength from various input combinations) also confirmed that the ANN model with all the nine input variables with a network architecture of 9:6:1 is good for prediction (showing value of slope of the trend line close to 1).
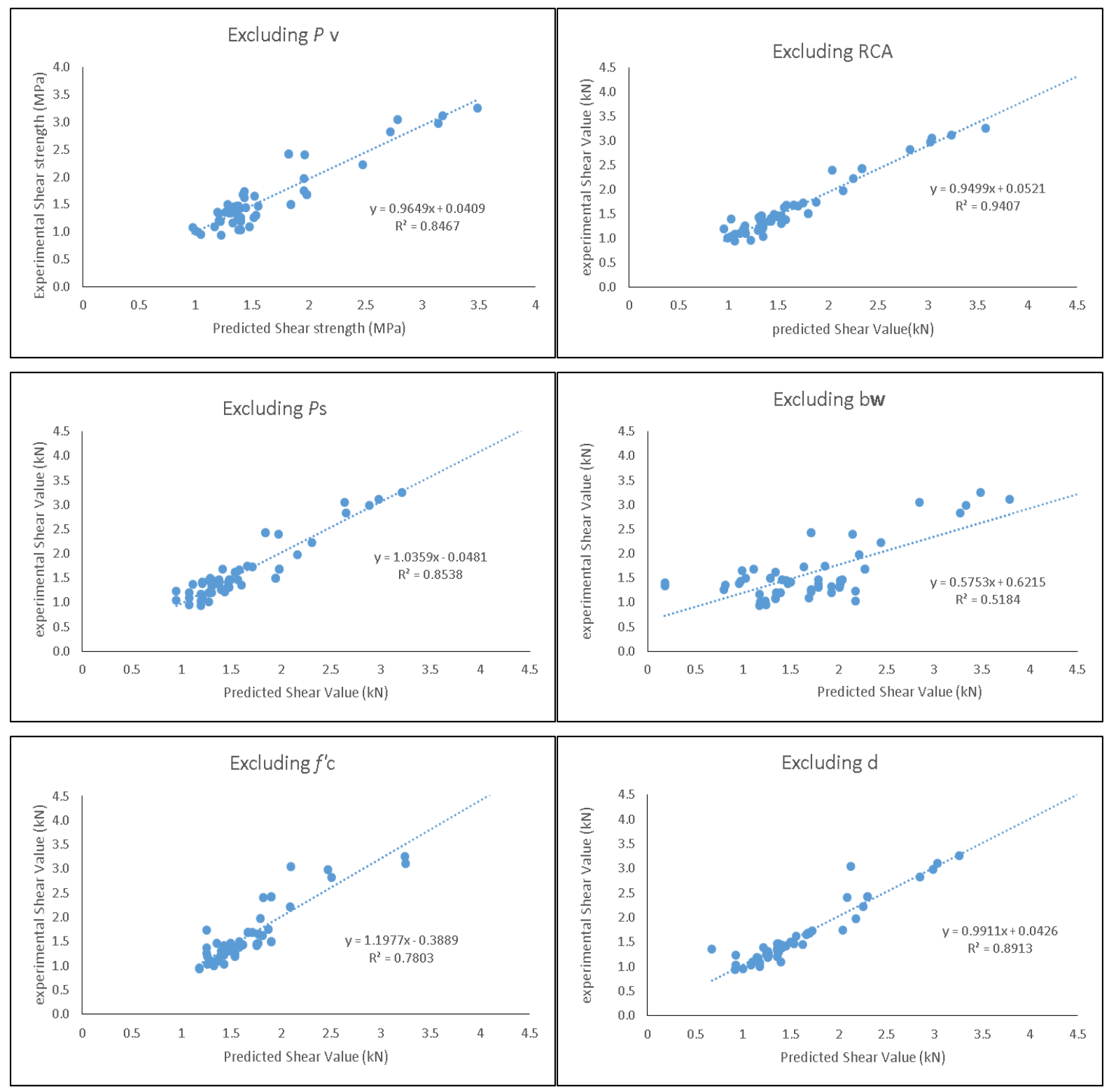

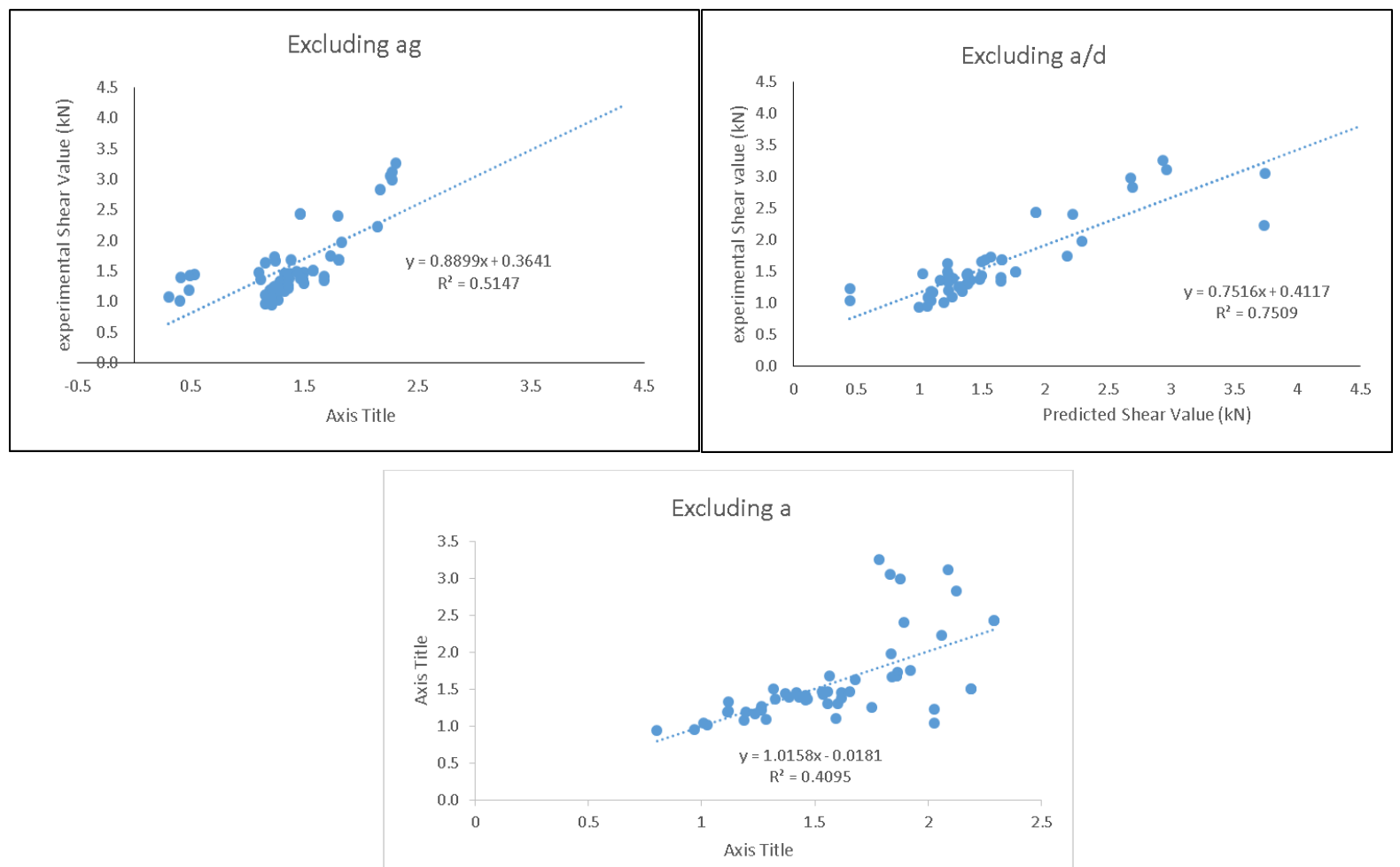

Figure 4.7 Predicted to experimental shear strength from various input combinations for Model 3

Table 4.7 Evaluation of input combinations with 6 hidden neurons for Model 3 (Beams without stirrups)

\begin{tabular}{|c|c|c|c|c|c|c|c|c|c|c|c|}
\hline $\begin{array}{l}\text { Excluded } \\
\text { variables }\end{array}$ & i:h:o * & $\xi$ & $v_{p} / V_{e}$ & MSE & RMSE & $\mathbf{V}_{\text {avg }}$ & $v_{\sigma}$ & $V_{\text {range }}$ & $\mathrm{V}_{\text {min }}$ & $\mathrm{V}_{\max }$ & $\mathrm{V}_{\mathrm{cv}}$ \\
\hline None & $9: 6: 1$ & 0.9901 & 1.0157 & 0.0191 & 0.1380 & 0.0010 & 0.0104 & 0.0010 & 0.0009 & -0.0001 & 0.0008 \\
\hline $\mathrm{a}$ & $8: 6: 1$ & 0.8623 & 0.9956 & 0.1976 & 0.4445 & 0.0071 & 0.2161 & 0.8244 & -0.1396 & -0.9641 & 0.2312 \\
\hline $\mathrm{a} / \mathrm{d}$ & $8: 6: 1$ & 0.9475 & 0.9877 & 0.1111 & 0.3333 & 0.0196 & 0.0893 & 0.9762 & -0.4910 & 0.4852 & 0.4264 \\
\hline$a_{g}$ & $8: 6: 1$ & 0.8938 & 0.8677 & 0.2096 & 0.4578 & 0.2114 & 0.1131 & 0.3122 & -0.6378 & -0.9501 & 0.3394 \\
\hline $\mathrm{b}_{\mathrm{w}}$ & $8: 6: 1$ & 0.8667 & 1.0623 & 0.2655 & 0.5153 & 0.0995 & 0.1469 & 1.2935 & -0.7601 & 0.5334 & 0.4304 \\
\hline RCA & $8: 6: 1$ & 0.9888 & 1.0185 & 0.0216 & 0.1469 & 0.0295 & 0.0123 & 0.3088 & 0.0143 & 0.3231 & 0.3663 \\
\hline $\mathrm{d}$ & $8: 6: 1$ & 0.9806 & 0.9821 & 0.0372 & 0.1929 & 0.0286 & 0.0277 & 0.2750 & -0.2672 & 0.0079 & 0.3543 \\
\hline$f^{\prime}{ }_{c}$ & $8: 6: 1$ & 0.9433 & 1.0381 & 0.0843 & 0.2904 & 0.0609 & 0.1533 & 0.2366 & 0.2366 & 0.0000 & 0.2596 \\
\hline$p_{\mathrm{s}}$ & 8:6:1 & 0.9725 & 0.9944 & 0.0493 & 0.2221 & 0.0090 & 0.0631 & 0.0440 & 0.0038 & -0.0402 & 0.3277 \\
\hline$p_{\mathrm{v}}$ & $8: 6: 1$ & 0.9715 & 1.0098 & 0.0519 & 0.2278 & 0.0157 & 0.0271 & 0.2003 & 0.0309 & 0.2313 & 0.3450 \\
\hline
\end{tabular}

\section{*Network Architecture}

In general, all nine input parameters are found influential in affecting the shear strength of RAC beams. The results also show that shear span to depth ratio $(a / d)$, concrete compression strength $\left(f^{\prime} c\right)$, the web reinforcement ratio and width of the beam are the most influential input parameters. 


\subsubsection{Validating the performance ANN models}

The performance of ANN models 1, 2 and 3 with a network architecture of 9:8:1, 9:6:1 and 9:6:1, respectively is validated by predicting shear strength of additional 12 beams without stirrups from the experimental studies conducted by Han et al. (2001) and Pellegrino and Faleschini (2013).

All three models are found to predict shear strength of RAC beams with good agreement based on $V_{p} / V_{e}$, degree of agreement ( $\xi$ ), MSE and RMSE values as presented in Tables 4.8, 4.9 and 4.10. $V_{p} / V_{e}$ values presented in Figures 4.8 to 4.10 also exhibits similar information. However, Model 2 shows slightly better agreement as it is particularly derived for RAC beams without stirrups with comparatively worse agreement is found for Model 3 which is applicable to only beams with shear reinforcement.

It is interesting to note that developed ANN models clearly simulating the effect of web/shear reinforcement in the prediction of shear strength of RAC beams. Model 1 is more robust than the other two as it is applicable to RAC beams with and without web reinforcement.

Table 4.8 Validation of Model 1 using data from Han et al. (2001) and (Pellegrino and Faleschini 2013)

\begin{tabular}{|c|l|c|l|l|}
\hline Trial\# & $\mathrm{V}_{\mathrm{p}} / \mathrm{V}_{\mathrm{e}}$ & $\xi$ & MSE & RMSE \\
\hline 1 & 1.05043 & 0.98583 & 0.08754 & 0.29586 \\
\hline 2 & 0.99047 & 0.98124 & 0.08254 & 0.2873 \\
\hline 3 & 1.07522 & 0.97736 & 0.0896 & 0.29934 \\
\hline 4 & 0.99423 & 0.96699 & 0.08285 & 0.28784 \\
\hline
\end{tabular}

Table 4.9 Validation of Model 2 using data from Han et al. (2001) and (Pellegrino and Faleschini 2013)

\begin{tabular}{|c|l|c|l|l|}
\hline Trial\# & $\mathrm{V}_{\mathrm{p}} / \mathrm{V}_{\mathrm{e}}$ & $\xi$ & MSE & RMSE \\
\hline 1 & 1.0024 & 0.9968 & 0.02439 & 0.1561 \\
\hline 2 & 1.1232 & 0.8385 & 1.22259 & 1.1057 \\
\hline 3 & 1.0376 & 0.9896 & 0.07719 & 0.2778 \\
\hline 4 & 1.0942 & 0.9737 & 0.26014 & 0.5100 \\
\hline
\end{tabular}


Table 4.10 Validation of Model 3 using data from Han et al. (2001) and (Pellegrino and Faleschini 2013)

\begin{tabular}{|c|l|c|l|l|}
\hline Trial\# & $\mathrm{V}_{\mathrm{p}} / \mathrm{V}_{\mathrm{e}}$ & $\xi$ & MSE & RMSE \\
\hline 1 & 0.97991 & 0.9635 & 0.16331 & 0.40412 \\
\hline 2 & 1.03377 & 0.99189 & 0.17229 & 0.41508 \\
\hline 3 & 1.00056 & 0.99965 & 0.16676 & 0.40836 \\
\hline 4 & 1.05890 & 0.93359 & 0.17648 & 0.42010 \\
\hline
\end{tabular}

\section{ANN Model}

Model 1

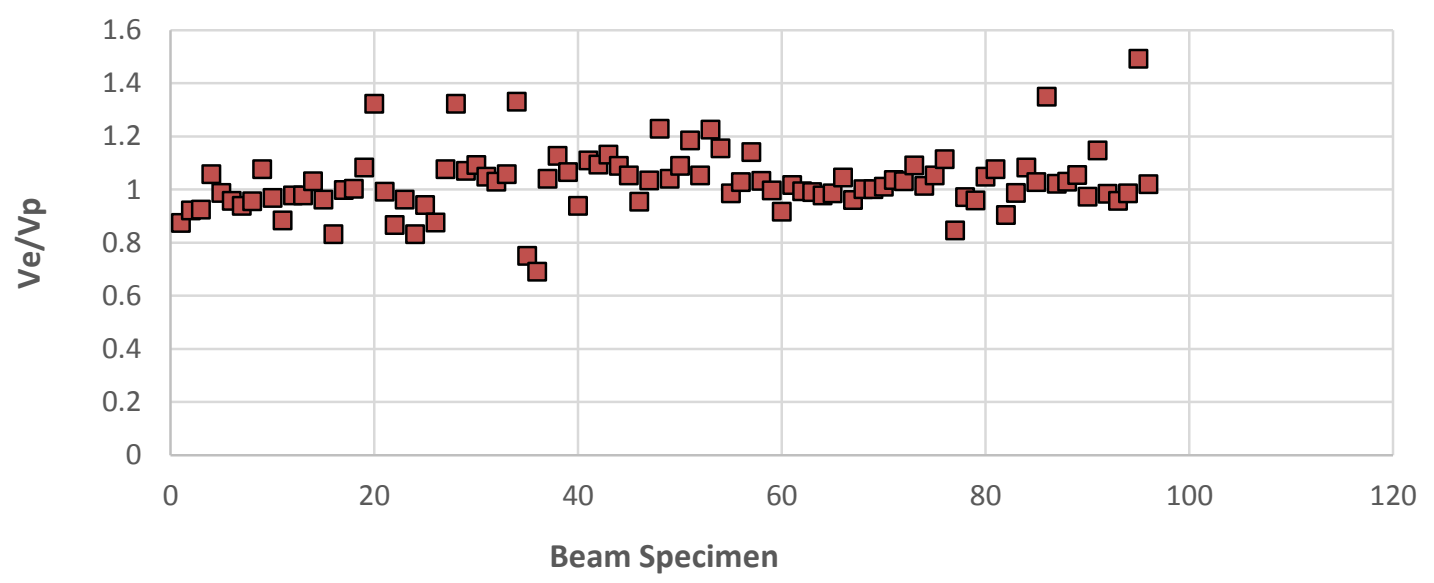

Figure 4.7 Experiment-to-predicted shear strength ratio for ANN Model 1: beams with and without stirrups 


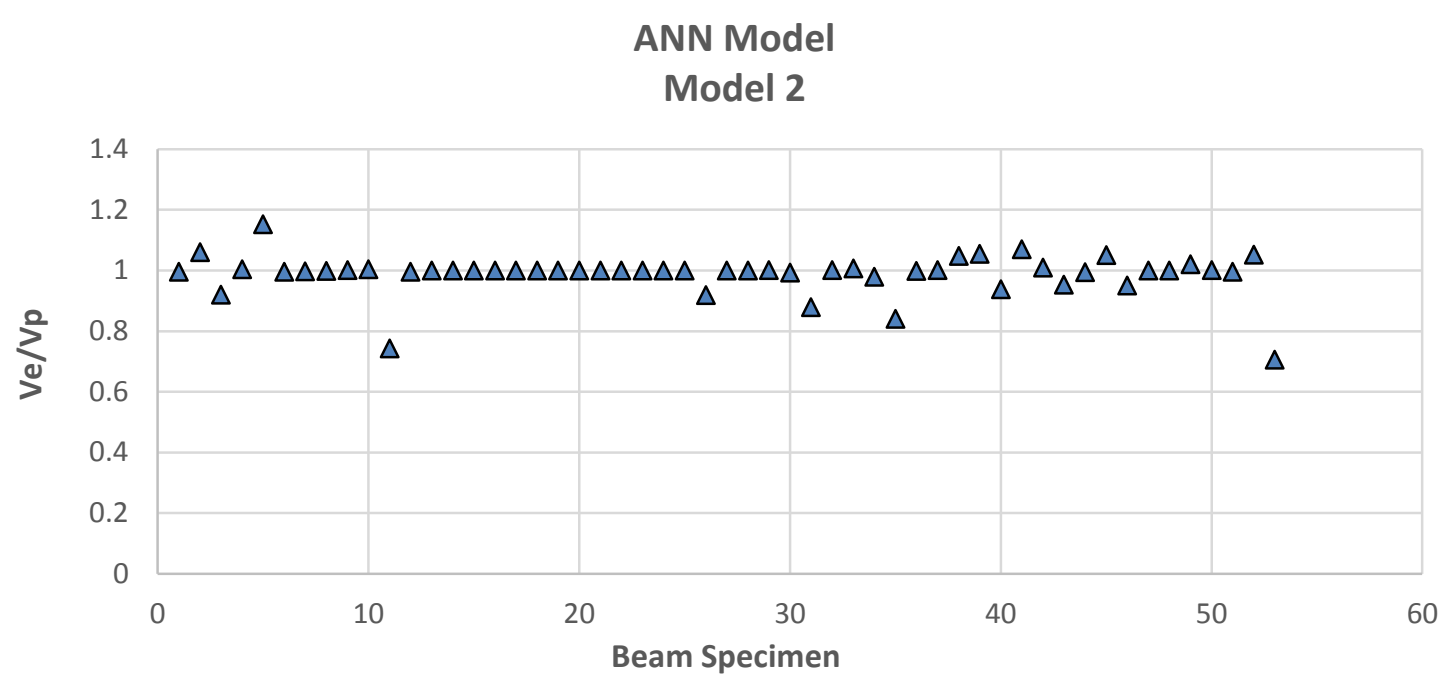

Figure 4.8 Experiment-to-predicted shear strength ratio for ANN Model 2: beams without stirrups

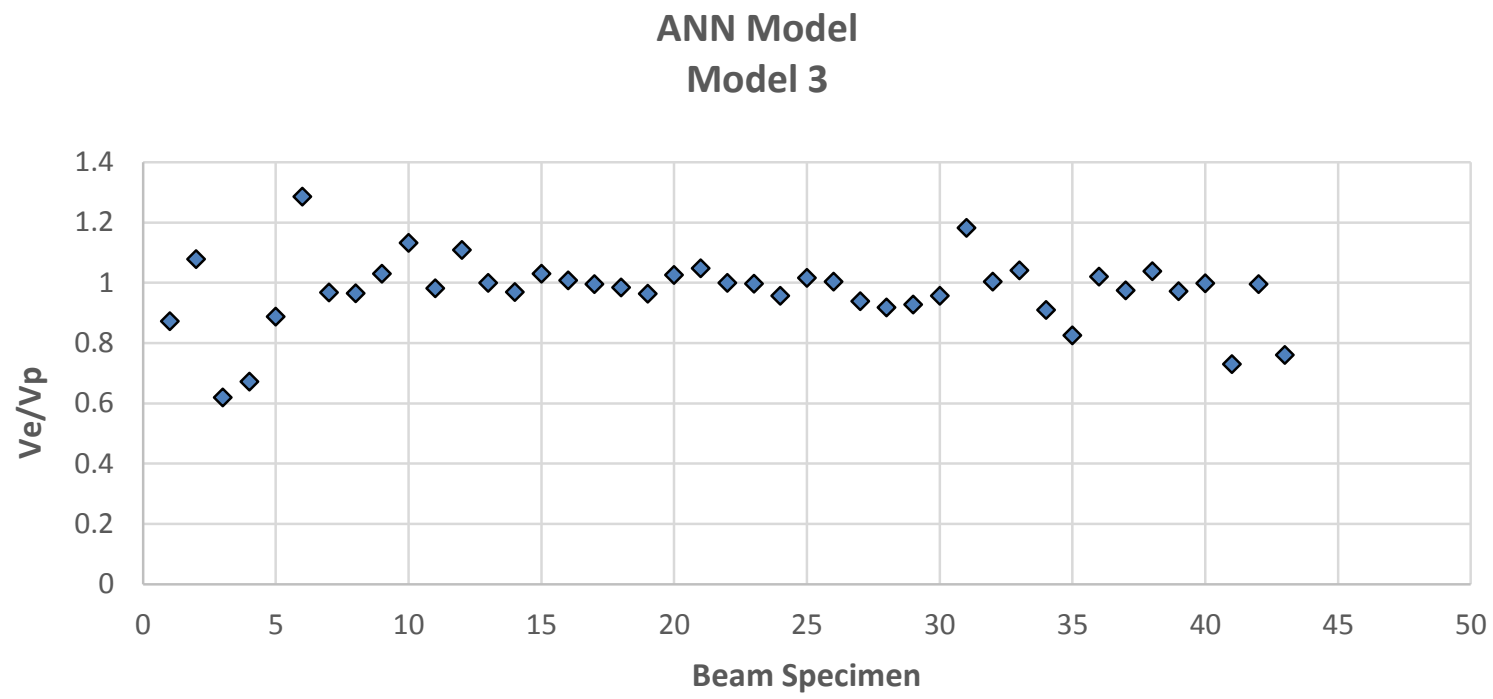

Figure 4.9 Experiment-to-predicted shear strength ratio for ANN Model 3: beams with stirrups 


\section{CHAPTER FIVE \\ CONCLUSIONS AND RECOMMANDATIONS}

\subsection{GENERAL}

This research was intended to conduct a literature review on the use of recycled concrete aggregate (RCA) in concrete, to study the shear behavior of recycled aggregate concrete (RAC) beams with and without shear reinforcements and evaluate the performance of various Code based/other existing equations in predicting shear strength of RAC beams. In addition, three artificial neural network (ANN) models for predicting the shear strength RAC beams with and without shear reinforcements are also developed and their performance validated by using 108 experimental beams from available research studies.

\subsection{Conclusions}

The following conclusions are drawn from the study:

- Literature review suggests great potential for RCA to be use in concrete for sustainable construction. There are lack of research studies on the long term durability and structural performance of RAC. Especially, this study reveals lack of available research data on the shear resistance of RAC beams with and without stirrups. The performance of Code based/other existing equations for the prediction of RAC beams is also not fully understood.

- Most of the Codes and existing methods (ACI Code: ACI318-11, Canadian: CSA A23.304, Australian: AS 3600, European: Eurocode-2/CEB-FIP, Spanish: EHE-08 and New Zealand: NZS 3110 as well as equations proposed by Cladera and Mari, Zsutty, Gastebled and May) underestimate the shear capacity of RAC beams (with and with without stirrups) with ACI 318 showing the highest underestimation. The method proposed by Zsutty with an average value of 1.08 for experimental to predicted shear strength $\left(V_{e} / V_{p}\right)$ is found to be more accurate than Codes/other existing methods for RAC beams without stirrup. For RAC beams with stirrups, Eurocode -2 and the method proposed by Cladera and Mari with an average value of $V_{e} / V_{p}$ of 1.07 are found to be more accurate. 
- However, over estimation by these Codes/existing methods for small percent of RAC beams needs to be carefully addressed when using such Codes or methods for shear strength prediction.

- All three ANN models are found to predict shear strength of RAC beams showing good agreement with experimental values. Developed ANN models are able to simulate the effect of web/shear reinforcement on the shear strength of RAC beams. Model 1 (developed for RAC beams with and without web reinforcement) is more robust than Model 2 and Model 3 developed for beams with and without web reinforcement, respectively. The developed ANN models can be used for the prediction of shear strength of RAC beams falling within the range of input parameters.

\subsection{Recommendations for future studies}

- More experimental investigations should be conducted on the long term durability and structural performance of RAC structural elements.

- The performance of Codes and other existing methods should be investigated with more experimental data having wide range of geometric and material parameters. New equations or modified Code based/existing equations should be derived based on wide range of experimental data.

- Developed ANN models should be updated with more experimental data. 


\section{REFERENCES}

AASHTO LRFD (2010). Bridge Design Specifications and Commentary (4th Ed.). American Association of State and Highway Transportation Officials. Washington, DC.

Ajdukiewicz A and Kliszczewicz A T. (2007). Comparative tests of beams and columns made of recycled aggregate concrete and natural aggregate concrete. Journal of Advanced Concrete Technology, Japan Concrete Institute, 5(2), 259-273.

Akbarnezhad A, Ong K G, Zhang M H, Tam C T and Foo T W J. (2011). Microwave assisted beneficiation of recycled concrete aggregate. Construction and Building Materials, 25, 3469-3479.

Akbarnezhad A, Ong K G and Zhang M H. (2013). Effects of the parent concrete properties and crushing procedure on the properties of coarse recycled concrete aggregates. Journal of Materials in Civil Engineering, 25(12), 1795-1802.

Al-Zahraa F, El-Mihilmy M and Bahaa T. (2011). Experimental investigation of shear strength of concrete beams with recycled concrete aggregates. Int. J. Materials and Structural Integrity, 5 (4), 291-309.

ACI Committee (2011). Building code requirements for structural concrete ACI 318-11 and commentary 318R-11. Farmington Hills, MI: American Concrete Institute.

Anderson K W, Uhlmeyer J S and Russell M A. (2009). Use of Recycled Concrete Aggregate in PCCP: Literature Search. Transportation Research Board.http://144.171.11.39/view.aspx?id=902140 accessed on May 7, 2012.

Arezoumandi M, Smith A, Volz J and Khayat K. (2014). An Experimental Study on Shear Strength of Reinforced Concrete Beams with 100\% Recycled Concrete Aggregate. Construction and Building Material 53, 612-620.

AS 3600 (2009). Concrete structures. Standards Australia, Sydney; 2009.

ASCE-ACI Committee 426. (1973). The shear strength of reinforced concrete members. Journal of Structural Engineering, ASCE, 99(6), 1091-1187.

ASCE-ACI Committee 445. (1998). Recent approaches to shear design of structural concrete. State-of-the- Art-Report by ASCE-ACI Committee 445 on shear and Torsion. ASCEJournal of Structural Engineering 124, No. 12, 1375-1417.

Bentz E, Vecchio F and Collins M. (2006). Simplified Modified Compression Field Theory for Calculating Shear Strength of Reinforced Concrete Elements. ACI Structural Journal, 103(4), 614-624. 
Buck A D. (1977). Recycled Concrete as a Source of Aggregate. ACI Journal, 74, 212-219.

CSA standard A23.3-04 (2004). Canadian Standard Association (CSA), Design of concrete structures. CSA standard A23.3-04. Rexdale, Ontario.

CIB-FIP model code (1990). Comitè Euro-International du Bèton (CEB)-Federation International de la Precontrainte (FIP). UK: Thomas Telford London; 1993. p. 437.

Cladera A and Mar1' A R. (2004). Shear design procedure for reinforced normal and high-strength concrete beams using artificial neural networks. Part II: beams with stirrups. Engineering Structures 26, 927- 936 .

Cladera A and Marı' AR. (2004). Shear design procedure for reinforced normal and high-strength concrete be A.ams using artificial neural networks. Part I: beams without stirrups. Engineering Structures 26, 917-926.

Construction Materials Recycling Association: CMRA (2010).Concrete Materials Website; http://www.ConcreteRecycling.org.

Corinaldesi V. (2011). Structural Concrete Prepared with Course Recycled Concrete Aggregate: From Investigation to Design. (P. Monteiro, Ed.) Advances in Civil Engineering, 2011(10.1155), p. 6 Pages.

Dhir R, Paine K and Dyer T. (2004). Recycling construction and demolition wastes in concrete. Concrete (London), 38, 25-28.

Dosho Y. (2007). Development of a Sustainable Concrete Waste Recycling System: Application of Recycled Aggregate Concrete Produced by Aggregate Replacing Method. Sustainable construction materials and technologies, 11-13 June 2007 Coventry, Special Papers Proceedings, 142-156.

EHE-08. (2011).Spanish Structural Concrete Code EHE-08. Catalogo general de publicatioes officiales: http://www.060.es.

Environmental Council of Concrete Organizations, ECCO. Recycling Concrete and Masonry. EV 22, Skokie, Illinois; http://www.ecco.org/pdfs/ev22.pdf.

Etxeberria M, Marı' A R and Va'zquez E. (2007). Recyceled Aggregate Concrete as Structural Material. Material and Structure, 40, 529-541.

Eurocode 2 (2004). Design of concrete structures - Part 1-1: General rules and rules for buildings, CEN, EN 1992-1-1, Brussels, Belgium, 225 p. 
European Committee for Standardization. (2012). EN 206 - Concrete - Specification, performance, production and conformity. European Committee for Standardization. . Brussels: European Committee for Standardization.

Fathifazl G, Razaqpur AG, Isgor B, Abbas A and Fournier B, Foo S. (2011). Shear Capacity Evaluation of Steel Reinforced Recycled Concrete (RRC) Beams. Engineering Structures, $33,1025-1033$.

Gastebled OJ, May. L. (2001). Mechanics model applied to shear failure of reinforced concrete beams without stirrups. ACI Structural Journal, 184-190.

González-Fonteboa B and Martínez-Abella F. (2007). Shear strength of recycled concrete beams.Construction and Building Materials, 21(4), 887-893.

González-Fonteboa B, Martínez-Abella F, Martínez-Lage I and Eiras-López J. (2009). Structural shear behaviour of recycled concrete with silica fume. Construction and Building Materials, 23(11), 3406-3410.

Han B C, Yun H D and Chang SY. (2001). Shear Capacity of reinforced Concrete Beams Made with Recycled -Aggregate. Recent Advanced in Concrete Technology.200, 504-515.

Hansen T C and Narud H. (2003). Strength of Recycled Concrete made from Crushed Concrete Coarse Aggregate. Conc. Inter-Design and Const., 5(1), 79-83.

Hong S G and Ha T. (2001). Shear-friction truss model for reinforced concrete beams. 26TH Conference on Our World in Concrete \& Structures. Singapore: http://cipremier.com/100026034, 309-316.

Kasai Y. (1974). Durability of Concrete Using Recycled Course Aggregate, RILEM; Reuse of Demolition Waste. Chapman and Hall, 2,623-632.

Knaack AM and Kurama YC. (2014). Behavior of reinforced concrete beams with recycled concrete coarse aggregates. Journal of Structural Engineering. http://dx.doi.org/10.1061/ (ASCE) ST.1943-541X.0001118.

Kou S C, Mahgoub H S and Nazef A. (2002). Investigation of Recycled Concrete Made with Limestone Aggregate for a Base Course in Flexible Pavement. Transportation Research Record, 1787, 99-108.

Kou S C, Poo C S and Dixon. (2007). Influence of Fly Ash as Cement Replacement on the Properties of Recycled Aggregate Concrete. Journal of Material in Civil Engineering, ASCE, 19(9), 709-717. 
Kou S C, Poo C S (2015). Effect of the quality of parent concrete on the properties of high performance recycled aggregate concrete. Construction and Building Materials, 77, 501508.

Li X. (2008). Recycling and reuse of waste concrete in China. Part I. Material behavior of recycled aggregate concrete. Resources, Conservation and Recycling, 53, 36-44.

Malhotra V M. (1976). Use of Recycled Concrete as a New Aggregate. A Report 76-18, Canadian Centre for Mineral and Energy Technology, Ottawa, Canada.

Manzi S, Mazzotti C and Bignozzi M C. (2013). Short and Long-term Behavior of Structural Concrete with Recycled Concrete Aggregate. Cement \& Concrete Composites, 37, 312318.

Mukai T and Kikuchi M. (1988). Properties of reinforced concrete beams containing recycled aggregate. 2th Int. Symposium RILEM "Demolition and Reuse of Concrete and Masonry. Tokyo, 1988, Chapman \& Hall, London-New York, 2, 670-679.

Nilson A H, Darwin D and Dolan C W. (2004). Design of Concrete Structures (13 ${ }^{\text {th }}$ ed.). New York: McGraw Hill.

NZS 3101 (2006), New Zealand Standard, Concrete Structures Standard.Part1- The Design of Concrete Structures. Standards New Zealand, Private Bag 2439, Wellington 6140.

Oikonomou N D. (2005). Recycled concrete aggregates. Cement \& Concrete Composites, 27(2), 315-318.

Parekh D N and Modhera C D. (2011). Characterization of Recycled Aggregate Concrete. International Journal of Advanced Engineering Technology, II (IV), 321-330.

Pellegrino C and Faleschini F. (2013). Experimental Behavior of Reinforced Concrete Beams with Electric Furnace Slag as Recycled Aggregate. ACI Material Journal, 110(2), 197-205.

Ravindrarajah R and Tam C T. (2012). Properties of Concrete made with Crushed Recycled Materials Resource Center, RMRC. College of Engineering, University of Wisconsin, Madison; USA.

Rumelhart DE, Hinton GE and William RJ. (1986). Learning Internal Representations by Error Propagation. Parallel Distributed Processing, Foundations, D.E. Rumelhart and J.L. McClelland, eds., MIT Press (1): 318-62.

Ryu, J S. (2002). Improvement on strength and impermeability of recycled concrete made from crushed concrete coarse aggregate. . Journal of Material Science, 21(20), 1565-1567. 
Sanad A and Saka MP. (2001). Prediction of ultimate shear strength of reinforced-concrete deep beams using neural networks. . Journal of Structural Engineering, 127(7):818-28.

Sharma J and Singla S. (2014). Study of Recycled Concrete Aggregates. International Journal of Engineering Trends and Technology (IJETT), 13(3), 123-125.

Silva R V, Brito J. de and Dhir R.K. (2015). Prediction of the shrinkage behavior of recycled aggregate concrete: A review. Construction and Building Materials 77, 327-339.

Sonigo P, Hestin M and Mimid S. (2010). Management of Construction and Demolition Waste in Europe. Brussels, Stakeholders Workshop.

Thomas HK, Woosuk K, Yoon-Keun K and Sung-Gul H. (2014). Flexural Testing of Reinforced Concrete Beams with Recycled Concrete Aggregates. ACI Structural Journal, 111(3), 607616.

Topçu İ B and Mustafa S. (1997). Prediction of Properties of Waste AAC Aggregate Concrete using Artificial Neural Network. Computational Materials Science, 41(1), 117-125.

Warner R F, Rangan B V, Hall A S and Faulkes K A. (1998).Concrete Structures, Longman, Melbourne, Australia, 1998.

Wight J K and MacGregor J G. (2009). Reinforced Concrete Mechanics and Design (5th Ed.). Pearson-Prentice Hall. Pearson-Prentice Hall.

World Business Council for Sustainable Development (WBCSD) Report (2012). Recycling concrete. http://www.wbcsdcement.org/pdf/CSI-RecyclingConcrete-FullReport.pdf

Zsutty TC (1971). Shear strength prediction for separate categories of simple beam tests. ACI Structural Journal 1971; 68:138-143. 


\section{APPENDIX A}

\section{Spreadsheets of evaluation of shear capacity based on code provisions and compare them by experimental shear values for tested beams without stirrups}

Table A.1 Shear strength comparison results for beams without stirrups based on CSA A23.3-04

\section{Part I}

\begin{tabular}{|c|c|c|c|c|c|c|}
\hline \multicolumn{2}{|c|}{ Beam } & \multicolumn{2}{|c|}{ Vc-CSA A23.3-04 } & \multirow[b]{2}{*}{ Ve $(\mathbf{K N})$} & \multicolumn{2}{|c|}{ CSA A23.3-04 } \\
\hline Paper & ID & simplified & General & & $\begin{array}{l}\text { simplified- } \\
\text { Ve/Vp }\end{array}$ & General-Ve/Vp \\
\hline \multirow{12}{*}{$\begin{array}{l}\text { Arezoum } \\
\text { andi et } \\
\text { al.,(2014) }\end{array}$} & CC-NS-4-1 & 111.5493641 & 48.24624583 & 121.2 & 1.086514486 & 0.96172747 \\
\hline & CC-NS-4-2 & 106.8133992 & 48.45158763 & 129.9 & 1.216139557 & 1.027688131 \\
\hline & CC-NS-6-1 & 111.5493641 & 57.0038152 & 143.2 & 1.283736587 & 1.067982545 \\
\hline & CC-NS-6-2 & 106.8133992 & 62.28956993 & 167 & 1.563474257 & 1.189756206 \\
\hline & CC-NS-8-1 & 111.5493641 & 69.06537666 & 173.5 & 1.555365208 & 1.176067874 \\
\hline & CC-NS-8-1 & 106.8133992 & 63.70693739 & 170.8 & 1.599050318 & 1.197880795 \\
\hline & RAC-NS-4-1 & 100.0399142 & 38.8116504 & 114.8 & 1.147541968 & 0.995601428 \\
\hline & RAC-NS-4-2 & 106.6571249 & 42.05556863 & 113 & 1.059469773 & 0.949659366 \\
\hline & RAC-NS-6-1 & 100.0399142 & 48.41313883 & 143.2 & 1.431428657 & 1.14009339 \\
\hline & RAC-NS-6-2 & 106.6571249 & 46.18669086 & 124.1 & 1.163541583 & 1.021921774 \\
\hline & RAC-NS-8-1 & 100.0399142 & 44.423788 & 131.4 & 1.313475737 & 1.106234722 \\
\hline & RAC-NS-8-2 & 106.6571249 & 52.21589627 & 140.3 & 1.31543017 & 1.094889141 \\
\hline \multirow{12}{*}{$\begin{array}{l}\text { Knaack et } \\
\text { al.,(2014) }\end{array}$} & so-1a & 30.04819527 & 27.4405345 & 31.1 & 1.035003923 & 1.143381421 \\
\hline & so-1b & 30.04819527 & 27.4405345 & 36.9 & 1.228027163 & 1.143381421 \\
\hline & SO-2a & 37.32446449 & 34.08535009 & 40.4 & 1.08239999 & 1.00388974 \\
\hline & so-2b & 37.32446449 & 34.08535009 & 42.3 & 1.13330494 & 1.00388974 \\
\hline & S50-1a & 34.74984226 & 31.73416029 & 44 & 1.266192798 & 1.047877377 \\
\hline & S50-1b & 34.74984226 & 31.73416029 & 39.1 & 1.125184964 & 1.047877377 \\
\hline & S50-2a & 33.36741935 & 30.47170765 & 43.7 & 1.309660767 & 1.073713949 \\
\hline & $S 50-2 b$ & 33.36741935 & 30.47170765 & 41.2 & 1.234737382 & 1.073713949 \\
\hline & S100-1a & 33.86177841 & 30.92316495 & 36.4 & 1.074958307 & 1.064281 \\
\hline & S100-1b & 33.86177841 & 30.92316495 & 38 & 1.122209222 & 1.064281 \\
\hline & S100-2a & 31.44442814 & 28.71559864 & 39.9 & 1.268905251 & 1.112643273 \\
\hline & $S 100-2 b$ & 31.44442814 & 28.71559864 & 36.1 & 1.148057132 & 1.112643273 \\
\hline
\end{tabular}


Part II

\begin{tabular}{|c|c|c|c|c|c|c|}
\hline \multicolumn{2}{|c|}{ Beam } & \multicolumn{2}{|c|}{ Vc-CSA A23.3-04 } & \multirow[b]{2}{*}{ Ve $(\mathbf{K N})$} & \multicolumn{2}{|c|}{ CSA A23.3-04 } \\
\hline Paper & ID & simplified & General & & $\begin{array}{l}\text { simplified- } \\
\text { Ve/Vp }\end{array}$ & $\begin{array}{c}\text { General- } \\
\text { Ve/Vp }\end{array}$ \\
\hline \multirow{18}{*}{$\begin{array}{l}\text {.Fathifazl } \\
\text { et } \\
\text { al.(2011) }\end{array}$} & EM-1.5 & 63.07605747 & 61.99553718 & 186.7 & 2.959918668 & 3.011507094 \\
\hline & EM-2 & 62.92424965 & 61.8463299 & 169.5 & 2.693715077 & 2.74066384 \\
\hline & EM-2.7 & 64.55660025 & 63.8554033 & 103.9 & 1.609440392 & 1.627113676 \\
\hline & CL-2.7 & 61.65948255 & 60.98975334 & 92.8 & 1.505040201 & 1.521567065 \\
\hline & EM-4 & 63.90090457 & 63.02879613 & 83.2 & 1.302015997 & 1.320031559 \\
\hline & EV-1.5 & 68.52651108 & 67.35262215 & 195.3 & 2.849991878 & 2.89966439 \\
\hline & EV-2 & 68.52651108 & 67.35262215 & 179 & 2.612127733 & 2.65765451 \\
\hline & CG-2.7 & 58.44820461 & 57.81335546 & 150 & 2.56637481 & 2.594556203 \\
\hline & EV-4 & 69.42263389 & 68.47516585 & 105.6 & 1.521117741 & 1.542164939 \\
\hline & EM-L & 45.44958701 & 41.53700991 & 89.3 & 1.964814333 & 2.149889946 \\
\hline & EM-M & 64.55660025 & 63.8554033 & 103.9 & 1.609440392 & 1.627113676 \\
\hline & CL-M & 61.65948255 & 60.98975334 & 92.8 & 1.505040201 & 1.521567065 \\
\hline & EM-H & 75.75796641 & 78.73433222 & 99.5 & 1.313393227 & 1.263743493 \\
\hline & EM-VH & 88.9824005 & 98.36625233 & 104.6 & 1.175513353 & 1.063372829 \\
\hline & EV-L & 49.37692292 & 45.12625684 & 122.6 & 2.482941276 & 2.716821837 \\
\hline & CG-M & 58.44820461 & 57.81335546 & 150 & 2.56637481 & 2.594556203 \\
\hline & EV-H & 75.75796641 & 78.73433222 & 111.7 & 1.474432397 & 1.418694956 \\
\hline & EV-VH & 96.67144235 & 106.8661605 & 119.6 & 1.237180258 & 1.119156892 \\
\hline
\end{tabular}


Table A.2 Shear strength comparison results for beams without stirrups based on ACI 318-11

\begin{tabular}{|c|c|c|c|c|c|c|}
\hline \multicolumn{2}{|c|}{ Beam } & \multicolumn{2}{|c|}{ Vc-ACI 318-11 } & \multirow[b]{2}{*}{ Ve $(\mathbf{K N})$} & \multicolumn{2}{|c|}{ ACI318-11 } \\
\hline Paper & ID & $\begin{array}{c}\text { Equation } \\
(11-3)\end{array}$ & $\begin{array}{c}\text { Equation } \\
(11-5)\end{array}$ & & $\begin{array}{l}\mathrm{Ve} / \mathrm{Vp} \\
(11-3)\end{array}$ & $\begin{array}{l}\text { Ve/Vp } \\
(11-5)\end{array}$ \\
\hline \multirow{12}{*}{$\begin{array}{l}\text { Arezoum } \\
\text { andi et } \\
\text { al.,(2014) }\end{array}$} & CC-NS-4-1 & 122.14745 & 113.4064 & 121.2 & 0.9922434 & 1.0687229 \\
\hline & CC-NS-4-2 & 116.96153 & 108.9613 & 129.9 & 1.1106216 & 1.1921662 \\
\hline & CC-NS-6-1 & 122.14745 & 118.6178 & 143.2 & 1.1723536 & 1.2072385 \\
\hline & CC-NS-6-2 & 116.96153 & 114.1727 & 167 & 1.4278199 & 1.4626959 \\
\hline & CC-NS-8-1 & 122.14745 & 123.2807 & 173.5 & 1.4204144 & 1.4073577 \\
\hline & CC-NS-8-1 & 116.96153 & 118.8356 & 170.8 & 1.4603092 & 1.4372798 \\
\hline & RAC-NS-4-1 & 109.54451 & 102.6039 & 114.8 & 1.0479758 & 1.1188662 \\
\hline & RAC-NS-4-2 & 116.79041 & 108.8146 & 113 & 0.9675452 & 1.0384632 \\
\hline & RAC-NS-6-1 & 109.54451 & 107.8153 & 143.2 & 1.3072312 & 1.3281974 \\
\hline & RAC-NS-6-2 & 116.79041 & 114.0261 & 124.1 & 1.0625872 & 1.0883476 \\
\hline & RAC-NS-8-1 & 109.54451 & 112.4782 & 131.4 & 1.1995124 & 1.1682269 \\
\hline & RAC-NS-8-2 & 116.79041 & 118.6889 & 140.3 & 1.2012973 & 1.1820817 \\
\hline \multirow{12}{*}{$\begin{array}{l}\text {. Knaack et } \\
\text { al.,(2014) }\end{array}$} & So-1a & 64.498062 & 62.141196 & 31.1 & 2.8946606 & 3.0044481 \\
\hline & so-1b & 64.342832 & 62.865284 & 36.9 & 2.6343261 & 2.6962417 \\
\hline & SO-2a & 66.433004 & 63.569116 & 40.4 & 1.5639817 & 1.6344415 \\
\hline & so-2b & 63.451678 & 61.013695 & 42.3 & 1.4625303 & 1.52097 \\
\hline & S50-1a & 65.57303 & 62.751146 & 44 & 1.2688143 & 1.3258722 \\
\hline & $550-1 b$ & 70.071392 & 66.918336 & 39.1 & 2.7871574 & 2.9184826 \\
\hline & S50-2a & 70.071392 & 67.775479 & 43.7 & 2.5545375 & 2.6410732 \\
\hline & $550-2 b$ & 60.147061 & 58.181166 & 41.2 & 2.4938874 & 2.5781539 \\
\hline & S100-1a & 71.239249 & 67.607906 & 36.4 & 1.4823289 & 1.5619475 \\
\hline & $\mathrm{S} 100-1 \mathrm{~b}$ & 43.213702 & 42.138436 & 38 & 2.0664742 & 2.1192054 \\
\hline & S100-2a & 66.433004 & 63.569116 & 39.9 & 1.5639817 & 1.6344415 \\
\hline & $\mathrm{s} 100-2 \mathrm{~b}$ & 63.451678 & 61.013695 & 36.1 & 1.4625303 & 1.52097 \\
\hline \multirow{18}{*}{$\begin{array}{l}\text {.Fathifazl } \\
\text { et } \\
\text { al.(2011) }\end{array}$} & EM-1.5 & 81.912539 & 78.967168 & 186.7 & 1.2147102 & 1.2600173 \\
\hline & EM-2 & 102.33693 & 97.760441 & 169.5 & 1.022114 & 1.0699624 \\
\hline & EM-2.7 & 46.947833 & 45.33912 & 103.9 & 2.6114091 & 2.7040666 \\
\hline & CL-2.7 & 60.147061 & 58.181166 & 92.8 & 2.4938874 & 2.5781539 \\
\hline & EM-4 & 81.912539 & 78.967168 & 83.2 & 1.3636496 & 1.4145119 \\
\hline & EV-1.5 & 111.17994 & 105.34017 & 195.3 & 1.0757336 & 1.1353693 \\
\hline & EV-2 & 28.548205 & 26.272019 & 179 & 1.0893855 & 1.1837689 \\
\hline & CG-2.7 & 28.548205 & 26.272019 & 150 & 1.2925506 & 1.4045361 \\
\hline & EV-4 & 35.461246 & 32.197483 & 105.6 & 1.1392719 & 1.2547565 \\
\hline & EM-L & 35.461246 & 32.197483 & 89.3 & 1.1928515 & 1.3137673 \\
\hline & EM-M & 33.015148 & 30.100827 & 103.9 & 1.3327216 & 1.4617538 \\
\hline & CL-M & 33.015148 & 30.100827 & 92.8 & 1.1843049 & 1.2989676 \\
\hline & EM-H & 31.701735 & 28.975045 & 99.5 & 1.3784735 & 1.5081944 \\
\hline & EM-VH & 31.701735 & 28.975045 & 104.6 & 1.2996134 & 1.4219133 \\
\hline & EV-L & 32.171416 & 29.377628 & 122.6 & 1.1314392 & 1.2390381 \\
\hline & CG-M & 32.171416 & 29.377628 & 150 & 1.1811728 & 1.2935013 \\
\hline & EV-H & 29.874738 & 27.409048 & 111.7 & 1.3355765 & 1.4557237 \\
\hline & EV-VH & 29.874738 & 27.409048 & 119.6 & 1.2083788 & 1.3170833 \\
\hline
\end{tabular}


Table A.3 Shear strength comparison results for beams without stirrups based on AS 3600

\begin{tabular}{|c|c|c|c|c|}
\hline \multicolumn{2}{|c|}{ Beam } & \multirow{2}{*}{ As3600 } & \multirow{2}{*}{ Ve $(K N)$} & \multirow{2}{*}{$\begin{array}{c}\text { As3600 } \\
\mathrm{Ve} / \mathrm{Vp}\end{array}$} \\
\hline Paper & ID & & & \\
\hline \multirow{12}{*}{$\begin{array}{l}\text { Arezoum } \\
\text { andi et } \\
\text { al.,(2014) }\end{array}$} & CC-NS-4-1 & 123.37076 & 121.2 & 0.9824046 \\
\hline & CC-NS-4-2 & 119.85367 & 129.9 & 1.0838217 \\
\hline & CC-NS-6-1 & 141.22426 & 143.2 & 1.0139901 \\
\hline & CC-NS-6-2 & 137.1982 & 167 & 1.2172171 \\
\hline & CC-NS-8-1 & 155.43742 & 173.5 & 1.1162049 \\
\hline & CC-NS-8-1 & 151.00616 & 170.8 & 1.1310797 \\
\hline & RAC-NS-4-1 & 114.7316 & 114.8 & 1.0005962 \\
\hline & RAC-NS-4-2 & 119.73674 & 113 & 0.9437371 \\
\hline & RAC-NS-6-1 & 131.33489 & 143.2 & 1.0903424 \\
\hline & RAC-NS-6-2 & 137.06435 & 124.1 & 0.9054142 \\
\hline & RAC-NS-8-1 & 144.55276 & 131.4 & 0.9090107 \\
\hline & RAC-NS-8-2 & 150.85883 & 140.3 & 0.9300085 \\
\hline \multirow{12}{*}{$\begin{array}{l}\text {. Knaack et } \\
\text { al.,(2014) }\end{array}$} & so-1a & 64.049891 & 186.7 & 2.9149152 \\
\hline & so-1b & 73.201136 & 169.5 & 2.3155378 \\
\hline & so-2a & 76.94437 & 103.9 & 1.3503262 \\
\hline & so-2b & 74.624769 & 92.8 & 1.2435549 \\
\hline & S50-1a & 87.565917 & 83.2 & 0.9501414 \\
\hline & $S 50-1 b$ & 67.688432 & 195.3 & 2.8852788 \\
\hline & S50-2a & 77.483912 & 179 & 2.310157 \\
\hline & $S 50-2 b$ & 72.010728 & 150 & 2.083023 \\
\hline & S100-1a & 92.540354 & 105.6 & 1.1411238 \\
\hline & $\mathrm{S} 100-1 \mathrm{~b}$ & 58.087844 & 89.3 & 1.5373268 \\
\hline & S100-2a & 76.94437 & 103.9 & 1.3503262 \\
\hline & $S 100-2 b$ & 74.624769 & 92.8 & 1.2435549 \\
\hline \multirow{18}{*}{$\begin{array}{l}\text {.Fathifazl } \\
\text { et } \\
\text { al.(2011) }\end{array}$} & EM-1.5 & 93.296676 & 99.5 & 1.0664903 \\
\hline & EM-2 & 104.45522 & 104.6 & 1.001386 \\
\hline & EM-2.7 & 61.387692 & 122.6 & 1.997143 \\
\hline & CL-2.7 & 72.010728 & 150 & 2.083023 \\
\hline & EM-4 & 93.296676 & 111.7 & 1.197256 \\
\hline & EV-1.5 & 110.3891 & 119.6 & 1.0834403 \\
\hline & EV-2 & 35.057864 & 31.1 & 0.8871048 \\
\hline & CG-2.7 & 35.057864 & 36.9 & 1.0525456 \\
\hline & EV-4 & 40.510622 & 40.4 & 0.9972693 \\
\hline & EM-L & 40.510622 & 42.3 & 1.0441706 \\
\hline & EM-M & 38.625586 & 44 & 1.1391413 \\
\hline & CL-M & 38.625586 & 39.1 & 1.0122824 \\
\hline & EM-H & 37.594265 & 43.7 & 1.1624113 \\
\hline & EM-VH & 37.594265 & 41.2 & 1.0959118 \\
\hline & EV-L & 37.964676 & 36.4 & 0.958786 \\
\hline & CG-M & 37.964676 & 38 & 1.0009304 \\
\hline & EV-H & 36.135632 & 39.9 & 1.1041733 \\
\hline & EV-VH & 36.135632 & 36.1 & 0.9990139 \\
\hline
\end{tabular}


Table A.4 Shear strength comparison results for beams without stirrups based on CEB-FIP

\begin{tabular}{|c|c|c|c|c|}
\hline \multicolumn{2}{|c|}{ Beam } & \multirow{2}{*}{ CEB-FIP } & \multirow{2}{*}{ Ve $(K N)$} & \multirow{2}{*}{$\begin{array}{c}\text { CEB-FIP } \\
\text { Ve/Vp }\end{array}$} \\
\hline Paper & ID & & & \\
\hline \multirow{12}{*}{$\begin{array}{l}\text { Arezoum } \\
\text { andi et } \\
\text { al.,(2014) }\end{array}$} & CC-NS-4-1 & 111.18274 & 121.2 & 1.0900972 \\
\hline & CC-NS-4-2 & 108.01311 & 129.9 & 1.2026318 \\
\hline & CC-NS-6-1 & 129.99744 & 143.2 & 1.1015601 \\
\hline & CC-NS-6-2 & 126.29144 & 167 & 1.3223383 \\
\hline & CC-NS-8-1 & 143.13941 & 173.5 & 1.212105 \\
\hline & CC-NS-8-1 & 139.05875 & 170.8 & 1.2282578 \\
\hline & RAC-NS-4-1 & 103.39706 & 114.8 & 1.110283 \\
\hline & RAC-NS-4-2 & 107.90773 & 113 & 1.047191 \\
\hline & RAC-NS-6-1 & 120.89424 & 143.2 & 1.1845064 \\
\hline & RAC-NS-6-2 & 126.16823 & 124.1 & 0.9836074 \\
\hline & RAC-NS-8-1 & 133.11593 & 131.4 & 0.9871095 \\
\hline & RAC-NS-8-2 & 138.92308 & 140.3 & 1.0099114 \\
\hline \multirow{12}{*}{$\begin{array}{l}\text { Knaack et } \\
\text { al.,(2014) }\end{array}$} & So-1a & 71.370412 & 186.7 & 2.61593 \\
\hline & so-1b & 74.109073 & 169.5 & 2.2871693 \\
\hline & so-2a & 71.490921 & 103.9 & 1.4533314 \\
\hline & so-2b & 69.335722 & 92.8 & 1.3384154 \\
\hline & S50-1a & 70.788881 & 83.2 & 1.1753258 \\
\hline & $S 50-1 b$ & 75.424816 & 195.3 & 2.5893335 \\
\hline & S50-2a & 78.444969 & 179 & 2.2818544 \\
\hline & $S 50-2 b$ & 66.906952 & 150 & 2.2419195 \\
\hline & S100-1a & 74.810249 & 105.6 & 1.4115713 \\
\hline & $\mathrm{S} 100-1 \mathrm{~b}$ & 54.43914 & 89.3 & 1.6403639 \\
\hline & S100-2a & 71.490921 & 103.9 & 1.4533314 \\
\hline & $S 100-2 b$ & 69.335722 & 92.8 & 1.3384154 \\
\hline \multirow{18}{*}{$\begin{array}{l}\text {.Fathifazl } \\
\text { et } \\
\text { al.(2011) }\end{array}$} & EM-1.5 & 86.208424 & 99.5 & 1.1541796 \\
\hline & EM-2 & 100.04441 & 104.6 & 1.0455357 \\
\hline & EM-2.7 & 57.531714 & 122.6 & 2.1309986 \\
\hline & CL-2.7 & 66.906952 & 150 & 2.2419195 \\
\hline & EM-4 & 86.208424 & 111.7 & 1.295697 \\
\hline & EV-1.5 & 105.72773 & 119.6 & 1.1312075 \\
\hline & EV-2 & 29.233619 & 31.1 & 1.0638436 \\
\hline & CG-2.7 & 29.233619 & 36.9 & 1.2622453 \\
\hline & EV-4 & 33.780498 & 40.4 & 1.1959563 \\
\hline & EM-L & 33.780498 & 42.3 & 1.2522018 \\
\hline & EM-M & 32.208627 & 44 & 1.3660936 \\
\hline & CL-M & 32.208627 & 39.1 & 1.2139605 \\
\hline & EM-H & 31.348642 & 43.7 & 1.3939998 \\
\hline & EM-VH & 31.348642 & 41.2 & 1.3142515 \\
\hline & EV-L & 31.657516 & 36.4 & 1.1498059 \\
\hline & CG-M & 31.657516 & 38 & 1.2003469 \\
\hline & EV-H & 30.132335 & 39.9 & 1.3241589 \\
\hline & EV-VH & 30.132335 & 36.1 & 1.1980485 \\
\hline
\end{tabular}


Table A.5 Shear strength comparison results for beams without stirrups based on Cladera \& Mari

\begin{tabular}{|c|c|c|c|c|}
\hline \multicolumn{2}{|c|}{ Beam } & \multirow[b]{2}{*}{$\begin{array}{l}\text { Cladera\& } \\
\text { Mari }\end{array}$} & \multirow[b]{2}{*}{$\operatorname{Ve}(\mathbf{K N})$} & \multirow{2}{*}{$\begin{array}{c}\text { Cladera\& } \\
\text { Mari } \\
\text { Ve/Vp }\end{array}$} \\
\hline Paper & ID & & & \\
\hline \multirow{12}{*}{$\begin{array}{l}\text { Arezoum } \\
\text { andi et } \\
\text { al.,(2014) }\end{array}$} & CC-NS-4-1 & 109.51949 & 121.2 & 1.1066523 \\
\hline & CC-NS-4-2 & 107.63534 & 129.9 & 1.2068527 \\
\hline & CC-NS-6-1 & 138.46422 & 143.2 & 1.0342022 \\
\hline & CC-NS-6-2 & 136.08211 & 167 & 1.2272003 \\
\hline & CC-NS-8-1 & 159.98313 & 173.5 & 1.0844893 \\
\hline & CC-NS-8-1 & 157.23081 & 170.8 & 1.0863011 \\
\hline & RAC-NS-4-1 & 104.85132 & 114.8 & 1.0948837 \\
\hline & RAC-NS-4-2 & 107.57232 & 113 & 1.0504561 \\
\hline & RAC-NS-6-1 & 132.56231 & 143.2 & 1.0802467 \\
\hline & RAC-NS-6-2 & 136.00243 & 124.1 & 0.9124837 \\
\hline & RAC-NS-8-1 & 153.16399 & 131.4 & 0.857904 \\
\hline & RAC-NS-8-2 & 157.13875 & 140.3 & 0.8928415 \\
\hline \multirow{12}{*}{$\begin{array}{l}\text {. Knaack et } \\
\text { al.,(2014) }\end{array}$} & So-1a & 52.944414 & 186.7 & 3.5263399 \\
\hline & So-1b & 64.78093 & 169.5 & 2.6165107 \\
\hline & so-2a & 68.937843 & 103.9 & 1.5071548 \\
\hline & so-2b & 67.683278 & 92.8 & 1.371092 \\
\hline & S50-1a & 84.102658 & 83.2 & 0.9892672 \\
\hline & $S 50-1 b$ & 54.729034 & 195.3 & 3.5684898 \\
\hline & S50-2a & 67.029103 & 179 & 2.6704818 \\
\hline & $S 50-2 b$ & 66.250613 & 150 & 2.26413 \\
\hline & S100-1a & 86.937541 & 105.6 & 1.2146651 \\
\hline & $\mathrm{S} 100-1 \mathrm{~b}$ & 55.171951 & 89.3 & 1.6185761 \\
\hline & S100-2a & 68.937843 & 103.9 & 1.5071548 \\
\hline & $\mathrm{s} 100-2 \mathrm{~b}$ & 67.683278 & 92.8 & 1.371092 \\
\hline \multirow{18}{*}{$\begin{array}{l}\text {.Fathifazl } \\
\text { et } \\
\text { al.(2011) }\end{array}$} & EM-1.5 & 86.220409 & 99.5 & 1.1540191 \\
\hline & EM-2 & 98.50215 & 104.6 & 1.0619058 \\
\hline & EM-2.7 & 57.031655 & 122.6 & 2.1496833 \\
\hline & CL-2.7 & 66.250613 & 150 & 2.26413 \\
\hline & EM-4 & 86.220409 & 111.7 & 1.2955169 \\
\hline & EV-1.5 & 101.8224 & 119.6 & 1.1745942 \\
\hline & EV-2 & 32.223574 & 31.1 & 0.9651319 \\
\hline & CG-2.7 & 32.223574 & 36.9 & 1.1451244 \\
\hline & EV-4 & 35.143401 & 40.4 & 1.1495757 \\
\hline & EM-L & 35.143401 & 42.3 & 1.2036399 \\
\hline & EM-M & 34.152892 & 44 & 1.2883243 \\
\hline & CL-M & 34.152892 & 39.1 & 1.1448518 \\
\hline & EM-H & 33.602795 & 43.7 & 1.3004871 \\
\hline & EM-VH & 33.602795 & 41.2 & 1.2260885 \\
\hline & EV-L & 33.801055 & 36.4 & 1.0768895 \\
\hline & CG-M & 33.801055 & 38 & 1.1242253 \\
\hline & EV-H & 32.814352 & 39.9 & 1.2159314 \\
\hline & EV-VH & 32.814352 & 36.1 & 1.1001284 \\
\hline
\end{tabular}


Table A.6 Shear strength comparison results for beams without stirrups based on Eurocode-2

\begin{tabular}{|c|c|c|c|c|}
\hline \multicolumn{2}{|c|}{ Beam } & \multirow[b]{2}{*}{ Eurocode-2 } & \multirow[b]{2}{*}{ Ve $(\mathrm{KN})$} & \multirow{2}{*}{$\begin{array}{c}\text { Eurocode-2 } \\
\mathrm{Ve} / \mathrm{Vp}\end{array}$} \\
\hline Paper & ID & & & \\
\hline \multirow{12}{*}{$\begin{array}{l}\text { Arezoum } \\
\text { andi et } \\
\text { al.,(2014) }\end{array}$} & CC-NS-4-1 & 131.15751 & 121.2 & 0.9240798 \\
\hline & CC-NS-4-2 & 127.41843 & 129.9 & 1.0194758 \\
\hline & CC-NS-6-1 & 153.35241 & 143.2 & 0.9337969 \\
\hline & CC-NS-6-2 & 148.98059 & 167 & 1.1209514 \\
\hline & CC-NS-8-1 & 168.85542 & 173.5 & 1.0275062 \\
\hline & CC-NS-8-1 & 164.04164 & 170.8 & 1.041199 \\
\hline & RAC-NS-4-1 & 121.97307 & 114.8 & 0.9411913 \\
\hline & RAC-NS-4-2 & 127.29412 & 113 & 0.8877079 \\
\hline & RAC-NS-6-1 & 142.61375 & 143.2 & 1.0041107 \\
\hline & RAC-NS-6-2 & 148.83524 & 124.1 & 0.8338079 \\
\hline & RAC-NS-8-1 & 157.03115 & 131.4 & 0.8367766 \\
\hline & RAC-NS-8-2 & 163.8816 & 140.3 & 0.8561059 \\
\hline \multirow{12}{*}{$\begin{array}{l}\text {. Knaack et } \\
\text { al.,(2014) }\end{array}$} & So-1a & 66.823721 & 186.7 & 2.7939181 \\
\hline & so-1b & 76.371281 & 169.5 & 2.2194207 \\
\hline & SO-2a & 80.303199 & 103.9 & 1.2938463 \\
\hline & SO-2b & 77.882341 & 92.8 & 1.191541 \\
\hline & S50-1a & 91.371606 & 83.2 & 0.9105673 \\
\hline & S50-1b & 70.619836 & 195.3 & 2.7655119 \\
\hline & S50-2a & 80.839532 & 179 & 2.2142632 \\
\hline & $S 50-2 b$ & 75.154189 & 150 & 1.9958967 \\
\hline & S100-1a & 96.562236 & 105.6 & 1.0935952 \\
\hline & s100-1b & 61.926621 & 89.3 & 1.4420293 \\
\hline & s100-2a & 80.303199 & 103.9 & 1.2938463 \\
\hline & $\mathrm{s} 100-2 \mathrm{~b}$ & 77.882341 & 92.8 & 1.191541 \\
\hline \multirow{18}{*}{$\begin{array}{l}\text {.Fathifazl } \\
\text { et } \\
\text { al.(2011) }\end{array}$} & EM-1.5 & 98.549089 & 99.5 & 1.0096491 \\
\hline & EM-2 & 114.36569 & 104.6 & 0.91461 \\
\hline & EM-2.7 & 65.444542 & 122.6 & 1.8733419 \\
\hline & CL-2.7 & 75.154189 & 150 & 1.9958967 \\
\hline & EM-4 & 98.549089 & 111.7 & 1.1334453 \\
\hline & EV-1.5 & 120.86256 & 119.6 & 0.9895537 \\
\hline & EV-2 & 37.39456 & 31.1 & 0.8316718 \\
\hline & CG-2.7 & 37.39456 & 36.9 & 0.9867745 \\
\hline & EV-4 & 43.210759 & 40.4 & 0.9349523 \\
\hline & EM-L & 43.210759 & 42.3 & 0.9789229 \\
\hline & EM-M & 41.20008 & 44 & 1.0679591 \\
\hline & CL-M & 41.20008 & 39.1 & 0.9490273 \\
\hline & EM-H & 40.100019 & 43.7 & 1.089775 \\
\hline & EM-VH & 40.100019 & 41.2 & 1.0274309 \\
\hline & EV-L & 40.495119 & 36.4 & 0.8988738 \\
\hline & CG-M & 40.495119 & 38 & 0.9383847 \\
\hline & EV-H & 38.544164 & 39.9 & 1.0351762 \\
\hline & EV-VH & 38.544164 & 36.1 & 0.936588 \\
\hline
\end{tabular}


Table A.7 Shear strength comparison results for beams without stirrups based on EHE-08

\begin{tabular}{|c|c|c|c|c|}
\hline \multicolumn{2}{|c|}{ Beam } & \multirow[b]{2}{*}{ EHE-08 } & \multirow[b]{2}{*}{ Ve $(\mathrm{KN})$} & \multirow{2}{*}{$\begin{array}{l}\text { EHE-08 } \\
\mathrm{Ve} / \mathrm{Vp}\end{array}$} \\
\hline Paper & ID & & & \\
\hline \multirow{12}{*}{$\begin{array}{l}\text { Arezoum } \\
\text { andi et } \\
\text { al.,(2014) }\end{array}$} & CC-NS-4-1 & 109.29792 & 121.2 & 1.1088957 \\
\hline & CC-NS-4-2 & 106.18202 & 129.9 & 1.2233709 \\
\hline & CC-NS-6-1 & 127.79367 & 143.2 & 1.1205563 \\
\hline & CC-NS-6-2 & 124.15049 & 167 & 1.3451417 \\
\hline & CC-NS-8-1 & 140.71285 & 173.5 & 1.2330075 \\
\hline & CC-NS-8-1 & 136.70137 & 170.8 & 1.2494389 \\
\hline & RAC-NS-4-1 & 101.64423 & 114.8 & 1.1294296 \\
\hline & RAC-NS-4-2 & 106.07843 & 113 & 1.0652495 \\
\hline & RAC-NS-6-1 & 118.84479 & 143.2 & 1.2049329 \\
\hline & RAC-NS-6-2 & 124.02937 & 124.1 & 1.0005695 \\
\hline & RAC-NS-8-1 & 130.8593 & 131.4 & 1.004132 \\
\hline & RAC-NS-8-2 & 136.568 & 140.3 & 1.027327 \\
\hline \multirow{12}{*}{$\begin{array}{l}\text {. Knaack et } \\
\text { al.,(2014) }\end{array}$} & So-1a & 55.686434 & 186.7 & 3.3527017 \\
\hline & so-1b & 63.642734 & 169.5 & 2.6633048 \\
\hline & SO-2a & 66.919332 & 103.9 & 1.5526156 \\
\hline & SO-2b & 64.901951 & 92.8 & 1.4298492 \\
\hline & S50-1a & 76.143005 & 83.2 & 1.0926808 \\
\hline & S50-1b & 58.849864 & 195.3 & 3.3186143 \\
\hline & S50-2a & 67.366277 & 179 & 2.6571158 \\
\hline & $S 50-2 b$ & 62.628491 & 150 & 2.3950761 \\
\hline & S100-1a & 80.46853 & 105.6 & 1.3123143 \\
\hline & s100-1b & 51.605517 & 89.3 & 1.7304351 \\
\hline & s100-2a & 66.919332 & 103.9 & 1.5526156 \\
\hline & $\mathrm{s} 100-2 \mathrm{~b}$ & 64.901951 & 92.8 & 1.4298492 \\
\hline \multirow{18}{*}{$\begin{array}{l}\text {.Fathifazl } \\
\text { et } \\
\text { al.(2011) }\end{array}$} & EM-1.5 & 82.124241 & 99.5 & 1.2115789 \\
\hline & EM-2 & 95.304741 & 104.6 & 1.097532 \\
\hline & EM-2.7 & 54.537118 & 122.6 & 2.2480102 \\
\hline & CL-2.7 & 62.628491 & 150 & 2.3950761 \\
\hline & EM-4 & 82.124241 & 111.7 & 1.3601343 \\
\hline & EV-1.5 & 100.7188 & 119.6 & 1.1874645 \\
\hline & EV-2 & 31.162134 & 31.1 & 0.9980061 \\
\hline & CG-2.7 & 31.162134 & 36.9 & 1.1841294 \\
\hline & EV-4 & 36.008966 & 40.4 & 1.1219428 \\
\hline & EM-L & 36.008966 & 42.3 & 1.1747074 \\
\hline & EM-M & 34.3334 & 44 & 1.2815509 \\
\hline & CL-M & 34.3334 & 39.1 & 1.1388327 \\
\hline & EM-H & 33.416683 & 43.7 & 1.30773 \\
\hline & EM-VH & 33.416683 & 41.2 & 1.2329171 \\
\hline & EV-L & 33.745932 & 36.4 & 1.0786485 \\
\hline & CG-M & 33.745932 & 38 & 1.1260616 \\
\hline & EV-H & 32.120137 & 39.9 & 1.2422114 \\
\hline & EV-VH & 32.120137 & 36.1 & 1.1239055 \\
\hline
\end{tabular}


Table A.8 Shear strength comparison results for beams without stirrups based on Gastebled \& May

\begin{tabular}{|c|c|c|c|c|}
\hline \multicolumn{2}{|c|}{ Beam } & \multirow{2}{*}{$\begin{array}{c}\text { Gastebled } \\
\text { \& May }\end{array}$} & \multirow[b]{2}{*}{ Ve $(\mathrm{KN})$} & \multirow{2}{*}{$\begin{array}{c}\text { Gastebled } \\
\text { \&May } \\
\text { Ve/Vp }\end{array}$} \\
\hline Paper & ID & & & \\
\hline \multirow{12}{*}{$\begin{array}{l}\text { Arezoum } \\
\text { andi et } \\
\text { al.,(2014) }\end{array}$} & CC-NS-4-1 & 114.8183 & 121.2 & 1.0555808 \\
\hline & CC-NS-4-2 & 111.38383 & 129.9 & 1.1662375 \\
\hline & CC-NS-6-1 & 121.35969 & 143.2 & 1.1799634 \\
\hline & CC-NS-6-2 & 117.72956 & 167 & 1.4185053 \\
\hline & CC-NS-8-1 & 125.14465 & 173.5 & 1.3863956 \\
\hline & CC-NS-8-1 & 121.4013 & 170.8 & 1.4069042 \\
\hline & RAC-NS-4-1 & 106.39114 & 114.8 & 1.0790372 \\
\hline & RAC-NS-4-2 & 111.26974 & 113 & 1.0155502 \\
\hline & RAC-NS-6-1 & 112.45242 & 143.2 & 1.2734274 \\
\hline & RAC-NS-6-2 & 117.60896 & 124.1 & 1.0551917 \\
\hline & RAC-NS-8-1 & 115.95958 & 131.4 & 1.1331534 \\
\hline & RAC-NS-8-2 & 121.27694 & 140.3 & 1.1568563 \\
\hline \multirow{12}{*}{$\begin{array}{l}\text { Knaack et } \\
\text { al.,(2014) }\end{array}$} & So-1a & 84.176448 & 186.7 & 2.2179601 \\
\hline & so-1b & 80.322739 & 169.5 & 2.1102368 \\
\hline & SO-2a & 75.604459 & 103.9 & 1.3742576 \\
\hline & SO-2b & 73.213112 & 92.8 & 1.2675325 \\
\hline & S50-1a & 68.487656 & 83.2 & 1.2148175 \\
\hline & S50-1b & 89.204436 & 195.3 & 2.189353 \\
\hline & S50-2a & 85.264237 & 179 & 2.0993561 \\
\hline & $S 50-2 b$ & 70.522675 & 150 & 2.1269755 \\
\hline & S100-1a & 72.578528 & 105.6 & 1.4549758 \\
\hline & $\mathrm{S} 100-1 \mathrm{~b}$ & 61.653949 & 89.3 & 1.4484068 \\
\hline & S100-2a & 75.604459 & 103.9 & 1.3742576 \\
\hline & $\mathrm{S} 100-2 \mathrm{~b}$ & 73.213112 & 92.8 & 1.2675325 \\
\hline \multirow{18}{*}{$\begin{array}{l}\text {.Fathifazl } \\
\text { et } \\
\text { al.(2011) }\end{array}$} & EM-1.5 & 83.669404 & 99.5 & 1.1892041 \\
\hline & EM-2 & 92.599189 & 104.6 & 1.1295995 \\
\hline & EM-2.7 & 65.336634 & 122.6 & 1.8764358 \\
\hline & CL-2.7 & 70.522675 & 150 & 2.1269755 \\
\hline & EM-4 & 83.669404 & 111.7 & 1.3350161 \\
\hline & EV-1.5 & 98.13028 & 119.6 & 1.2187879 \\
\hline & EV-2 & 35.951696 & 31.1 & 0.8650496 \\
\hline & CG-2.7 & 35.951696 & 36.9 & 1.0263772 \\
\hline & EV-4 & 41.84485 & 40.4 & 0.9654713 \\
\hline & EM-L & 41.84485 & 42.3 & 1.0108771 \\
\hline & EM-M & 39.802788 & 44 & 1.1054502 \\
\hline & CL-M & 39.802788 & 39.1 & 0.9823432 \\
\hline & EM-H & 38.687649 & 43.7 & 1.1295595 \\
\hline & EM-VH & 38.687649 & 41.2 & 1.0649393 \\
\hline & EV-L & 39.08799 & 36.4 & 0.9312323 \\
\hline & CG-M & 39.08799 & 38 & 0.9721656 \\
\hline & $\mathrm{EV}-\mathrm{H}$ & 37.113089 & 39.9 & 1.0750924 \\
\hline & EV-VH & 37.113089 & 36.1 & 0.9727027 \\
\hline
\end{tabular}


Table A.9 Shear strength comparison results for beams without stirrups based on NZS3101

\begin{tabular}{|c|c|c|c|c|}
\hline \multicolumn{2}{|c|}{ Beam } & \multirow{2}{*}{ NZS3101 } & \multirow{2}{*}{ Ve $(K N)$} & \multirow{2}{*}{$\begin{array}{c}\text { NZS3101 } \\
\text { Ve/Vp }\end{array}$} \\
\hline Paper & ID & & & \\
\hline \multirow{12}{*}{$\begin{array}{l}\text { Arezoum } \\
\text { andi et } \\
\text { al.,(2014) }\end{array}$} & CC-NS-4-1 & 101.23206 & 121.2 & 1.1972491 \\
\hline & CC-NS-4-2 & 97.290764 & 129.9 & 1.335173 \\
\hline & CC-NS-6-1 & 146.57694 & 143.2 & 0.9769613 \\
\hline & CC-NS-6-2 & 140.35384 & 167 & 1.1898499 \\
\hline & CC-NS-8-1 & 146.57694 & 173.5 & 1.1836787 \\
\hline & CC-NS-8-1 & 140.35384 & 170.8 & 1.2169243 \\
\hline & RAC-NS-4-1 & 91.653829 & 114.8 & 1.2525391 \\
\hline & RAC-NS-4-2 & 97.160712 & 113 & 1.1630215 \\
\hline & RAC-NS-6-1 & 131.45341 & 143.2 & 1.0893593 \\
\hline & RAC-NS-6-2 & 140.14849 & 124.1 & 0.8854894 \\
\hline & RAC-NS-8-1 & 131.45341 & 131.4 & 0.9995937 \\
\hline & RAC-NS-8-2 & 140.14849 & 140.3 & 1.001081 \\
\hline \multirow{12}{*}{$\begin{array}{l}\text {. Knaack et } \\
\text { al.,(2014) }\end{array}$} & So-1a & 65.788023 & 186.7 & 2.8379026 \\
\hline & so-1b & 77.211398 & 169.5 & 2.1952717 \\
\hline & so-2a & 68.89888 & 103.9 & 1.5080071 \\
\hline & so-2b & 66.001031 & 92.8 & 1.4060386 \\
\hline & S50-1a & 78.687636 & 83.2 & 1.0573453 \\
\hline & S50-1b & 71.47282 & 195.3 & 2.7325073 \\
\hline & S50-2a & 67.264253 & 179 & 2.661146 \\
\hline & $S 50-2 b$ & 62.788944 & 150 & 2.3889556 \\
\hline & S100-1a & 85.487098 & 105.6 & 1.2352741 \\
\hline & $\mathrm{S} 100-1 \mathrm{~b}$ & 51.856442 & 89.3 & 1.7220618 \\
\hline & S100-2a & 68.89888 & 103.9 & 1.5080071 \\
\hline & $S 100-2 b$ & 66.001031 & 92.8 & 1.4060386 \\
\hline \multirow{18}{*}{$\begin{array}{l}\text {.Fathifazl } \\
\text { et } \\
\text { al.(2011) }\end{array}$} & EM-1.5 & 98.295046 & 99.5 & 1.0122585 \\
\hline & EM-2 & 109.81962 & 104.6 & 0.952471 \\
\hline & EM-2.7 & 56.337399 & 122.6 & 2.1761743 \\
\hline & CL-2.7 & 62.788944 & 150 & 2.3889556 \\
\hline & EM-4 & 95.273968 & 111.7 & 1.1724084 \\
\hline & EV-1.5 & 118.73338 & 119.6 & 1.0072989 \\
\hline & EV-2 & 25.058466 & 31.1 & 1.2410975 \\
\hline & CG-2.7 & 25.058466 & 36.9 & 1.4725562 \\
\hline & EV-4 & 30.617934 & 40.4 & 1.3194881 \\
\hline & EM-L & 30.617934 & 42.3 & 1.3815432 \\
\hline & EM-M & 28.650782 & 44 & 1.5357347 \\
\hline & CL-M & 28.650782 & 39.1 & 1.3647097 \\
\hline & EM-H & 27.594535 & 43.7 & 1.5836469 \\
\hline & EM-VH & 27.594535 & 41.2 & 1.4930492 \\
\hline & EV-L & 27.972253 & 36.4 & 1.3012895 \\
\hline & CG-M & 27.972253 & 38 & 1.3584891 \\
\hline & EV-H & 26.125265 & 39.9 & 1.5272573 \\
\hline & EV-VH & 26.125265 & 36.1 & 1.3818042 \\
\hline
\end{tabular}


Table A.10 Shear strength comparison results for beams without stirrups based on Zsutty

\begin{tabular}{|c|c|c|c|c|c|}
\hline \multicolumn{2}{|c|}{ Beam } & \multicolumn{2}{|c|}{ Vc-Zsutty } & \multirow[b]{2}{*}{ Ve $(\mathbf{K N})$} & \multirow[b]{2}{*}{ Zsutty } \\
\hline Paper & ID & $(\mathrm{a} / \mathrm{d}>2.5)$ & $(\mathrm{a} / \mathrm{d}<2.5)$ & & \\
\hline \multirow{12}{*}{$\begin{array}{l}\text { Arezoum } \\
\text { andi et } \\
\text { al.,(2014) }\end{array}$} & CC-NS-4-1 & 143.34106 & & 121.2 & 0.8455358 \\
\hline & CC-NS-4-2 & 139.25465 & & 129.9 & 0.9328234 \\
\hline & CC-NS-6-1 & 167.5977 & & 143.2 & 0.854427 \\
\hline & CC-NS-6-2 & 162.81977 & & 167 & 1.0256739 \\
\hline & CC-NS-8-1 & 184.54083 & & 173.5 & 0.9401713 \\
\hline & CC-NS-8-1 & 179.27989 & & 170.8 & 0.9527003 \\
\hline & RAC-NS-4-1 & 133.30346 & & 114.8 & 0.8611929 \\
\hline & RAC-NS-4-2 & 139.11879 & & 113 & 0.8122555 \\
\hline & RAC-NS-6-1 & 155.86151 & & 143.2 & 0.9187644 \\
\hline & RAC-NS-6-2 & 162.66093 & & 124.1 & 0.7629368 \\
\hline & RAC-NS-8-1 & 171.61818 & & 131.4 & 0.7656532 \\
\hline & RAC-NS-8-2 & 179.10498 & & 140.3 & 0.7833395 \\
\hline \multirow{12}{*}{$\begin{array}{l}\text {. Knaack et } \\
\text { al.,(2014) }\end{array}$} & so-1a & & 144.12068 & 31.1 & 1.2954421 \\
\hline & so-1b & & 112.23821 & 36.9 & 1.5101809 \\
\hline & SO-2a & 87.193399 & & 40.4 & 1.191604 \\
\hline & SO-2b & 84.564826 & & 42.3 & 1.097383 \\
\hline & S50-1a & 86.086306 & & 44 & 0.966472 \\
\hline & $\mathrm{S} 50-1 \mathrm{~b}$ & & 152.30787 & 39.1 & 1.2822712 \\
\hline & S50-2a & & 118.80493 & 43.7 & 1.5066715 \\
\hline & $S 50-2 b$ & 81.602593 & & 41.2 & 1.8381769 \\
\hline & S100-1a & 90.976689 & & 36.4 & 1.1607369 \\
\hline & S100-1b & 59.981368 & & 38 & 1.4887956 \\
\hline & S100-2a & 87.193399 & & 39.9 & 1.191604 \\
\hline & $\mathrm{S} 100-2 \mathrm{~b}$ & 84.564826 & & 36.1 & 1.097383 \\
\hline \multirow{18}{*}{$\begin{array}{l}\text {.Fathifazl } \\
\text { et } \\
\text { al.(2011) }\end{array}$} & EM-1.5 & 110.02073 & & 186.7 & 0.9043751 \\
\hline & EM-2 & 133.59059 & & 169.5 & 0.7829893 \\
\hline & EM-2.7 & 63.388784 & & 103.9 & 1.9340961 \\
\hline & CL-2.7 & 81.602593 & & 92.8 & 1.8381769 \\
\hline & EM-4 & 110.02073 & & 83.2 & 1.0152633 \\
\hline & EV-1.5 & 141.17959 & & 195.3 & 0.8471479 \\
\hline & EV-2 & 32.169664 & & 179 & 0.9667493 \\
\hline & CG-2.7 & 32.169664 & & 150 & 1.1470434 \\
\hline & EV-4 & 37.173203 & & 105.6 & 1.0868044 \\
\hline & EM-L & 37.173203 & & 89.3 & 1.1379165 \\
\hline & EM-M & 35.443463 & & 103.9 & 1.2414137 \\
\hline & CL-M & 35.443463 & & 92.8 & 1.1031653 \\
\hline & EM-H & 34.497107 & & 99.5 & 1.2667729 \\
\hline & EM-VH & 34.497107 & & 104.6 & 1.1943031 \\
\hline & EV-L & 34.837002 & & 122.6 & 1.044866 \\
\hline & CG-M & 34.837002 & & 150 & 1.0907942 \\
\hline & EV-H & 33.158641 & & 111.7 & 1.2033062 \\
\hline & EV-VH & 33.158641 & & 119.6 & 1.0887056 \\
\hline
\end{tabular}


Table A.11 Shear strength comparison results for beams with stirrups based on CSA A23.3-04

\begin{tabular}{|c|c|c|c|c|c|c|c|c|c|}
\hline \multicolumn{2}{|c|}{ Beam } & \multicolumn{2}{|c|}{ Vc-CSA A23.3-04 } & \multirow[b]{2}{*}{ Vs } & \multirow[b]{2}{*}{$\begin{array}{c}\text { Vu } \\
\text { Simplified }\end{array}$} & \multirow[b]{2}{*}{$\begin{array}{c}\text { Vu } \\
\text { General }\end{array}$} & \multirow[b]{2}{*}{$\operatorname{Ve}(\mathbf{K N})$} & \multicolumn{2}{|c|}{ CSA A23.3-04 } \\
\hline Paper & ID & Simplified & General & & & & & $\begin{array}{l}\mathbf{V e} / \mathbf{V} \mathbf{p} \\
\text { Simplified }\end{array}$ & $\begin{array}{l}\text { Ve/Vp } \\
\text { General }\end{array}$ \\
\hline \multirow{6}{*}{$\begin{array}{l}\text { Gonzalez } \\
\text { et } \\
\text { al.,(2007) }\end{array}$} & $\mathrm{V} 13 \mathrm{CC}$ & 60.48631 & 60.24594 & 85.49145 & 145.9778 & 145.7374 & 190.29 & 1.303555 & 1.305705 \\
\hline & V13RC & 62.69456 & 62.44542 & 85.49145 & 148.186 & 147.9369 & 233.59 & 1.57633 & 1.578984 \\
\hline & $\mathrm{V} 17 \mathrm{CC}$ & 61.6161 & 61.37124 & 65.37581 & 126.9919 & 126.7471 & 150.83 & 1.187713 & 1.190008 \\
\hline & V17RC & 63.48756 & 63.23527 & 65.37581 & 128.8634 & 128.6111 & 176.99 & 1.37347 & 1.376164 \\
\hline & $\mathrm{V} 24 \mathrm{CC}$ & 61.67913 & 61.43403 & 46.30787 & 107.987 & 107.7419 & 127.97 & 1.18505 & 1.187746 \\
\hline & V24RC & 61.73424 & 61.48891 & 46.30787 & 108.0421 & 107.7968 & 164.29 & 1.520611 & 1.524072 \\
\hline \multirow{6}{*}{$\begin{array}{l}\text { Gonzalez } \\
\text { et } \\
\text { al.,(2009) }\end{array}$} & V13CC & 64.44437 & 64.18827 & 85.49145 & 149.9358 & 149.6797 & 150.07 & 1.000895 & 1.002607 \\
\hline & V13RC & 63.45695 & 63.20478 & 85.49145 & 148.9484 & 148.6962 & 147.33 & 0.989134 & 0.990812 \\
\hline & V17CC & 66.23597 & 65.97275 & 65.37581 & 131.6118 & 131.3486 & 199.79 & 1.518025 & 1.521067 \\
\hline & V17RC & 65.74279 & 65.48153 & 65.37581 & 131.1186 & 130.8573 & 192.92 & 1.47134 & 1.474277 \\
\hline & V24CC & 65.12666 & 64.86785 & 46.30787 & 111.4345 & 111.1757 & 220.08 & 1.974971 & 1.979569 \\
\hline & V24RC & 64.82014 & 64.56255 & 46.30787 & 111.128 & 110.8704 & 202.36 & 1.820963 & 1.825194 \\
\hline \multirow{14}{*}{$\begin{array}{l}\text { Ajdukiewicz, } \\
\text { (2007) }\end{array}$} & ORNm-b2 & 64.51171 & 61.84709 & 38.51348 & 103.0252 & 100.3606 & 118.5 & 1.150204 & 1.180743 \\
\hline & GNN/- b2 & 52.56053 & 50.38955 & 38.51348 & 91.07401 & 88.90303 & 108.5 & 1.191339 & 1.220431 \\
\hline & GRN/-b2 & 52.96641 & 50.77867 & 38.51348 & 91.47988 & 89.29214 & 116.5 & 1.273504 & 1.304706 \\
\hline & GRRI-b2 & 50.55287 & 48.46481 & 38.51348 & 89.06634 & 86.97829 & 113 & 1.268717 & 1.299175 \\
\hline & GRNm-b2 & 65.227 & 62.53284 & 38.51348 & 103.7405 & 101.0463 & 118.5 & 1.142274 & 1.17273 \\
\hline & GNNh-b2 & 81.65404 & 78.28138 & 38.51348 & 120.1675 & 116.7949 & 125 & 1.040215 & 1.070253 \\
\hline & GRNh-b2 & 79.75228 & 76.45817 & 38.51348 & 118.2658 & 114.9716 & 121 & 1.023119 & 1.052433 \\
\hline & GRRh-b2 & 76.60201 & 73.43801 & 38.51348 & 115.1155 & 111.9515 & 127.5 & 1.107583 & 1.138886 \\
\hline & BNNm-b2 & 65.88037 & 63.15923 & 38.51348 & 104.3938 & 101.6727 & 119 & 1.139914 & 1.170422 \\
\hline & BRNm-b2 & 65.227 & 62.53284 & 38.51348 & 103.7405 & 101.0463 & 119 & 1.147093 & 1.177678 \\
\hline & BRRm-b2 & 64.12325 & 61.47468 & 38.51348 & 102.6367 & 99.98815 & 118 & 1.149686 & 1.18014 \\
\hline & BNNh-b2 & 84.86915 & 81.36368 & 38.51348 & 123.3826 & 119.8772 & 131 & 1.061738 & 1.092785 \\
\hline & BRNh-b2 & 87.72303 & 84.09969 & 38.51348 & 126.2365 & 122.6132 & 130.5 & 1.033774 & 1.064323 \\
\hline & BRRh-b2 & 84.70076 & 81.20225 & 38.51348 & 123.2142 & 119.7157 & 128 & 1.038841 & 1.0692 \\
\hline \multirow{8}{*}{$\begin{array}{c}\text { Etxeberri } \\
\text { a,(2007) }\end{array}$} & $\mathrm{HC}-2$ & 64.79669 & 64.81303 & 87.18435 & 151.981 & 151.9974 & 213 & 1.401491 & 1.40134 \\
\hline & $\mathrm{HC}-3$ & 64.79669 & 64.81303 & 66.67039 & 131.4671 & 131.4834 & 177 & 1.346345 & 1.346177 \\
\hline & HR25-2 & 65.15901 & 65.17544 & 87.18435 & 152.3434 & 152.3598 & 186.5 & 1.224208 & 1.224076 \\
\hline & HR25-3 & 65.15901 & 65.17544 & 66.67039 & 131.8294 & 131.8458 & 169 & 1.28196 & 1.2818 \\
\hline & HR50-2 & 64.35454 & 64.37077 & 87.18435 & 151.5389 & 151.5551 & 220 & 1.451773 & 1.451617 \\
\hline & HR50-3 & 64.35454 & 64.37077 & 66.67039 & 131.0249 & 131.0412 & 176 & 1.343256 & 1.343089 \\
\hline & HR100-2 & 63.10482 & 63.12074 & 87.18435 & 150.2892 & 150.3051 & 189.5 & 1.260903 & 1.260769 \\
\hline & HR100-3 & 63.10482 & 63.12074 & 66.67039 & 129.7752 & 129.7911 & 163 & 1.256018 & 1.255864 \\
\hline \multirow{9}{*}{$\begin{array}{c}\text { Al-Zahraa } \\
\text { et al., } \\
\text { (2011) }\end{array}$} & B4 & 18.04516 & 16.41011 & 20.13705 & 38.18221 & 36.54716 & 44.5 & 1.165464 & 1.217605 \\
\hline & B5 & 19.30593 & 17.55664 & 20.13705 & 39.44298 & 37.69369 & 49.75 & 1.261315 & 1.31985 \\
\hline & B6 & 17.43957 & 15.85939 & 20.13705 & 37.57662 & 35.99644 & 42 & 1.117716 & 1.166782 \\
\hline & B7 & 19.74563 & 17.9565 & 35.50479 & 55.25042 & 53.46129 & 75 & 1.357456 & 1.402884 \\
\hline & $\mathrm{B} 8$ & 19.30593 & 17.55664 & 35.50479 & 54.81072 & 53.06144 & 61 & 1.112921 & 1.149611 \\
\hline & B9 & 17.43957 & 15.85939 & 35.50479 & 52.94436 & 51.36419 & 58 & 1.09549 & 1.129191 \\
\hline & B10 & 19.74563 & 17.9565 & 20.13705 & 39.88267 & 38.09355 & 37 & 0.927721 & 0.971293 \\
\hline & B11 & 17.68546 & 16.083 & 20.13705 & 37.8225 & 36.22005 & 47.25 & 1.249256 & 1.304526 \\
\hline & B12 & 17.43957 & 15.85939 & 20.13705 & 37.57662 & 35.99644 & 34.25 & 0.911471 & 0.951483 \\
\hline
\end{tabular}


Table A.12 Shear strength comparison results for beams with stirrups based on NZS 3101

\begin{tabular}{|c|c|c|c|c|c|c|}
\hline \multicolumn{2}{|c|}{ Beam } & \multicolumn{3}{|c|}{ NZS3101 } & \multirow{2}{*}{$\mathbf{V}_{\mathbf{e}}$} & NZS3101 \\
\hline Paper & ID & $\mathbf{V}_{\mathbf{c}}$ & $\mathbf{V}_{\mathbf{s}}$ & $\mathbf{V}_{\mathbf{u}}$ & & $\mathbf{V}_{\mathrm{e}} / \mathbf{V}_{\mathbf{p}}$ \\
\hline \multirow{6}{*}{$\begin{array}{l}\text { Gonzalez } \\
\text { et } \\
\text { al.,(2007) }\end{array}$} & V13CC & 74.37771 & 66.42692 & 140.8046 & 190.29 & 1.351447 \\
\hline & V13RC & 77.09311 & 66.42692 & 143.52 & 233.59 & 1.627578 \\
\hline & V17CC & 75.76697 & 50.79706 & 126.564 & 150.83 & 1.191729 \\
\hline & V17RC & 78.06823 & 50.79706 & 128.8653 & 176.99 & 1.37345 \\
\hline & V24CC & 75.84448 & 35.98125 & 111.8257 & 127.97 & 1.14437 \\
\hline & V24RC & 75.91223 & 35.98125 & 111.8935 & 164.29 & 1.468271 \\
\hline \multirow{6}{*}{$\begin{array}{l}\text { Gonzalez } \\
\text { et } \\
\text { al.,(2009) }\end{array}$} & V13CC & 79.24478 & 66.42692 & 145.6717 & 150.07 & 1.030193 \\
\hline & V13RC & 78.03059 & 66.42692 & 144.4575 & 147.33 & 1.019885 \\
\hline & V17CC & 81.44784 & 50.79706 & 132.2449 & 199.79 & 1.510758 \\
\hline & V17RC & 80.8414 & 50.79706 & 131.6385 & 192.92 & 1.465529 \\
\hline & $\mathrm{V} 24 \mathrm{CC}$ & 80.08377 & 35.98125 & 116.065 & 220.08 & 1.896179 \\
\hline & V24RC & 79.70686 & 35.98125 & 115.6881 & 202.36 & 1.749186 \\
\hline \multirow{14}{*}{$\begin{array}{c}\text { Ajdukiewicz, } \\
\text { (2007) }\end{array}$} & ORNm-b2 & 76.35444 & 29.925 & 106.2794 & 118.5 & 1.114985 \\
\hline & GNN/- b2 & 62.20932 & 29.925 & 92.13432 & 108.5 & 1.177628 \\
\hline & GRN/- b2 & 62.68971 & 29.925 & 92.61471 & 116.5 & 1.257899 \\
\hline & GRRI- b2 & 59.8331 & 29.925 & 89.7581 & 113 & 1.258939 \\
\hline & GRNm-b2 & 77.20104 & 29.925 & 107.126 & 118.5 & 1.106174 \\
\hline & GNNh-b2 & 96.64368 & 29.925 & 126.5687 & 125 & 0.987606 \\
\hline & GRNh-b2 & 94.3928 & 29.925 & 124.3178 & 121 & 0.973312 \\
\hline & GRRh-b2 & 90.66422 & 29.925 & 120.5892 & 127.5 & 1.057308 \\
\hline & BNNm-b2 & 77.97435 & 29.925 & 107.8994 & 119 & 1.10288 \\
\hline & BRNm-b2 & 77.20104 & 29.925 & 107.126 & 119 & 1.110841 \\
\hline & BRRm-b2 & 75.89466 & 29.925 & 105.8197 & 118 & 1.115105 \\
\hline & BNNh-b2 & 100.449 & 29.925 & 130.374 & 131 & 1.004802 \\
\hline & BRNh-b2 & 103.8268 & 29.925 & 133.7518 & 130.5 & 0.975688 \\
\hline & BRRh-b2 & 100.2497 & 29.925 & 130.1747 & 128 & 0.983294 \\
\hline \multirow{8}{*}{$\begin{array}{c}\text { Etxeberri } \\
a,(2007)\end{array}$} & $\mathrm{HC}-2$ & 80.01609 & 67.74231 & 147.7584 & 213 & 1.441542 \\
\hline & $\mathrm{HC}-3$ & 80.01609 & 51.80294 & 131.819 & 177 & 1.34275 \\
\hline & HR25-2 & 80.46351 & 67.74231 & 148.2058 & 186.5 & 1.258385 \\
\hline & HR25-3 & 80.46351 & 51.80294 & 132.2664 & 169 & 1.277724 \\
\hline & HR50-2 & 79.47009 & 67.74231 & 147.2124 & 220 & 1.494439 \\
\hline & HR50-3 & 79.47009 & 51.80294 & 131.273 & 176 & 1.340717 \\
\hline & HR100-2 & 77.92683 & 67.74231 & 145.6691 & 189.5 & 1.300893 \\
\hline & HR100-3 & 77.92683 & 51.80294 & 129.7298 & 163 & 1.256458 \\
\hline \multirow{9}{*}{$\begin{array}{c}\text { Al-Zahraa } \\
\text { et al., } \\
\text { (2011) }\end{array}$} & B4 & 20.2594 & 15.6465 & 35.9059 & 44.5 & 1.239351 \\
\hline & B5 & 21.67487 & 15.6465 & 37.32137 & 49.75 & 1.333016 \\
\hline & B6 & 19.5795 & 15.6465 & 35.226 & 42 & 1.192301 \\
\hline & B7 & 22.16852 & 27.58725 & 49.75577 & 75 & 1.507363 \\
\hline & B8 & 21.67487 & 27.58725 & 49.26212 & 61 & 1.238274 \\
\hline & B9 & 19.5795 & 27.58725 & 47.16675 & 58 & 1.22968 \\
\hline & B10 & 22.16852 & 15.6465 & 37.81502 & 37 & 0.978447 \\
\hline & B11 & 19.85556 & 15.6465 & 35.50206 & 47.25 & 1.330909 \\
\hline & B12 & 19.5795 & 15.6465 & 35.226 & 34.25 & 0.972293 \\
\hline
\end{tabular}


Table A.13 Shear strength comparison results for beams with stirrups based on ACI 318-11

\begin{tabular}{|c|c|c|c|c|c|c|c|c|c|}
\hline \multicolumn{2}{|c|}{ Beam } & \multicolumn{2}{|c|}{ Vc- ACI 318-11 } & \multirow[b]{2}{*}{ Vs } & \multirow[b]{2}{*}{ Simplified } & \multirow[b]{2}{*}{$\begin{array}{c}\text { Vu } \\
\text { General }\end{array}$} & \multirow[b]{2}{*}{$\operatorname{Ve}(\mathrm{KN})$} & \multicolumn{2}{|c|}{ ACI 318-11 } \\
\hline Paper & ID & Equ. (11-3) & Equ. (11-5) & & & & & $\begin{array}{l}\mathbf{V e} / \mathbf{p} \\
\text { Equ. (11-3) }\end{array}$ & $\begin{array}{l}\mathbf{V e} / \mathbf{V p} \\
\text { Equ. (11-5) }\end{array}$ \\
\hline \multirow{6}{*}{$\begin{array}{l}\text { Gonzalez } \\
\text { et } \\
\text { al.,(2007) }\end{array}$} & V13CC & 61.98142 & 62.50813 & 66.42692 & 128.4083 & 128.9351 & 190.29 & 1.481913 & 1.475859 \\
\hline & V13RC & 64.24426 & 64.4477 & 66.42692 & 130.6712 & 130.8746 & 233.59 & 1.787617 & 1.784838 \\
\hline & V17CC & 63.13914 & 63.50046 & 50.79706 & 113.9362 & 114.2975 & 150.83 & 1.323811 & 1.319626 \\
\hline & V17RC & 65.05686 & 65.14422 & 50.79706 & 115.8539 & 115.9413 & 176.99 & 1.5277 & 1.526549 \\
\hline & V24CC & 63.20373 & 63.55582 & 35.98125 & 99.18498 & 99.53707 & 127.97 & 1.290216 & 1.285652 \\
\hline & V24RC & 63.2602 & 63.60422 & 35.98125 & 99.24145 & 99.58547 & 164.29 & 1.655458 & 1.649739 \\
\hline \multirow{6}{*}{$\begin{array}{l}\text { Gonzalez } \\
\text { et } \\
\text { al.,(2009) }\end{array}$} & $\mathrm{V} 13 \mathrm{CC}$ & 66.03732 & 65.98461 & 66.42692 & 132.4642 & 132.4115 & 150.07 & 1.13291 & 1.13336 \\
\hline & V13RC & 65.02549 & 65.11733 & 66.42692 & 131.4524 & 131.5443 & 147.33 & 1.120786 & 1.120003 \\
\hline & V17CC & 67.8732 & 67.55823 & 50.79706 & 118.6703 & 118.3553 & 199.79 & 1.683573 & 1.688053 \\
\hline & V17RC & 67.36783 & 67.12505 & 50.79706 & 118.1649 & 117.9221 & 192.92 & 1.632634 & 1.635995 \\
\hline & V24CC & 66.73647 & 66.58388 & 35.98125 & 102.7177 & 102.5651 & 220.08 & 2.142571 & 2.145758 \\
\hline & V24RC & 66.42238 & 66.31466 & 35.98125 & 102.4036 & 102.2959 & 202.36 & 1.976102 & 1.978183 \\
\hline \multirow{14}{*}{$\begin{array}{l}\text { Ajdukiewicz, } \\
\qquad(2007)\end{array}$} & ORNm-b2 & 63.6287 & 58.84763 & 29.925 & 93.5537 & 88.77263 & 118.5 & 1.266652 & 1.334871 \\
\hline & GNN/- b2 & 51.8411 & 48.74398 & 29.925 & 81.7661 & 78.66898 & 108.5 & 1.326956 & 1.379197 \\
\hline & GRN/- b2 & 52.24143 & 49.08712 & 29.925 & 82.16643 & 79.01212 & 116.5 & \begin{tabular}{|l|}
1.417854 \\
\end{tabular} & 1.474457 \\
\hline & GRRI- b2 & 49.86092 & 47.04668 & 29.925 & 79.78592 & 76.97168 & 113 & 1.41629 & 1.468072 \\
\hline & GRNm-b2 & 64.3342 & 59.45235 & 29.925 & 94.2592 & 89.37735 & 118.5 & 1.257172 & 1.325839 \\
\hline & GNNh-b2 & 80.5364 & 73.33995 & 29.925 & 110.4614 & 103.2649 & 125 & 1.131617 & 1.210479 \\
\hline & GRNh-b2 & 78.66066 & 71.73218 & 29.925 & 108.5857 & 101.6572 & 121 & 1.114328 & 1.190275 \\
\hline & GRRh-b2 & 75.55351 & 69.0689 & 29.925 & 105.4785 & 98.9939 & 127.5 & 1.208777 & 1.287958 \\
\hline & BNNm-b2 & 64.97863 & 60.00472 & 29.925 & 94.90363 & 89.92972 & 119 & 1.253904 & 1.323256 \\
\hline & BRNm-b2 & 64.3342 & 59.45235 & 29.925 & 94.2592 & 89.37735 & 119 & 1.262476 & 1.331434 \\
\hline & BRRm-b2 & 63.24555 & 58.51922 & 29.925 & 93.17055 & 88.44422 & 118 & 1.266495 & 1.334174 \\
\hline & BNNh-b2 & 83.70749 & 76.05803 & 29.925 & 113.6325 & 105.983 & 131 & 1.152839 & 1.236047 \\
\hline & BRNh-b2 & 86.52232 & 78.47073 & 29.925 & 116.4473 & 108.3957 & 130.5 & 1.120678 & 1.203922 \\
\hline & BRRh-b2 & 83.54141 & 75.91567 & 29.925 & 113.4664 & 105.8407 & 128 & 1.128087 & 1.209365 \\
\hline \multirow{8}{*}{$\begin{array}{c}\text { Etxeberri } \\
a,(2007)\end{array}$} & $\mathrm{HC}-2$ & 66.68007 & 66.52868 & 67.74231 & 134.4224 & 134.271 & 213 & 1.584558 & 1.586344 \\
\hline & $\mathrm{HC}-3$ & 66.68007 & 66.52868 & 51.80294 & 118.483 & 118.3316 & 177 & 1.493885 & 1.495796 \\
\hline & HR25-2 & 67.05292 & 66.84827 & 67.74231 & 134.7952 & 134.5906 & 186.5 & 1.38358 & 1.385684 \\
\hline & HR25-3 & 67.05292 & 66.84827 & 51.80294 & 118.8559 & 118.6512 & 169 & 1.42189 & 1.424343 \\
\hline & HR50-2 & 66.22508 & 66.13869 & 67.74231 & 133.9674 & 133.881 & 220 & 1.642191 & 1.64325 \\
\hline & HR50-3 & 66.22508 & 66.13869 & 51.80294 & 118.028 & 117.9416 & 176 & 1.491171 & 1.492264 \\
\hline & HR100-2 & 64.93903 & 65.03636 & 67.74231 & 132.6813 & 132.7787 & 189.5 & 1.428234 & 1.427187 \\
\hline & HR100-3 & 64.93903 & 65.03636 & 51.80294 & 116.742 & 116.8393 & 163 & 1.396242 & 1.395078 \\
\hline \multirow{9}{*}{$\begin{array}{c}\text { Al- } \\
\text { Zahraa et } \\
\text { al., } \\
\text { (2011) }\end{array}$} & B4 & 16.88283 & 17.40243 & 15.6465 & 32.52933 & 33.04893 & 44.5 & 1.367996 & 1.346488 \\
\hline & B5 & 18.06239 & 18.41348 & 15.6465 & 33.70889 & 34.05998 & 49.75 & 1.475872 & 1.460659 \\
\hline & B6 & 16.31625 & 16.91679 & 15.6465 & 31.96275 & 32.56329 & 42 & 1.31403 & 1.289796 \\
\hline & B7 & 18.47377 & 18.76608 & 27.58725 & 46.06102 & 46.35333 & 75 & 1.628275 & 1.618007 \\
\hline & B8 & 18.06239 & 18.41348 & 27.58725 & 45.64964 & 46.00073 & 61 & 1.336265 & 1.326066 \\
\hline & B9 & 16.31625 & 16.91679 & 27.58725 & 43.9035 & 44.50404 & 58 & 1.321079 & 1.303253 \\
\hline & $\mathrm{B} 10$ & 18.47377 & 18.1798 & 15.6465 & 34.12027 & 33.8263 & 37 & 1.0844 & 1.093823 \\
\hline & B11 & 16.5463 & 16.52768 & 15.6465 & 32.1928 & 32.17418 & 47.25 & 1.46772 & 1.468569 \\
\hline & B12 & 16.31625 & 16.3305 & 15.6465 & 31.96275 & 31.977 & 34.25 & 1.07156 & 1.071082 \\
\hline
\end{tabular}


Table A.14 Shear strength comparison results for beams with stirrups based on Cladera \& Mari

\begin{tabular}{|c|c|c|c|c|c|c|}
\hline \multicolumn{2}{|c|}{ Beam } & \multicolumn{3}{|c|}{ Cladera \& Mari } & \multirow{2}{*}{$\mathbf{V}_{\mathbf{e}}$} & $\begin{array}{c}\text { Cladera \& } \\
\text { Mari }\end{array}$ \\
\hline Paper & ID & $\mathbf{V}_{\mathbf{c}}$ & $\mathbf{V}_{\mathbf{s}}$ & $\mathbf{V}_{\mathbf{u}}$ & & $\mathbf{V}_{\mathrm{e}} / \mathbf{V}_{\mathbf{p}}$ \\
\hline \multirow{6}{*}{$\begin{array}{l}\text { Gonzalez } \\
\text { et } \\
\text { al.,(2007) }\end{array}$} & V13CC & 99.8902568 & 89.6763462 & 189.5666 & 190.29 & 1.003816 \\
\hline & V13RC & 105.931902 & 89.6763462 & 195.6082 & 233.59 & 1.194173 \\
\hline & V17CC & 90.9264702 & 68.5760294 & 159.5025 & 150.83 & 0.945628 \\
\hline & V17RC & 97.0603324 & 68.5760294 & 165.6364 & 176.99 & 1.068546 \\
\hline & V24CC & 86.1141999 & 48.5746875 & 134.6889 & 127.97 & 0.950116 \\
\hline & V24RC & 93.6262327 & 48.5746875 & 142.2009 & 164.29 & 1.155337 \\
\hline \multirow{6}{*}{$\begin{array}{l}\text { Gonzalez } \\
\text { et } \\
\text { al.,(2009) }\end{array}$} & V13CC & 104.998782 & 89.6763462 & 194.6751 & 150.07 & 0.770874 \\
\hline & V13RC & 101.472877 & 89.6763462 & 191.1492 & 147.33 & 0.770759 \\
\hline & V17CC & 102.788741 & 68.5760294 & 171.3648 & 199.79 & 1.165876 \\
\hline & V17RC & 101.293539 & 68.5760294 & 169.8696 & 192.92 & 1.135695 \\
\hline & V24CC & 92.8078869 & 48.5746875 & 141.3826 & 220.08 & 1.556627 \\
\hline & V24RC & 92.0656865 & 48.5746875 & 140.6404 & 202.36 & 1.438847 \\
\hline \multirow{14}{*}{$\begin{array}{c}\text { Ajdukiewicz, } \\
\text { (2007) }\end{array}$} & ORNm-b2 & 61.4003296 & 40.39875 & 101.7991 & 118.5 & 1.164058 \\
\hline & GNN/- b2 & 54.9308493 & 40.39875 & 95.3296 & 108.5 & 1.138156 \\
\hline & GRN/-b2 & 56.4223746 & 40.39875 & 96.82112 & 116.5 & 1.20325 \\
\hline & GRR/-b2 & 54.819318 & 40.39875 & 95.21807 & 113 & 1.18675 \\
\hline & GRNm-b2 & 61.671746 & 40.39875 & 102.0705 & 118.5 & 1.160962 \\
\hline & GNNh-b2 & 68.6810492 & 40.39875 & 109.0798 & 125 & 1.14595 \\
\hline & GRNh-b2 & 67.3030697 & 40.39875 & 107.7018 & 121 & 1.123472 \\
\hline & GRRh-b2 & 67.3920447 & 40.39875 & 107.7908 & 127.5 & 1.182847 \\
\hline & BNNm-b2 & 62.0050761 & 40.39875 & 102.4038 & 119 & 1.162066 \\
\hline & BRNm-b2 & 61.7583637 & 40.39875 & 102.1571 & 119 & 1.164872 \\
\hline & BRRm-b2 & 61.1659005 & 40.39875 & 101.5647 & 118 & 1.161822 \\
\hline & BNNh-b2 & 70.8488611 & 40.39875 & 111.2476 & 131 & 1.177553 \\
\hline & BRNh-b2 & 71.7009315 & 40.39875 & 112.0997 & 130.5 & 1.164142 \\
\hline & BRRh-b2 & 70.2480183 & 40.39875 & 110.6468 & 128 & 1.156835 \\
\hline \multirow{8}{*}{$\begin{array}{c}\text { Etxeberri } \\
a,(2007)\end{array}$} & $\mathrm{HC}-2$ & 103.296105 & 91.4521154 & 194.7482 & 213 & 1.09372 \\
\hline & $\mathrm{HC}-3$ & 97.113998 & 69.9339706 & 167.048 & 177 & 1.059576 \\
\hline & HR25-2 & 99.0419118 & 91.4521154 & 190.494 & 186.5 & 0.979033 \\
\hline & HR25-3 & 95.8418021 & 69.9339706 & 165.7758 & 169 & 1.019449 \\
\hline & HR50-2 & 104.12992 & 91.4521154 & 195.582 & 220 & 1.124848 \\
\hline & HR50-3 & 96.6656546 & 69.9339706 & 166.5996 & 176 & 1.056425 \\
\hline & HR100-2 & 98.302458 & 91.4521154 & 189.7546 & 189.5 & 0.998658 \\
\hline & HR100-3 & 93.4882809 & 69.9339706 & 163.4223 & 163 & 0.997416 \\
\hline \multirow{9}{*}{$\begin{array}{c}\text { Al-Zahraa } \\
\text { et al., } \\
\text { (2011) }\end{array}$} & B4 & 23.3817502 & 21.122775 & 44.50453 & 44.5 & 0.999898 \\
\hline & B5 & 24.9317845 & 21.122775 & 46.05456 & 49.75 & 1.08024 \\
\hline & B6 & 22.6243858 & 21.122775 & 43.74716 & 42 & 0.960062 \\
\hline & B7 & 28.8461697 & 37.2427875 & 66.08896 & 75 & 1.134834 \\
\hline & B8 & 26.6849021 & 37.2427875 & 63.92769 & 61 & 0.954203 \\
\hline & B9 & 25.1943427 & 37.2427875 & 62.43713 & 58 & 0.928934 \\
\hline & B10 & 22.7930079 & 21.122775 & 43.91578 & 37 & 0.842522 \\
\hline & B11 & 23.6624575 & 21.122775 & 44.78523 & 47.25 & 1.055035 \\
\hline & B12 & 21.1371888 & 21.122775 & 42.25996 & 34.25 & 0.81046 \\
\hline
\end{tabular}


Table A.15 Shear strength comparison results for beams with stirrups based on Eurocode-2

\begin{tabular}{|c|c|c|c|c|c|c|}
\hline \multicolumn{2}{|c|}{ Beam } & \multicolumn{3}{|c|}{ Eurocode-2 } & \multirow{3}{*}{$\mathbf{V}_{\mathbf{e}}$} & \multirow{2}{*}{$\begin{array}{c}\text { Eurocode- } \\
2 \\
\end{array}$} \\
\hline \multirow{2}{*}{ Paper } & \multirow{2}{*}{ ID } & \multirow{2}{*}{$\mathbf{V}_{\mathbf{c}}$} & \multirow[b]{2}{*}{$\mathbf{V}_{\mathbf{s}}$} & \multirow[b]{2}{*}{$\mathbf{V}_{\mathbf{u}}$} & & \\
\hline & & & & & & $\mathbf{V}_{\mathrm{e}} / \mathbf{V}_{\mathrm{p}}$ \\
\hline \multirow{6}{*}{$\begin{array}{l}\text { Gonzalez } \\
\text { et } \\
\text { al.,(2007) }\end{array}$} & V13CC & 93.74539 & 80.70871 & 174.4541 & 190.29 & 1.090774 \\
\hline & V13RC & 96.01338 & 80.70871 & 176.7221 & 233.59 & 1.321793 \\
\hline & V17CC & 94.90913 & 61.71843 & 156.6276 & 150.83 & 0.962985 \\
\hline & V17RC & 96.82131 & 61.71843 & 158.5397 & 176.99 & 1.116376 \\
\hline & V24CC & 94.97385 & 43.71722 & 138.6911 & 127.97 & 0.922698 \\
\hline & V24RC & 95.0304 & 43.71722 & 138.7476 & 164.29 & 1.184092 \\
\hline \multirow{6}{*}{$\begin{array}{l}\text { Gonzalez } \\
\text { et } \\
\text { al.,(2009) }\end{array}$} & V13CC & 97.79166 & 80.70871 & 178.5004 & 150.07 & 0.840727 \\
\hline & V13RC & 96.79018 & 80.70871 & 177.4989 & 147.33 & 0.830033 \\
\hline & V17CC & 99.59582 & 61.71843 & 161.3142 & 199.79 & 1.238514 \\
\hline & V17RC & 99.10082 & 61.71843 & 160.8192 & 192.92 & 1.199608 \\
\hline & V24CC & 98.48068 & 43.71722 & 142.1979 & 220.08 & 1.547702 \\
\hline & V24RC & 98.17144 & 43.71722 & 141.8887 & 202.36 & 1.426189 \\
\hline \multirow{14}{*}{$\begin{array}{c}\text { Ajdukiewicz, } \\
\text { (2007) }\end{array}$} & ORNm-b2 & 76.14952 & 36.35888 & 112.5084 & 118.5 & 1.053255 \\
\hline & GNN/- b2 & 66.42751 & 36.35888 & 102.7864 & 108.5 & 1.055587 \\
\hline & GRN/- b2 & 66.76905 & 36.35888 & 103.1279 & 116.5 & 1.129665 \\
\hline & GRR/-b2 & 64.72499 & 36.35888 & 101.0839 & 113 & 1.117884 \\
\hline & GRNm-b2 & 76.71137 & 36.35888 & 113.0702 & 118.5 & 1.048021 \\
\hline & GNNh-b2 & 89.10319 & 36.35888 & 125.4621 & 125 & 0.996317 \\
\hline & GRNh-b2 & 87.71426 & 36.35888 & 124.0731 & 121 & 0.975231 \\
\hline & GRRh-b2 & 85.38893 & 36.35888 & 121.7478 & 127.5 & 1.047247 \\
\hline & BNNm-b2 & 77.22279 & 36.35888 & 113.5817 & 119 & 1.047704 \\
\hline & BRNm-b2 & 76.71137 & 36.35888 & 113.0702 & 119 & 1.052443 \\
\hline & BRRm-b2 & 75.84352 & 36.35888 & 112.2024 & 118 & 1.051671 \\
\hline & BNNh-b2 & 91.42705 & 36.35888 & 127.7859 & 131 & 1.025152 \\
\hline & BRNh-b2 & 93.46534 & 36.35888 & 129.8242 & 130.5 & 1.005205 \\
\hline & BRRh-b2 & 91.30607 & 36.35888 & 127.6649 & 128 & 1.002624 \\
\hline \multirow{8}{*}{$\begin{array}{c}\text { Etxeberri } \\
a,(2007)\end{array}$} & $\mathrm{HC}-2$ & 97.97086 & 82.3069 & 180.2778 & 213 & 1.18151 \\
\hline & $\mathrm{HC}-3$ & 97.97086 & 62.94057 & 160.9114 & 177 & 1.099984 \\
\hline & HR25-2 & 98.33573 & 82.3069 & 180.6426 & 186.5 & 1.032425 \\
\hline & HR25-3 & 98.33573 & 62.94057 & 161.2763 & 169 & 1.047891 \\
\hline & HR50-2 & 97.52467 & 82.3069 & 179.8316 & 220 & 1.223367 \\
\hline & HR50-3 & 97.52467 & 62.94057 & 160.4652 & 176 & 1.096811 \\
\hline & HR100-2 & 96.25798 & 82.3069 & 178.5649 & 189.5 & 1.061239 \\
\hline & HR100-3 & 96.25798 & 62.94057 & 159.1985 & 163 & 1.023879 \\
\hline \multirow{9}{*}{$\begin{array}{c}\text { Al-Zahraa } \\
\text { et al., } \\
\text { (2011) }\end{array}$} & B4 & 25.63737 & 19.0105 & 44.64787 & 44.5 & 0.996688 \\
\hline & B5 & 26.81802 & 19.0105 & 45.82852 & 49.75 & 1.085569 \\
\hline & B6 & 25.06052 & 19.0105 & 44.07102 & 42 & 0.953007 \\
\hline & B7 & 27.22368 & 33.51851 & 60.74219 & 75 & 1.234727 \\
\hline & B8 & 26.81802 & 33.51851 & 60.33653 & 61 & 1.010996 \\
\hline & B9 & 25.06052 & 33.51851 & 58.57903 & 58 & 0.990115 \\
\hline & B10 & 27.22368 & 19.0105 & 46.23418 & 37 & 0.800274 \\
\hline & B11 & 25.29553 & 19.0105 & 44.30603 & 47.25 & 1.066446 \\
\hline & B12 & 25.06052 & 19.0105 & 44.07102 & 34.25 & 0.777155 \\
\hline
\end{tabular}


Table A.16 Shear strength comparison results for beams without stirrups based on AS 3600

\begin{tabular}{|c|c|c|c|c|c|c|}
\hline \multicolumn{2}{|c|}{ Beam } & \multicolumn{3}{|c|}{ As 3600} & \multirow{2}{*}{$\mathbf{V}_{\mathbf{e}}$} & As 3600 \\
\hline Paper & ID & $\mathbf{V}_{\mathbf{c}}$ & $\mathbf{V}_{\mathbf{s}}$ & $\mathbf{V}_{\mathbf{u}}$ & & $\mathbf{V}_{\mathrm{e}} / \mathbf{V}_{\mathbf{p}}$ \\
\hline \multirow{6}{*}{$\begin{array}{l}\text { Gonzalez } \\
\text { et } \\
\text { al.,(2007) }\end{array}$} & V13CC & 89.84712 & 66.42692 & 156.274 & 190.29 & 1.217669 \\
\hline & V13RC & 92.0208 & 66.42692 & 158.4477 & 233.59 & 1.47424 \\
\hline & V17CC & 90.96247 & 50.79706 & 141.7595 & 150.83 & 1.063985 \\
\hline & V17RC & 92.79513 & 50.79706 & 143.5922 & 176.99 & 1.232588 \\
\hline & V24CC & 91.02449 & 35.98125 & 127.0057 & 127.97 & 1.007592 \\
\hline & V24RC & 91.0787 & 35.98125 & 127.0599 & 164.29 & 1.293012 \\
\hline \multirow{6}{*}{$\begin{array}{l}\text { Gonzalez } \\
\text { et } \\
\text { al.,(2009) }\end{array}$} & V13CC & 93.72514 & 66.42692 & 160.1521 & 150.07 & 0.937047 \\
\hline & V13RC & 92.7653 & 66.42692 & 159.1922 & 147.33 & 0.925485 \\
\hline & V17CC & 95.45427 & 50.79706 & 146.2513 & 199.79 & 1.366073 \\
\hline & V17RC & 94.97986 & 50.79706 & 145.7769 & 192.92 & 1.323392 \\
\hline & $\mathrm{V} 24 \mathrm{CC}$ & 94.3855 & 35.98125 & 130.3668 & 220.08 & 1.688161 \\
\hline & V24RC & 94.08912 & 35.98125 & 130.0704 & 202.36 & 1.555773 \\
\hline \multirow{14}{*}{$\begin{array}{c}\text { Ajdukiewicz, } \\
\text { (2007) }\end{array}$} & ORNm-b2 & 72.67784 & 29.925 & 102.6028 & 118.5 & 1.154939 \\
\hline & GNN/- b2 & 63.39906 & 29.925 & 93.32406 & 108.5 & 1.162616 \\
\hline & GRN/-b2 & 63.72502 & 29.925 & 93.65002 & 116.5 & 1.243993 \\
\hline & GRR/-b2 & 61.77416 & 29.925 & 91.69916 & 113 & 1.232291 \\
\hline & GRNm-b2 & 73.21407 & 29.925 & 103.1391 & 118.5 & 1.148934 \\
\hline & GNNh-b2 & 85.04095 & 29.925 & 114.966 & 125 & 1.087278 \\
\hline & GRNh-b2 & 83.71534 & 29.925 & 113.6403 & 121 & 1.064763 \\
\hline & GRRh-b2 & 81.49602 & 29.925 & 111.421 & 127.5 & 1.144308 \\
\hline & BNNm-b2 & 73.70218 & 29.925 & 103.6272 & 119 & 1.148347 \\
\hline & BRNm-b2 & 73.21407 & 29.925 & 103.1391 & 119 & 1.153782 \\
\hline & BRRm-b2 & 72.38579 & 29.925 & 102.3108 & 118 & 1.153349 \\
\hline & BNNh-b2 & 87.25886 & 29.925 & 117.1839 & 131 & 1.117901 \\
\hline & BRNh-b2 & 89.20422 & 29.925 & 119.1292 & 130.5 & 1.095449 \\
\hline & BRRh-b2 & 87.1434 & 29.925 & 117.0684 & 128 & 1.093378 \\
\hline \multirow{8}{*}{$\begin{array}{c}\text { Etxeberri } \\
a,(2007)\end{array}$} & $\mathrm{HC}-2$ & 93.44523 & 67.74231 & 161.1875 & 213 & 1.321442 \\
\hline & $\mathrm{HC}-3$ & 93.44523 & 51.80294 & 145.2482 & 177 & 1.218604 \\
\hline & HR25-2 & 93.79325 & 67.74231 & 161.5356 & 186.5 & 1.154545 \\
\hline & HR25-3 & 93.79325 & 51.80294 & 145.5962 & 169 & 1.160745 \\
\hline & HR50-2 & 93.01966 & 67.74231 & 160.762 & 220 & 1.368483 \\
\hline & HR50-3 & 93.01966 & 51.80294 & 144.8226 & 176 & 1.21528 \\
\hline & HR100-2 & 91.81147 & 67.74231 & 159.5538 & 189.5 & 1.187687 \\
\hline & HR100-3 & 91.81147 & 51.80294 & 143.6144 & 163 & 1.134984 \\
\hline \multirow{9}{*}{$\begin{array}{c}\text { Al-Zahraa } \\
\text { et al., } \\
\text { (2011) }\end{array}$} & B4 & 23.73672 & 15.6465 & 39.38322 & 44.5 & 1.129923 \\
\hline & B5 & 24.82985 & 15.6465 & 40.47635 & 49.75 & 1.229113 \\
\hline & B6 & 23.20264 & 15.6465 & 38.84914 & 42 & 1.081105 \\
\hline & B7 & 25.20543 & 27.58725 & 52.79268 & 75 & 1.420651 \\
\hline & B8 & 24.82985 & 27.58725 & 52.4171 & 61 & 1.163742 \\
\hline & B9 & 23.20264 & 27.58725 & 50.78989 & 58 & 1.141959 \\
\hline & B10 & 25.20543 & 15.6465 & 40.85193 & 37 & 0.90571 \\
\hline & B11 & 23.42023 & 15.6465 & 39.06673 & 47.25 & 1.209469 \\
\hline & B12 & 23.20264 & 15.6465 & 38.84914 & 34.25 & 0.881615 \\
\hline
\end{tabular}


Table A.17 Shear strength comparison results for beams without stirrups based on EHE-08

\begin{tabular}{|c|c|c|c|c|c|c|}
\hline \multicolumn{2}{|c|}{ Beam } & \multicolumn{3}{|c|}{ EHE-08 } & \multirow{2}{*}{$\mathbf{v}_{\mathbf{e}}$} & EHE-08 \\
\hline Paper & ID & $\mathbf{V}_{\mathbf{c}}$ & $\mathbf{V}_{\mathbf{s}}$ & $\mathbf{V}_{\mathbf{u}}$ & & $\mathbf{V}_{\mathrm{e}} / \mathbf{V}_{\mathbf{p}}$ \\
\hline \multirow{6}{*}{$\begin{array}{l}\text { Gonzalez } \\
\text { et } \\
\text { al.,(2007) }\end{array}$} & V13CC & 78.12115 & 64.56697 & 142.6881 & 190.29 & 1.333608 \\
\hline & V13RC & 80.01115 & 64.56697 & 144.5781 & 233.59 & 1.615666 \\
\hline & V17CC & 79.09094 & 49.37474 & 128.4657 & 150.83 & 1.174088 \\
\hline & V17RC & 80.68442 & 49.37474 & 130.0592 & 176.99 & 1.360842 \\
\hline & $\mathrm{V} 24 \mathrm{CC}$ & 79.14487 & 34.97378 & 114.1186 & 127.97 & 1.121377 \\
\hline & V24RC & 79.192 & 34.97378 & 114.1658 & 164.29 & 1.439048 \\
\hline \multirow{6}{*}{$\begin{array}{l}\text { Gonzalez } \\
\text { et } \\
\text { al.,(2009) }\end{array}$} & V13CC & 81.49305 & 64.56697 & 146.06 & 150.07 & 1.027454 \\
\hline & V13RC & 80.65848 & 64.56697 & 145.2255 & 147.33 & 1.014492 \\
\hline & V17CC & 82.99652 & 49.37474 & 132.3713 & 199.79 & 1.509316 \\
\hline & V17RC & 82.58402 & 49.37474 & 131.9588 & 192.92 & 1.461972 \\
\hline & V24CC & 82.06723 & 34.97378 & 117.041 & 220.08 & 1.880367 \\
\hline & V24RC & 81.80953 & 34.97378 & 116.7833 & 202.36 & 1.732782 \\
\hline \multirow{14}{*}{$\begin{array}{c}\text { Ajdukiewicz, } \\
\text { (2007) }\end{array}$} & ORNm-b2 & 63.45793 & 29.0871 & 92.54503 & 118.5 & 1.280458 \\
\hline & GNN/- b2 & 55.35626 & 29.0871 & 84.44336 & 108.5 & 1.284885 \\
\hline & GRN/- b2 & 55.64087 & 29.0871 & 84.72797 & 116.5 & 1.374989 \\
\hline & GRR/-b2 & 53.93749 & 29.0871 & 83.02459 & 113 & 1.361043 \\
\hline & GRNm-b2 & 63.92614 & 29.0871 & 93.01324 & 118.5 & 1.274012 \\
\hline & GNNh-b2 & 74.25266 & 29.0871 & 103.3398 & 125 & 1.209602 \\
\hline & GRNh-b2 & 73.09522 & 29.0871 & 102.1823 & 121 & 1.184158 \\
\hline & GRRh-b2 & 71.15744 & 29.0871 & 100.2445 & 127.5 & 1.27189 \\
\hline & BNNm-b2 & 64.35233 & 29.0871 & 93.43943 & 119 & 1.273552 \\
\hline & BRNm-b2 & 63.92614 & 29.0871 & 93.01324 & 119 & 1.279388 \\
\hline & BRRm-b2 & 63.20293 & 29.0871 & 92.29003 & 118 & 1.278578 \\
\hline & BNNh-b2 & 76.18921 & 29.0871 & 105.2763 & 131 & 1.244345 \\
\hline & BRNh-b2 & 77.88778 & 29.0871 & 106.9749 & 130.5 & 1.219913 \\
\hline & BRRh-b2 & 76.0884 & 29.0871 & 105.1755 & 128 & 1.217014 \\
\hline \multirow{8}{*}{$\begin{array}{c}\text { Etxeberri } \\
a,(2007)\end{array}$} & $\mathrm{HC}-2$ & 81.64238 & 65.84552 & 147.4879 & 213 & 1.444186 \\
\hline & $\mathrm{HC}-3$ & 81.64238 & 50.35246 & 131.9948 & 177 & 1.340962 \\
\hline & HR25-2 & 81.94644 & 65.84552 & 147.792 & 186.5 & 1.261909 \\
\hline & HR25-3 & 81.94644 & 50.35246 & 132.2989 & 169 & 1.27741 \\
\hline & HR50-2 & 81.27056 & 65.84552 & 147.1161 & 220 & 1.495418 \\
\hline & HR50-3 & 81.27056 & 50.35246 & 131.623 & 176 & 1.337152 \\
\hline & HR100-2 & 80.21498 & 65.84552 & 146.0605 & 189.5 & 1.297408 \\
\hline & HR100-3 & 80.21498 & 50.35246 & 130.5674 & 163 & 1.248397 \\
\hline \multirow{9}{*}{$\begin{array}{c}\text { Al-Zahraa } \\
\text { et al., } \\
\text { (2011) }\end{array}$} & B4 & 21.36447 & 15.2084 & 36.57287 & 44.5 & 1.216749 \\
\hline & B5 & 22.34835 & 15.2084 & 37.55675 & 49.75 & 1.324662 \\
\hline & B6 & 20.88377 & 15.2084 & 36.09217 & 42 & 1.163687 \\
\hline & B7 & 22.6864 & 26.81481 & 49.50121 & 75 & 1.515115 \\
\hline & B8 & 22.34835 & 26.81481 & 49.16316 & 61 & 1.240766 \\
\hline & B9 & 20.88377 & 26.81481 & 47.69858 & 58 & 1.215969 \\
\hline & B10 & 22.6864 & 15.2084 & 37.8948 & 37 & 0.976387 \\
\hline & B11 & 21.07961 & 15.2084 & 36.28801 & 47.25 & 1.302083 \\
\hline & B12 & 20.88377 & 15.2084 & 36.09217 & 34.25 & 0.948959 \\
\hline
\end{tabular}


Table A.18 Shear strength comparison results for beams without stirrups based on CEB-FIP

\begin{tabular}{|c|c|c|c|c|c|c|}
\hline \multicolumn{2}{|c|}{ Beam } & \multicolumn{3}{|c|}{ CEB-FIP } & \multirow{2}{*}{$\mathbf{V}_{\mathbf{e}}$} & CEB-FIP \\
\hline Paper & ID & $\mathbf{V}_{\mathbf{c}}$ & $\mathbf{V}_{\mathbf{s}}$ & $\mathbf{V}_{\mathbf{u}}$ & & $\mathbf{V}_{\mathrm{e}} / \mathbf{V}_{\mathbf{p}}$ \\
\hline \multirow{6}{*}{$\begin{array}{l}\text { Gonzalez } \\
\text { et } \\
\text { al.,(2007) }\end{array}$} & V13CC & 76.98331 & 59.78423 & 136.7675 & 190.29 & 1.391339 \\
\hline & V13RC & 78.84577 & 59.78423 & 138.63 & 233.59 & 1.684989 \\
\hline & V17CC & 77.93897 & 45.71735 & 123.6563 & 150.83 & 1.219752 \\
\hline & V17RC & 79.50924 & 45.71735 & 125.2266 & 176.99 & 1.413358 \\
\hline & V24CC & 77.99211 & 32.38313 & 110.3752 & 127.97 & 1.159409 \\
\hline & V24RC & 78.03856 & 32.38313 & 110.4217 & 164.29 & 1.487842 \\
\hline \multirow{6}{*}{$\begin{array}{l}\text { Gonzalez } \\
\text { et } \\
\text { al.,(2009) }\end{array}$} & V13CC & 80.30609 & 59.78423 & 140.0903 & 150.07 & 1.071237 \\
\hline & V13RC & 79.48368 & 59.78423 & 139.2679 & 147.33 & 1.057889 \\
\hline & V17CC & 81.78766 & 45.71735 & 127.505 & 199.79 & 1.566919 \\
\hline & V17RC & 81.38117 & 45.71735 & 127.0985 & 192.92 & 1.517878 \\
\hline & V24CC & 80.87191 & 32.38313 & 113.255 & 220.08 & 1.943225 \\
\hline & V24RC & 80.61796 & 32.38313 & 113.0011 & 202.36 & 1.790779 \\
\hline \multirow{14}{*}{$\begin{array}{c}\text { Ajdukiewicz, } \\
\text { (2007) }\end{array}$} & ORNm-b2 & 63.17838 & 26.9325 & 90.11088 & 118.5 & 1.315047 \\
\hline & GNN/- b2 & 55.11239 & 26.9325 & 82.04489 & 108.5 & 1.322447 \\
\hline & GRN/- b2 & 55.39575 & 26.9325 & 82.32825 & 116.5 & 1.415067 \\
\hline & GRRI- b2 & 53.69988 & 26.9325 & 80.63238 & 113 & 1.401422 \\
\hline & GRNm-b2 & 63.64452 & 26.9325 & 90.57702 & 118.5 & 1.308279 \\
\hline & GNNh-b2 & 73.92555 & 26.9325 & 100.8581 & 125 & 1.239366 \\
\hline & GRNh-b2 & 72.77321 & 26.9325 & 99.70571 & 121 & 1.213571 \\
\hline & GRRh-b2 & 70.84397 & 26.9325 & 97.77647 & 127.5 & 1.303995 \\
\hline & BNNm-b2 & 64.06883 & 26.9325 & 91.00133 & 119 & 1.307673 \\
\hline & BRNm-b2 & 63.64452 & 26.9325 & 90.57702 & 119 & 1.313799 \\
\hline & BRRm-b2 & 62.9245 & 26.9325 & 89.857 & 118 & 1.313198 \\
\hline & BNNh-b2 & 75.85357 & 26.9325 & 102.7861 & 131 & 1.274492 \\
\hline & BRNh-b2 & 77.54466 & 26.9325 & 104.4772 & 130.5 & 1.249077 \\
\hline & BRRh-b2 & 75.7532 & 26.9325 & 102.6857 & 128 & 1.246522 \\
\hline \multirow{8}{*}{$\begin{array}{c}\text { Etxeberri } \\
a,(2007)\end{array}$} & HC-2 & 80.45324 & 60.96808 & 141.4213 & 213 & 1.506138 \\
\hline & $\mathrm{HC}-3$ & 80.45324 & 46.62265 & 127.0759 & 177 & 1.392868 \\
\hline & HR25-2 & 80.75287 & 60.96808 & 141.721 & 186.5 & 1.315966 \\
\hline & HR25-3 & 80.75287 & 46.62265 & 127.3755 & 169 & 1.326786 \\
\hline & HR50-2 & 80.08684 & 60.96808 & 141.0549 & 220 & 1.559676 \\
\hline & HR50-3 & 80.08684 & 46.62265 & 126.7095 & 176 & 1.389004 \\
\hline & HR100-2 & 79.04663 & 60.96808 & 140.0147 & 189.5 & 1.353429 \\
\hline & HR100-3 & 79.04663 & 46.62265 & 125.6693 & 163 & 1.297055 \\
\hline \multirow{9}{*}{$\begin{array}{c}\text { Al-Zahraa } \\
\text { et al., } \\
\text { (2011) }\end{array}$} & B4 & 24.87796 & 14.08185 & 38.95981 & 44.5 & 1.142203 \\
\hline & B5 & 26.02364 & 14.08185 & 40.10549 & 49.75 & 1.240479 \\
\hline & B6 & 24.3182 & 14.08185 & 38.40005 & 42 & 1.093749 \\
\hline & B7 & 26.41728 & 24.82853 & 51.24581 & 75 & 1.463534 \\
\hline & B8 & 26.02364 & 24.82853 & 50.85217 & 61 & 1.199556 \\
\hline & B9 & 24.3182 & 24.82853 & 49.14673 & 58 & 1.18014 \\
\hline & B10 & 24.52363 & 14.08185 & 38.60548 & 37 & 0.958413 \\
\hline & B11 & 22.78672 & 14.08185 & 36.86857 & 47.25 & 1.281579 \\
\hline & B12 & 22.57502 & 14.08185 & 36.65687 & 34.25 & 0.934341 \\
\hline
\end{tabular}

